\title{
Moderate alcohol consumption and risk of coronary heart disease : an experimental approach
}

Citation for published version (APA):

Veenstra, J. (1991). Moderate alcohol consumption and risk of coronary heart disease : an experimental approach. [Doctoral Thesis, Maastricht University]. Rijksuniversiteit Limburg. https://doi.org/10.26481/dis.19910412jv

Document status and date:

Published: 01/01/1991

DOI:

10.26481/dis.19910412jv

Document Version:

Publisher's PDF, also known as Version of record

\section{Please check the document version of this publication:}

- A submitted manuscript is the version of the article upon submission and before peer-review. There can be important differences between the submitted version and the official published version of record.

People interested in the research are advised to contact the author for the final version of the publication, or visit the DOI to the publisher's website.

- The final author version and the galley proof are versions of the publication after peer review.

- The final published version features the final layout of the paper including the volume, issue and page numbers.

Link to publication

\footnotetext{
General rights rights.

- You may freely distribute the URL identifying the publication in the public portal. please follow below link for the End User Agreement:

www.umlib.nl/taverne-license

Take down policy

If you believe that this document breaches copyright please contact us at:

repository@maastrichtuniversity.nl

providing details and we will investigate your claim.
}

Copyright and moral rights for the publications made accessible in the public portal are retained by the authors and/or other copyright owners and it is a condition of accessing publications that users recognise and abide by the legal requirements associated with these

- Users may download and print one copy of any publication from the public portal for the purpose of private study or research.

- You may not further distribute the material or use it for any profit-making activity or commercial gain

If the publication is distributed under the terms of Article $25 \mathrm{fa}$ of the Dutch Copyright Act, indicated by the "Taverne" license above, 


\section{MODERATE ALCOHOL CONSUMPTION AND RISK OF CORONARY HEART DISEASE}


Cover illustration: Antique winecup from Greece $( \pm 400 \mathrm{BC})$.

In ancient Greece the philosopher Plato (429-347 BC) looked upon moderate wine consumption as a beneficial pleasure. Its use, he said, promotes health. He took a very critical view, however, of drunkenness and had the opinion that drinking wine should be forbidden for children under 18 . 


\title{
MODERATE ALCOHOL CONSUMPTION AND RISK OF CORONARY HEART DISEASE
}

\author{
an experimental approach
}

\section{PROEFSCHRIFT}

ter verkrijging van de graad van doctor aan de

Rijksuniversiteit Limburg te Maastricht, op gezag van de Rector Magnificus,

Prof. Mr. M.J. Cohen,

volgens het besluit van het College van Dekanen,

in het openbaar te verdedigen op

vrijdag, 12 april 1991 om 14.00 uur

door

JAN VEENSTRA

geboren te Roden 
Promotor:

Prof. Dr. Ir. R.J.J. Hermus

Co-promotores:

Dr. C. Kluft

Dr. Ir. G. Schaafsma

Beoordelingscommissie: Prof. Dr. M.J. Drop (voorzitter)

Dr. F. Bär

Prof.Dr. J.G.A.J. Hautvast (Landbouw-

universiteit Wageningen)

Dr. G. Hornstra

Prof.Dr. A.C. Nieuwenhuijzen Kruseman

The study described in this thesis was conducted at the TNO Toxicology and Nutrition Institute, P.O. Box 360. 3700 AJ Zeist, the Netherlands.

Financial support by the Netherlands Heart Foundation for the publication of this thesis is gratefully acknowledged. 


\section{TABLE OF CONTENTS}

1. Introduction 9

Scope 9

Aim of the study 10

$\begin{array}{ll}\text { Outline of the thesis } & 10\end{array}$

2. Moderate alcohol use and coronary heart disease:

A U-shaped curve?

(World Review of Nutrition and Dietetics, 1991;65:38-71)

3. Alcohol and fubrinolysis

(Fibrinolysis, 1990;4 Supp2:64-8)

4. High-density lipoprotein cholesterol during 20 weeks of moderate alcohol consumption (Submitted)

5. Effects of four days of moderate wine and coffee consumption on fibrinolysis and platelet aggregation (Fibrinolysis, in press)

6. Effects of four days of moderate alcohol consumption on blood lipids and lipoproteins in healthy volunteers (Submitted)

7. Effects of moderate alcohol consumption on platelet function, tissue-type plasminogen activator and plasminogen activator inhibitor (Thrombosis and Haemostasis, 1990;63:345-8)

8. Effects of a moderate dose of alcohol on blood lipids and lipoproteins postprandially and in the fasting state (Alcohol and Alcoholism, 1990;25:371-7)

9. Moderate alcohol consumption and platelet aggregation in healthy middle-aged men

(Alcohol: an International Biomedical Journal, in press) 
Promotor:

Prof. Dr. Ir. R.J.J. Hermus

Co-promotores: $\quad$ Dr. C. KJuft

Dr. Ir. G. Schaafsma

Beoordelingscommissie: Prof. Dr. M.J. Drop (voorzitter)

Dr. F. Bär

Prof. Dr. J.G.A.J. Hautvast (Landbouw-

universiteit Wageningen)

Dr. G. Hornstra

Prof.Dr. A.C. Nieuwenhuijzen Kruseman

The study described in this thesis was conducted at the TNO Toxicology and Nutrition Institute, P.O. Box 360, 3700 AJ Zeist, the Netherlands.

Financial support by the Netherlands Heart Foundation for the publication of this thesis is gratefully acknowledged. 


\section{TABLE OF CONTENTS}

1. Introduction 9

$\begin{array}{lr}\text { Scope } & 9\end{array}$

$\begin{array}{ll}\text { Aim of the study } & 10\end{array}$

$\begin{array}{ll}\text { Outline of the thesis } & 10\end{array}$

2. Moderate alcohol use and coronary heart disease:

A U-shaped curve?

(World Review of Nutrition and Dietetics, 1991;65:38-71)

3. Alcohol and fibrinolysis

(Fibrinolysis, 1990;4 Supp2:64-8)

4. High-density lipoprotein cholesterol during 20 weeks of moderate alcohol consumption (Submitted)

5. Effects of four days of moderate wine and coffee consumption on fibrinolysis and platelet aggregation (Fibrinolysis, in press)

6. Effects of four days of moderate alcohol consumption on blood lipids and lipoproteins in healthy volunteers (Submitted)

7. Effects of moderate alcohol consumption on platelet function, tissue-type plasminogen activator and plasminogen activator inhibitor (Thrombosis and Haemostasis, 1990;63:345-8)

8. Effects of a moderate dose of alcohol on blood lipids and lipoproteins postprandially and in the fasting state (Alcohol and Alcoholism, 1990;25:371-7)

9. Moderate alcohol consumption and platelet aggregation in healthy middle-aged men

(Alcohol: an International Biomedical Journal, in press) 
10. Acute effects of moderate alcohol consumption on fibrinolytic factors in thealthy middle-aged men (Submitted)

11. Alcohol consumption in relation to food intake and smoking habits in the Dutch National Food Consumption Study

(Accepted in revised form by the European Journal of Clinical Nutrition)

12. General discussion and conclusions 145

Cholesterol metabolism 145

Platelet function $\quad 146$

Fibrinolysis $\quad 147$

Possible underlying mechanisms $\quad 149$

Possible mutual relationships $\quad 152$

Different types of alcoholic beverage 154

Consequences of the observed effects for the risk of CHD 155

Food intake and smoking habits 155

Conclusions 156

General implications $\quad 156$

$\begin{array}{ll}\text { References } & 157\end{array}$

Moderate alcohol consumption and risk

of coronary heart disease

Summary

Matig alcoholgebruik en het risico

op coronaire hartziekten

Samenvatting

Appendix 1:

Effects of moderate alcohol consumption on platelet aggregation, fibrinolysis, and blood lipids.

(Metabolism 1987;36:538-43)

Appendix 2:

Regular moderate wine consumption for five weeks increases plasma activity of the plasminogen activator inhibitor 1 (PAI-1) in healthy volunteers.

(Fibrinolysis, 1990;4 Supp2:69-70) 


\section{Preface}

In this preface I would like to thank all who have contributed to this study and the realization of this thesis.

Petra, I am greatly indebted to you for the chance you have given me to pick up my school career after our marriage and for your continuous trust and support.

Dr Theo Ockhuizen, I would like to thank you for your confidence ever since we met in Groningen. You have aroused my interest in scientific research; my work has become my hobby since.

Professor Ruud J.J. Hermus, you have initiated the Alcohol Documentation Centre and the Alcohol Research at the TNO Toxicology and Nutrition Institute. I am grateful for your confidence and support and for the opportunity given to do this work.

Dr Gertjan Schaafsma, thank you very much for your patience and support and for all you have taught me.

Dr Cees Kluft, I would like to thank you for your support and for the opportunity to collaborate with you and your co-workers at the Gaubius Institute.

The members of the Steering Group of Alcohol Research are gratefully acknowledged for financially supporting this study, and the Netherlands Heart Foundation for sponsoring the publication of this thesis.

Finally, I would like to thank all my TNO colleagues all volunteers in the experiments and all students without whose help I could not have managed to complete this study. Thank you for your support, for your work during the experiments and especially for your perseverance during the evening and night experiments, for conducting the laboratory and statistical analyses and for scientific and editorial support in writing the manuscripts. It has been a great privilege to work with you all. 


\section{INTRODUCTION}

\section{Scope}

Life-style factors such as smoking, physical exercise and dietary habits have been found to influence the risk of coronary heart disease (CHD). Excessive alcohol consumption is another widely recognized CHD risk factor. In contrast, a large number of epidemiological studies, including ecological, case-control and cohort studies, indicate that moderate alcohol consumption may have a protective effect against $\mathrm{CHD}$.

Food consumption studies show that alcohol forms part of the diet in almost all industrialized countries. The type of alcoholic beverage and the occasion at which alcohol is consumed is olten based on cultural differences from early days. However, in the past decades, the marked differences in national alcohol usage are slowly disappearing. In addition, the large differences in total per capita alcohol consumption between countries are levelling off as well. In the Netherlands, per capita alcohol consumption has increased from a relatively and historically low level of $2 \mathrm{~L} /$ year in the post-war period, to $9.4 \mathrm{~L} /$ year in 1979, and has stabilized since. In 1988, the per capita alcohol consumption was $8.3 \mathrm{~L} /$ year.

In spite of the fact that alcohol is consumed in moderate amounts by a vast majority of the people, not much alcohol research is focussed on moderate alcohol consumption. However, the possibility that habitual moderate alcohol consumption may lower the risk of CHD in a large part of the population is of potential importance for public health.

Several biological mechanisms have been put forward to explain the observed lower risk of CHD in moderate users of alcohol. First, moderate alcohol consumption may have a favourable effect on cholesterol metabolism. Second, consumption of alcohol has been suggested to influence platelet function. Third, alcohol may have an effect on fibrinolysis. The effects of alcohol consumption on these factors, which play an important role in the aetiology of $\mathrm{CHD}$, can be investigated in epidemiological as well as in experimental studies.

Biological mechanisms as mentioned above, however, do not provide the only possible explanation for the observed relationship between alcohol consumption and $\mathrm{CHD}$. The lower risk of $\mathrm{CHD}$ may well be altributable to factors other than alcohol, such as differences in stress susceptibility, personality, life-style including dietary habits, or a combination of these. 


\section{Aim of the study}

The primary aim of the studies presented in this thesis was to investigate mechanisms which could explain the lower risk of CHD in moderate alcohol users, as observed in epidemiological studies. Therefore, the long-term and acute effects of moderate alcohol consumption on factors related to cholesterol metabolism, platelet function and fibrinolysis were investigated in human volunteers, under controlled conditions. In addition, the relationship between alcohol consumption, food intake and smoking habits was evaluated using data from the Dutch National Food Consumption Study in order to investigate the possibility of moderate alcohol consumption being associated with a healthier life-style.

\section{Outline of the thesis}

The literature data on the relation between alcohol consumption and CHD as well as CHD risk factors is reviewed in Chapter 2. A more detailed description of the literature on alcohol and fibrinolysis is given in Chapter 3.

In Chapters 4 to 10 the results of four experimental studies with human volunteers are presented. These studies have been preceded by a five-week study, the results of which are reproduced in Appendices 1 and 2 to provide an overall picture. In Chapter 4, the effects of 20 weeks of moderate alcohol consumption ( $34 \mathrm{~g}$ per day in white wine) on high-density lipoprotein cholesterol and its subfractions in healthy young men (experimental group $n=12$, control group $n=6$ ) are described. This study was followed by a study into the effects of four days of moderate alcohol consumption ( $40 \mathrm{~g}$ per day in red wine) on haemostasis, blood lipids and lipoproteins in the fasting state in 8 healthy young men, the results of which are presented in Chapters 5 and 6.

Two studies on the acute effects of alcohol consumption have been performed. In the first one, the effects of the consumption of a moderate dose of alcohol ( $30 \mathrm{~g}$ in red port and wine) during dinner on platelet function, fibrinolysis, blood lipids and lipoproteins were studied. The study comprised both young and middle-aged men (20-30 and 45-55 years old) to investigate the effects of age as well. The results are reported in Chapters 7 and 8. Chapters 9 and 10 deal with the acute effects of moderate alcohol consumption on platelet function and fibrinolysis in middle-aged men studied in more detail and under even more strictly controlled conditions. Two glasses of red wine were consumed during diner 


\section{CHAPTER 1}

and two glasses of Hollands gin (geneva) in the evening, 5 hours after dinner ( $40 \mathrm{~g}$ allcohol in total).

The interrelationships between alcohol consumption, energy and food intake and smoking habits among men and women aged 22-49, on the basis of data contained in the Dutch National Food Consumption Study, are described in Chapter 11.

Finally, in Chapter 12 the results presented in this thesis are discussed in view of the association between alcohol consumption and CHD as observed in epidemiological studies. 



\title{
INTRODUCTION: MODERATE ALCOHOL USE AND CORONARY HEART DISEASE: A U-SHAPED CURVE?
}

\author{
J. Veenstra \\ (World Review of Nutrition and Dietetics, 1991,65:38-71) \\ Contents
}

Introduction

Epidemiological research on alcohol and CHD:

Ecological studies

Case-control studies

Cohort studies

Summary

Epidemiological research into CHD risk factors:

Blood pressure

Cholesterol metabolism

Haemostasis

Summary

Experimental research on CHD risk factors:

Blood pressure

Cholesterol metabolism

Haemostasis

Summary

Final considerations 


\section{Introduction}

About $40-50 \%$ of total mortality in the affluent society is caused by cardiovascular disease (CVD). Most of the CVD death cases can be attributed to coronary heart disease (CHD). In the past decades evidence has been found that life-style factors influence the risk of CHD. Besides smoking, lack of physical exercise, stress, and a surplus of dietary cholesterol, saturated fatty acids, salt and energy contribute to a higher risk of CHD.

Excessive alcohol-use is another CHD risk factor. In contrast, in the past decade, moderate alcohol use has frequently been claimed to reduce this risk. The association between alcohol consumption and CHD risk or between alcohol consumption and total mortality has often been reported to be U-shaped; i.e. moderate drinkers would be at lower risk than both teetotallers and heavy drinkers.

This paper aims at critically reviewing the literature on this subject and finding an answer to the question whether the association between CHD and alcohol use is U-shaped indeed. On the basis of epidemiological and experimental studies those mechanisms are discussed that could explain such an U-shaped curve.

\section{Epidemiological research on alcohol and CHD}

In many epidemiological studies an inverse correlation between moderate alcohol use and CHD incidence has been found. These studies can be classified into ecological studies, case-control studies and cohort studies.

\section{Ecological studies}

A number of ecological studies have investigated the relation between average alcohol consumption and CHD prevalence in various countries. In 1969, Brummer (1) compared alcohol consumption and CHD mortality data of 20 Western countries. An inverse association between alcohol consumption and CHD mortality was observed for both men and women in three different age categories. St. Leger et al. (2), in a comparable study, investigated CHD mortality among men and women aged 55-64 in 18 countries. In this study, alcohol was classified into wine, beer and spirits. A clear inverse relation between average total alcohol consumption and $\mathrm{CHD}$ mortality was found. Besides, St. Leger et al. observed that the effect of alcohol was not attributable to differences in known risk factors of $\mathrm{CHD}$ such as smoking, cholesterol intake, fat intake or total energy intake. Wine 
appeared to be the predominant form of alcohol responsible for the favourable effect of alcohol consumption (Figure 1).

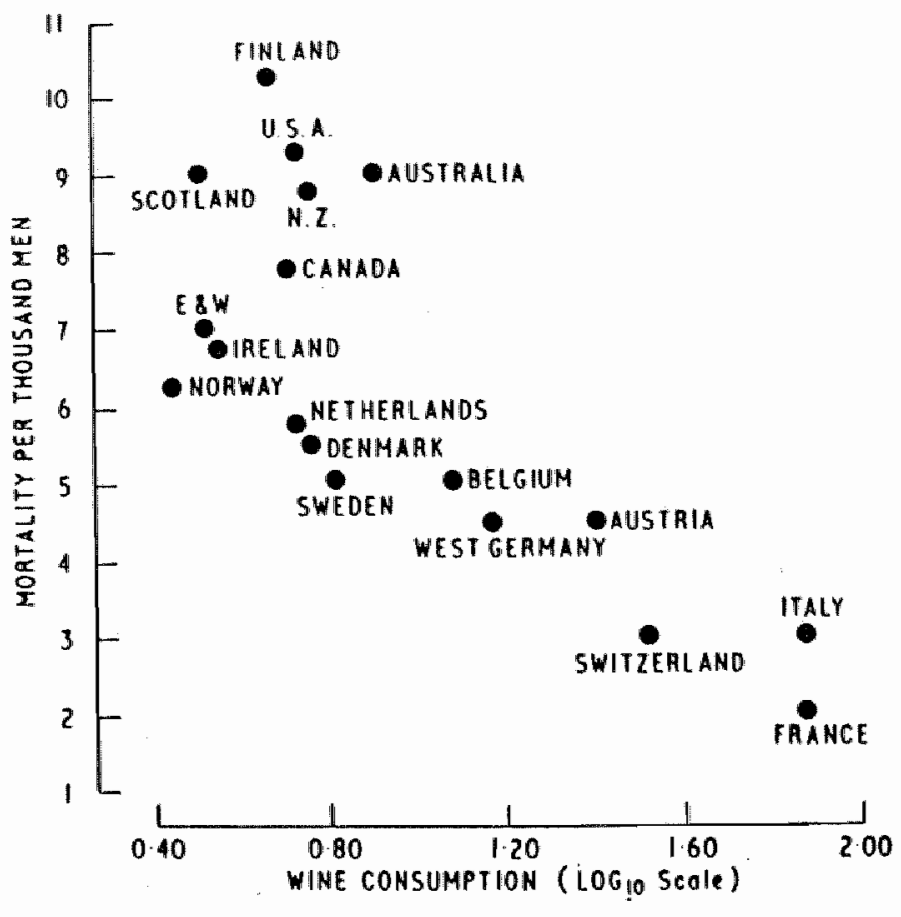

Figure 1. Relationship between CHD mortality-rate in men aged 55.64 and wine consumption (2).

Comparable results have been reported by LaPorte et al. (3), Hegsted and Ausman (4), and Schmidt and Popham (5). Schmidt and Popham also reported significant negative correlations between the consumption of total alcohol, wine and spirits and CHD mortality in the 50 states of the USA. LaPorte et al. (3) have also paid attention to trends in alcohol use and CHD incidence rates. The strongest relation they found applied for beer. Figure 2 presents the relation between average beer consumption (1945-1975) and CHD mortality (1950-1975) in the USA. Taking into account a 5-year lag period, the correlation coefficient between beer consumption and CHD mortality was -0.943 . The predictive value of beer consumption appeared to be even higher than that of fall consumption and smoking. A similar pattern was found for total alcohol consumption. 


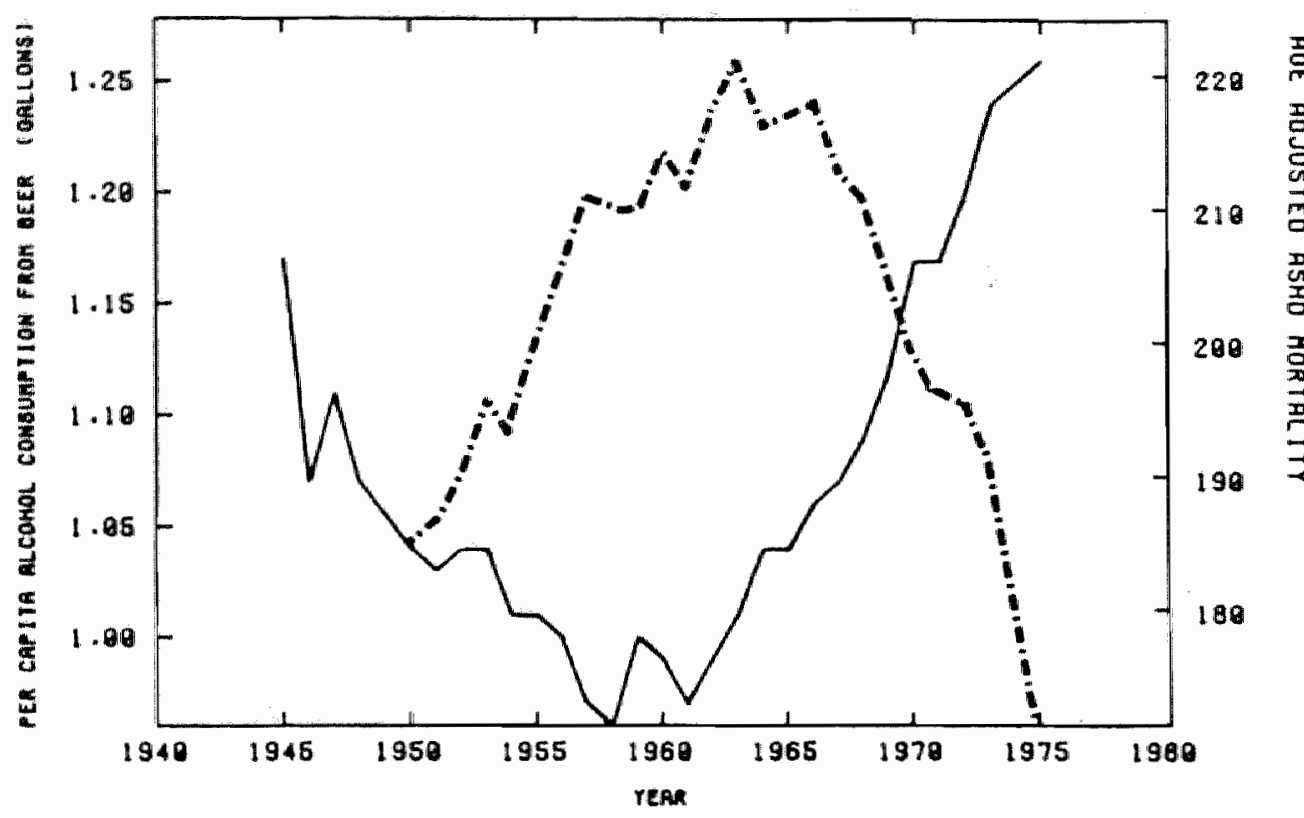

Figure 2. Relationship of changes in adult per capita intake of alcohol beer (1945-1975) to changes in total United States age-adjusted heart disease death rates (1950-1975). CHD death-rate, beer consumption (3).

Ecological studies are no real proof of a favourable effect of alcohol consumption on CHD development. Results just indicate a relationship on a population level, and differences between countries with regard to culture and living and working conditions are not taken into account. A second drawback of these studies is that alcohol consumption data are derived from alcohol sales data, uncorrected for sales to visitors from abroad.

Finally, the hypothetical U-shaped curve poses an insurmountable problem for ecological studies since the use of sales statistics does not differentiate between non-drinkers, moderate drinkers and heavy drinkers.

In spite of these objections, the fact that the CHD mortality rate for Frenchmen aged 55-64 is so much (almost 3-fold) lower than for their Dutch 


\section{CHAPTER 2}

contemporaries is most intriguing and suggests the need for further research.

\section{Case-control studies}

In many case-control studies alcohol consumption among $\mathrm{CHD}$ cases has been compared with that among controls $(6-13)$. The results of these studies fairly consistently point at an inverse relation between moderate alcohol consumption and CHD incidence for both men and women. Only Kaufman et al. (13) found no effect of moderate alcohol consumption.

Petitti et al. (9) found among women the relative risk (RR) of acute myocardial infarction for non-drinkers versus drinkers to be $3.1(95 \% \mathrm{Cl}$ (confidence interval) 1.6-6.0). These results were confirmed by Stason et al. (6) for both men and women. In another study among women, Rosenberg et al. (11) arrived at similar conclusions; they found significantly lower RRs among drinkers for wine, beer and spirits separately $(0.5,0.8,0.9$ respectively).

The studies mentioned above have not differentiated for consumption level. Hennekens et al. (7), however, classified their study population into three categories, with an average daily consumption of $0,0-31 / 2$ and $>31 \frac{1}{2}$ glasses respectively. The relative risk was found to be significantly lower for moderate drinkers than for non-drinkers $(R R=0.4)$, but the difference between the highest consumption category and the non-drinkers was not significant ( $R R=0.7$ ). In contrast, Klatsky et al. (8) found the relative risk to decrease with increasing consumption level $(0.4,0.7$ and 1.0 for categories with a daily consumption levell of $>5,3-5$ and $<3$ glasses respectively).

As for ecological studies, some critical comments could be made on case-control studies. First, many case-control studies have been conducted in a hospital, so that CHD patients dying before arrival at the hospital have been left aside. However, the results of two studies in which the CHD cases who had died before admission were included $(7,9)$ did not diverge from other results.

Second, the group defined as 'non-drinkers at the time of investigation' may comprise former alcoholics who have recently stopped drinking alongside people who have never drunk. Since the group of nondrinkers is usually the reference group ( $R R=1.0$ ) this classification bias can yield erroneous results. Klatsky et al. (8), therefore, defined non-drinkers as people who had not drunk any alcohol in the past year at least, and the control group of Rosenberg et al. (11) comprised exclusively lifelong teetotallers. In both studies an inverse relationship 
between moderate alcohol consumption and CHD incidence could still be found.

Third, the category of moderate drinkers could be characterized by a life-style leading to a reduced risk of $\mathrm{CHD}$, regardless of drinking pattern.

In some studies of CHD cases the extent of occlusion of coronary arteries has been established by arteriography (14-17). Barboriak et al. (14) have studied the effects of smoking and of alcohol consumption on coronary artery occlusion in a group of 2989 men. Figure 3 summarizes the results of that study. Smoking was found to have a dose-dependent occlusive effect, whereas the effect of alcohol was associated with lower

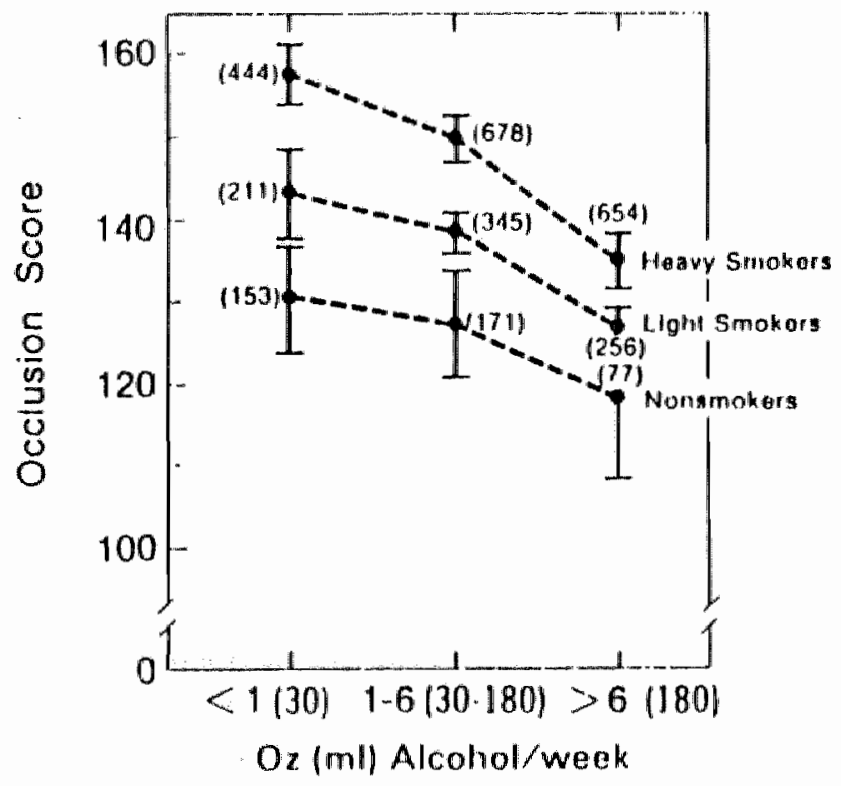

Figure 3. Interrelationships between the extent of coronary occlusion, alcohol intake and smoking. Number of patiens in parentheses. Vertical bars $=$ SEM (14).

occlusion scores in non-smokers, light smokers as well as heavy smokers. Gruchow et al. (16) have investigated, within the same study framework, the effect of alcohol consumption pattern by classifying the subjects into non-drinkers, occasional drinkers, regular drinkers adhering to a more or less fixed dose, and regular drinkers varying the amounts consumed. Regular users of moderate doses of alcohol were found to be at 


\section{CHAPTER 2}

significantly lower risk of occlusion of coronary arteries. Irregular drinkers were at higher risk irrespective of dose.

Fried et al. (18) have studied in a group of 31 men with coronary arteries of normal diameter the effects of smoking and of alcohol consumption on the diameter of three main coronary arteries. Smoking and alcohol use appeared to affect these diameters highly significantly and independently. Smoking was found to have a vasoconstrictive effect, whereas alcohol consumption promoted vasodilatation.

\section{Cohort studies}

In cohort studies, also called prospective studies or longitudinal studies, large study populations are classified into categories varying in alcohol consumption level. After a number of years the association between alcohol consumption and $\mathrm{CHD}$ incidence is studied. In the past few years the effect of moderate drinking on $\mathrm{CHD}$ incidence has been investigated in many cohorts all over the world (19-45). A reduced risk of CHD has been found among moderate drinkers in Framingham, MA (19, 39, 40), Chicago (25), San Francisco (26, 27), western Australia (28), Yugoslavia (29), eastern Finland (30), Puerto Rico (31), Albany, NY (32), London (33) and Japan $(34,35)$.

In two studies - one in Ireland (36), another in California (37) - no effects of alcohol use were found. A recent study in Finland showed, in contrast to all other studies, a positive association between consumption of alcohol, in particular consumption of spirits, and CHD incidence (38).

It is from cohort studies in particular that the U-shaped curve has arisen. In 1980, Dyer et al. (25), who had followed 1899 employees of the Western Electric Company from 1957 to 1974, were the first to suggest the $U$-shaped curve. They found CHD incidence to decrease with increasing alcohol consumption up to a daily dose of 5 glasses and to increase at higher dosages. However these results lost their significance after correction for smoking habits, serum cholesterol level and blood pressure. In 1981 the U-shaped curve was confirmed by Klatsky et al. (26), who had followed 8060 Californian men and women for 10 years, and by Marmot et al. (33) in a comparable study among 1422 male civil servants in London (Figure 4).

In the study of Marmot et al. the decreasing left-hand part of the $U$ shaped curve was attributed primarily to a decrease in CHD mortality rate with increasing alcohol consumption, and the increasing right-hand part to an increase in mortality unrelated to CHD at an average daily alcohol dose above 34 g. In 1986, Friedman and Kimball (39) found support for an Ushaped association between alcohol consumption and CHD incidence in their 
studiy among 5209 men and women in Framingham during a 24-year follow-up period. The decreased $\mathrm{CHD}$ incidence among moderate drinkers as compared to non-drinkers has been confirmed in various other studies (see above).

A serious drawback of many of these studies is that the category of non-drinkers considered in these studies may comprise former heavy drinkers as well as people who have given up alcohol on medical advice

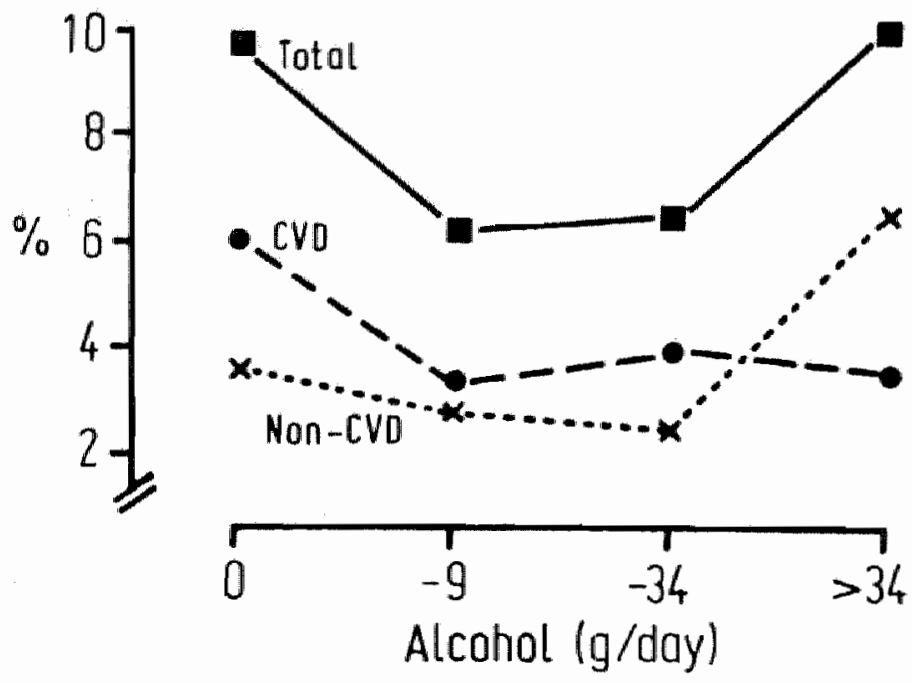

Figure 4. Relationship between 10-year mortality (CVD- and non-CVD related) and daily alcohol consumption (33).

based, for example, on a heart condition. This possible bias has recently been studied by Shaper et al. (41) in a cohort of 7735 men living in 24 different towns in England, Scotland and Wales. They found a L-shaped relationship between alcohol consumption and total mortality and an inverse relationship between alcohol consumption and cardiovascular disease (CVD) mortality, in fair correspondence with the results of Marmot et al. (Figure 4). At the start of the follow-up study, when the average age of the subjects was 50 years, $24.2 \%$ of the subjects had a heart condition. The associations between alcohol and total mortality and between alcohol and CVD mortality were studied for both sub-cohorts separately (men suffering from and men free from heart disorders). In the category initially free from heart disorders a U-shaped or inverse 
relationship could no longer be found. Shaper et al. concluded that the $U$ shaped curve could largely be explained from the fact that people suffering from CVD disorders tend to reduce or even give up alcohol consumption so that the curvature camnot be attributed to any favourable effects of moderate alcohol use. The Lancet paper of Shaper et all. (41) has evoked a lively discussion in that journal as to whether moderate alcohol use protects against CHD (42-44).

In the Honolulu Heart Study (23), in which the non-drinkers were classified into lifetime teetotallers and former drinkers, a higher CHD incidence as compared to drinkers was found for both categories. This finding has been supported by the results of a case-control study among 513 cases and 918 controls (11) and other studies (27, 34, 35). In the Honolulu Heart Study (23) and in a study by Klatsky et al. (27) no significant differences in CHD risk were found between lifetime teetotallers and former drinkers. Finally. Stampfer et al. (45), in a cohort of as many as 87,526 nurses, has recently searched into any changes in drinking habits over the past ten years. Subjects who had given up drinking on medical advice could be excluded from the study this way. The $\mathrm{CHD}$ risk for the non-drinkers group were found to be up to $2 \frac{1}{2}$ times as high as for the drinkers categories.

The results of the various studies are less consistent for the righthand part of the U-shaped curve, i.e. the higher CHD risk for excessive drinkers. Some studies, however, work with relatively low upper limits. In Marmot et al.'s study (33), for example, all people with a daily alcohol consumption over $34 \mathrm{~g}$ have been assigned to one and the same category (Figure 4), although adverse effects of alcohol use on CHD may apply for far higher levels.

In most cohort studies alcoholic beverages are not categorized. However, there are marked (culturally based) differences in popularity of particular beverages, which could be reflected by the results of the various studies.

\section{Summary}

In most epidemiological studies an inverse relationship between moderate alcohol use and CHD incidence has been found. In some studies excessive alcohol use has been found to increase CHD risk, which could imply a U-shaped, or J-shaped, relationship. All three types of study ecological, case-control and cohort studies - are subject to criticism. The strongest objection against these types of research could be that the association between alcohol consumption and CHD found may well be attributable to factors other than alcohol, such as differences in 
personality, life-style or nutrition, or a combination of these. If so, these unknown factors must increase CHD risk for non-drinkers in populations as diverse as Japanese in Japan, Japanese in Hawaii, people in various regions of the USA, Puerto Ricans, Yugoslavians, London civil servants, and inhabitants of Busselton, Australia. Moreover, these factors must be most dominant in countries with the lowest alcohol consumption. Of course, such factors or such a complex of factors could exist. However, a preventive effect of moderate alcohol use on CHD far more simply explains the effects observed.

The question how moderate alcohol use can influence CHD risk is discussed below.

\section{Epidemiological research into CHD risk factors}

Several factors have been found to influence CHD risk. In search of explanations for the favourable effect of moderate alcohol use on CHD risk many epidemiologists have studied the relationships between alcohol use and these risk factors.

\section{Blood pressure}

The popularity of blood pressure measurements in population research is reflected by the large number of epidemiological studies on the relationship between alcohol use and blood pressure. As early as 1915, Camille Lian (46) reported an elevated blood pressure as a result of excessive alcohol use. Many epidemiological studies have fairly consistently confirmed the hypertensive effect of excessive alcohol use (47-55), even after correction for other CHD risk factors such as smoking, obesity, excessive salt intake and high serum cholesterol level.

There is much less consensus as to the question of the level at which alcohol consumption has a hypertensive effect. Some studies have found a continuous increase, from no alcohol use to heavy use $(47,48,58,59)$. Some other studies have established a threshold above which alcohol use was found to be positively associated with blood pressure. In still other studies $(51,52,60)$ a J-shaped relationship between alcohol use and blood pressure was found, in particular for women (Figure 5).

So, it is hard to tell whether or to what extent moderate alcohol use contributes to hypertension incidence. Hypertension increases CHD risk, but moderate alcohol use is certainly not positively rellated to CHD incidence. Hypertension also increases the risk of cerebral haemorrhage, which appears to be positively related to excessive alcohol use (61-63). 


\section{Cholesterol metabolism}

Cholesterol is a well known CHD risk factor. An essential element in the body's defence against cholesterol accumulation in tissues - where cholesterol can damage vascular wall - is 'reverse cholesterol transport', i.e. transport from the tissues to the liver, where

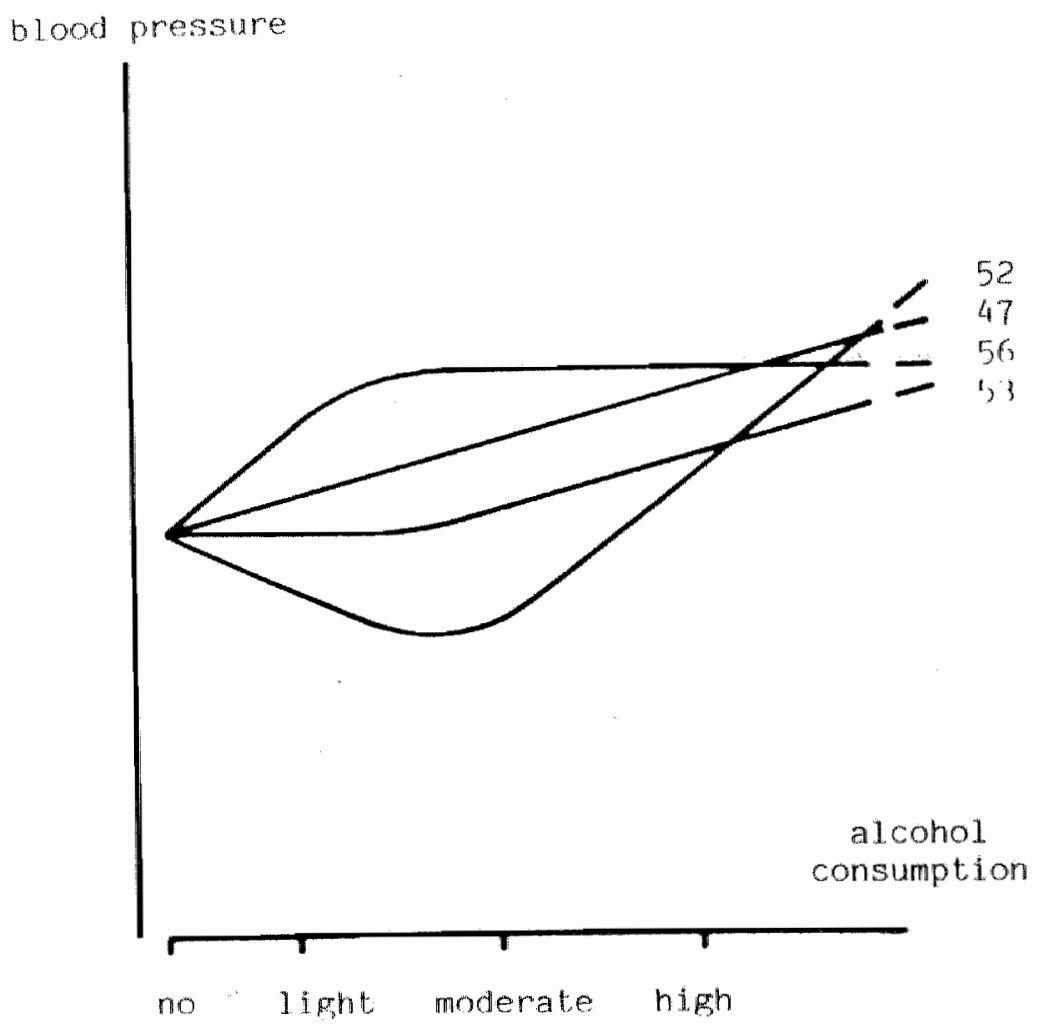

Figure 5. Relationship between alcohol consumption and blood pressure in different studies $(47,52,53,56),(57)$.

cholesterol is converted into bile acids and excreted via the bile. The lipoprotein that probably plays an important role in this reverse cholesterol transport is high-density lipoprotein (HDL). HDL consists of proteins for about $50 \%$, among which apoliproteins $\mathrm{A}_{1}$ and $\mathrm{A}_{2}$ (Apo- $\mathrm{A}_{1}$ and 
Apo- $\mathrm{A}_{2}$ ) are predominant. These proteins are essential not only as an envelope for lipids to be transported but also for particle recognition.

Epidemiological studies (64-71) have established that a high blood HDL-cholesterol (HDL-C) level decreases CVD risk. Apo- $A_{1}$ and Apo- $A_{2}$ concentrations may be even better indicators of CVD risk. A great deal of epidemiological studies (72-95) all over the world have consistently proved a positive association between alcohol consumption and blood HDL-C level. When the research populations were classified according to gender and type of alcoholic beverage consumed (Figure 6), as in the Tromsa Heart Study (77), the correlations in all categories were significantly positive. Even low alcohol doses increased HDL-C levels.

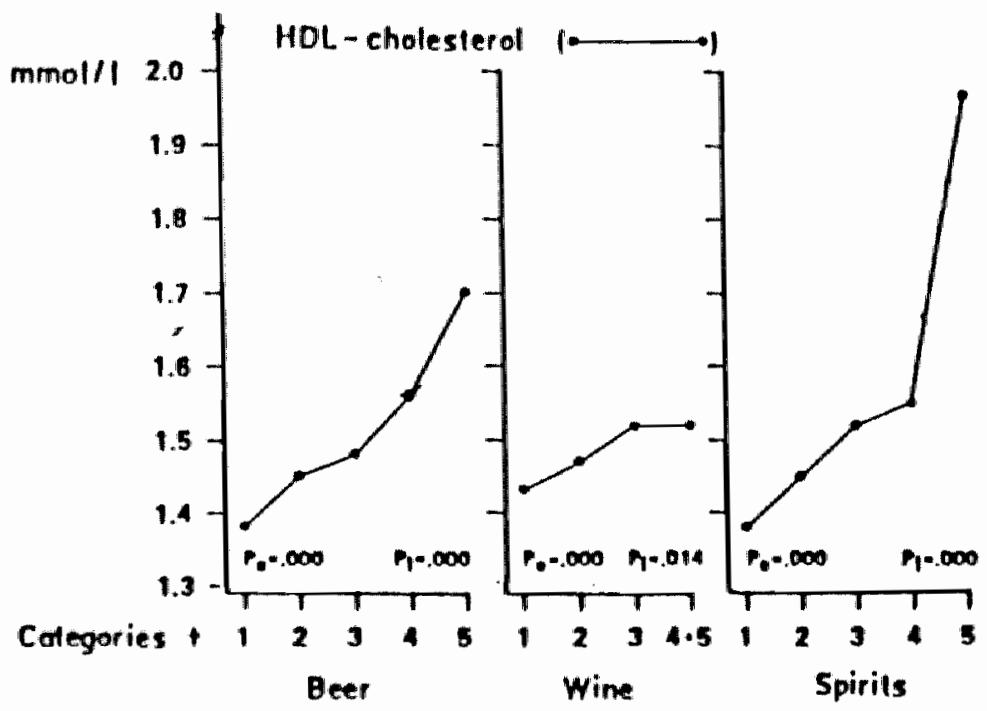

Pe:p-value for test of equal group means

Pi:p-value for test of linear trend

- Also adjusted for time since last meal

+ Categories as in table I

Figure 6. Relationship between HDL-C and alcohol consumption (77).

One could wonder whether this apparently linear relationship between alcohol consumption and blood HDL-C level can explain a favourable effect of alcohol use on CHD incidence. Initially it seemed so in view of the increase of the HDL-C level induced by alcohol consumption. Later doubts 
about the protective effect of alcohol along the HDL-C pathway are based on the fact that HDL-C consists of two subfractions, $\mathrm{HDL}_{2}-\mathrm{C}$ and $\mathrm{HDL}_{3}-\mathrm{C}$. In epidemiological studies $\mathrm{HDL}_{2}-\mathrm{C}$ has been associated with $\mathrm{CHD}$ risk, but $\mathrm{HDL}_{3} \mathrm{C}$ far less so (96). The increase of the $\mathrm{HDL}-\mathrm{C}$ induced by moderate alcohol use, however, has been attributed predominantly to the $\mathrm{HDL}_{3}-\mathrm{C}$ fraction (96) whereas elevated values for $\mathrm{HDL}_{2} \mathrm{C}$ - the subfraction most related to $\mathrm{CHD}$ risk - have been found particularly in alcoholics. Alcoholics, however, run highly increased health risks along other pathways and hence draw little benefit from an increased $\mathrm{HDL}_{2}$-C level. Recently, however, Miller et al. (97), in the first large-scale epidemiological study (4860 men) on the effects of alcohol on HDL-C subfraction levels, found comparable positive associations between alcohol consumption and both $\mathrm{HDL}_{2}$-C and $\mathrm{HDL}_{3}$-C.

Few epidemiologists studying the effects of moderate alcohol use have taken the apoproteins $A$ po- $\mathrm{A}_{1}$ and $\mathrm{Apo}_{\mathrm{A}} \mathrm{A}_{2}$ into consideration. Phillips et al. (98) have found a positive association between alcohol use and Apo- $A_{1}$ level in a group of 289 Californian men and women, but have not measured Apo-A $_{2}$. Haffner et al. ((99); 77 men) and Williams et al. ((95); 50 men and women) have found positive correlations for both Apo- $A_{1}$ and $A$ po- $A_{2}$. In these two studies alcohol use was found to correlate positively with $\mathrm{HDL}_{3}$ $\mathrm{C}$ level, but not with $\mathrm{HDL}_{2}$-C level.

\section{Haemostasis}

Besides impairment of vascular walls, haemostasis plays an important part in the occurrence of a myocardial or cerebral infarction. Haemostasis is the balance between clot formation, in which blood platelets are involved, and fibrinolysis, the dissolution of such clots. In a study into the causes of occlusion of coronary arteries in cases of myocardial infarction, in most cases the artery was found to be blocked by a clot primarily consisting of thrombocytes (100). In normal physiological conditions the formation of thrombocyte clots, called platelet aggregation, is continually inhibited by prostacycline, a substance formed by endothelial cells covering the blood vessels. The platelets themselves produce thromboxane, which stimulates platelet aggregation. Most probably platelets constantly aggregate to some extent, depending on the balance of thromboxane and prostacycline production. Besides, several fibrinolytic factors play a part in continually dissolving newly formed clots.

Recently a large-scale epidemiological study proved that influencing the thromboxane/prostacycline balance by a dose of $350 \mathrm{mg}$ aspirin every other day' favourably affects myocardial infarction risk (101). A lowered fibrinolytic activity has been found in infarct patients (102-106). Good 
results have been achieved in stimulating fibrinolytic activity immediately upon occurrence of the infarct and thus making the clot blocking the blood vessel redissolve (107). Of course, if alcohol influences this complex and delicate haemostatic balance this could explain the favourable effect of alcohol consumption on $\mathrm{CHD}$ risk.

In epidemiological studies on the physiological consequences of moderate alcohol use hardly any research effort has been devoted to the platelet aggregation process. Epidemiological research in this field is primarily hampered by analytical problems. Most analytical methods for the measurement of thrombocyte function are complicated and time-consuming, and analyses must be carried out soon (within one hour) after blood sampling, which makes analyses of this kind hard to use in large-scale population studies. That is why only one research team has included this variable in their study. Meade et al. (108) have investigated the association between alcohol consumption and platelet aggregation in a population of 685 British men and 273 British women (Northwick Park Heart Study). They found an inverse relationship for both adenosine diphosphate (ADP)-induced and adrenaline-induced platelet aggregation.

Some new analytical methods for determining platelet function are easier to use in large study populations and are likely to be used in future epidemiological alcohol studies, e.g. the platelet factor betathromboglobulin and platelet factor 4 (PF-4), which are indicators of in vivo platelet aggregation. To date, however, investigations into the association between alcohol use and platelet function are almost exclusively confined to experimental research.

Meade et al. have also investigated the effect of alcohol on fibrinolysis in men and women of the Northwick Park Heart Study population (109). They found moderate alcohol use to be associated with a decreased plasma fibrinogen level and an increased fibrinolytic activity.

\section{Summary}

In epidemiological research on the association between alcohol use and CHD risk indicators a number of possible explanations of the beneficial effect of moderate alcohol use on $\mathrm{CHD}$ incidence have been studied. Excessive alcohol use has been found to elevate blood pressure. The effect of moderate alcohol use on blood pressure is still uncertain. Alcohol use affects cholesterol metabolism. Moderate alcohol use appears to be associated with an increased HDL-C level. Initially this increase was assumed to (partly) explain the favourable effects of moderate alcohol use. Later, moderate alcohol use has been found to be associated primarily with an increase of the $\mathrm{HDL}_{3}-\mathrm{C}$ fraction, whereas it is the other fraction, 
$\mathrm{HDL}_{2}-\mathrm{C}$, that is claimed to have a beneficial effect on $\mathrm{CHD}$ risk. However alcohol consumption has recently been proved to be positively associated with both $\mathrm{HDL}_{2}-\mathrm{C}$ and $\mathrm{HDL}_{3}$-C. In addition, alcohol can affect cholesterol metabolism favourably by increasing the levels of $A_{p o-} A_{1}$ and $A p o-A_{2}$ apolipoproteins.

Alcohol might also protect against CHD by influencing haemostasis. Just one research group has paid attention to the effects of alcohol on platelet aggregation and found an inverse relationship between alcohol use and platelet aggregation rate.

In one epidemiological study, in which fibrinolysis was among the subjects of investigation, evidence has been produced that moderate alcohol use is associated with an increase of fibrinolytic activity, thereby promoting the efficient removal of clots from the circulation.

\section{Experimental research on CHD risk factors}

An association between alcohol use and CHD risk has been demonstrated in many epidemiological studies. Other epidemiological work suggests that alcohol consumption influences several CHD risk factors. However in these observational studies it is difficult to assess the possible causal nature of the associations seen.

Experimental research enables the establishment of the direct effect of a particular treatment on variables such as blood pressure, cholesterol metabolism indices and haemostasis. However experimental studies have their limitations as well. Such experiments are usually confined to a period of a few weeks, and long-term effects cannot be pronounced upon. In contrast, in epidemiological research effects and between-group differences can be surveyed over many years or even during a life time. Further, experimental studies are conducted in selected groups of limited size. Experimental alcohol studies are often confined to only one beverage type and one or two dosages. In experimental research, therefore, the study design should be chosen such that relevant conclusions on the effects of moderate alcohol use can be given in spite of the limitations mentioned.

\section{Blood pressure}

In experimental research the effect of alcohol on blood pressure has been studied for normotensive subjects, hypertensive subjects as well as CHD patients. 
Potter et al. (110) have studied the effect of a single alcohol dose on the blood pressure of 16 young male students. Blood pressure was measured over a 5-hour period after the ingestion of either $600 \mathrm{ml}$ nonalcoholic beer or $600 \mathrm{ml}$ non-alcoholic beer spiked with alcohol $(0.75 \mathrm{~g}$ per $\mathrm{kg}$ body weight). All volunteers were subjected to both treatments in a cross-over design. The period between both treatments was at least one week. The blood pressure course roughly paralleled the blood alcohol level: after a rapid increase by ca. $7 \mathrm{mmHg}$ within one hour blood pressure gradually decreased. Similar acute effects have been observed by Ireland et al. $(111,112)$.

Studies of this design have the drawback that the two treatments are not isocaloric: the caloric value of the alcohol is not compensated for in the control treatment. In a study by Stott et al. (113) this energy effect has been taken into account. In their study, the design of which was comparable to Potter et al." $s$ for the rest, an isocaloric amount of glucose was added to the non-alcoholic drink. A slight increase of blood pressure was observed one hour after alcohol ingestion, followed by a decrease. However, the picture was similar for the glucose treatment. Stott et al. concluded that the increase of blood pressure after the ingestion of a single moderate dose of alcohol does not differ from the decrease after the ingestion of an isocaloric amount of glucose.

An increase in plasma adrenaline and noradrenaline levels after alcohol ingestion found in some studies $(112,114-116)$ have been connected with a rise in blood pressure. However these studies have not allowed for the caloric value of alcohol, in spite of indications that energy intake alone can increase plasma catecholamine level (117). Further, rapid ingestion of alcohol in experimental conditions can evoke aspecific stress response and feelings of discomfort (118). Stott et al., who have allowed for these aspects as far as possible, have not found effects of alcohol consumption on plasma catecholamine level (113).

In various investigations the effects of alcohol consumption on the blood pressure of hypertensive subjects have been studied (119-121). Puddy et al. (119), in a study among 44 hypertensives accustomed to the daily consumption of at least 3 glasses of alcoholic beverage (6 to 7 glasses on the average), investigated the effect of the consumption of low-alcohol beer $(0.9 \% \mathrm{v} / \mathrm{v}$ alcohol) versus regular beer $(5 \% \mathrm{v} / \mathrm{v}$ alcohol). After a 6 week period in which they consumed regular beer in amounts equivalent to the alcohol dose they were accustomed to they switched over to low-alcohol beer for another 6-week period. Their blood pressure was found to be significantly higher in the period of regular beer consumption. Similar results among hypertensives have been found by Potter and Beevers (120) and Malhotra et al. (121), albeit over shorter periods (4 and 5 days 
respectively). In Puddy et al.'s study not only blood pressure but also body weight was significantly higher in the period of regular beer consumption. This body weight increase has undoubtedly strengthened the effect of alcohol on blood pressure. To date no studies among hypertensives have been conducted in which the effect of alcohol energy versus non-alcohol energy has been investigated.

Kelbaek et al. $(122,123)$ have recently studied the effect of a single alcohol dose $(0.9 \mathrm{~g}$ per $\mathrm{kg}$ body weight) on the heart function of 20 male $\mathrm{CHD}$ and cardiopathy patients. Ten controls with a similar clinical picture received an equal amount of an isocaloric non-alcoholic drink. A slight but significant decrease $(6 \%)$ of the systemic arterial blood pressure was found after alcohol ingestion. Alcohol was found to have no effect on the central venous pressure, on pulmonary artery pressure, on cardiac output. on stroke volume or on global peripheral resistance. Kelbaek et al. concluded that ingestion of a moderate dose of alcohol by CHD patients is unlikely to evoke disease symptoms.

\section{Cholesterol metabolism}

Experimental studies into the effect of alcohol use on cholesterol metabolism can be classified in various ways, for example according to experimental period, alcohol dose, beverage type or variables measured. Besides, in some studies alcoholics have been included.

In many studies a promotive effect of alcohol on HDL or HDL-C level has been found within some weeks after alcohol ingestion (124-133). Only two studies have not found any effect $(134,135)$. However it should be noted that the experimental period was rather short in one of these studies (134) and that the alcohol dose was very low in the other one (135). Moore et al. (135) did find an increased Apo- $A_{1}$ level after a daily consumption of one glass of beer for 8 weeks. Table 1 surveys the doses and beverage types applied in the studies mentioned and the length of the experimental periods.

The HDL-C fractions $\mathrm{HDL}_{2}-\mathrm{C}$ and $\mathrm{HDL}_{3}-\mathrm{C}$ have been determined separately in six studies $(126,128-130,132,135)$. The results of these studies are conflicting. Haskell et al. (126) and Pikaar et al. (130) have found an increase of $\mathrm{HDL}_{3}-\mathrm{C}$, but not of $\mathrm{HDL}_{2}-\mathrm{C}$. Burr et al. (128) and Contaldo et al. (132), however, have reported that the HDL-C rise found in their studies could be attributed primarily to an increase of $\mathrm{HDL}_{2} \sim \mathrm{C}$ level. Masarei et al. (129) have found significant increases for both $\mathrm{HDL}_{2}-\mathrm{C}$ and $\mathrm{HDL}_{3}$-C. Moore et al. (135) have not found an effect of alcohol on HDL-C, nor on any of its fractions. 
Table 1. Survey of studies into the effects of some weeks of alcohol use on HDL or HDL-C level.

\begin{tabular}{llll}
\hline $\begin{array}{l}\text { Allcohol dose } \\
\text { (g/day) }\end{array}$ & Type of beverage & $\begin{array}{l}\text { Duration of } \\
\text { study (weeks) }\end{array}$ & Reference \\
\hline 28 & beer & 3 & 124 \\
39 & white wine & 6 & 125 \\
31 (average) & optional & 6 & 126 \\
31 & red wine & 5 & 127 \\
18.4 (average) & optional & 4 & 128 \\
24 & beer & 6 & 129 \\
23 or 46 & red wine & 5 & 130 \\
75 & alcohol or beer & 5 & 131 \\
75 & red wine & 5 & 132 \\
90 & diluted alcohol & 4 & 133 \\
34 or 53 & wodka & 2 & $\mathbb{1 3 4}$ \\
12.6 & beer & 8 & 135 \\
\hline
\end{tabular}

Apo- $A_{1}$ levels have been determined in just three of the above papers (127, 129, 135) and Apo-A $A_{2}$ in just one of these (129). Alcohol has consistently been found to increase Apo-A $A_{1}$ levels, and in Masarei et al.'s studly (129) Apo- $\mathrm{A}_{2}$ levels were found to be significantly higher after beer consumption for 6 weeks. Camargo et al. (136) have studied the effect of alcohol ( 3 weeks, $37.8 \mathrm{ml}$ on the average) on apolipoproteins in 24 healthy volunteers and found similar results for both Apo-A $A_{1}$ and $A$ po- $A_{2}$.

Increased HDL-C levels are frequently found in alcoholics. In some studies the course of the HDL levels over a period of abstention has been studied. Vallimäki et al. (137) have studied the changes in blood lipid levels in 12 alcoholics who had presented themselves for therapy in an alcohol rehabilitation centre at Helsinki. All of them were still under the influence of alcohol at the start of the study. As soon as two days after the start of abstention a significant decrease was found for levels of $\mathrm{HDL}_{2}(16 \%), \mathrm{HDL}_{2}-\mathrm{C}(30 \%)$ and $\mathrm{HDL}_{3}-\mathrm{C}(14 \%) . \mathrm{HDL}_{2}$ and $\mathrm{HDL}_{2}-\mathrm{Clevels}$ continued to decrease in the next days to a total decrease of $38 \%$ and $47 \%$ respectively. The effects observed in the $\mathrm{HDL}_{2}$ fraction were much stronger than those for $\mathrm{HDL}_{3}$, which made the authors conclude that changes in HDL in chronic alcoholics are primarily explained by changes in $\mathrm{HDL}_{2}$. The rapid decline of HDL-C levels found leads to the conclusion that increased HDL $-C$ levels are maintained only as long as alcohol is consumed on a 
regular basis and return to normal levels upon abstention. The decrease of HDL levels in alcoholics upon abstention has been confirmed by other studies (138-143). The HDL 2 and $\mathrm{HDL}_{3}$ fractions have only been studied separately in a study by Taskinen et al. (143), who belonged to the same research group as Välimäki et al. Changes upon abstention were found to apply primarily to the $\mathrm{HDL}_{2}$ fraction in this study too.

The observed short-term effects in alcoholics during abstention was the reason for another study by Välimäki (144) in which the effects of moderate (30 g/day) and heavy alcohol consumption $(60 \mathrm{~g} /$ day) were compared. The consumption levels differed in their effect on the HDL fractions. The high level increased $\mathrm{HDL}_{2}$ levels within two days and gradually increased $\mathrm{HDL}_{3}$ levels later on, whereas the lower level affected $\mathrm{HDL}_{3}$ levels only.

In all studies mentioned above, blood lipid levels have been determined in the fasting state, usually after an overnight fast. Recently some groups have studied the acute effects of alcohol on blood lipid levels in the postprandial state. Goldberg et al. (145) and Franceschini et al. (146), using a comparable experimental design, have studied the effects of a single dose of $40 \mathrm{~g}$ alcohol. The alcohol $(120 \mathrm{ml}$ whisky) was drunk at 09.00 after a 14-hour fast. In Franceschini et al.'s study $100 \mathrm{~g}$ mayonnaise and $25 \mathrm{~g}$ bread were combined with the whisky. Blood lipid levels were measured $4,6,8,10$ and 12 hours after breakfast. Both studies departed from the assumption that the alcohol had been fully metabolized after 4 hours. Goldberg et al. found a significant increase of HDL-C level after alcohol consumption. Moreover, the activity of hepatic lipase, an enzyme essential to reverse cholesterol transport, was found to have decreased by $67 \%$. Franceschini et al. found a decrease of HDL-C level after consumption of alcohol, mayonnaise and bread relative to the treatment without alcohol.

Recently in our Department of Nutrition studies have been performed on the effects of moderate alcohol use in the postprandial phase, one hour after alcohol ingestion when the blood alcohol concentration is assumed to peak. To date no studies seem to have considered the possibility that the contended favourable effect of moderate alcohol use on cholesterol metabolism is effective when the alcohol is still in the circulation. In our studies the effects of a moderate alcohol dose have been investigated in a situation approximating reality as far as possible. In one of these studies (manuscript submitted), each of 8 men aged 20-30 and 8 men aged 45-55 combined alcohol consumption with a dinner early in the evening. Half an hour before dinner they drunk one glass of port, and during dinner two glasses of red wine. For comparison, they drank similar amounts of mineral water instead of alcohol on another day. One hour after dinner, we 
found higher HDL-C levels for the alcohol treatment than for the mineral water treatment. The HDL-C-promoting effect was more prominent in the middle-aged men and was most evident for the $\mathrm{HDL}_{2}$-C fraction.

\section{Haemostasis}

In experimental research attention has also been paid to effects of alcohol on haemostasis. Research on platelet function is characterized by broad variation in methodology. The most commonly used parameter is platelet aggregation. In a platelet suspension in plasma aggregation is induced by adding collagen or another catalyst. Collagen induces platelet aggregation also under physiological conditions, when tissue damage leads to haemorrhage. Besides, aggregation can be induced by many other stimuli. A serious drawback of determinations of this type is that the results of in vitro measurements of platelet function are not necessarily applicable to the in vivo situation. First, stimulation of platelet aggregation in vitro asks for stimulus levels far above physiological concentrations. Second, the platelet-rich plasma suspension contains no cells but platelets, whereas aggregation in vivo is a combined action of various types of blood cells and endothelial cells of the vascular wall, in which a regulatory role is played by the various mediators produced by these cells. Third, the risk of an infarct is determined by the spontaneous tendency towards aggregation of the platelets in vivo, which can be started off by a shift in haemostatic balance. No reliable conclusions with regard to this process can be drawn from in vitro determinations of platelet aggregation.

Bleeding time is the time after which a wound (puncture or incision) stops bleeding. The drawbacks of platelet aggregation measurements mentioned above do not apply to this parameter. However measurement of bleeding time is imprecise and hard to standardize.

Finally, statements as to the tendency towards aggregation can also be given on the basis of the activity of the aggregation promoter thromboxane and of the aggregation inhibitor prostacycline.

Table 2 summarizes studies into the effects of alcohol consumption by healthy volunteers on platelet function. From this table it can be concluded that, in spite of the multiplicity of studies in this area, there is still lack of clarity as to the effects of alcohol on platelet function. In some studies considerable amounts of alcohol were consumed. Hillbom et al. have found in two studies $(156,157)$ an increase of the tendency towards aggregation after a single alcohol dose of $1.5 \mathrm{~g}$ per $\mathrm{kg}$ body weight. In a subsequent study of similar design (158) they have not 
CHAPTER 2

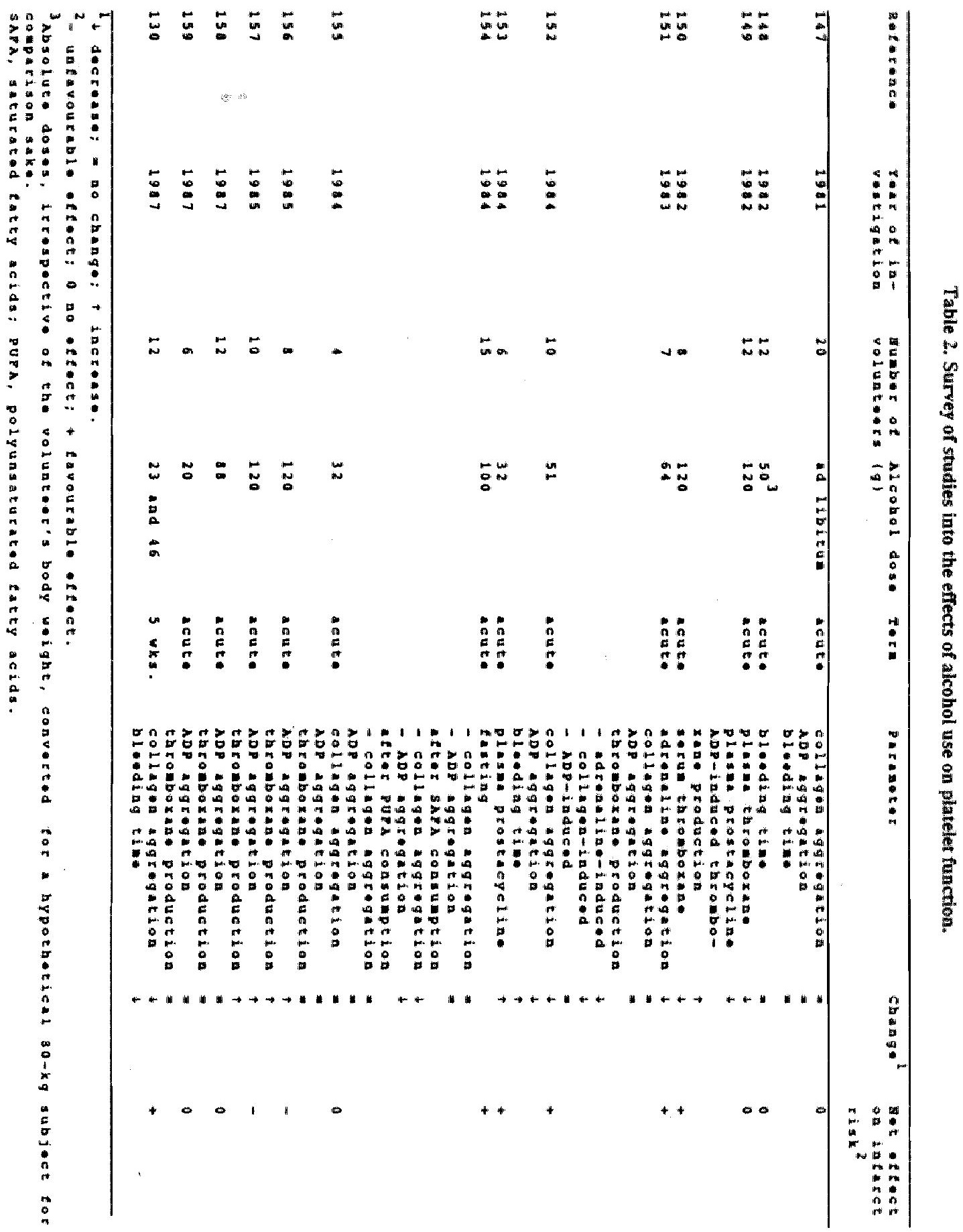


found an effect after ingestion of $1.1 \mathrm{~g}$ per $\mathrm{kg}$ body weight. In accordance with Hillbom et al., Kangasaho et al. (149) have reported an increase of ADP-induced thromboxane production, but they have found lower thromboxane and prostacycline concentrations in plasma after ingestion of a high dose of alcohol. Provided stimulation during blood sampling is avoided, plasma analyses can produce an indication of in vivo concentrations of these mediators. Landolfi et al. (153) have observed an increase of plasma prostacycline level after ingestion of a moderate dose of alcohol (32 g). An increased prostacycline production by endothelial cells (160) and by leucocytes (161) has also been demonstrated in vitro. Elmér et al. (152) have found an extended bleeding time in connection with a lowered aggregation tendency after ingestion of a single dose of $0.64 \mathrm{~g}$ alcohol per $\mathrm{kg}$ body weight.

Pikaar et al.'s study (130) is the only one we know of in which the effect of alcohol consumption has been studied over a longer period ( 5 weeks). In this study, carried out in our Department, a decrease in platelet aggregation was found at a time at which no alcohol was present in the circulation. In a sequel to this study no effects were observed within a 4-day period of moderate alcohol consumption, which could indicate that the acute effects observed result in a permanent decrease of aggregation tendency on the long run. This hypothesis is supported by the results of the epidemiological study of Meade et al. (108) who have found an inverse relation between alcohol and platelet aggregation tendency. So far, virtually all research has focused on acute effects of - usually excessive - alcohol doses. More research is needed to arrive at clefinite conclusions as to the effect of moderate alcohol use on platelet function, particularly to the effect on the longer run.

Stimulation of platelets induces the release of beta-thromboglobulin and platelet factor 4. Levels of these proteins in plasma may be indicative of platelet activation in the circulation, provided activation is avoided during blood sampling. To date such analyses have not been taken into consideration in alcohol research.

Only few studies have paid attention to the effects of alcohol on fibinolytic parameters. Elmér et al. (152) have found effects on bleeding time and platelet aggregation after whisky consumption, but have not found any effects on librinolytic parameters. Anderson et al. (162), however, have reported a dose-dependent decrease of fibrinolytic activity after consumption of cider. This finding has been confirmed by Olsen and Sterud (163) for a mixture of pure alcohol and fruit juice. In contrast, in a recent study of Sumi et al. (164) increased fibrinolytic activity was observed one hour after the consumption of shochu (a spirit), sake and beer. These increases were attributed to a specific urokinase-type 


\section{CHAPTER 2}

plasminogen activator (uk-PA). Pikaar et al. (130) studying the longerterm effects of a dose of 2 and 4 glasses of wine on another activator, tissue-type plasminogen activator (t-PA), have found a dose-dependent decrease. The acute effect of moderate alcohol consumption on t-PA has also been investigated in our study mentioned earlier. One hour after the consumption of one glass of port and two glasses of wine, in combination with dinner, t-PA was found to have decreased considerably, particularly in middle-aged male subjects $(165,166)$.

Further research is needed to provide more insight into the net effect of moderate alcohol consumption on fibrinolysis. It is essential that the effects on various fibinolytic parameters be studied simultaneously.

\section{Summary}

The association between alcohol consumption and blood pressure found in epidemiological research has initially been confirmed by experimental studies. However these studies have not taken the caloric value of alcohol into account. Neither in a study among healthy volunteers nor in a study among CHD patients, in which the acute effects of alcohol intake were measured relative to those of an isocaloric amount of a non-alcoholic beverage, an alcohol-specific increase of blood pressure was found. So far, no well controlled isocaloric research into the long-term association between alcohol consumption and blood pressure has been carried out.

In many studies an increase of HDL-C level has been found among healthy volunteers after some weeks of alcohol consumption. In some of these studies increases of $A$ po- $A_{1}$ and $A p o-A_{2}$ levels have also been observed. There is still some controversy as to the question which HDL-C fraction is increased by alcohol consumption.

Alcoholism has been associated with an increase of HDL-C levels, particularly of the $\mathrm{HDL}_{2}$ fraction. These levels decrease rapidly, within two days, upon alcohol abstention. In healthy volunteers a high intake of alcohol ( $60 \mathrm{~g} /$ day) has been found to increase $\mathrm{HDL}_{2}$ levels within two days even in the fasting state. The mechanism by which alcohol influences HDL-C levels is still unknown.

Only few studies have paid any attention to the acute effects of a moderate alcohol dose on cholesterol metabolism in the postprandial phase. These effects are still unclear. However a constant moderate alcohol use might protect against $\mathrm{CHD}$ through the reiterative, relatively brief favourable effect on reverse cholesterol transport. This might also explain why the daily intake of a moderate dose of alcohol has a more favourable effect than an irregular drinking pattern. 
There is still much uncertainty as to the effects of moderate alcohol use on hacmostasis. In some studies a decreased platelet reactivity has been found soon after alcohol ingestion. An increase of the aggregation intibitor prostacycline in plasma has also been observed. However other studies have not confirmed this finding; in contrast, even an increase of aggregation shortly after ingestion of a high alcohol dose $(1.5 \mathrm{~g}$ per $\mathrm{kg}$ body weight) has been reported. Hardly any attention has been paid to the effect of alcohol use over a period of some days or some weeks. In one study aggregation has been found to decrease after consumption of 2 or 4 glasses of red wine a day over a period of 5 weeks, whereas no effect has been found after 4 days.

Fibrinolytic parameters also appear to be affected by alcohol, but the various types of plasminogen activator have been reported to change in the opposite direction.

\section{Final considerations}

Many epidemiological studies have proved that moderate users of alcohol are at lower risk of CHD than teetotallers. In contrast, excessive alcohol use is supposed to increase CHD risk and entails other health risks as well.

Several biological mechanisms could explain the U-shaped relationship between alcohol use and CHD risk. First, there may be a U-shaped or $J$ shaped connection between alcohol use and blood pressure. Second, alcohol consumption may have a favourable effect on cholesterol metabolism. Third, alcohol has been suggested to affect haemostasis favourably.

Excessive alcohol use, even on an irregular basis, entails increased health risks and is also detrimental in a social context. Measures directed at alcohol moderation, therefore, should aim at driving back alcohol abuse. In contrast, there are, from the viewpoint of health policy, no reasonable arguments for general discouragement or suppression of moderate and sensible alcohol consumption. However, propagation of moderate alcohol use is not free of risk since alcohol consumption even in moderate amounts may be harmful in for example traffic or during pregnancy. Furthermore it may encourage heavy users to be faithful to theif tisky habits and moderate users to turn their sensible drinking pattern into a less prudent one. The latter may be especially true for people who are at high risk for alcoholism.

Finally, favourable effects of alcohol use have primarily been observed on a population level and are not necessarily applicable to individuals. 


\section{Acknowledgment}

Prof. Dr. Ir. R.J.J. Hermus, Dr. Ir. G. Schaafsma, Dr. Th. Ockhuizen, who are all involved in alcohol research in our institute, and D.G. van der Heij are greatfully acknowledged for their support in writing this manuscript.

\section{References}

1. Brummer P. Coronary mortality and living standard, II. Coffee, tea, cacao, alcohol and tobacco. Acta Med Scand 1969;186:61-3.

2. St.Leger AS, Cochrane AL, Moore F. Factors associated with cardiac mortality in developed countries with particular reference to the consumption of wine. Lancet 1979; I:1017-20.

3. LaPorte RE, Cresanta JL, Kuller LH. The relationship of alcohol consumption to atherosclerotic heart disease. Prev Med 1980;9:22-40.

4. Hegsted DM, Ausman LM. Diet, alcohol and coronary heart disease in men. J Nutr 1988:118:1184-9.

5. Schmidt W, Popham RE. Alcohol consumption and ischemic heart disease: Some evidence from population studies. Br J Addic 1981;76:407-17.

6. Stason WB, Neff RK, Miettinen OS, Jick H. Alcohol consumption and nonfatal myocardial infarction. Am J Epidemiol 1976;104:603-8.

7. Hennekens $\mathrm{CH}$. Rosner B, Cole DS. Daily alcohol consumption and fatal coronary heart disease. Am J Epidemiol 1978;107:196-200.

8. Klatsky AL, Friedman GD, Siegelaub AB. Alcohol consumption before myocardial infarction. Results from the Kaiser-Permanente epidemiologic study of myocardial infarction. Ann Intern Med 1974;81:294-301.

9. Petitti DB, Wingerd J, Pellegrin F, Ramcharan S. Risk of vascular disease in woman. Smoking, oral contraceptives, noncontraceptive estrogens, and other factors. JAMA 1979:242:1150-54.

10. Ramsay LE. Alcohol and myocardial infarction in hypertensive men. Am Heart J 1979:98:402-3.

11. Rosenberg L, Slone D, Shapiro S, Kaufman DW. Miettinen OS, Stolley PD. Alcoholic beverages and myocardial infarction in young woman. Am J Publ Health 1981:71:82-5.

12. Ross RK, Mack TM, Paganini-Hill A, Arthur M, Henderson BE. Menopausal oestrogen therapy and protection from death from ischaemic heart disease. Lancet 1981;I:858-60. 
13. Kaufman DW, Rosenberg $L_{*}$ Hemrich SP, Shapiro S. Alcoholic beverages and myocardial infarction in young men. Am J Epidemiol 1985;121:54854.

14. Barboriak JJ, Anderson AJ, Hoffmann RG. Smoking, alcohol and coronary artery occlusion. Atherosclerosis 1982;43:277-82.

15. Barboriak JJ, Anderson AJ, Rimm AA, Tristani FE. Alcohol and coronary arteries. Alcoholism: Clin Exp Res 1979;3:29-32.

16. Gruchow HW, Hoffmann RG, Anderson A.J, Barboriak JJ. Effects of drinking patterns on the relationship between alcohol and coronary occlusion. Atherosclerosis 1982;43:393-404.

17. Pearson TA, Bulkley BH, Achuff SC, Kwiterovich PO, Gordis L. The association of low levels of HDL-cholesterol and arteriographically defined coronary artery disease. Am J Epidemiol 1979;109:285-95.

18. Fried LP, Moore RD, Pearson TA. Long-term effects of cigarette smoking and moderate alcohol consumption on coronary artery diameter. Am J Med 1986;80:27-44.

19. Gordon T, Kannel WB. Drinking habits and cardiovascular disease: The Framingham Study. Am Heart J 1983;105:667-73.

20. Kannel WB, Castelli WP, McNamara PM. The coronary profile: 12-year follow-up in the Framingham Study. J Occup Med 1967;12:611-19.

21. Colditz GA, Branch LG, Lipnick RJ, Willett WC, Rosner B, Posner B, Hennekens $\mathrm{CH}$. Moderate alcohol and decreased cardiovascular mortality in an elderly cohort. Am Heart J 1985;109:886-89.

22. Yano K, Reed DM, McGee DL. Ten-year incidence of coronary heart disease in the Honolulu Heart Program. Am J Epidemiol 1984;119:653-66.

23. Yano K, Rhoads GG, Kagan A. Coffee, alcohol and risk of coronary heart disease among Japanese men living in Hawaii. $N$ Engl $J$ Med 1977:297:405-9.

24. Blackwelder WC, Yano K, Rhoads GG, Kagan A, Gordon T, Palesch Y. Alcohol and mortality: The Honolulu Heart Study. Am J Med 1980;68:1648.

25. Dyer AR, Stamler J, Paul O, Lepper MH, Shekelle RB, McKean H, Garside D. Alcohol consumption and 17-year mortality in the Chicago Western Electric Company Study. Prev Med 1980;9:78-90.

26. Klatsky AL, Friedman GD. Siegelaub AB. Alcohol and mortality. A tenyear Kaiser-Permanente Experience. Ann Intern Med 1981;95:139-45.

27. Klatsky AL, Armstrong MA. Friedman GD. Relations of alcoholic beverage use to subsequent coronary artery disease hospitalization. Am J Cardiol 1986:58:710-4.

28. Cullen K. Stenhouse NS, Wearne KL. Alcohol and mortality in the Busselton Study. Internat J Epidemiol 1982;11:67-70. 
29. Kozararevic D, Vojvodic N, Dawber T, McGee D, Racic Z, Gordon T. Frequency of alcohol consumption and morbidity and mortality: The Yugoslavia cardiovascular disease study. Lancet 1980;1:613-6.

30. Salonen JT, Puska P, Nissinen A. Intake of spirits and beer and risk of myocardial infarction and death. A longitudinal study in eastern Finland. J Chron Dis 1983:36:533-43.

31. Kittner SJ, Garcia-Palmleri MR, Costas R, Cruz-Vidal M. Abbott RD, Havlik RJ. Alcohol and coronary heart disease in Puerto Rico. Am J Epidemiol 1983;1 17:538-50.

32. Gordon T, Doyle JT. Drinking and coronary heart disease: The Albany Study. Am Heart J 1985:110:331-4.

33. Marmot MG, Shipley MJ, Rose G, Thomas BJ. Alcohol and mortality: A Ushaped curve. Lancet 1981;1:580-3.

34. Kono S, Ikeda M, Ogata M, Tokudome S, Nishizumi M, Kuratsune M. The relationship between alcohol and mortality among Japanese physicians. Int J Epidemiol 1983;12:437-41.

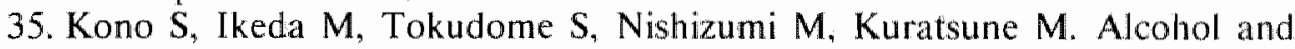
mortality: A cohort of male Japanese physicians. Int $J$ Epidemiol 1 98:6:15:527-32.

36. Greig M, Pemberton J, Hay I, MacKenzie G. A propective study of the development of coronary heart disease in a group of 1202 middle-aged men. J Epidem Comm Health 1980;34:23-30.

37. Camacho TC, Kaplan GA, Richard D. Alcohol consumption and mortality in Almeda County. J Chronic Dis 1987:40:229-36.

38. Suhonen O, Aromaa A, Reunanen A, Knekt P. Alcohol consumption and sudden coronary death in middle-aged Finnish men. Acta Med Scand 1987:221:335-41.

39. Friedman LA, Kimball AW. Coronary heart disease mortality and alcohol consumption in Framingham. Am J Epidemiol 1986:124:481-9.

40. Wolf PA, Kannel WB, Verter J. Current status of stroke risk factors. Neurol Clin 1983;1:317-343.

41. Shaper AG, Wannamethee G, Walker M. Alcohol and mortality in British men: explaining the U-shaped curve. Lancet 1988:11:1267-73.

42. Alcohol and the U-shaped curve. Lancet 1989;1:105.

43. Alcohol and the U-shaped curve. Lancet 1989;I:224-25.

44. Alcohol and the U-shaped curve. Lancet 1989:I:336.

45. Stampfer MJ, Colditz GA. Willett WC, Speizer FE, Hennekens CH. A prospective study of moderate alcohol consumption and the risk of coronary disease and stroke in women. N Engl J Med 1988;319:267-73.

46. Lian C. L'alcoholisme, cause d'hypertension art'rielle. Bull Acad Natl Med Paris 1915;74:525-8. 
47. Arkwright PD, Beilin LJ, Rouse I, Armstrong BK, Vandongen R. Alcohol: effect on blood pressure and predisposition to hypertension. Clin Sci $1981 ; 61: 373 \mathrm{~s}-5 \mathrm{~s}$.

48. Cooke KM, Frost GW, Stokes GS. Blood pressure and its relationship to low levels of alcohol consumption. Clin Exp Pharmacol Physiol 1983;10:229-33.

49. Dyer AR, Stamler E, Oglesby P. Alcohol consumption, cardiovascular risk factors, and mortality in two Chicago epidemiologic studies. Circulation 1977;56:1067-74.

50. Gordon T, Kannel WB. Drinking and its relation to smoking, blood pressure, blood lipids, and uric acid. Arch Intern Med 1983;143:136674.

51. Gyntelberg F, Meyer J. Relationship between blood pressure and physical fitness and alcohol consumption in Copenhagen males aged 4059. Acta Med Scand 1974;195:375-80.

52. Harburg E, Ozgoren F, Hawthorne VM, Schork MA. Community norms of alcohol usage and blood pressure: Tecumseh Michican. Am J Public Health 1980;70:813-20.

53. Klatsky AL, Friedman GD, Siegelaub AB, Gerard MJ. Alcohol consumption and blood pressure. N Engl J Med 1977;296:1194-200.

54. Myrhed $M$. Alcohol consumption in relation to factors associated with ischemic heart disease. Acta Med Scand 1974;195 S:567.

55. Pincherle G, Robinson D. Mean blood pressure and its relation to other factors determined at a routine executive health examination. J Chronic Dis 1974;27:245-60.

56. Mitchell PI, Morgan MJ, Boadle DJ. Role of alcohol in the aetiology of hypertension. Med J Aust 1980;23:198-200.

57. Grobbee DE, Hofman A. Alcohol en bloeddruk. Ned Tijdschr Geneeskd 1985:129:634-8.

58. Cairns V, Keil U, Kleinbaum D, Doering A, Stieber J. Alcoholconsumption as a risk factor for high blood pressure. Hypertension $1984 ; 6: 124-31$.

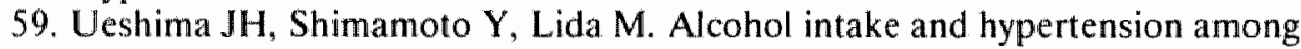
urban and rural Japanese populations. J Chron Dis 1984;37:585-92.

60. Harlan WR, Hull AL, Schmouder RL, Landis JR, Thompson FE, Larkin FA. Blood pressure and nutrition in adults. Am J Epidemiol 1984;120:17-28.

61. Gill JS, Zezulka AV, Shipley MJ, Gill SK, Beevers DG. Stroke and alcohol consumption. N Engl J Med 1986;315:1041-6.

62. Gorelic PB. Alcohol and stroke. Stroke 1987;19:268-71.

63. Hillbom M. What supports the role of alcohol as a risk factor for stroke? Acta Med Scand 1987;S 717:93-106. 


\section{CHAPTER 2}

64. Carlson LA, Ericsson M. Quantitative and qualitative serum lipoprotein analysis. Part 2. Studies in male survivors of myocardial infarction. Atherosclerosis 1975:21:435-50.

65. Castelli WP, Doyle JT, Gordon T, Hames CG, Hjortland MC, Hulley SB, Kagan A, Zukel WK. HDL cholesterol and other lipids in coronary heart disease. Circulation 1977;55:767-72.

66. Goldbourt U, Medali JH. High-density lipoprotein cholesterol and incidence of coronary heart disease-The Israeli ischemic heart disease study. Am J Epidemiol 1979;109:296-308.

67. Gordon T, Castelli WP, Hjortland MC, Kannel WB, Dawber TR. Highdensity lipoprotein as a protective factor against coronary heart disease. Am J Med 1977;62:707-14.

68. Jensen G, Schnohr P, Faergeman O, Meinertz H, Nyboe J, Hansen AT. HDLcholesterol and ischaemic cardiovascular disease in the Copenhagen city heart study. Danish Med Bull 1980;27:139-42.

69. Keys A. Alpha lipoprotein HDL) cholesterol in the serum and the risk of coronary heart disease and death. Lancet 1980;1I:603-6.

70. Miller NE, Thelle DS, Forde OH, Mjos OD. The Tromsø Heart Study. Highdensity lipoprotein and coronary heart disease: A prospective casecontrol study. Lancet 1977; I:965-7.

71. Rhoads GG, Gulbrandsen CL, Kagan A. Serum lipoproteins and coronary heart disease in a population study of Hawaii Japanese men. $\mathrm{N}$ Engl J Med 1976;294:293-98.

72. Allen JK, Adena MA. The association between plasma cholesterol, highdensity lipoprotein cholesterol, triglycerides and uric acid in ethanol consumers. Ann Clin Biochem 1985;22:62-6.

73. Angelico F, Bucci A, Capocaccia R, Morisi G, Terzino M, Ricci G. Further considerations on alcohol intake and coronary risk factors in a Rome working population group: HDL-cholesterol. Ann Nutr Metab 1982;26:73-6.

74. Barboriak JJ, Anderson AJ, Hoffmann RG. Interrelationship between coronary artery occlusion high-density lipoprotein cholesterol, and alcohol intake. J Lab Clin Med 1979;94:348-53.

75. Barboriak JJ, Gruchow HW, Anderson AJ. Alcohol consumption in the diet-heart controversy. Alcohol Clin Exp Res 1983;7:31-4.

76. Barrett-Connor E, Suarez L. A community study of alcohol and other factors associated with the distribution of high-density lipoprotein cholesterol in older vs. younger men. Am J Epidemiol 1982;115:888-93.

77. Brenn $T$. The Tromsø Heart Studly: alcoholic beverages and coronary risk factors. J Epidemiol Commun Health 1986;40:249m56. 
78. Castelli WP, Gordon T, Hjortland MC, Kagan A, Doyle JT, Hames CG. Hulley SB, Zukel W.J. Alcohol and blood lipids. The cooperative lipoprotein phenotyping study. Lancet 1977;11:153-55.

79. Chen $H$, Zhuang $H$, Han Q. Serum high-density lipoprotein cholesterol and factors influencing its levels in healthy Chinese. Atherosclerosis 1983:48:71-9.

80. Croft $\mathrm{JB}$, Freedman DS, Cresanta JL, Srinivasan SR, Burke GL, Hunter SM, Webber LS, Smoak CG, Berenson GS. Adverse influences of alcohol, tobacco, and oral contraceptive use on cardiovascular risk factors during transition to adulthood. Am J Epidemiol 1987;126:202-213.

81. Diehl AK, Fuller JH, Mattock MB, Salter AM, Gohari RE, Keen H. The relationship of high-density lipoprotein subfractions to alcohol consumption, other lifestyle factors and coronary heart disease. Atherosclerosis 1988;69:145-53.

82. Donahue RP, Orchard TJ, Kuller LH, Drash AL. Lipids and lipoproteins in a young adult population. Am J Epidemiol 1985;122:458-67.

83. Ernst N, Fisher M, Smith W, Gordon T, Rifkind BM, Little JA, Mishkel MA, Williams OD. The association of plasma high-density lipoprotein cholesterol with dietary intake and alcohol consumption. The Lipid Research Clinics program prevalence study. Circulation 1980;62 (suppl IV): $41-52$.

84. Gordon T, Doyle JT. Alcohol consumption and its relationship to smoking, weight, blood pressure, and blood lipids: The Albany study. Arch Intern Med 1986;146:262-5.

85. Gruchow HW, Hoffmann RG, Anderson AJ, Barboriak JJ. Effects of drinking patterns on the relationship between alcohol and coronary occlusion. Atherosclerosis 1982;43:393-404.

86. Hulley SB, Cohen R, Widdowson G. Plasma high-density lipoprotein cholesterol level. JAMA 1977;238:2269-71.

87. Hulley SB, Gordon S. Alcohol and high-density lipoprotein cholesterol. Causal inference from diverse study designs. Circulation 1981:64(SHI):57-63.

88. Jacqueson $A$, Richard JL, Ducimetiere $P$, Claude JR. High-density lipoprotein cholesterol and alcohol consumption in a French male population. Atheroscle rosis 1983;48:131-8.

89. Kagan A, Yano K, Rhoads GG, McGee DL. Alcohol and cardiovascular disease: The Hawaiian experience. Circulation 1981;64(SIII):27-31.

90. Kuller LH, Hulley SB, LaPorte R, Neston J, Dai WS. Environmental determinants, liver function and high-density lipoprotein cholesterol levels. Am J Epidemiol 1983;117:406-18.

91. Stamford BA, Matter S, Fell RD, Sady S, Cresanta MK, Papanek P. Cigarette smoking, physical activity, and alcohol consumption: 
Relationship to blood lipids and lipoproteins in premenopausal females. Metabolism 1984;33:585-90.

92. Taylor KG, Carter TJ, Valente AJ, Wright AD, Smith HJ, Matthews KA. Sex differences in the relationship between obesity, alcohol consumption and cigarette smoking in serum lipid and apolipoprotein concentrations in a normal population. Atherosclerosis 1981;38:11-18.

93. Willett W, Hennekens CH, Siegel AJ, Adner MM, Castelli WP. Alcohol consumption and high-density lipoprotein cholesterol in marathon runners. N Engl J Med 1980;303:1159-61.

94. Williams P, Robinson D, Baily A. High-density lipoprotein and coronary risk factors in normal men. Lancet 1979;1:72-75.

95. Williams PT, Kraus RM, Wood PD, Albers JJ, Dreon D, Ellsworth N. Associations of diet and alcohol intake with high-density lipoprotein subclasses. Metab Clin Exp 1985;34:524-30.

96. Moore RD, Pearson TA. Moderate alcohol consumption and coronary artery disease. A review. Medicine 1986;65:242-67.

97. Miller NE, Bolton CH, Hayes TM, Bainton D, Yarnell JWG, Baker IA, Sweetnam PM. Associations of alcohol consumption with plasma highdensity lipoprotein cholesterol and its major subfractions: The Caerphilly and Speedwell Collaborative Heart Disease Studies. J Epidemiol Community Health 1988;42:220-5.

98. Phillips NR, Havel RJ, Kane JP. Serum apolipoprotein A-1 levels. Relationship to lipoprotein lipid levels ans selected demographic varaibles. Am J Epidemiol 1982;116:302-13.

99. Haffner SM, Applebaum-Bowden D, Wahl PW, Hoover JJ, Warnick GR, Albers JJ, Hazzard WR. Epidemiological correlates of high-density lipoprotein subfractions, apolipoproteins A-I, A-II, and D, and lecithin cholesterol acyltransferase. Effects of smoking, alcohol, and adiposity. Arteriosclerosis 1985:5:169-77.

100. DeWood MA, Spores J, Notske R. Prevelance of total, coronary occlusion during the early hours of transmural, myocardial infarction. N Engl J Med 1980;303:897-902.

101. The Steering Committee of The Physicians' Health Study., Preliminary report: Findings from the aspirin component of the, ongoing Physicians' Health Study. N Engl J Med 1988;318:262-264.

102. Chakrabarti R, Hocking ED, Fearnley GR. Fibrinolytic, activity and coronary artery disease. Lancet 1968;1:987-990.

103. Franzen J, Nilsson B, Johansson BW, Nilsson IM. Fibrinolytic activity in men with acute myocardial infarction before 60 years of age. Acta Med Scand 1983;214:339-344. 
104. Hamsten A, Wiman B, de Faire U, Blomback M. Increased plasma, levels of a rapid inhibitor of tissue plasminogen activator in, young survivors of myocardial infarction. N Engl J Med 1985;313:1557-1563.

105. Hamsten A, Blomback M, Wiman B, Svensson J, Szamosi A, de Faire U, Mettinger $\mathrm{L}$. Haemostatic function in myocardial, infarction. $\mathrm{Br}$ Heart J 1986;55:58-66.

106. Nilsson TK, Johnson $O$. The extrinsic fibrinolytic system in, survivors of myocardial infarction. Thromb Res 1987;48:621-630.

107. Arnold AER, Simoons ML, Lubsen J. Trombolytische therapie van het acute hartinfarct anno 1988. Ned Tijdschr Geneeskd 1989;133:341-9.

108. Meade TW, Vickers MV, Thompson SG, Stirling Y, Haines AP, Miller GJ. Epidemiological characteristics of platelet aggregability. $\mathrm{Br}$ Med J 1985;290:428-32.

109. Meade TW, Chakrabarti R, Haines AP, North WRS, Stirling Y. Characteristics affecting fibrinolytic activity and plasma fibrinogen concentrations. Br Med J 1979;1:153-6.

110. Potter JF, Watson RDS, Skan W, Beevers DG. The pressor and metabolic effects of alcohol in normotensive subjects. Hypertension 1986;8:62531.

111. Ireland M, Vandongen R, Davidson L, Beilin LJ, Rouse IL. Pressor effect of moderate alcohol consumption in man: A proposed mechanism. Clin Exp Pharmacol Physiol 1983;10:375-9.

112. Ireland $M$, Vandongen $R$, Davidson $L$, Beilin LJ, Rouse IL. Acute effects of moderate alcohol consumption on blood pressure and plasma catecholamines. Clin Sci 1984;66:643-8.

113. Stott DJ, Ball SG, Inglis GC, Davies DL, Fraser R, Murray GD, McInnes GT. Effects of a single moderate dose of alcohol on blood pressure, heart rate and associated metabolic and endocrine changes. Clin Sci 1987:73:4111-6.

114: Potter JF, Macdonald IA, Beevers DG. Alcohol raises blood pressure in hypertensive patients. J Hypertension 1986:4:435-11.

115. Howes $\mathrm{LG}$, Reid JL. Changes in plasma free 3,4-dihydroxyphenylethylene glycol and noradrenaline levels after acute alcohol administration. Clin Sci 1985;69:423-8.

116. Puddey IB, Vandongen R, Beilin LJ, Rouse IL. Alcohol stimulation of renin release in man: its relationship to the haemodynamic, electrolyte, and sympathoadrenal responses to drinking. $\mathrm{J}$ Clin Endocrinol Metab 1985;61:37-42.

117. Young JB, Rowe JW, Pallotta JA, Sparrow D, Landsberg L. Enhanced plasma norepineprine response to upright posture and oral glucose administration in elderly human subjects. Metabolism 1980;29:532-9. 


\section{CHAPTER 2}

118. Grollman A. The influence of alcohol on the circulation. Quaterly Journal of Studies on Alcohol 1942;3:5-14.

119. Puddey IB, Beilin LJ Vandongen R. Regular alcohol use raises blood pressure in treated hypertensive subjects: A randomised controlled trial. Lancet 1987;: :647-51.

120. Potter JF, Beevers DG. Pressor effeets of alcohol in hypertension. Lancet 1984;I:119-22.

121. Malhotra H, Mehta SR, Mathur D, Khandelwal PD. Pressor effects of alcohol in normotensive and hypertensive subjects. Lancet 1985;11:584-6.

122. Kelbaek H. Heslet L, Skagen K. Munck O, Christensen N., Godtfredsen J. Cardiac function after alcohol ingestion in patients with ischemic heart disease and cardiomyopathy: $\mathrm{A}$ controlled study. Alcohol Alcoholism 1988;23:17-21.

123. Kelbaek H, Heslet L. Skagen K, Christensen NJ, Godtfredsen J, Munck O. Hemodynamic effects of alcohol at rest and during upright exercise in coronary artery disease. Am J Cardiol 1988;61:61-4.

124. Hartung GH, Foreyt JP, Mitchell RE, Mitchell JG, Reeves RS, Gotto AM. Effect of alcohol intake on high-density lipoprotein cholesterol levels in runners and inactive men. J Am Med Assoc 1983;249:747-50.

125. Thornton J, Symes C, Heaton K. Moderate alcohol intake reduces bile cholesterol saturation and raises $\mathrm{HDL}$ cholesterol. Lancet 1983;II:819-21.

126. Haskell WL, Camargo C, Williams PT, Vranizan KM, Krauss RM, Lindgren FT, Wood PD. The effect of cessation and resumption of moderate alcohol intake on serum high-density lipoprotein subfractions. $\mathrm{N}$ Engl J Med $1984 ; 310: 805-10$.

127. Couzigou P, Fleury B, Crockett R, Rautou JJ, Blanchard P, Lemoine F, Richard-Molard B, Amouretti M, Béraud C. High-density lipoprotein cholesterol and apoprotein Al in healthy volunteers during long-term moderate alcohol intake. Ann Nutr Metab 1984;28:377-84.

128. Burr ML, Fehily AM, Butland BK. Alcohol and high-density lipoprotein cholesterol: a randomized controlled trial. Br J Nutr 1986:56:81 -6.

129. Masarei JRL, Puddey IB, Rouse IL, Lynch WJ, Vandongen R, Beilin LJ. Effects of alcohol consumption on serum lipoprotein lipid and apolipoprotein concentrations: Results from an intervention study in healthy subjects. Atherosclerosis 1986;60:79-87.

130. Pikaar NA, Wedel M, van der Beek E, van Dokkum W, Kempen HJM, Kluft C. Ockhuizen T, Hermus RJJ. Effects of moderate alcohol consumption on platelet aggregation, fibrinolysis, and blood lipids. Metabolism $1987 ; 36: 538-47$. 
131. Belfrage P, Berg B, Hagerstrand I, Nilsson-Ehle $P$, Tornquist $H$, Wiebe T. Alterations of lipid metabolism in healthy volunteers during longterm ethanol intake. Eur J Clin Invest 1977;7:127-31.

132. Contaldo $F$, D'Arrigo $E$, Carandente V. Cortese $C$, Coltorti A, Mancini M. Taskinen MR, Nikkilä EA. Short-term effects of moderate alcohol consumption on lipid metabolism and energy balance in normal men. Metabolism 1989:38:166-71.

133. Crouse JR, Grundy SM. Effects of alcohol on plasma lipoproteins and cholesterol and triglyceride metabolism in man. J Lipid Res 1984;25:486-96.

134. Glueck CJ, Hogg E, Allen C, Gartside PS. Effects of alcohol ingestion on lipids and lipoproteins in normal men: Isocaloric metabolic studies. Am J Clin Nutr 1980;33:2287-93.

135. Moore RD, Smith CR, Kwiterovich PO, Pearson TA. Effect of low-dose alcohol use versus abstention on apolipoproteins A1 and B. Am J Med 1988;84:884-90.

136. Camargo CA, Williams PT, Vranizan KM, Albers JJ, Wood PD. The effect of moderate alcohol intake on serum apolipoproteins A-I and A-II. J Am Med Assoc 1985;263:2854-7.

137. Välimäki M, Nikkilä EA, Taskinen MR, Ylikahri R. Rapid decrease in high-density lipoprotein subfractions and postheparin plasma lipase activities after cessation of chronic alcohol intake. Atherosclerosis 1986;59:147-53.

138. Johansson BG, Medhus A. Increase in plasma alpha-lipoproteins in chronic alcoholics after acute abuse. Acta Med Scand 1974;195:273-7.

139. Danielsson B, Ekman R, Fex G, Johansson BG, Kristensson H, NillsonEhle P. Wadstein J. Changes in plasma high-density lipoproteins in chronic male alcoholics during and after abuse. Scand J Clin Lab Invest 1978;38:113-9.

140. Devenyi P, Robinson GM, Kapur BM, Roncari DAK. High-density lipoprotein cholesterol in male alcoholics with and without severe liver disease. Am J Med 1981:71:589-94.

141. Bell H, Stromme JH, Steensland H, Bache-Wiig JE. Plasma HDL cholesterol and estimated ethanol consumption in 104 patients with alcohol dependence syndrome. Alcohol Alcoholism 1985;20:35-40.

142. Cushman P, Barboriak J, Kalbfleisch J. Alcohol: High-density lipoproteins, apolipoproteins. Alcohol Clin Exp Res 1986;10:154-7.

143. Taskinen MR, Välimäki M, Nikkilä EA, Kurisi T, Ehuholm C, Ylikahri R. High-density lipoprotein subfractions and postheparin plasma lipases in alcoholic men before and after alcohol withdrawal. Metabolism 1982;31:1168-73. 
144. Välimäki $M$, Taskinen $M R$, Ylikahri $R$, Roine $R$, Kunsi T, Nikkilä EA. Comparison of the effects of two different dosis of alcohol on serum lipoproteins, HDL-subfractions and apolipoproteins A-I and A-II: a controlled study. Eur J Clin Invest 1988;18:472-480.

145. Goldberg CS, Tall AR, Krumholz S. Acute inhibition of hepatic lipase and increase in plasma lipoproteins after alcohol intake. J Lipid Res 1984:25:714-20.

146. Franceschini G, Moreno Y, Apebe P. Calabresi L, Gatti E, Noe D, de Fabiani E, Zoppi F, Sirtori CR. Alterations in high-density lipoprotein subfractions during postprandial lipidaemia induced by fat with and without ethanol. Clin Sci 1988;75:135-42.

147. Dunn EL, Cohen RG, Moore EE, Hamstra RD. Acute alcohol ingestion and platelet function. Arch Surg 1981;116:1082-3.

148. Deykin D, Janson P, McMahon L. Ethanol potentiation of aspirininduced prolongation of the bleeding time. N Engl J Med 1982;306: $852-4$

149. Kangasaho $M$, Hillbom $M$, Kaste $M$, Vapaatalo $H$. Effects of ethanol intoxication and hangover on plasma levels of thromboxane $B_{2}$, and $6-$ Keto-Prostaglandin $F_{1 a}$, and on Thromboxane $B_{2}$, formation by platelets in man. Thromb Haemostas 1982;48:232-34.

150. Kontula K, Viinikka L, Ylikorkala O, Ylikahri R. Effect of acute ethanol intake on thromboxane and prostacyclin in human. Life Sciences 1982;31:261-4.

151. Mikhailidis DP, Jeremy JY, Barradas MA, Green N, Dandona P. Effect of ethanol on vascular prostacyclin prostaglandin $\mathrm{I}_{2}$ ) synthesis, platelet aggregation, and platelet thromboxane release. $\mathrm{Br}$ Med J $1983 ; 287: 1495-98$.

152. Elmér O, Göransson G, Zoucas E. Impairment of primary hemostasis and platelet function after alcohol ingestion in man. Haemostasis 1984;14:223-8.

153. Landolfi R, Steiner M. Ethanol raises prostacyclin in vivo and in vitro. Blood 1984;64:679-82.

154. Fenn CG, Littleton JM. Interactions between ethanol and dietary fat in determining human platelet function. Thromb Haemostas 1984;51:503.

155. Galli C. Colli S, Gianfranceschi G. Maderna P, Petroni A. Tremoli E. Marinovich M. Sirtori CR. Acute effects of ethanol, caffeine, or both on platelet aggregation, thromboxane formation, and plasma-free fally acids in human subjects. Drug Nutr Interact 1984;3:61-7.

156. Hillbom M, Kangasaho M, Löwbeer C, Kaste M, Muuronen A, Numminen $H$. Effects of ethanol on platelet function. Alcohol 1985:2:429-32. 
157. Hillbom $M$, Kangasaho $M$, Kaste $M$, Numminen $H$, Vapaatalo $H$. Acute ethanol ingestion increases platelet reactivity: Is there a relationship to stroke? Stroke 1985;16:19-23.

158. Hillbom M, Muuronen A, Neiman J, Björk G, Egberg N, Kangasaho $M$. Effects of vitamin $E$ therapy on ethanol-induced changes in platelet aggregation, thromboxane formation, factor VIII levels and serum lipids. Eur J Clin Invest 1987;17:68-74.

159. Neiman J, Jones AW, Numminen H, Hillibom M. Combined effect of a small dose of ethanol and $36 \mathrm{hr}$ fasting on blood-glucose response, breathacetone profiles and platelet function in healthy men. Alcohol Alcoholism 1987:22:265-70.

160. James MJ, Walsh JA. Effects of aspirin and alcohol on platelet thromboxane synthesis and vascular prostacyclin synthesis. Thrombosis Res 1985:39:587-93.

161. Mehta P. Mehta J, Lawson D, Patel S. Ethanol stimulates prostacyclin biosynthesis by human neutrophils and potentiates anti-platelet aggregatory effects of prostacyclin. Thrombosis Res 1987;48:653-61.

162. Anderson JA, Gow LA, Ogston D. Influence of cider on the fibrinolytic enzyme system. Acta Haematologica 1983;69:344-8.

163. Olsen H, Osterud B. Effects of ethanol on human blood fibrinolysis and coagulation. Alcohol Alcoholism Suppl 1987;1:591-4.

164. Sumi H, Hamada $H$, Tsushima $H$, Mihara $H$. Lirokinase-like plasminogen activator increased in pllasma after alcohol drinking. Alcohol Alcoholism 1988;23:33-43.

165. Veenstra J, Kluft C, Ockhuizen Th, v d Pol H, Wedel M, Schaafsma G. Effects of moderate alcohol consumption on platelet function, tissuetype plasminogen activator and plasminogen activator inhibitor. Thrombosis and Haemostas 1990:63:345-8.

166. Veenstra J, te Wierik E, Kluft C. Alcohol and fibrinolysis. Fibrinolysis 1990:4 Supp2:64-8. 


\title{
ALCOHOL AND FIBRINOLYSIS: A REVIEW
}

\author{
J. Veenstra, E. te Wierik and C. Kluft
}

(Fibrinolysis 1990;4 Supp2:64-8)

\section{Summary}

This review summarizes the literature on the effects of alcohol consumption on fibrinolysis. In epidemiological studies a positive association between alcohol consumption and fibrinolytic activity has been reported.

Experimental studies, on the other hand, rather consistently have shown decreases in fibrinolytic activity directly after alcohol consumption and after regular consumption for more than four days. The changes are characterized by an increased PAI activity and a decreased tPA activity.

The apparent contradiction between epidemiological and experimental studies requires further study with respect to, amongst other things, selection of individuals, the chronicity of alcohol consumption necessary to stabilize the acute effects, and the possibility of a rebound in fibrinolysis on the long term in case of moderate alcohol consumption.

KEYWORDS. Alcohol. Fibrinolysis. Review.

\section{Introduction}

An inverse relationship between moderate alcohol consumption and coronary heart disease (CHD) has been reported in many epideniological studies (reviews: 1,2). One of the possible mechanisms involved is a relation between alcohol consumption and fibrinolysis. This relationship has been investigated in epidemiological as well as experimental studies.

\section{Epidemiological studies}

The first epidemiological study on the relation between alcohol consumption and fybrinolysis was reported by Meade et al. in 1979 (3). Fibrinolytic activity and plasma fibrinogen concentrations were measured 
in 1601 men and 707 women aged 18-64 in north-west London. Fibrinolytic activity showed a positive and plasma fibrinogen concentration a negative association with alcohol consumption. These results were confirmed in several other epidemiological studies (4-7). Yarnell et al. (4) also reported lower fibrinogen levels with increasing alcohol consumption. Rogers et al. (5) concluded from a 7 -day weighed dietary inventory in a subsample $(n=665)$ of the Cearphilly cohort of 2512 men that alcohol use is negatively associated with both fibrinogen and antithrombin III. BonitonKopp et al. (6) found in 251 middle-aged men participating in the Paris Prospective Study II that alcohol is negatively associated with antithrombin III, fibrinogen en alpha 2-antiplasmin, but the latter two associations were not significant. Finally, Bain (7) observed a negative association between alcohol consumption and fibrinogen in women, but not in men.

On the other hand, no correlation between alcohol consumption and fibrinogen was observed by Balleisen et al. (8) in 2880 men and 1306 women in the Münster Arteriosclerosis study, a prospective longitudinal study.

\section{Experimental studies}

Experimental studies into the effects of alcohol on fibrinolysis can be classified into studies on long-term effects, those on acute effects, and in-vitro studies.

\section{Experimental studies into long-term effects}

In a large randomized controlled trial, Burr et al. (9) studied the effects of 4 weeks of alcohol consumption as compared to 4 weeks of total abstinence in 48 men and 52 women aged $19-60$. Alcohol consumption was not standardized and varied from less than two drinks a week to more than 20 a week (mean intake $18.4 \mathrm{~g}$ alcohol per day). The type of alcoholic beverage was a matter of free choice. Half of the subjects received the alcohol treatment first, followed by the period of abstinence, while the other half abstained lirst, followed by the drinking period. At the end of each experimental period a fasting blood sample was laken from each subject for lipid and haematological analyses relevant to $\mathrm{CHD}$. Haematological variables measured were haemoglobin, plasma fibrinogen and plasma viscosity. No statistically significant effect of alcohol consumption on either one of these variables was observed. 
The long-term effects of moderate alcohol consumption on variables relevant to CHD have also been studied by Pikaar et al. (10). They studied the effects of four different standardized amounts of red wine during a 5week experimental period in 12 male volunteers between 21 and 29 years of age. The treatments consisted of 0,2 and 4 glasses of red wine (providing 0,23 and $46 \mathrm{~g}$ of alcohol respectively) per day. Besides, the effect of "binge drinking" was studied over a period of 5 weeks in which 14 glasses of red wine were consumed each week, during the weekend. This study confirmed the observation of Burr et al. (9) that alcohol has no effect on plasma fibrinogen levels within a few weeks. The levels of plasminogen and t-PA activity, however, appeared to be clearly affected by wine consumption. Plasminogen levels moderately increased with an increasing dose of wine. t-PA activity, on the other hand, showed a large and dosedependent decrease, the level at the four-glass dose being roughly one third of that in abstinence. Additional analyses reveiled that the decrease in t-PA activity was caused by a large increase in PAI aclivity (11). No effects of alcohol on bleeding time were observed in the study of Pikaar et al.(10).

\section{Experimental studies into acute effects}

Table 1 summarizes the experimental studies into the acute effects of alcohol on fibrinolytic parameters.

In 1960, Fearnly et al. (12) observed by chance an unusual prolonged blood clot lysis time in a small group of healthy subjects after consumption of one glass of beer. Subsequently they investigated the effects of a few other alcoholic beverages and found that beer, white wine and cider reduced fibrinolytic activity, whereas gin, whisky and pure alcohol did not.

In 1961, Nilsson et al. (13) also reported that ingestion of red and white wine and beer results in a decrease in blood fibrinolytic activity. In addition, they showed in in-vitro experiments that wine and beer, but not cider, contained a pectic substance that inhibited fibrinolytic activators.

More recently, Anderson et al. (14) also investigated the influence of cider on the fibrinolytic system. In agreement with Fearnly et al. and Nilsson et al, they observed inhibition of fibrinolysis as measured by the euglobulin lysis time. Unfermented apple juice had no significant effect. 
Table 1. Experimental studies into the acute effects of alcohol on fibrinolysis.

\begin{tabular}{|c|c|c|c|c|c|c|}
\hline $\begin{array}{l}\text { First } \\
\text { author }\end{array}$ & Ref. & $\begin{array}{l}\text { Publ. } \\
\text { year }\end{array}$ & $\begin{array}{l}\text { Amount of } \\
\text { alcohol }\end{array}$ & $\begin{array}{l}\text { Type of } \\
\text { beverage }\end{array}$ & Parameter & Effect \\
\hline Fearnly & 12 & 1960 & $20-40 \mathrm{~g}$ & $\begin{array}{l}\text { beer/cider/ } \\
\text { white wine } \\
\text { gin/whisky/ } \\
\text { alcohol }\end{array}$ & $\begin{array}{l}\text { blood clot lysis time } \\
\text { blood clot lysis time }\end{array}$ & + \\
\hline Nilsson & 13 & 1961 & $25-100 \mathrm{~g}$ & $\begin{array}{l}\text { beer/wine } \\
\text { alcohol }\end{array}$ & $\begin{array}{l}\text { fibrinolytic activity } \\
\text { fibrinolytic activity }\end{array}$ & $\overline{=}$ \\
\hline Andersor & $n 14$ & 1983 & $90 \mathrm{~g}$ & cider & euglobulin lysis time & + \\
\hline Hillbom & 15,16 & 1983 & $1.5 \mathrm{~g} / \mathrm{kg}$ & alcohol & $\begin{array}{l}\text { fibrinolytic activity } \\
\text { euglobulin lysis time } \\
\text { fibrin degr. products } \\
\text { factor VIII:C activity } \\
\text { factor VIII: antigen } \\
\text { factor VIII:R cofactor } \\
\text { antithrombin III }\end{array}$ & $\begin{array}{l}- \\
+ \\
= \\
+ \\
+ \\
+ \\
=\end{array}$ \\
\hline Elmér & 17 & 1984 & $0.8 \mathrm{~g} / \mathrm{kg}$ & whisky & $\begin{array}{l}\text { factor VIII } \\
\text { fibrin degr. products } \\
\text { plasminogen } \\
\text { fibrinogen } \\
\text { fibrinolytic activity } \\
\text { euglobulin clot lysis time } \\
\text { antithrombin III }\end{array}$ & $\begin{array}{l}= \\
= \\
= \\
= \\
= \\
= \\
=\end{array}$ \\
\hline Olsen & 18 & 1987 & $0.5-1.0 \mathrm{~g} / \mathrm{L}$ & ethanol & blood clot lysis time & + \\
\hline Sumi & 19 & 1988 & $23.7-47.4 \mathrm{~g}$ & $\begin{array}{l}\text { shochu/sake/ } \\
\text { beer }\end{array}$ & $\begin{array}{l}\text { euglobulin lysis time } \\
\text { fibrin degr. products } \\
\text { fibrinolytic activity }\end{array}$ & $\begin{array}{l}- \\
= \\
+\end{array}$ \\
\hline Veenstra & 20 & 1990 & $30 \mathrm{~g}$ & $\begin{array}{l}\text { red wine and } \\
\text { port }\end{array}$ & $\begin{array}{l}\text { t-PA activity } \\
\text { PAI activity }\end{array}$ & + \\
\hline Veenstra & 21 & 1990 & $40 \mathrm{~g}$ & $\begin{array}{l}\text { red wine and } \\
\text { Hollands gin }\end{array}$ & $\begin{array}{l}\text { PAI activity } \\
\text { PAI antigen } \\
\text { t-PA activity } \\
\text { t-PA antigen } \\
\text { total UK-PA antigen } \\
\text { pro UK-PA antigen } \\
\text { UK-PA inhibitor complex }\end{array}$ & $\begin{array}{l}t \\
= \\
- \\
+ \\
= \\
= \\
=\end{array}$ \\
\hline
\end{tabular}

+ increased, = no effect, - decreased 
Hillbom et al. $(15,16)$ studied the effects of alcohol intoxication on a number of fibrinolytic parameters. Twelve healthy men drank $1.5 \mathrm{~g} / \mathrm{kg}$ alcohol in fruit juice, after a 10-hour fast. A decreased fibrinolytic activity after alcohol consumption was observed in 10 of the 12 volunteers. Furthermore, factor VIIl coagulant activity, factor VIII related antigen and factor VIII ristocetin cofactor significantly increased. No significant effects were observed on fibrin degradation products and antithrombin $11 \mathrm{I}$.

The absence of an effect on euglobulin clot lysis time after the consumption of $0.8 \mathrm{~g} / \mathrm{kg}$ alcohol in whisky was reported by Elmér et al. (17). None of the other fibrinolytic factors was significantly influenced by alcohol consumption either.

Olson and Osterud (18) investigated the effects of low and high blood alcohol concentration in eight healthy volunteers. Serum alcohol levels of approximately 0.5 and $1.0 \mathrm{~g} / \mathrm{L}$ were compared to a control treatment without alcohol. A strong and dose dependent decrease in fibrinolytic activity was observed as measured by whole blood clot lysis time. They also studied the effect of 0.5 and $1.0 \mathrm{~g} / \mathrm{L}$ ethanol on fibrinolytic activity in vitro, but no effects were observed.

Recently, Sumi et al. (19) investigated the effects of consumption of shochu, sake and beer on fibrinolytic parameters in 78 volunteers. Shochu is a local Japanese spirit and sake a Japanese rice wine. In contrast to the experimental studies mentioned above, the consumption of shochu resulted in an acute decrease in euglobulin clot lysis time. Euglobulin clot lysis time after sake and beer drinking also tended to decrease, but to a lesser extent. Sumi et al. attempted to isolate the plasma enzyme which increased after shochu drinking using column chromatography techniques and revealed that some of the enzymes appearing in the plasma after drinking are related to urokinase-like plasminogen activalor.

Very recently, we performed two studies $(20,21)$ on the acute effects of moderate alcohol consumption on fibrinolytic factors, which is a continuation of the work of Pikaar et al. (10). In the first one (20), the effects of a moderate amount of alcohol at dinner on the activities of $t$ PA and PAI were studied in two age groups of volunteers (20-30 and 45-55 years), each consisting of eight healthy men. The alcohol treatment comprised an aperitif (red port) and two glasses of red wine $(30 \mathrm{~g}$ of alcohol in total) taken half an hour before and during the meal. respectively. The same volumes of mineral water were consumed during the control treatment. Alcohol resulted in a strong decrease in t-PA activity in the middle-aged group $(-70 \%, p<0.001)$ and in a smaller decrease in the young men $(-29 \%, p=0.037)$ at one hour after dinner. PAI activity levels significantly increased in the middle-aged men $(+60 \%, p=0.010)$, whereas 


\section{CHAPTER 3}

the increase in young men $(+34 \%)$ was not statistically significant $(p=0.144)$.

The observed differences between young and middle-aged men prompted us to investigate the acute effects of moderate alcohol consumption in middle-aged men in further detail and under strictly controlled conditions (21). In this second study, eight healthy middle-aged men (45-55 years) were housed in the metabolic ward of our Institute. The subjects received standard diets and were not allowed to consume any food or drinks but the meals and drinks supplied by the Institute. On the experimental days, they received 2 glasses of red wine during dinner early in the evening and 2 glasses of Hollands gin in combination with a snack during the evening (40 $\mathrm{g}$ of alcohol in total). In view of the circadian variation in fibrinolytic parameters all meals and drinks were taken and all measurements were done always at the same time of the day. In the evening, one hour after the consumption of the Hollands gin, PAl activity had increased by $230 \%$ $(p<0.001)$ and $t$-PA activity had decreased by $95 \%(p<0.001)$. The next morning, after an overnight fast, PAI activity was still significantly higher. This time we also measured PAI-1 and t-PA antigen levels and a number of parameters of the urokinase-plasminogen activator system. PAI-1 antigen was not significantly affected. The level of t-PA antigen, however, significantly increased after alcohol consumption in the evening $(+42 \%, p<0.01)$. No effects of alcohol on the parameters of the urokinaseplasminogen activator system were observed.

\section{In-vitro studies}

The effects of alcohol on fibrinolytic parameters has also been studied in vitro. Laugh (22) investigated the effect of alcohol on the secretion of t-PA by cloned bovine endothelial cells. These cells produced and secreted t-PA at a constant rate. Exposure to alcohol increased the secretion of t.PA in a concentration-dependent manner. Even alcohol concentrations as low as $0.1 \mathrm{~g} / \mathrm{L}$ showed an increase of approximately $30 \%$. Kjaeldgaard et al. (23) confirmed the increasing effect of alcohol on t-PA production in a t-PA-producing human melanoma cell line.

Another very interesting observation in the study of Laugh (22) was that other aliphatic alcohols such as propanol and butanol also considerably increased t-PA production and secretion, whereas methanol and isopropanol had no effect. Thus, the efficiency of aliphatic alcohols to enhance fibrinolysis seems to increase with elongation of the hydrocarbon chain. 
Anderson et al. (14) not only investigated the effects of cider in human volunteers, but also in in-vitro experiments by adding cider to different test sytems. The fibrinolytic activities of plasmin, urokinase and tissue-type plasminogen activator on fibrin plates were inhibited by cider in a concentration-dependent manner. The inhibitory agent was heatstable and non-dialysable.

\section{Alcoholism and fibrinolysis}

The antigen levels of plasminogen activators and plasminogen activator inhibitors in chronic alcoholics were studied by Tran-Thang et al. (24) in order to establish whether the variations in fibrinolytic activity observed in alcoholics are primarilly due to varying levels in activators, inhibitors or both. In chronic alcoholics with normal liver tests t-PA antigen levels were within the normal range. In a group of alcoholics with abnormal liver function tests, but without signs of cirrhosis, I-PA antigen levels were approximately twice as high as those in the control group, and in alcoholics with cirrhosis t-PA antigen levels even had increased sixfold. A good correlation was observed between t-PA and gamma glutamyl transferase, indicating a relationship between t-PA antigen levels and the severity of the disease. Urokinase-PA and PAI-1 antigen levels were significantly increased in all three patient groups.

Increased levels of t-PA and PAI-1 antigen in patients with mild and severe liver cirrhosis were also observed by Leebeek (25). In addition, he reported an increased t-PA activity in a subgroup of patients. Booth et al. (26) reported an increase in both tissue-type and urokinase-type plasminogen activator activity in patients with alcoholic cirrhosis.

\section{Conclusions}

Most experimental studies on alcohol and fibrinolysis show a decrease in blood fibrinolytic activity, both acutely and on the longer term 15 weeks). An increase in PAI-1 levels in the circulation appears to cause the effect.

The results of epidemiological studies on alcohol consumption and fibrinolysis, on the other hand, show an increased fibrinolytic activity of blood with increasing alcohol consumption. It has not been analysed with specific methods whether this increase resides in reduction in PAI-1 or increase in t-PA, or in changes in other factors. 
This discrepancy between experimental and epidemiological studies cannot easily be explained at present. The effects of alcohol consumption for periods longer than 5 weeks remain to be investigated. A possible rebound in fibrinolysis on the longer term in case of moderate alcohol consumption would explain the epidemiological findings of a positive association between alcohol consumption and fibrinolytic activity. It also remains possible that in epidemiological studies the "spontaneous" level of alcohol consumption reflects a fenotype that is linked to a fibrinolysis fenotype. In this respect, an experimental study on volunteers with variable "spontaneous" alcohol consumption levels would be interesting, with the questions what happens in periods of abstinance and of various levels of alcohol consumption.

Finally, in new and on-going epidemiological studies, the use of newer assay strategies might provide us with more detailed data on the changes in t-PA and especially PAI-1.

\section{References}

1. Moore RD, Pearson TA. Moderate alcohol consumption and coronary artery disease. Medicine 1986;65:242-67.

2. Veenstra J. Moderate alcohol use and coronary heart disease: A Ushaped curve? World Review of Nutrition and Dietetics, 1990 In press.

3. Meade TW, Chakrabarti R, Haines AP, North WRS, Stirling Y. Characteristics affecting fibrinolytic activity and plasma fibrinogen concentrations. Br Med J 1979;1:153-6.

4. Yarnell JWG, Fehily AM, Milbank J, Kubicki AJ, Eastham R, Hayes TM. Determinants of plasma lipoproteins and coagulation factors in men from Caerphilly, South Wales J Epidemiol Community Health. $1983 ; 37: 137-40$.

5. Rogers S, Yarnell JWG, Fehily M. Nutritional determinants of haemostatic lactors in the Caerphilly study. Eur J Clin Nutr 1988:42:197-205.

6. Boniton-Kopp C, Scarabin P, Bara L, Castanier M, Jacqueson A, Roger M. Relationship between sex hormones and haemostatic factors in healthy middle-aged men. Atherosclerosis 1988;71:71-6.

7. Bain BJ. Some influences on the ESR and the fibrinogen level in healthy subjects. Clin Lab Haemat 1983;5:45-54.

8. Balleisen L, Bailey J, Epping $\mathrm{PH}$, Schulte $\mathrm{H}$, van de Loo J. Epidemiological study on factor VII, factor VIII and fibrinogen in an industrial population. Thrombosis and Haemostasis 1985;5:475-9. 
9. Burr ML, Fehily AM, Butland BK. Alcohol and high-density-lipoprotein cholesterol: a randomized controlled trial. Br J Nutr 1986:56:81-6.

10. Pikaar NA, Wedel M, van der Beek E, van Dokkum W, Kempen HJM, Kluft C, Ockhuizen Th, Hermus RJJ. Effects of moderate alcohol consumption on platelet aggregation, fubrinolysis and blood lipids. Metabolism 1987;36:538-43.

11. Kluft C, Veenstra J, Schaafsma G, Pikaar NA. Regular moderate wine consumption for five weeks increases plasma activity of the plasminogen activator inhibitor 1 (PAl-1) in healthy young volunteers. Fibrinolysis 1990;4 supp 2:64-8.

12. Fearnly GR, Ferguson J, Chakrabarti R, Vincent CT. Effect of beer on blood fibrinolytic activity. Lancet 1960;1:184-6.

13. Nilsson IM, Björkman SE, v. Studnitz W, Hallen A. Antifibrinolytic activity of certain pectins. Thromb Diath Haemorrh 1962;6:177-87.

14. Anderson JA, Gow LA, Ogston D. Influence on the fibrinolytic enzyme system. Acta haemat 1983;69:344-8.

15. Hillbom M, Kaste M, Rasi V. Effects of ethanol on the hemocoagulation in healthy male volunteers. Acta Neurol Scand 1982;65:182-3.

16. Hillbom M, Kaste M, Rasi V. Can ethanol intoxication affect hemocoagulation to increase the risk of brain infarction in young adults? Neurology 1983;33:381-4.

17. Elmer O, Göransson G, Zoucas E. Impairment of primary hemostasis and platelet function after alcohol ingestion in man. Haemostasis $1984 ; 14: 223-8$.

18. Olsen $H$, Østerud B. Effects of ethanol on human blood fibrinolysis and coagulation. Alcohol \& Alcoholism 1987;suppl 1:591-4.

19. Sumi $H$, Hamada $H_{*}$ Tsushima $H$, Mihara $H$. Urokinase-like plasminogen activator increased in plasma after alcohol drinking. Alcohol \& Alcoholism 1988;23:33-43.

20. Veenstra J, Kluft $C$, Ockhuizen Th, v d Pol $H$, Wedel $M$, Schaafsmá $G$. Effects of moderate alcohol consumption on platelet function, tissuetype plasminogen activator and plasminogen activator inhibitor. Thrombosis and Haemostas 1990;63:345-8.

21. Veenstra J, Kluft C, $v$ d Pol $\mathbb{H}$, Schaafsma G. Acute effects of moderate alcohol consumption on fibrinolytic factors in healthy middle-aged men. 1990; Submitted for publication.

22. Laugh WE. Ethyl alcohol enhances plasminogen activator secretion by endothelial cells. JAMA 1983;250:772-6.

23. Kjaeldgaard A, Ahlesteen I, Larsson B, Astedt B. Progestogen regulation of tissue plasminogen activator in a human melanoma cell line. Thrombosis Research 1988;49:287-97. 
24. Tran-Thang $C_{w}$ Fasel-Felley J, Pralong G, Hofstetter JR, Bachmann $F$, Kruithof EKO. Plasminogen activators and plasminogen activator inhibitors in liver deficiencies caused by chronic alcoholism or infectious hepatitis. Thromb Haemostas 1989:62:651-3.

25. Leebeek FWG. A shift in balance between profibrinolytic and antifibrinolytic factors causes enhanced fibrinolysis in liver cirrhosis: Role of tissue-type plasminogen activator, plasminogen activator inhibitor and alpha 2-antiplasmin. From: Clinical studies on fibrinolysis inhibitors synthesized by the liver. Thesis 1989. Erasmus University Rotterdam, the Netherlands.

26. Booth NA, Anderson JA, Bennet B. Plasminogen activators in alcoholic cirrhosis: demonstration of increased tissue type and urokinase type activator. J Clin Pathol 1984;37:772-7. 


\title{
HIGH-DENSITY LIPOPROTEIN CHOLESTEROL DURING 20 WEEKS OF MODERATE ALCOHOL CONSUMPTION
}

\author{
J. Veenstra, Th. Ockhuizen, N.A. Pikaar and G. Schaafsma
}

(Subnitted)

\section{Summary}

The effect of 20 weeks of moderate daily alcohol consumption on highdensity lipoprotein cholesterol and its subfractions was studied in human volunteers (experimental group $n=12$, control group $n=6$ ). The alcohol ( $34 \mathrm{~g}$ per day in white wine) was consumed during dinner ( 2 glasses) and in the evening ( 2 glasses). Measurements were performed in weeks $0,5,10,15$ and 20, after an overnight fast. In the experimental group HDL-C levels increased significantly by up to $17.5 \%$ as compared to the control group $(\mathrm{P}=0.015)$. This effect of alcohol on HDL-C was mainly attributable to a significant effect on the $\mathrm{HDL}_{3}-\mathrm{C}$ subfraction $(\mathrm{P}<0.05) . \mathrm{HDL}_{2}$-C was not significantly influenced by alcohol consumption. This is the first experimental study on moderate alcohol consumption and HDL-C over a period much longer than 5 weeks.

\section{Introduction}

A positive association between high-density lipoprotein cholesterol (HDL-C) and alcohol consumption has been observed in many epidemiological studies (Reviews 1,2). Increased HDL-C levels have epidemiologically been shown to be associated with lower risk of coronary heart disease (CHD).

$\mathrm{HDL}-\mathrm{C}$ consists of two major subfractions, $\mathrm{HDL}_{2}-\mathrm{C}$ and $\mathrm{HDL}_{3}-\mathrm{C}$. The relation with low $\mathrm{CHD}$ risk has been predominantly observed for $\mathrm{HDL}_{2}-\mathrm{C}$. The effects of alcohol consumption on HDL-C subfractions seem to depend on the alcohol dose. Moderate alcohol consumption mainly raises the $\mathrm{HDL}_{3}-\mathrm{C}$ subfraction, higher doses of alcohol $(60 \mathrm{~g}$ daily for 3 weeks) increase the $\mathrm{HDL}_{2}-\mathrm{C}$ subfraction (3). Moreover, the $\mathrm{HDL}_{2}$ level is raised in chronic alcoholics $(4,5)$. In a previous study we have observed an increase in $\mathrm{HDL}_{3}-\mathrm{C}$ levels after 5 weeks of moderate alcohol consumption, whereas $\mathrm{HDL}_{2}$ $C$ remained unaffected (6). Experimental data on HDL-C and moderate alcohol consumption over periods longer than 5 weeks are scarce. 
The purpose of the present study was to investigate the effects of moderate alcohol consumption on HDL-C subfractions over a period of 20 weeks in order to answer two questions: (1) Does moderate alcohol consumption for more than 5 weeks influence $\mathrm{HDL}_{2}-\mathrm{C}$ levels; and (2) Is the alcohol-induced increase in $\mathrm{HDL}_{3}-\mathrm{C}$ still present after 20 weeks of moderate alcohol consumption.

\section{Methods}

\section{Subjects}

Eighteen apparently healthy, non-smoking volunteers, between 21 and 28 years of age, participated in this study. Their average habitual consumption of alcohol varied between 10 and $40 \mathrm{~g}$ per day. They all had a normal liver function, had no familial history of alcoholism and were used to a normal, western life style, including dietary habits. No drugs were used during the experiment. The study protocol was approved by the Institute's external Medical-Ethical Committee and the participants signed the informed consent form.

\section{Study design}

The subjects were randomly assigned to an experimental group $(n=12)$ and a control group $(n=6)$. In the 5 weeks preceding the experiment, all volunteers abstained from drinking alcoholic beverages. During the subsequent 20 weeks the volunteers in the control group persisted in abstainance, and those in the experimental group consumed four 100-ml glasses of white wine $(34 \mathrm{~g}$ alcohol) daily, two glasses during dinner at 1800 and two glasses during the evening. The subjects did not change their habitual diet and life style. Compliance was tested at regular intervals by means of a questionnaire. Measurements were performed in weeks 0,5 , 10, 15 and 20. Two and four months after the study the subjects of the experimental group were questioned about their drinking habits. None of them reported a change in this respect.

\section{Analytical methods}

Blood was taken from a vena mediana cubiti by means of a catheter. For HDL subfractionation we used essentially the method of Gidez et al. (7). VLDL and LDL were first removed by precipitation with heparin $(140 \mathrm{U} / \mathrm{mg}$, $1.5 \mathrm{~g} / \mathrm{L}$ final concentration) and $\mathrm{MnCl}_{2}(100 \mathrm{mmol} / \mathrm{L})$ for $20 \mathrm{~min}$ at $0{ }^{\circ} \mathrm{C}$. 
Then dextran sulphate (MW 15,000) was added to a final concentration of $1.4 \mathrm{~g} / \mathrm{L}$ and the mixture left for 30 minutes at $0{ }^{\circ} \mathrm{C}$ before centrifugation. Cholesterol in $\mathrm{HDL}_{2}$ (redissolved dextran sulphate precipitate) and in $\mathrm{HDL}_{3}$ (final supernatant) were determined by the method of Abell et al. (8). $\mathrm{HDL}-\mathrm{C}$ was calculated as the sum of $\mathrm{HDL}_{2}-\mathrm{C}$ and $\mathrm{HDL}_{3}-\mathrm{C}$. Serum total cholesterol was determined by a enzymatic-colorimetric autoanalyser method on a Hitachi autoanalyser (Boehringer, Mannheim, FRG) using Boehringer biochemicals.

\section{Statistical analysis}

Statistical evaluation comprised one-way analysis of variance (ANOVA) of the measurements at weeks $0,5,10,15$ and 20 to determine differences between the experimental group and the control group.

\section{Results and discussion}

Figure $1 \mathrm{~A}$ shows the HDL-C levels in the experimental and the control group during the experiment. The $\mathrm{HDL}-\mathrm{C}$ subfractions $\mathrm{HDL}_{2}-\mathrm{C}$ and $\mathrm{HDL}_{3}-\mathrm{C}$ are shown in Figure $1 \mathrm{~B}$ and Figure $1 \mathrm{C}$.

The levels of HDL-C were significantly higher in the experimental group after 10 and 15 weeks of moderate alcohol consumption $(P=0.028$, $\mathrm{P}=0.015$, respectively). Moderate alcohol consumption had no significant effect on $\mathrm{HDL}_{2}-\mathrm{C}$ during the 20 -week experimental period. The $\mathrm{HDL}_{3}$-C level, however, was significantly higher after 5 weeks of alcohol consumption $(19.4 \%, \mathrm{P}=0.043)$, which is in agreement with our previous studly (6). The difference between the experimental group and the control group was even more pronounced after 10 weeks $(25.2 \%)$ and after 15 weeks $(20.7 \%)$ $\left(P=0.049\right.$ and $P=0.025$, respectively). After 20 weeks the $\mathrm{HDL}_{3}-\mathrm{C}$ level was still significantly higher then in the control group $(\mathrm{P}=0.032)$. No significant effects of alcohol on tolal cholesterol were observed (data not shown).

In both groups the $\mathrm{HDL}_{2}$ - $\mathrm{C}$ levels tended to decrease and the $\mathrm{HDL}_{3}-\mathrm{C}$ levels tended to increase during the experimental period, irrespective of alcohol treatment. These tendencies might reflect seasonal changes. The experiment starled in August, in the late summer, and lasted until December, just before Christmas, and therefore some changes in food pattern and life style of the volunteers are likely to have occurred.

Our results indicate that daily moderate alcohol consumption results in an increase of HDL.C within a few weeks and that this increase is mainly due to the $\mathrm{HDL}_{3}-\mathrm{C}$ subfraction. HDLs seem to be involved in the 


\section{CHAPTER 4}

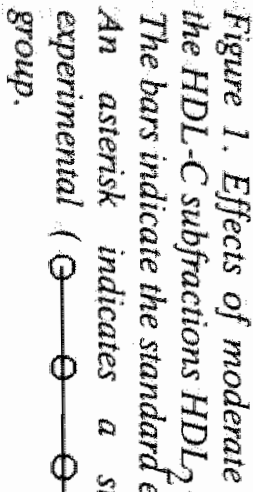

‥

녕 92

สㅇํำ

$- \pm \frac{1}{0}$

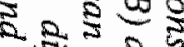

常合蛋

S 3

$38 \div 9$

है 25

๑ $0 \Rightarrow 0$

Q

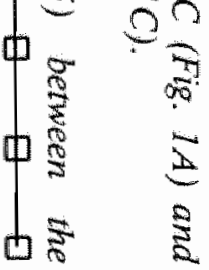

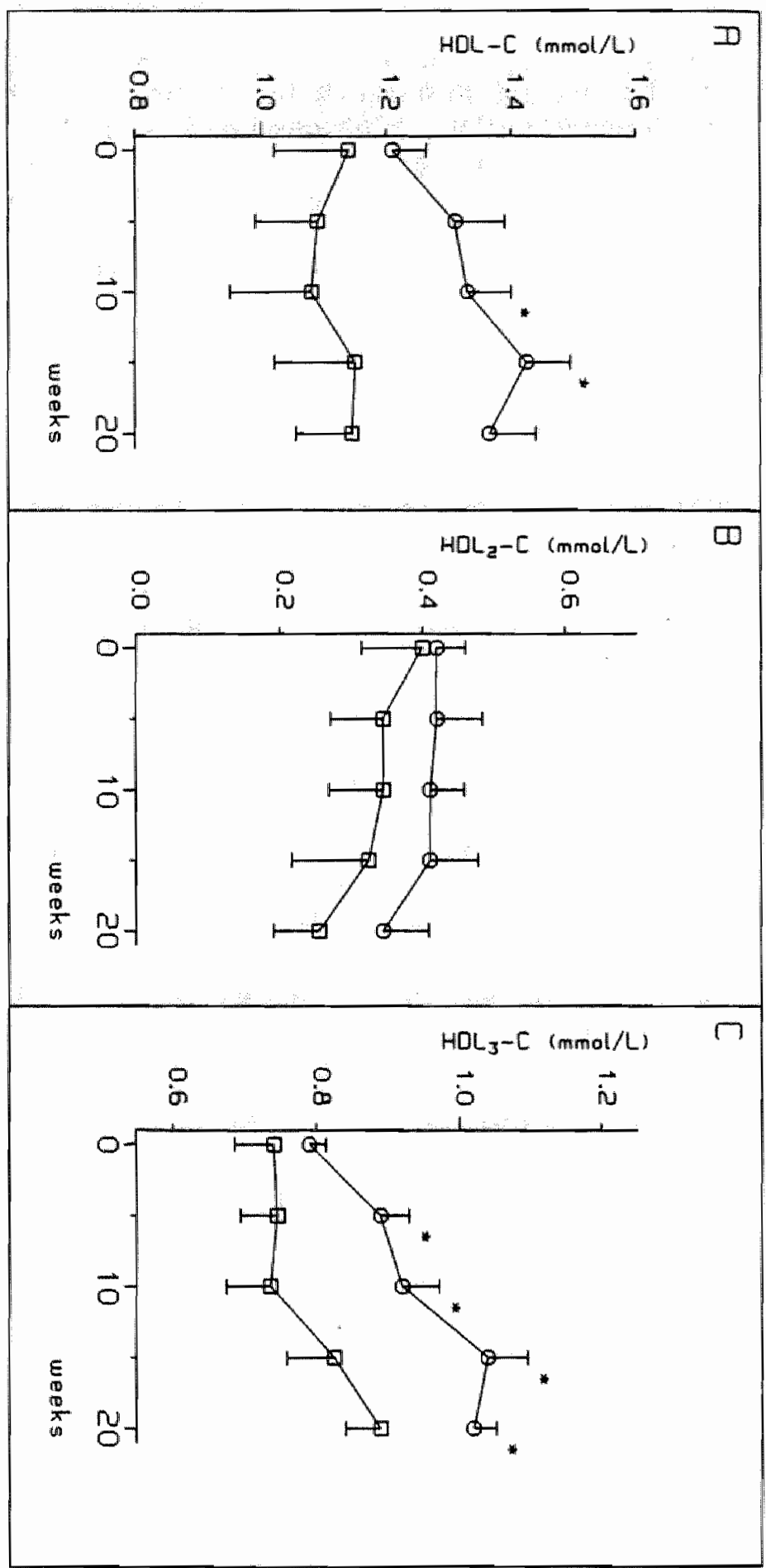


protection of the vascular system against accumulation of cholestertol $(9,10)$. Therefore, the alcohol-induced elevation of the $\mathrm{HDL}_{3}-\mathrm{C}$ subfraction could be beneficial. However, before any conclusions as to such a protective effect can be drawn, the underlying mechanism and consequence of alcohol-induced increases of $\mathrm{HDL}_{3}$ - $\mathrm{C}$ should be studied.

\section{Acknowledgment}

Supported by the Central Commodity Board for Arable Products, The Hague, Netherlands and the Commodity Board for Spirits, Schiedam, Netherlands.

\section{References}

1. Moore RD, Pearson TA. Moderate alcohol consumption and coronary artery disease. Medicine 1986;65:242-67.

2. Veenstra J. Moderate alcohol use and coronary heart disease: A Ushaped curve? Accepted for publication in World Review of Nutrition and Dietetics, 1990.

3. Välimäki M, Taskinen MR, Ylikahri R, Roine R, Kuusi T, Nikkilä EA. Comparison of the effects of two different dosis of alcohol on serum lipoproteins, HDL-subfractions and apolipoproteins A-I and A-II; a controlled study. Eur J Clin Invest 1988;18:472-80.

4. Välimäki M, Nikkilä EA, Taskinen MR, Ylikahri R. Rapid decrease in high-density lipoprotein subfractions and postheparin plasma lipase activities after cessation of chronic alcohol intake. Atherosclerosis 1986:59:147-53.

5. Taskinen MR, Välimäki M, Nikkilä EA, Kuusi T, Enholm C. Ylikahri $\mathbb{R}$. High-density lipoprotein subfractions and postheparin plasma lipases in alcoholic men before and after alcohol withdrawal. Metabolism 1982:31:1168-73.

6. Pikaar NA, Wedel M, vd Beek EJ, v Dokkum W, Kempen HJM, Kluft C. Ockhuizen Th. Hermus R.J. Effects of moderate alcohol consumption on platelet aggregation, fibrinolysis, and blood lipids. Metabolism 1987:36:538-44.

7. Gidez LI. Miller GJ, Burstein M, Slagle S, Eder HA. Separation and quantitation of subclasses of human high densily lipoprotein subclasses by a simple precipitation procedure. J Lipid Res $1982: 23: 1206-23$. 


\section{CHAPTER 4}

8. Abell $\mathrm{AA}$, Levy $\mathrm{BB}$, Brodie $\mathrm{BB}$, Kendall FF. A simplified method for the estimation of total cholesterol and the demonstration of its specificity. J Bial Chem 1952,195:357-66.

9. Oram JF, Albers $\mathbf{J}$, Cheung $\mathrm{MC}$, Bierman $\mathrm{EL}$. The effects of subfractions of high density lipoprotein on cholesterol efflux from cultured fibroblasts. J Biol Chem 1981;256:8348-56.

10. Stein $O$, Halparin $G$, Stein $Y$. Comparison of cholesterol egress from cultured cells enriched with cholesterolester after exposure to cationized LDL or to LDL and chloroquine. Biochim Biophys Acta $1979 ; 573: 1-11$. 


\title{
EFFECTS OF FOUR DAYS OF MODERATE WINE AND COFFEE CONSUMPTION ON FIBRINOLYSIS AND PLATELET AGGREGATION
}

\author{
J. Veenstra, C. Kluft, Th. Ockhuizen, N.A. Pikaar, \\ H. v.d. Pol, M. Wedel and G. Schaafsma
}

(Fibrinolysis, in press)

\section{Summary}

Moderate consumption of wine and coffee was studied in eight apparently healthy men (aged 20 - 30 years) during a four-day experimental period. After a wash-out period of 10 days, blood samples were taken after an overnight fast, at days $0,1,2$ and 4 of the experimental period. There were no clear effects of wine consumption on fibrinolysis or platelet aggregation. Coffee consumption had a clear effect on fibrinolysis: t-PA inhibition levels at day 2 and day 4 were significantly increased by coffee consumption and t-PA antigen levels tended to be higher after colfee consumption for four days. t-PA activity was not significantly affected. The effect of coffee on platelet aggregation seemed to be related to the type of dietary fat consumed during the experimental period. When coffee was consumed with a diet high in polyunsaturated fatty acids there was an increase in platelet aggregability; there was a decreased platelet aggregation when coffee was consumed with a diet rich in saturated fatty acids.

Keywords: Alcohol. Wine. Coffee. Fibrinolysis. Platelet aggregation.

\section{Introduction}

In the pathogenesis of cardiovascular diseases fibrinolysis and platelet aggregation are important processes. An increase in fibrinolysis and a decrease in platelet aggregation may contribute to a lower risk of cardiovascular diseases. These processes can be influenced by various components of the daily diet such as alcohol, coffee and fat (1-10).

Most studies on alcohol, fibrinolysis and platelet aggregation have been concerned with the effects of a single dose of alcohol in the postprandial phase, when the alcohol is still present in the circulation. 
Data on regular moderate alcohol consumption, fibrinolysis and platelet aggregation, however, are yery scarce. In a previous study we have found that moderate wine consumption for 5 weeks reduced platelet aggregation induced by collagen, increased plasminogen levels and lowered tissue-type plasminogen activator (t-PA) activity levels in plasma after an overnight fast (1).

The acute effects of alcohol consumption on platelet aggregation appeared to depend strongly on the type of fat in a meal taken together with the alcohol (2). When alcohol was taken with a meal high in saturated fatty acids, an inhibitory effect on platelet aggregation was observed, but no effect was found when alcohol was consumed together with a meal high in polyunsaturated fatty acids (2).

Alcohol has been shown to increase membrane fluidity. Chronic alcohol consumption, however, leads to adaptation of the cell membranes rendering them insensitive to the fluidizing effects of alcohol $(3,4)$. Changes in cell membrane fluidity may result in altered cell functions, in for example platelets and endothelial cells.

Besides alcohol and fat, caffeine is another component of our daily diet that has been reported to influence haemostasis. Samarrae et al. reported an increase in fibrinolytic activity within one hour after the consumption of two cups of coffee (5). In another study. Wojta et al. (6) have demonstrated a decrease in t-PA inhibition level when the caffeine consumption was continued until the morning of investigation. As regards the effects of coffee on platelet aggregation in vitro studies have shown an inhibitory effect of caffeine or coffee extracts (7-9). In vivo studies on acute effects of coffee on platelet aggregation have also shown inhibition (10). The effects of moderate coffee consumption on fibrinolysis and platelet aggregation in the fasting state are unknown.

In the present study we investigated the effects of moderate wine and colfee consumption on fibrinolysis, platelet aggregation, haematological parameters and erythrocyte membrane fluidity, after an overnight fast, over a period of four days. Possible interactions between wine and coffee consumption on the one hand, and between wine or coffee consumption and polyunsaturated or saturated fatty acids on the other hand were also examined. 


\section{Subjects and methods}

\section{Subjects}

Eight healthy non-smoking men aged 20 - 30 participated. Their habitual daily consumption of alcohol and coffee did not exceed 4 glasses (40 $\mathrm{g}$ alcohol) and 7 cups respectively. Their liver function was normal and they had no familial history of alcoholism. They were used to a normal Western life-style, including dietary habits. The study protocol was approved by the Institute's external medical-ethical committee, and the participants signed the informed consent form.

\section{Study Design}

The study comprised four periods of two weeks each. In the first ten days of each period the subjects consumed their habitual diet but had no drinks containing alcohol or caffeine. This wash-out period was followed by an experimental period of four days in which each subject received one of four different treatments. Treatments consisted of a combination of consumption of a standard diet, either high in polyunsaturated (PUFAs) or high in saturated fatty acids (SFAs), and whether or not consumption of wine or coffee. Subjects were divided at random into two groups of four. During the experimental periods four subjects were always on the PUFA-rich diet, whereas the other, four always received the SFA-rich diet. All possible combinations of the factors diet, wine and coffee were included in the study according to a factorial design (11). Treatments were given in a randomized order, according to a Latin square. Wine consumption comprised 2 glasses of red wine at dinner (in the evening) and 2 glasses of red wine during the evening. Coffee consumption comprised 6 cups of black filter coffee (approximately $75 \mathrm{mg}$ caffeine per cup): 2 cups in the morning, 2 cups in the afternoon, 1 cup after finishing dinner and 1 cup in the evening. The composition of the standard diets during the experimental periods is given in Table 1. Blood samples were taken after an overnight fast at days $0,1,2$ and 4 of each experimental period, always at the same time in the morning and always at the same days of the week.

\section{Analytical Methods}

Blood was taken by means of a venacatheter from resting volunteers in supine position. For fibrinolytic parameters blood was collected in prew cooled polycarbonate tubes on citrate (1 vol $32 \mathrm{~g} / \mathrm{l}$ sodium citrate, 9 wol bloody and processed to platelet-poor plasma as previously described in 
Table 1. Composition of the standard total daily diets during the experimental periods.

SFA-rich diet PUFA-rich diet

\begin{tabular}{llcc}
\hline Energy & $(\mathrm{kcal} / \mathrm{d})$ & 2766 & 2820 \\
& $(\mathrm{MJ})$ oule/d) & 11.6 & 11.8 \\
Weight & $(\mathrm{g} / \mathrm{d})$ & 1796 & 1795 \\
Protein & $(\mathrm{g} / \mathrm{d})$ & 80.8 & 82.6 \\
Carbohydrates & $(\mathrm{g} / \mathrm{d})$ & 319.7 & 319.5 \\
Total fat & $(\mathrm{g} / \mathrm{d})$ & 129.3 & 134.6 \\
Fatty acids: & $(\%$ of total) & & \\
\hline Saturated & & 59.9 & 38.5 \\
Monounsaturated & 35.5 & 29.5 \\
Polyunsaturated & 4.6 & 32.0 \\
\hline
\end{tabular}

${ }^{1}$ Polyunsaturated fatty acids consisted for $99 \%$ of linoleic acid

detail (12). Plasma was kept frozen at or below $-40^{\circ} \mathrm{C}$.

Plasminogen was analyzed in an activity assay using streptokinase for activation and $\mathrm{S} 2251$ (both obtained from Kabivitrum. Amsterdam) for assay of activity according to Friberger et al.(13) Results were expressed as a percentage relative to a pool plasma (12).

1-PA activity was determined in euglobulin fractions of plasma using the parabolic rate assay for t-PA as described in detail elsewhere (14). Activity, expressed in IU/. was determined on the basis of the International standard of $1-P A(15)$.

i-PA inhibition was determined by litration with purified 2-chain t-PA using a parabolic rate assay to measure residual t-PA as described (16). Inhibition was expressed relative to a pooled plasma sample which was estimated to inhibit $7.6 \mathrm{IU}$ of $\mathrm{t}-\mathrm{PA} / \mathrm{ml}$.

t-PA antigen is assayed by enzyme immunoassay using Imulyse 5 (TM) (Biopool AB. Lmeå. Sweden).

For platelet aggregation $18 \mathrm{ml}$ blood was collected by gentle suction into $2 \mathrm{ml}$ of $32 \mathrm{~g} / \mathrm{l}$ sodium citrate, $\mathrm{pH} \mathrm{7.4}$. Aggregation experiments were carried out in platelet-rich plasma (PRP) containing $220 \times 10^{6}$ platelets/mi on a Lumi Dual Aggrometer (Chrono-Log Corp, Havertown. PA). After 3 minutes preincubation of $450 \mu \mathrm{PRP}$ at $37^{\circ} \mathrm{C}, 50 \mu l$ collagen or thrombin suspension was added to induce aggregation. Aggregation curves 
were recorded for 5 minutes. For collagen (Hormon Chemie, München, FRG) the final concentrations used were $0.3,0.6$ and $1.0 \mathrm{mg} / \mathrm{l}$ and for thrombin (Sigma, St Louis, MO, USA) 60, 80 and $100 \mathrm{U} / 1$.

From the aggregation curves with collagen the percentage of maximal aggregation and the velocity of aggregation were measured. For thrombininduced aggregation this was done for the percentage of maximal aggregation and the time it took to reach maximal aggregation.

For haematological determinations $3 \mathrm{ml}$ of EDTA-K blood was collected and analyzed on a Sysmex CC-180 (TOA Medical Electronics Co Ltd, Carson, $\mathrm{CA})$. Haematological parameters were hemoglobin $(\mathrm{Hb})$, haematocrit $(\mathrm{Ht})$, white blood cell counts (WBC), red blood cell counts (RBC) and platelet counts (PLC).

For the analyses of erythrocyte membrane fluidity, erythrocyte membranes were isolated as described by Dodge et al.(17) and fluorescence polarization was measured on an Elscint MV-1a apparatus (Elscint Lid., Haifa, Israel) as described by van Hoeven et al. (18).

\section{Statistical Methods}

Statistical analysis comprised analysis of covariance (values were adjusted for day 0) of each variable at days 1, 2 and 4. Main effects of coffee, wine and diet were tested as well as two-factor interactions. Skewed variables were transformed by logarithms before statistical analysis. For these variables the normal means are presented in the figures. Effects with a $\mathrm{P}$ value $<0.05$ were considered to be significant.

\section{Results}

There were essentially no effects of wine consumption or significant interactions between wine and coffee consumption on the parameters of fibrinolysis, platelet aggregation, haematology and erylhrocyte membrane fluidity.

The effects of coffee consumption on the parameters of fibrinolysis are summarized in Figure 1. Coffee significantly increased t-PA inhibition levels after two and four days $(\mathrm{P}<0.05$ and $\mathrm{P}<0.001$, respectively). The observed variations and differences in t-PA activity and plasminogen levels (Fig. 1) were not significant due to large standard deviations and small differences, respectively. t-PA antigen values were only obtained in the samples of day 0 and 4 and showed a non-significant tendency of higher values in the coffee group (day $4,8.1 \pm 2.4 \mathrm{ng} / \mathrm{ml}$ ) than in the control group (day $4,6.3 \pm 2.0 \mathrm{ng} / \mathrm{ml}$ ). There were no effects of the type of fat 


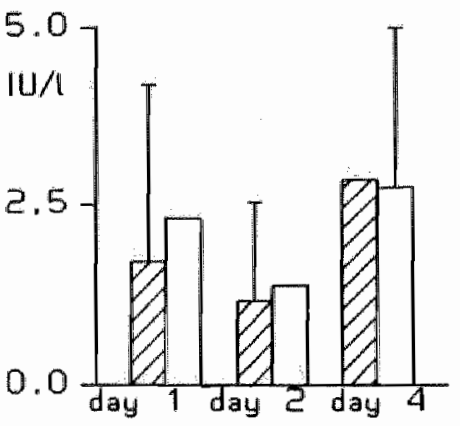

1-PR octivily

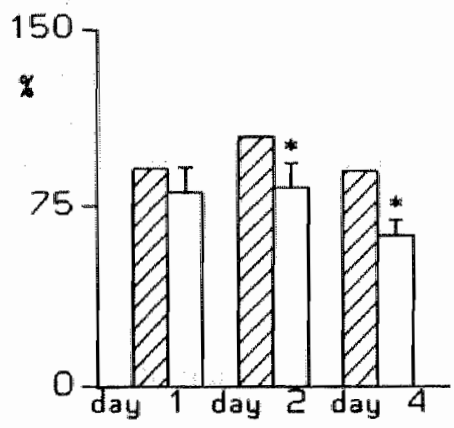

t-PA inhibition

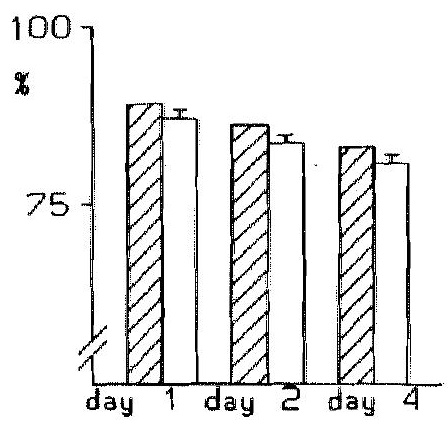

Plasminogen

ZZ Coffee $\square$ Na colfee

Figure 1. The influence of coffee consumption on the parameters of fibrinolysis. The asterisks indicate a significant difference between the measurements with and without coffee. The T-bars indicate the standard error of difference (SED) $(n=16)$ derived from the pooled error variance.

on the parameters of fibrinolysis.

No significant main effects of coffee treatment on platelet aggregation were observed. The type of fat consumed during the experimental period, however, showed a rather consistent interaction with coffee consumption for both collagen- and thrombin-induced platelet aggregation (Table 2). The significant interactions are shown in Figure 2. 
Table 2. Interactions between coffee consumption and the type of fat consumed during the experimental period. Values represent the means of the logarithms (see statistical methods). SED values $(n=8)$ are derived from the pooled error variance. The $P$ values in the table are the $P$ values for the interactive effect between coffee treatment and the type of dietary fat.

\section{$\frac{\text { PUFA-rich diet }}{\text { Coffee No coffee }} \quad \frac{\text { SFA-rich diet }}{\text { Coffee No coffee }}$ SED P value}

\begin{tabular}{|c|c|c|c|c|c|c|c|}
\hline \multicolumn{8}{|c|}{ Collagen $0.3 \mu \mathrm{g} / \mathrm{ml}$} \\
\hline$\%$ max aggr & Day 1 & 2.25 & 1.59 & 1.62 & 2.01 & 0.378 & 0.076 \\
\hline velo aggr & & 1.67 & 1.34 & 1.28 & 1.53 & 0.301 & 0.186 \\
\hline$\%$ max aggr & Day 2 & 2.44 & 2.32 & 1.90 & 2.80 & 0.363 & 0.071 \\
\hline velo aggr & & 1.92 & 1.92 & 1.57 & 2.37 & 0.260 & 0.047 \\
\hline$\%$ max aggr & Day 4 & 2.76 & 2.26 & 2.00 & 2.56 & 0.337 & 0.047 \\
\hline velo aggr & & 2.47 & 1.70 & 1.81 & 2.17 & 0.367 & 0.047 \\
\hline \multicolumn{8}{|c|}{ Thrombin \% max aggr } \\
\hline $0.06 \mathrm{U} / \mathrm{m}]$ & Day 1 & 2. 14 & 1.82 & 1.79 & 1.93 & 0.081 & 0.005 \\
\hline $0.08 \mathrm{U} / \mathrm{ml}$ & & 2.42 & 2.08 & 2.18 & 2.28 & 0.094 & 0.010 \\
\hline $0.06 \mathrm{U} / \mathrm{ml}$ & Day 2 & 1.82 & 1.88 & 1.95 & 1.90 & 0.166 & 0.662 \\
\hline $0.08 \mathrm{U} / \mathrm{ml}$ & & 2.03 & 2.20 & 2.04 & 2.25 & 0.142 & 0.845 \\
\hline $0.06 \mathrm{U} / \mathrm{ml}$ & Day 4 & 2.22 & 1.90 & 2.12 & 2.11 & 0.080 & 0.042 \\
\hline $0.08 \mathrm{U} / \mathrm{ml}$ & & 2.37 & 2.27 & 2.19 & 2.24 & 0.113 & 0.356 \\
\hline
\end{tabular}

When coffee was consumed with the PUFA-rich diet there was an increase in platelet aggregability. There was a decreased platelet aggregation. however, when coffee was consumed with the SFA-rich diet.

A small but significant increase in hemoglobin concentration was observed one and two days after coffee consumption $(p=0.001$ and $p=0.014$. respectively). This increase was no longer significant after 4 days. There were no significant effects of coffee consumption on the other parameters of haematology and erythrocyte membrane fluidity. 


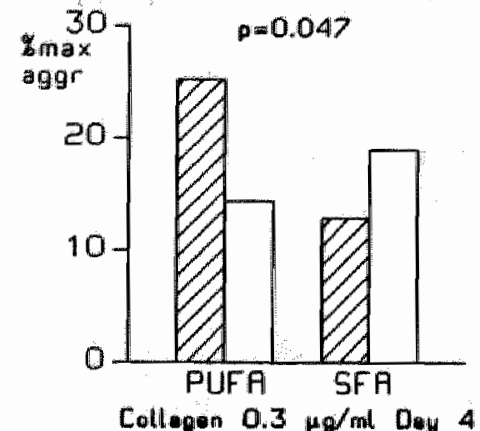

Collogen $0.3 \mu \mathrm{g} / \mathrm{ml}$ Dey 4

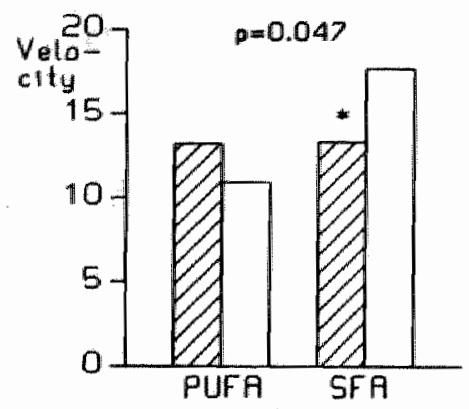

Collogan $0.3 \mu / \mathrm{ml}$ Dow 2

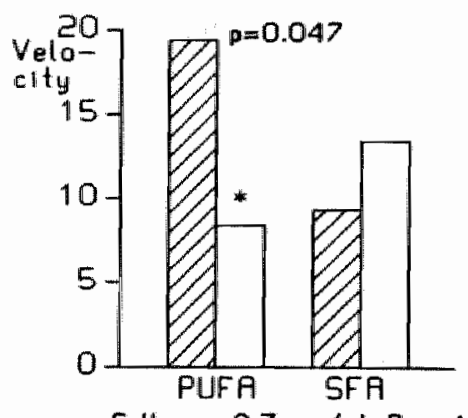

Collogen $0.3 \mu g / m i$ Day 4

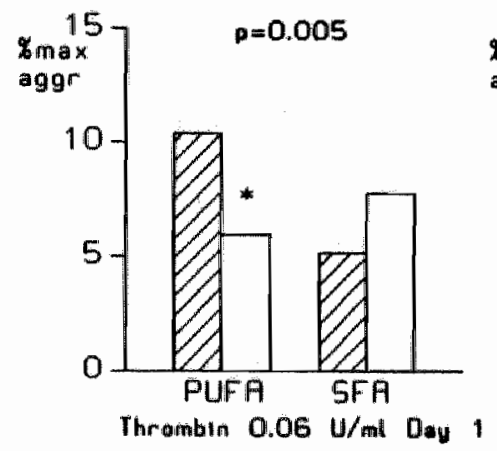

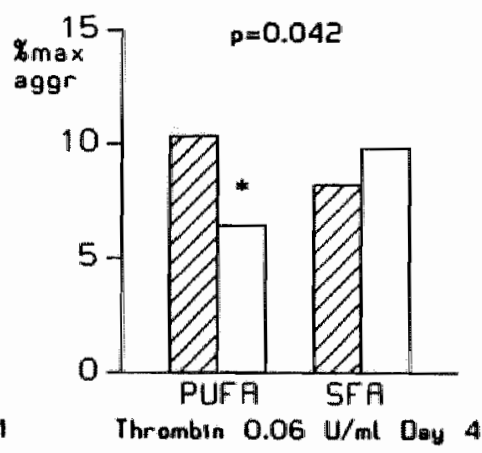

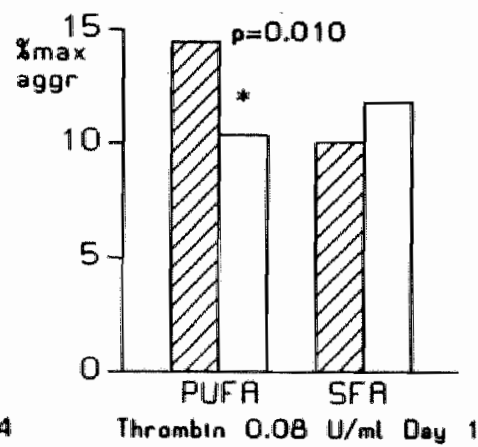

Figure 2. Significant interactions between coffee consumption and type of fat consumed during the experimental period. The $P$ values indicated in the figure pertain to the interactive effect between coffee treatment and the type of dietary fat. The asterisks indicate a significant difference between the measurements with and without coffee. 


\section{Discussion}

Previous studies on the effect of moderate wine consumption have demonstrated a reduction in t-PA activity (1), which has been attributed subsequently to an increase in the plasma level of plasminogen activator inhibitor-1 (PAI-1)(19). In the present study, such an effect of similar amounts of wine was not found, which may be due to the short period of wine consumption as compared to 5 weeks in our previous study.

Reports on alcohol and platelet aggregation are conflicting. When the acute effects of alcohol were investigated, no effects, $(10,20,21,22)$ inhibitory effects $(2,23,24)$ as well as stimulative effects $(11,25,26)$ were found. An explanation could be the large diversity in study protocols. In three studies $(2,25,26)$ the volunteers consumed $100 \mathrm{~g}$ of alcohol or more ( 1 drink contains approximately $10 \mathrm{~g}$ ), and in one study (20) alcohol was taken ad libitum for four hours. In the other studies the amount of alcohol consumed varied broadly between 15 and $90 \mathrm{~g}$. Furthermore, the studies varied considerably in type of alcoholic beverage (e.g. whiskey, white wine and alcohol in fruit juice). In all studies mentioned, the alcohol was consumed on an empty stomach, mostly in the morning.

In a previous study we have found an inhibitory effect on platelet aggregation of moderate wine consumption for 5 weeks (1). Other studies showed that platelet aggregability increases in alcoholics upon alcohol withdrawal $(26,27)$. Adaptation of the plasma membranes to the fluidizing effects of alcohol has been proposed as a possible mechanism through which alcohol influences platelet aggregation on the long term $(3,4)$. In the present study no effects were observed on platelet aggregation, or on membrane fluidity of 4 days of moderate wine consumption under habitual conditions.

The effect of coffee consumption on fibrinolysis in the present study mainly concerns an increase in level of inhibition for t-PA in plasma. The increase is moderate and remains within normal ranges. The increase in $1-$ PA inhibition level does not result in a significant reduction in t-PA activity, which may be related to a simultaneous increase in t-PA production as might be suspected from a tendency of increase in t-PA antigen. In several studies a correlation between plasma levels of t-PA (antigen) and the main t-PA inhibitor, PAI-1, has been demonstrated (2830). From this, it might be hypothesized that the regulation of t-PA and PAI production is coordinated and that coffee promotes the synthesis of both t-PA and PAI. In the genomic codes of t-PA and PAI-1 homologies have been found which possibly underlie a (partial) coordinated regulation (31). 
Our results differ from those of Wojta et al. (6) who have demonstrated a clear decrease in $\mathrm{t}-\mathrm{PA}$ inhibition level after caffeine ingestion. However, in their study caffeine ingestion was terminated on the morning just before blood sampling, whereas we collected blood after an overnight fast. In the study of Wojta et al. (6), a short-term effect of caffeine might also be operable.

The effect of coffee or caffeine on platelet aggregation has been investigated in some studies. In vitro studies have revealed that caffeine is an inhibitor of platelet aggregation (7-9), and so have in vivo studies in which the acute effects (1-3 hours after coffee consumption) were investigated (10). These effects are likely to be mediated by an accumulation of cyclic AMP in platelets. Methyl xanthines inhibit the enzyme cyclic AMP phosphodiesterase which converts cyclic AMP to 5'-AMP in a dose-dependent manner (for a review see ref. 32).

In our study the effect of 1,2 and 4 days of coffee consumption on platelet aggregation was studied in the fasting state. The time between consumption of the ewening cup of coffee and the induction of platelet aggregation was at least 12 hours so that caffeine concentrations in the platelet-rich plasma were expected to be low, in contrast to the in vitro and the acute in vivo studies mentioned.

The observed interaction between coffee and the type of fat is interesting and indicates that dietary fatty acids should be taken into account in research on coffee consumption and platelet aggregation. An explanation for the interaction may lie in a change in the production of arachidonic acid metabolites during aggregation. The fat of the PUFA-rich diet mainly consisted of linoleic acid, which can be converted into arachiclonic acid by elongation and desaturation (33). Since platelets may produce aggregation-enhancing as well as aggregation-inhibiting arachidonic acid metabolites by different enzyme systems (34), the type and amount of dietary fatty acids is likely to influence the effects of coffee on platelet aggregation.

A small increase in hemoglobin concentration was observed after one and two days of coffee consumption. Although not significantly, the red blood cell count and the hematocrit also tended to increase. This is possibly the result of the known weak diuretic effects of caffeine (35).

In conclusion, moderate wine consumption has no effect on fibrinolysis and platelet aggregation within four days, if measured after at least 12 hours of abstinence. Moderate coffee consumption, however, increases t-PA inhibition levels. Furthermore, the effect of moderate coffee consumption on platelet aggregation appears to depend on the fatty acid composition of the diet. 


\section{Acknowledgement}

Supported by the Central Commodity Board for Arable Products, The Hague, The Netherlands and the Commodity Board for Spirits, Schiedam. The Netherlands.

\section{References}

1. Pikaar NA, Wedel M, van der Beek EJ, van Dokkum W, Kempen HJM, Kluft C, Ockhuizen Th, Hermus RJJ. Effects of moderate alcohol consumption on platelet aggregation, fibrinolysis, and blood lipids. Metabolism $1987 ; 36: 538-43$.

2. Fenn CG, Littleton JM. Interactions between ethanol and dietary fat in determining human platelet function. Thromb Haemostas 1985;51:50-3.

3. Beaugé $F$, Stibler $H$, Borg $S$. Alterations of erythrocyte membrane organization in alcoholics. Alcohol Alcohol ism 1987;Suppl 1:561-5.

4. Beaugé $F$, Stibler $H$, Borg $S$. Abnormal fluidity and surface carbohydrate content of the erythrocyte membrane in alcoholic patients. Alcohol Clin Exp Res 1985;9:322-6.

5. Samarrae W AL, Truswell S. Short-term effect of coffee on fibrinolytic activity in healthy adults. Atherosclerosis 1977;26:255-69.

6. Wojta J, Kirchheimer JC, Peska MG, Binder BR. Effect of caffein ingestion on plasma fibrinolytic potential. Thromb Haemostas 1988;59:337-8.

7. Buchon AO, Tomas IG, Pastor JV, Llinares AO, Quiles JJ, Requena JE. Effects of $\mathrm{PgF}_{\mathrm{a}}$ and caffeine on platelet aggregation by $\mathrm{ADP}$ induced. Arch de Farmacol y Toxicol 1976; II:159-68.

8. Ardlie NG, Glew G, Schultz BG, Schwartz CJ. Inhibition and reversal of platelet aggregation by methyl xanthines. Thrombos Diathes Haemorrh 1967;18:670-3.

9. Wolfe SM, Shulman NR. Inhibition of platelet energy production and release reaction by PGE1, theophylline and $c$ - AMP. Biochim Biophys Res Commun 1970;41:128-35.

10. Galli C, Colli S, Gianfranceschi G. Acute effects of ethanol, caffeine, or both on platelet aggregation, thromboxane formation, and plasma free fatty acids in normal subjects. Drug-Nutrient Interactions 1984;3:61-7.

11. Cochran WG, Cox GM. Experimental designs. (Ed2). New York, John Willey \& Sons, Inc. 1957.

12. Kluft $C$, Brakman $P$, Veldhuyzen-Stolk. Screening of fibrinolytic activity in plasma euglobulin fractions on the fibrin plate. In: 


\section{CHAPTER 5}

Davidson J F, Samama $M M$, Desnoyers $P$ C (eds) Progress in chemical fibrinolysis and thrombolysis, Vol 2. Raven Press, New York, 1976:5765.

13. Friberger $P$, Knos $M$, Gustawsson $S$, Aurell $L$, Claeson $G$. Methods for determination of plasmin, antiplasmin and plasminogen by means of substrate $\mathrm{S}-2251$. Haemostasis 1978;7:138-45.

14. Verheijen $\mathrm{JH}$, Mullaart E, Chang GTG, Kluft C, Wijngaerds G. A simple, sensitive spectrophotometric assay for extrinsic (tissue-type) plasminogen activator applicable to measurement in plasma. Thromb Haemostas 1982;48:266-9.

15. Gaffney PJ, Curtis AD. A collaborative study of a proposed International standard for tissue plasminogen activator in human plasma. Thromb Haemostas 1985;53:134-6.

16. Verheijen JH, Chang GTG, Kluft C. Evidence for the occurrence of a fast-acting inhibitor for tissue-type plasminogen activator in human plasma: Thromb Haemostas 1984;51:392-5.

17. Dodge JT, Mitchell C, Hanahan DJ. The preparation and chemical characteristics of hemoglobin-free ghosts of human erythrocytes. Arch Biochem Biophys 1963:110:119-30.

18. van Hoeven RP, van Blitterswijk WJ, Emmelot P. Fluorescence polarization measurements on normal and tumour cells and their corresponding plasma membranes. Biochim Biophys Acta 1979;551:44-54.

19. Kluft C, Veenstra J, Schaafsma G, Pikaar NA. Regular moderate wine consumption for five weeks increases plasma activity of the plasminogen activator inhibitor 1 (PAI-1) in healthy young volunteers. Fibrinolysis, in press.

20. Dunn EL, Cohen RG, Moore EE, Hamstra RD. Acute alcohol ingestion and platelet function. Arch Surg 1981:116:1082-3.

21. Hillbom M, Muuronen A, Neiman J, Björk G, Egberg N, Kangasaho $M$. Effects of vilamin $E$ therapy on ethanol- induced changes in platelet aggregation, thromboxane formation, factor VIII levels and werum lipids. Eur J Clin Invest 1987;17:68-74.

22. Neiman J, Jones AW, Numminen $\mathrm{H}$, Hillbom M. Combined effect of a small dose of ethanol and $36 \mathrm{hr}$ fasting on blood-glucose response, breathacetone profiles and platelet function in healthy men. Alcohol Alcoholism 1987:22:265-70.

23. Mikhailidis DP. Jeremy JY, Barradas MA, Green N, Dandona P. Effect of ethanol on vascular prostacyclin synthesis, platelet aggregation and platelet thromboxane release. Br Med J 1983;287:1495-8.

24. Elmér O, Göransson G, Zoucas E. Impairment of primary hemostasis and platelet function after alcohol ingestion in man. Haemostasis $1984 ; 14: 223-8$. 


\section{CHAPTER 5}

25. Hillbom M, Kangasaho M, Kaste M, Numminen H, Vapaatalo H. Acute ethanol ingestion increases platelet reactivity: Is there a rellationship to stroke? Stroke 1985;16;19-23.

26. Hillbom M, Kangasaho M, Lowbeer C, Kaste A, Muuronen A, Numminen H. Effects of ethanol on platelet function. Alcohol 1985;2:429-32.

27. Hillbom M, Muronen A, Lowbeer $C$. Anggard $\mathbb{E}$, Beving $H$, Kangasaho $M$. Platelet thromboxane formation and bleeding time is influenced by ethanol withdrawal but not by cigarette smoking. Thromb Haemostas 1985:53:419-22.

28. Kruithof EKO, Nicolasa G, Bachmann F. Plasminogen activator inhibitor 1: Development on a radioimmunoassay and observations on its plasma concentration during venous occlusion and after platelet aggregation. Blood 1987;70:1645-53.

29. Gram J, Jespersen J, Kluft C, Rijken DC. On the usefulness of fibrinolysis variables in the characterization of a risk group for myocardial infarction. Acta Med Scand 1987:221:149-53.

30. Kluft C, Jie AFH, Rijken DC, Verheijen JH. Daytime fluctuations in blood of lissue-type plasminogen activator (t-PA) and its fast-acting inhibitor (PAll-1). Thromb Haemostas 1988;59:329-32.

31. Bosma PJ, van den Berg EA, Kooistra T, Siemieniak DR, Slightom JL. Human plasminogen activator inhibitor-1 gene. Promoter and structural gene nucleotide sequences. J Biol Chem 1988;263:9129-41.

32. Fredholm BB. Cardiovascular and renal actions of methyl-xanthines. Prog Clin Biol Res 1984;158:303-30.

33. Lands WEM. Renewed questions about polyunsaturated fatty acids. Nutrition Reviews 1986:44:189-95.

34. Lagarde M. Roles of cyclooxygenase and lipoxygenase metabolites in platelets. In: Macintyre and Gordon (eds) Platelets in Biology and Pathology III. Elsevier Science Publishers BV, Amsterdam, 1987:269-88.

35. Passmore AP, Kondowe GB, Johnston GD. Renal and cardiovascular effects of caffeine: a dose-response study. Clinical Science 1987:72:749-56. 


\title{
EFFECTS OF FOUR DAYS OF MODERATE ALCOHOL CONSUMPTION ON BLOOD LIPIDS AND LIPOPROTEINS IN HEALTHY VOLUNTEERS
}

\author{
J. Veenstra, Th. Ockhuizen, H. van de Pol, M. Wedel \\ and $G$. Schaafsma.
}

(Submitted)

\section{Summary}

During a four-day experimental period the effects of moderate alcohol consumption on blood lipids and lipoproteins were studied in 8 apparently healthy young men. Following a washout period of 10 days, blood samples were taken after an overnight fast at days $0,1,2$ and 4 of the experimental period. During this period the subjects received at random 4 glasses of wine per day or mineral water and a diet with a high content of either polyunsaturated fat or saturated fat. At day 4 , a significant increase in the Apo-A $/$ Apo-B ratio was observed upon alcohol consumption (238.0 versus $206.8 ; \mathrm{p}=0.025$ ). There were no significant main effects of alcohol on total cholesterol, triglycerides and the HDL-C subfractions $\mathrm{HDL}_{2}-\mathrm{C}$ and $\mathrm{HDL}_{3}-\mathrm{C}$. For $\mathrm{HDL}_{3}-\mathrm{C}$, however, a significant interaction was found between alcohol consumption and type of fat. Alcohol together with a diet high in polyunsaturated fatty acids significantly increased $\mathrm{HDL}_{3}$-C levels, whereas no effect of alcohol on $\mathrm{HDL}_{3}-\mathrm{C}$ could be observed when the diet consisted mainly of saturated fatty acids.

Keywords. Alcohol consumption, coronary heart disease, HDL cholesterol, HDL subfractions, apolipoproteins.

\section{Introduction}

In many epidemiological studies a positive association between alcohol consumption and high-density lipoprotein-cholesterol (HDL-C) has been shown (1-8). High levels of HDL-C are commonly found in chronic alcoholics (9-11), and even moderate alcohol consumption is reported to increase HDL$C(3,5,7,8,12)$. Since an increase in HDL-C is inversely related to the risk of coronary heart disease (CHD), this possibly explains the reported, but not generally accepted $(13,14)$, beneficial effects of moderate alcohol 
consumption on CHD risk (reviews 15-17). The proposed mechanism assumes that the elevated HDL-C levels decrease the risk of CHD by an improved transport of cholesterol from the tissue deposits to the liver, where it is metabolized. Plasma HDL-C consists of two major subfractions, differing slightly in density: $\mathrm{HDL}_{2}-\mathrm{C}$ and $\mathrm{HDL}_{3}-\mathrm{C}$. Of these two subfractions, particularly $\mathrm{HDL}_{2}-\mathrm{C}$ is epidemiologically associated with a lower risk of CHD (17). Besides HDL-C subfractions, the apolipoproteins Apo-A 1 and Apo-

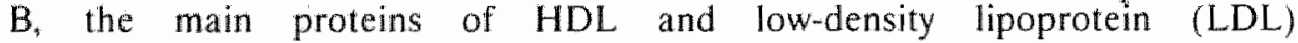
respectively, are of interest. Apo- $A_{1}$ is even more strongly associated with a lower risk of $\mathrm{CHD}$ than is $\mathrm{HDL}-\mathrm{C}$, and there is a strong positive correlation between Apo-B and the development of CHD (17).

In a previous study we have investigated the effects of 5 weeks of moderate alcohol consumption on platelet aggregation, fibrinolysis and blood lipids (18). A small but significant increase of $\mathrm{HDL}_{3}-\mathrm{C}$ was observed when 4 glasses of red wine were consumed daily. The changes in $\mathrm{HDL}_{2}-\mathrm{C}$ were not significant. Other studies have reported similar effects of moderate alcohol consumption for periods ranging from 3 to 6 weeks $(12,19-21)$.

A study in alcoholics has shown that upon cessation of drinking, $\mathrm{HDL}_{2}-$ $\mathrm{C}$ and $\mathrm{HDL}_{3}-\mathrm{C}$ levells fell significantly within two days, indicating a relatively short-term effect of alcohol (10). Data on short-term effects of moderate alcohol consumption in healthy non-alcoholic volunteers are scarce. Therefore the purpose of the present study was to investigate the effects of 1,2 and 4 days of moderate alcohol consumption in healthy male volunteers on serum cholesterol, triglycerides, HDL-C subfractions and the apolipoproteins $\mathrm{A}_{1}$ and $\mathrm{B}$ in a carefully controlled study design.

\section{Patients and methods}

\section{Subjects}

Eight healthy, non-smoking men aged 20 - 30 participated. Their habitual daily consumption of alcohol did not exceed 4 glasses $(40 \mathrm{~g}$ alcohol). Their liver function was normal and they had no familial history of alcoholism. They were used to a normal western life-style, including dietary habits. The study protocol was approved by the Institute's external medical-ethical committee, and the participants signed the informed consent form. 


\section{CHAPTER 6}

\section{Study design}

The study consisted of four periods of two weeks each. In the first ten days of each period the subjects consumed their habitual diet but refrained from alcohol consumption. This wash-out period was followed by an experimental period of four days in which the subjects received at random, according to a Latin square, alcohol or mineral water, while they were on a diet that had a high content of either polyunsaturated fat (PUFA) or saturated fat (SFA). The composition of the diets is given in Table 1. Alcohol consumption consisted of 2 glasses of red wine at dinner (always at the same time at the beginning of the evening) and 2 glasses of red wine during the evening. During the experimental periods the volunteers were not allowed to eat or drink anything apart from the food and drinks supplied. Blood samples were taken after an overnight fast at days $0,1,2$ and 4 of the experimental period.

Table 1. Composition of the standard total daily diets during the experimental periods (pooled portions of 2 days were analyzed).

\begin{tabular}{llcc}
\hline & & $\begin{array}{c}\text { Diet rich in } \\
\text { saturated } \\
\text { fatty acids }\end{array}$ & $\begin{array}{c}\text { Diet rich in } \\
\text { polyunsaturated } \\
\text { fatty acids }\end{array}$ \\
\hline Energy & $\begin{array}{l}\text { (kcal/day) } \\
(\mathrm{MJ} / \text { day) }\end{array}$ & 2766 & 2820 \\
Weight & $(\mathrm{g} / \mathrm{dlay})$ & 1796 & 11.8 \\
Protein & $(\mathrm{g} / \mathrm{day})$ & 80.8 & 1795 \\
Carbohydrates & $(\mathrm{g} / \mathrm{day})$ & 319.7 & 82.6 \\
Total fat & $(\mathrm{g} / \mathrm{day})$ & 129.3 & 319.5 \\
$\begin{array}{l}\text { Saturated fatty acids } \\
\text { Monounsaturated fatty }\end{array}$ & $(\%)$ & 59.9 & 134.6 \\
$\begin{array}{l}\text { acids } \\
\text { Polyunsaturated fatty }\end{array}$ & $(\%)$ & 35.5 & 38.5 \\
acids & & & 29.5 \\
& $(\%)$ & 4.6 & 32.0 \\
\hline
\end{tabular}

* Polyunsaturated fatty acids consisted for $99 \%$ of linoleic acid 


\section{Analytical methods}

Blood was taken from a vena mediana cubiti by means of a catheter. For HDL subfractionation the method of Gidez et al (22) was used. First, very low-density lipoprotein (VLDL) and LDL were removed by precipitation with heparin $\left(0.15 \%\right.$ w/v final concentration) and $\mathrm{MnCl}_{2}(100 \mathrm{mmol} / \mathrm{L})$ for $20 \mathrm{~min}$ at $0^{\circ} \mathrm{C}$. Then dextran sulphate (MW 15,000) was added to a final concentration of $0.14 \% \mathrm{~W} / \mathrm{v}$ and the mixture left for 30 minutes at $0^{\circ} \mathrm{C}$ before centrifugation. Cholesterol in $\mathrm{HDL}_{2}$ (redissolved dextran sulphate precipitate) and in $\mathrm{HDL}_{3}$ (final supernatant) were determined by the method of Abell et al. (23). Serum apolipoproteins were determined by rocket immunoelectrophoresis, using the Elphogram Apo $A_{1} / B$ test kit of Bio-Rad Laboratories $\mathrm{GmbH}$, München, FRG. Total serum cholesterol and total serum triglycerides were determined by enzymatic-colorimetric autoanalyzer methods on a Hitachi autoanalyzer (Boehringer, Mannheim, FRG) using Boehringer biochemicals.

\section{Statistical methods}

Statistical analysis comprised analysis of covariance (values were adjusted for day 0) of each variable at days 1,2 and 4. Main effects of alcohol and type of dietary fat were tested as well as two-factor interactions: Skewed variables were transformed by logarithms. For these variables geometrical means are presented. Effects with a $\mathrm{P}$ value $<0.05$ were considered to be significant.

\section{Results}

The effects of alcohol consumption on blood lipids and apolipoproteins are summarized in Table 2. All values were adjusted for day 0 . No significant effects on $\mathrm{HDL}-\mathrm{C}$ subfractions were observed although $\mathrm{HDL}_{3}-\mathrm{C}$ showed a tendency to be higher after 4 days of moderate alcohol consumption. Apo- $A_{1}$, which is the main apolipoprotein in HDL-C, showed a tendency to increase. Apo-B, on the other hand, tended to be lower when alcohol was consumed in the experimental period. A significant increase in Apo-A $/$ Apo-B tatio upon alcohol consumption was observed at day 4 of the experimental period $(\mathrm{p}=0.025)$. 
Table 2. Effects of alcohol consumption on blood lipid and apolipoprotein levels in healthy volunteers $(n=8)$. All values were adjusted for day 0.

$$
\text { Treatment }{ }^{*} \text { Day } 1 \mathrm{p} \text {-value Day } 2 \text { p-value Day } 4 \text {-value }
$$

\begin{tabular}{|c|c|c|c|c|c|c|c|c|}
\hline \multirow[t]{2}{*}{$\mathrm{HDL}_{2}-\mathrm{C}$} & \multirow[t]{2}{*}{$(\mathrm{mmol} / \mathrm{L})$} & \multirow[t]{2}{*}{+} & \multicolumn{2}{|l|}{0.33} & \multicolumn{2}{|l|}{0.35} & \multicolumn{2}{|l|}{0.38} \\
\hline & & & 0.37 & 0.110 & 0.36 & 0.890 & 0.36 & 0.468 \\
\hline \multirow[t]{2}{*}{$\mathrm{HDL}_{3}-\mathrm{C}$} & $(\mathrm{mmol} / \mathrm{L})$ & + & 0.98 & & 1.01 & & 1.00 & \\
\hline & & & 0.97 & 0.814 & 0.99 & 0.301 & 0.94 & 0.134 \\
\hline \multirow[t]{2}{*}{ Apo- $\mathrm{A}_{1}$} & $(\mathrm{~g} / \mathrm{L})$ & + & 1.54 & & 1.54 & & 1.73 & \\
\hline & & & 1.55 & 0.903 & 1.54 & 0.980 & 1.61 & 0.129 \\
\hline \multirow[t]{2}{*}{ Apo-B } & $(\mathrm{g} / \mathrm{L})$ & + & 0.78 & & 0.81 & & 0.77 & \\
\hline & & & 0.83 & 0.349 & 0.83 & 0.534 & 0.84 & 0.079 \\
\hline \multirow{2}{*}{\multicolumn{2}{|c|}{ Apo-A $1 /$ Apo-B }} & + & 2.08 & & 1.96 & & 2.38 & \\
\hline & & & 1.95 & 0.511 & 1.94 & 0.845 & 2.07 & 0.025 \\
\hline \multirow{2}{*}{\multicolumn{2}{|c|}{$\begin{array}{l}\text { Total cholesterol } \\
\qquad(\mathrm{mmol} / \mathrm{L})\end{array}$}} & + & 4.84 & & 5.12 & & 5.04 & \\
\hline & & - & 4.94 & 0.544 & 5.10 & 0.866 & 4.94 & 0.400 \\
\hline \multicolumn{2}{|c|}{ Triglycerides } & + & 0.82 & & 0.81 & & 0.82 & \\
\hline & $(\mathrm{mmol} / \mathrm{L})$ & - & 0.83 & 0.829 & 0.76 & 0.407 & 0.74 & 0.305 \\
\hline
\end{tabular}

+40 g alcohol per day; _ no alcohol.

No effects of alcohol consumption on tolal cholesterol and triglyceride levels were observed. The type of dietary fat, however, strongly affected total cholesterol level at day 2 and day 4. Serum total cholesterol levels were significantly lower for the PUFA diet than for the SFA diet (means at day 4: 4.77 and $5.22 \mathrm{mmol} / \mathrm{l}$, respectively: $p=0.002$ ).

For $\mathrm{HDL}_{3}-\mathrm{C}$ a clear interaction between alcohol and type of dietary fat was observed (Table 3). When the dietary fat mainly consisted of PUFA, alcohol consumption increased $\mathrm{HDL}_{3}$-C levels after 2 and 4 days by 10.6 and $14.4 \%\left(p=0.005\right.$ and $p=0.047$, respectively), whereas no changes in $\mathrm{HDL}_{3}-\mathrm{C}$ level occurred when alcohol was consumed in combination with a diet rich in SFA. 
Table 3. Interaction between alcohol consumption and dietary fatty acid composition on $\mathrm{HDL}_{3} \mathrm{C}(\mathrm{mmol} / \mathrm{L})$.

Diet rich in

saturated fatty acids
Diet rich in

polyunsaturated fatty acids
Alcohol No alcohol
Alcohol
No alcohol P-value
Day 1
$0.95^{a}$
$0.94^{\mathrm{a}}$
$1.00^{\mathrm{a}}$
$1.00^{\mathrm{a}}$
0.678
Day 2
$0.98^{a}$
$1.03^{\mathrm{a}}$
$1.04^{\mathrm{a}}$
$0.94^{\mathrm{b}}$
0.005
Day $4 \quad 0.97^{a b}$
$0.99^{\mathrm{a}}$
$1.03^{a}$
$0.90^{\mathrm{b}}$
0.047

Values sharing the same superscript (within days) do not differ significantly.

\section{Discussion}

Our results suggest that, although a tendency to an increased $\mathrm{HDL}_{3}{ }^{\mathrm{C}} \mathrm{C}$ level could be observed, the period of four days was too short to obtain a statistically significant main effect on HDL-C subfractions in healthy volunteers. The changes in the levels of $A p o-A_{1}$ and $A p o-B$ were also not

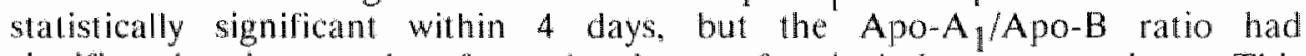
significantly increased after 4 days of alcohol consumption. This indicates that the ratio between these apoproteins is a sensitive parameter for the early effects of alcohol on lipoprotein metabolism.

The interaction between alcohol and type of dietary fat indicates that the effect of moderate alcohol consumption on $\mathrm{HDL}_{3}-\mathrm{C}$ levels is dependent on the type of dietary fat. Alcohol increased $\mathrm{HDL}_{3} \mathrm{C}$ levels only when a PUFA-rich diet was consumed. When no alcohol was consumed during the experimental period and the dietary fat consisted primarily of PUFAs, even a decrease of $\mathrm{HDL}_{3}+\mathrm{C}$ was observed (Table 3 ), which is in line with the literature (24-26). It appears from our study that alcohol prevents the decrease in $\mathrm{HDL}_{3}-\mathrm{C}$ induced by a PUFA-rich diet. Our finding that moderate alcohol consumption mainly affects $\mathrm{HDL}_{3}-\mathrm{C}$, and not $\mathrm{HDL}_{2}-\mathrm{C}$, is in agreement with the studies of Haskell et al. (20) and Vallimäki et al. (27). Burr et al. (28), on the other hand, observed an increase in HDL-C probably due to a rise in the $\mathrm{HDL}_{2}-\mathrm{C}$ subfraction after only $18.4 \mathrm{~g}$ alcohol per day, 


\section{CHAPTER 6}

whereas Masarei et al. (29) found an increase in both $\mathrm{HDL}_{2}-\mathrm{C}$ and $\mathrm{HDL}_{3}-\mathrm{C}$ subfractions. In epidemiological studies, however, mainly $\mathrm{HDL} 3^{-C}$ has been found to correlate with moderate alcohol intake $(5,7,8)$ whereas the risk of CHD is epidemiologically inversely associated with $\mathrm{HDL}_{2}-\mathrm{C}$. In relation to alcohol consumption, increased $\mathrm{HDL}_{2}-\mathrm{C}$ levels have been found mainly in chronic alcoholics (10) and in response to higher doses of alcohol than in our study ( $60 \mathrm{~g}$ daily for 3 weeks)(27).

Apparently alcohol consumption affects lipid metabolism in two different ways: moderate drinking increases $\mathrm{HDL}_{3}$, and heavy drinking increases $\mathrm{HDL}_{2}$. This may be explained by the hypothesis that alcohol influences $\mathrm{HDL}_{3}$ and $\mathrm{HDL}_{2}$ by different mechanisms (review 17). One of the proposed mechanisms for the effect of alcohol on $\mathrm{HDL}_{3}$ is an increased synthesis of $\mathrm{HDL}_{3}$ by enzyme induction in the liver, which is the primary site of production of $\mathrm{HDL}_{3}$. The effects of large amounts of alcohol on $\mathrm{HDL}_{2}$ are probably due to increases in lipoprotein lipase (LPL) activity and a subsequent increase in chylomicron and VLDL metabolism as observed in alcoholics. LPL activity does not increase upon moderate alcohol consumption. Furthermore, a moderate dose of alcohol ( $40 \mathrm{~g}$ ) has been shown to inhibit the activity of hepatic lipase and to increase the $\mathrm{HDL}_{3}-\mathrm{C}$ level 6 hours after intake (30). After 10 hours, however, these effects have disappeared. In man, an inverse association between hepatic lipase and $\mathrm{HDL}_{2}$ has been described (31). The question which subfraction is influenced by moderate alcohol consumption is of major importance since it is mainly the $\mathrm{HDL}_{2}-\mathrm{C}$ level that is associated with a lower risk for $\mathrm{CHD}$ (17), although $\mathrm{HDL}_{3}-\mathrm{C}$ may be not entirely inactive $(8,32)$. When it turns out that favourable changes in HDL-C subfractions can only be achieved through mechanisms induced by drinking large amounts of alcohol, and not by moderate drinking, it must be concluded that the positive effects of moderate alcohol consumption on $\mathrm{CHD}$ are probably not mediated by a change in HDL subfractions.

Less inconsistency exists as to the relationship between alcohol consumption and apolipoprotein levels. This may be explained by the fact that both $\mathrm{HDL}$ subfractions contain considerable amounts of $A P O-\mathrm{A}_{1}$, so that increases of $\mathrm{HDL}_{2}$ as well as $\mathrm{HDL}_{3}$ will result in increased $\mathrm{Apo}_{-} \mathrm{A}_{1}$ levels. A positive correlation between moderate alcohol consumption (up to $50 \mathrm{~g}$ ) and both Apo- $\mathrm{A}_{1}$ and Apo- $\mathrm{A}_{2}$ has been observed in a cross-sectional study reported by Williams et al. (5). This has been confirmed in a number of experimental studies $(21,29,33)$. Approximately $21 \%$ of the apoprotein fraction of $\mathrm{HDL}_{3}$ is $\mathrm{Apo}-\mathrm{A}_{2}$, whereas this is only about $6 \%$ for $\mathrm{HDL}_{2}$. The reported increase in $\mathrm{Apo}^{-} \mathrm{A}_{2}$ upon moderate alcohol consumption. therefore possibly reflects the rise in $\mathrm{HDL}_{3}$. The effects of moderate alcohol consumption on Apo-B have been investigated in only two studies, one 
investigating the effects of normal beer $(165 \mathrm{~g}$ alcohol per week for 6 weeks) versus low-alcohol beer (29), the other investigating the effects of the daily intake of one glass of beer for 8 weeks (33). In both studies no effects on Apo-B were observed. The significant increase of the Apo$A_{1} / A$ po-B ratio observed in the present study resulted from a small increase in $A$ po- $A_{1}$ and a small decrease in Apo-B. If alcohol induces changes in both parameters, but in opposite directions, the ratio between these lipoproteins is a more sensitive parameter than are the apolipoproteins alone. Such an inverse relation has also been described for the effects of alcohol on HDL-C and LDL-C in epidemiological studies (34) as well as in experimental studies (29).

In conclusion, moderate alcohol consumption affects both $\mathrm{HDL}_{3}-\mathrm{C}$ and apolipoproteins. The alcohol-induced changes in $\mathrm{HDL}_{3}-\mathrm{C}$ appear to be dependent on the type of dietary fat. Furthermore, our finding that the Apo-A $/$ Apo-B ratio has significantly increased after moderate alcohol consumption for only 4 days indicates that alcohol affects apolipoprotein levels rapidly. Since an increased $A$ po- $A_{1} / A p o-B$ ratio has been associated with a lower risk of CHD the influence of alcohol on these apolipoproteins may partly explain the reported beneficial effects of moderate alcohol consumption. The exact pathway along which alcohol influences lipid metabolism is still unknown, and the question to what extent this influence contributes to the inverse relationship between moderate alcohol consumption and $\mathrm{CHD}$ remains to be answered.

\section{References}

1. Gruchow HW, Hoffmann RG, Anderson AJ et al. Effects of drinking patterns on the relationship between alcohol and coronary occlusion. Atherosclerosis 1982;43:393-404.

2. Angelico F, Bucci A, Capocaccia R et al. Further consideration on alcohol intake and coronary risk factors in a Rome working population group. Ann Nutr Metab 1982;26:73-6.

3. Jaqueson A, Richard $\mathrm{JL}$, Ducimetière $\mathrm{P}$ et al. High density lipoprotein cholesterol and alcohol consumption in a French male population. Atherosclerosis 1983;48:131-8.

4. Stamford BA. Malter S, Fell RD et al. Cigarette smoking, physical activity, and alcohol consumption: relationship to blood lipids and lipoproteins in premenopausal females. Metabolism 1984;33:585-90.

5. Williams PT, Kraus RM, Wood PD et al. Association of diet and alcohol intake with high-density lipoprotein subclasses. Metab Clin Exp 1985;34:524-30. 
6. Brenn T. The Tromsø heart study: Alcoholic beverages and coronary risk factors. J Epidemiol Commun Health 1986:40:249-56.

7. Taskinen MR, Nikkilä EA, Välimäki $M$ et all. Alcohol-induced changes in serum lipoproteins and in their metabolism. Am Heart $\mathbb{J} 1987: 113: 458$ 64.

8. Diehl AK, Fuller JH, Mattock MB et al. The relationship of highdensity lipoprotein subfractions to alcohol consumption, other lifestyle factors, and coronary heart disease. Atherosclerosis 1988;69:145-53.

9. Bell H, Stremme JH, Steensland $\mathrm{H}$ et al. Plasma HDL-cholesterol and estimated ethanol consumption in 104 patients with alcohol dependency syndrome. Alcohol Alcoholism 1985;20:35-50.

10. Välimäki $M$, Nikkilä EA, Taskinen $M R$ et al. Rapid decrease in highdensity lipoproteinsubfractions and postheparin plasma lipase activities after cessation of chronic alcohol intake. Atherosclerosis 1986;59:147-53.

11. Cushman P, Barboriak J, Kalbfleisch $\mathbf{J}$ et al. Alcohol: high density lipoproteins, apolipoproteins. Alcohol Clin Exp Res 1986:10:154-7.

12. Hartung GH, Foreyt JP, Mitchell RE et al. Effects of alcohol intake on high-density lipoprotein cholesterol levels in runners and inactive men. JAMA 1983;249:747-50.

13. Shaper AG, Wannamethee G, Walker M. Alcohol and mortality in British men: explaining the U-shaped curve. Lancet 1988;2:1267-73.

14. Stampfer MJ, Colditz GA, Willett WC et al. A prospective study of moderate alcohol consumption and the risk of coronary disease and stroke in woman. $\mathrm{N}$ Engl J Med 1988:319:267-73.

15. Marmot MG. Alcohol and coronary heart disease. Int J Epidemiol $1984: 13: 160-7$.

16. Rohan TE. Alcohol and ischemic heart disease, a review. Aust $\mathrm{N} Z \mathrm{Z}$ Med $1984 ; 14: 75-80$.

17. Moore RD, Pearson TA. Moderate alcohol consumption and coronary artery disease. Medicine 1986:65:242-67.

18. Pikaar NA, Wedel M, vd Beek EJ et al. Effects of moderate alcohol consumption on platelet aggregation, fibrinolysis, and blood lipids. Metabolism 1987:36:538-44.

19. Thornton J, Symes $C$, Heaton $\mathbb{K}$. Moderate alcohol intake reduces bile cholesterol saturation and raises HDL cholesterol. Lancet 1983;2:819. 21.

20. Haskell WL, Camargo C, Williams PT et al. The effect of cessation and resumption of moderate alcohol intake on serum high-densitylipoprotein subfractions: a controlled study. $N$ Engl $J$ Med $1984: 310: 805-10$. 
21. Couzigou P, Fleury B, Crockett $R$ et al. High density lipoprotein cholesterol and apoprotein $\mathrm{Al}$ in healthy volunteers during long-term moderate alcohol intake. Ann Nutr Metab 1984;28:377-84.

22. Gidez LI, Miller GJ, Burstein $M$ et al. Separation and quantitation of subclasses of human high density lipoprotein subclasses by a simple precipitation procedure. J Lipid Res 1982;23:1206-23.

23. Abell $\mathrm{AA}_{3}$ Levy $\mathrm{BB}$, Brodie $\mathrm{BB}$ et al. $\mathrm{A}$ simplified method for the estimation of total cholesterol and the demonstration of its specificity. J Biol Chem 1952;195:357-66.

24. Shepherd J, Packard CJ, Patsch RJ et al. Effects of dietary polyunsaturated and saturated fats on the properties of high density lipoproteins and the metabolism of apolipoprotein A-1. J Clin Invest 1978:61:1582-92.

25. Schaefer EJ, Levy RI, Ernst ND et al. The effects of low cholesterol, high polyunsaturated fat, and low fat diets on plasma lipid and lipoprotein cholesterol levels in normal and hypercholesterolemic subjects. Am J Clin Nutr 1981;34:1758-63.

26. Mattson FH, Grundy SM. Comparison of effects of dietary saturated, monounsaturated, and polyunsaturated fatty acids on plasma lipids and lipoproteins in man. J Lipid Res 1985;26:194-202.

27. Välimäki $M$, Taskinen MR, Ylikahri $R$ et al. Comparison of the effects of two different dosis of alcohol on serum lipoproteins, HDLsubfractions and apolipoproteins A-I and A-II: a controlled study. Eur J Clin Invest 1988;18:472-80.

28. Burr ML, Fehily AM, Butland BK et al. Alcohol and high-density lipoprotein cholesterol: a randomized controlled trial. $\mathrm{Br} J$ Nutr 1986;56:81-6.

29. Masarei JRL, Puddey IB, Rouse IL et al. Effects of alcohol consumption on serum lipoprotein-lipid and apolipoprotein concentrations: results from intervention study in healthy subjects. Atherosclerosis 1986:60:79:87.

30. Goldberg CS, Tall AR, Krumholz S. Acute inhibition of hepatic lipase and increase in plasma lipoproteins after alcohol intake. J Lipid Res 1984;25:714-20.

31. Tikkanen MJ, Nikkilä EA. Kuusl T et al. High density lipoprotein 2 and hepatic lipase: reciprocal changes produced by estrogen and norgestrel. J Clin Endocrin Metab 1982;54:1113-7.

32. Levy RI, Brensike JF, Epstein SE et al. The influences of changes in lipid values induced by cholestyramine and diet on progression of coronary heart disease. Results of the NNHLBI Type II Coronary Intervention Study. Circulation 1984;9:325-37. 


\section{CHAPTER 6}

33. Moore RD, Smith CR, Kwiterovich PO et al. Effect of low-dose alcohol versus abstention on apolipoproteins A-1 and B. Am J Med 1988;84:88490.

34. Castelli WP, Gordon T, Hjortland MC et al. Alcohol and blood lipids. The Cooperative Lipoprotein Phenotyping Siudy. Lancet 1977;ii:153155. 



\title{
EFFECTS OF MODERATE ALCOHOL CONSUMPTION ON PLATELET FUNCTION, TISSUE-TYPE PLASMINOGEN ACTIVATOR AND PLASMINOGEN ACTIVATOR INHIBITOR
}

\author{
J.Venstra, C.Kluft, Th.Ockhuizen, H.v.d.Pol ${ }_{\text {, M. Wedel and }}$ \\ G.Schaafsma
}

(Thrombosis and Haemostasis, 1990;63:345-8)

\section{Summary}

Short-term effects of moderate alcohol consumption on platelet function, tissue-type plasminogen activator (t-PA) and plasminogen activator inhibitor (PAI) were studied in two age groups of volunteers (20-30 and 45-55 years), each consisting of eight healthy males. The alcohol ( $30 \mathrm{~g}$ in red port and wine) was consumed during a standard dinner. Two blood samples were drawn: one in the postprandial phase, and one the next morning after fasting overnight. Alcohol consumption tended to increase platelet aggregation and production of hydroxy fatty acids, reduced plasma t-PA activity and increased PAI activity in the postprandial phase. After the overnight fast the effects on t-PA and PAI had disappeared whereas at that time alcohol consumption tended to decrease platelet function. The effects of alcohol on t-PA and PAI activity appeared mainly in the older age group, whereas the t-PA activity in this group was already much lower, irrespective of alcohol consumption.

Key words : Alcohol - Platelet function - Tissue-type plasminogen activator - Plasminogen activator inhibitor - Age

\section{Introduction}

In several epidemiological studies it has been reported that moderate alcohol consumption may have a protective effect against cardiovascular disease (CVD)(1-5). Two mechanisms have been put forward to explain this tentative beneficial effect: alcohol affects lipid metabolism by increasing the level of high-density lipoproteins, and alcohol affects haemostasis by modulating platelet aggregability and the risk of thrombosis. However, recently some doubt was thrown upon the validity of 
the reported epidemiological results with respect to the non-users group $(6-9)$.

With regard to the effect of alcohol on platelet aggregation conflicting results have been reported (10-14). This is probably due to the diversity of the study protocols, which vary considerably in amount of alcohol consumed, type of beverage, duration of alcohol consumption, participants (alcoholics or non-alcoholics), type of stimulation of aggregation, and time of measurement (acute or after fasting overnight).

Besides platelet aggregability, plasma tissue-type plasminogen activator (t-PA) activity, a major determinant of fibrinolytic activity, appears a major factor related to the risk of CVD (15-20). r-PA activity in plasma is largely controlled by its fast-acting inhibitor PAI.

In previous studies we have found that moderate alcohol consumption by young men during a period of five weeks reduced platelet aggregation and lowered plasma t-PA activity, whereas no effects on these parameters were found within four days $(21,22)$. Since middle-aged men are known to have a higher risk for CVD it is of particular interest to studly the effects of alcohol consumption in this age group.

The aims of the present study were a) to investigate the short-term effects of moderate alcohol consumption on platelet function and t-PA and PAI activity in the postprandial phase in the evening and in the morning after an overnight fast, and b) to compare these effects in two different age groups.

\section{Materials and methods}

\section{Subjects}

Two groups of apparently healthy, non-smoking men participated in this study, one group of men $20-30$ years (young; $n=8$ ) and one group of men 45 - 55 years old (middle-aged; $n=8$ ). Their average habitual consumption of alcohol varied between 10 and $40 \mathrm{~g}$ per day. Some characteristics of the two groups, derived from the medical examination preceding the experiment, are given in Table 1. No drugs were used during the experiment. The study protocol was approved by the institute's Medical-Ethical Committee and the participants signed the informed consent form.

\section{Study design}

The total experimental period lasted eight weeks in which each subject had one experimental day every two weeks. The four treatments comprised 
two different dinners (in the evening), one rich in protein and the other rich in fat, and two different alcohol regimes, one with and one without alcohol. For each subject the experimental day was always on the same day of the week and the meal always started at exactly the same time in the

Table 1 Some characteristics of the two groups of volunteers.

\begin{tabular}{|c|c|c|c|c|}
\hline & & \multicolumn{2}{|c|}{ Young } & \multirow{2}{*}{$\frac{\text { Middle-aged }}{\text { mean (SD) }}$} \\
\hline & & mean & $(\mathrm{SD})$ & \\
\hline$\overline{\text { Age }}$ & (years) & 24.8 & $(2.8)$ & $49.4(3.8)^{*}$ \\
\hline Height & $(\mathrm{cm})$ & 182.5 & $(6.8)$ & $174.4(4.6)^{3}$ \\
\hline Weight & $(\mathrm{kg})$ & 69.8 & $(5.7)$ & $76.7(1.2 .5)$ \\
\hline Systolic blood pressure & $(\mathrm{mm} \mathrm{Hg})$ & 120.6 & $(9.8)$ & $130.0(12.2)$ \\
\hline Diastolic blood pressure & $(\mathrm{mm} \mathrm{Hg})$ & 73.1 & $(5.9)$ & $76.9(11.9)$ \\
\hline Serum cholesteral & $(\mathrm{mmol} / \mathrm{l})$ & 4.38 & $(0.85)$ & $5.86(0.64) *$ \\
\hline Serum triglycerides & $(\mathrm{mmol} / 1)$ & 0.78 & $(0.21)$ & $1.75(0.60)^{*}$ \\
\hline
\end{tabular}

$\mathrm{P}<0.05$

evening. All subjects were subjected to all four treatments in a randomized order, according to a Latin square design.

Two blood samples were drawn: one postprandially in the evening and one after fasting overnight, one hour and fifteen hours after dinner and alcohol consumption, respectively. The subjects continued their habilual drinking and food pattern during the eight weeks of the experiment. On the experimental days, however, all drinks and meals were supplied by the institute.

The composition of the standard dinners is given in Table 2. Alcohol treatment consisted of an aperitif (red port) and two glasses of red wine (30 $\mathrm{g}$ alcohol in total) taken half an hour before and during the meal, respectively. The same volume of mineral water was consumed in the treatment without alcohol. The intake of alcohol was checked by measuring blood alcohol levels one hour after the meal and by breath alcohol analysis every 15 minutes in the postprandial phase. The subjects always had blank values for the blood and breath alcohol determinations when no alcohol had been taken, whereas significant alcohol levels were found after alcohol ingestion. The mean blood alcohol concentration, one hour after alcohol intake, was $0.175 \mathrm{~g} / \mathrm{SD}=0.055)$. 


\section{Methods}

Blood was taken from a vena mediana cubiti by means of a catheter. Collagen and ADP induced platelet aggregation was performed as previously described (21). For collagen the final concentrations used were $0.2,0.4$ and $0.7 \mu \mathrm{g} / \mathrm{ml}$ and for ADP 0.5, 1.5 and $3.0 \mu \mathrm{M}$. From the aggregation curves

Table 2. Composition of the meals on the experimental day (pooled portions of 2 days were analyzed).

\begin{tabular}{llcc}
\hline & & $\begin{array}{c}\text { Meal rich } \\
\text { in protein }\end{array}$ & $\begin{array}{c}\text { Meal rich } \\
\text { in fat }\end{array}$ \\
\hline Energy & $(\mathrm{kcal})$ & 830.0 & 880.0 \\
$\begin{array}{l}\text { Protein } \\
\text { Carbohydrates }\end{array}$ & $\begin{array}{c}(\mathrm{MJ}) \\
\text { Total fat }\end{array}$ & 3.47 & 3.68 \\
$\begin{array}{l}\text { Ten\%) } \\
\begin{array}{l}\text { Saturated } \\
\text { fatty acids }\end{array}\end{array}$ & 40.0 & 14.0 \\
$\begin{array}{l}\text { Monounsaturated } \\
\text { fatty acids }\end{array}$ & $(\%)$ & 32.0 & 39.0 \\
$\begin{array}{l}\text { Polyunsaturated } \\
\text { fatty acids }\end{array}$ & $(\%)$ & 31.0 & 47.0 \\
\hline
\end{tabular}

the percentage of maximum aggregation and the velocity of aggregation were obtained. The collagen and ADP percentage of maximum aggregation and the collagen and ADP velocity of aggregation were expressed as the area under the curve when the percentage of maximum aggregation or the velocity of aggregation was plotted against the collagen or ADP concentrations used. The use of these derived variables reduces the number of variables obtained from aggregation studies and also increases the precision of the aggregation parameters.

Analysis of $\mathrm{TxB}_{2}$ production during platelet aggregation induced by 0.4 $\mu \mathrm{g}$ collagen/ml and $1.5 \mu \mathrm{M}$ ADP was measured using an enzyme immunoassay (EIA) method described by Pradelles et al. $(23,24)$. Furthermore, $\mathrm{TxB}_{2}$ was 
measured in blood which was allowed to clot for $120 \mathrm{~min}$ at room temperature.

For analysis of the production of hydroxy fatty acids by the platelets, platelet aggregation was induced by a $16 \mu \mathrm{g} / \mathrm{ml}$ overdose of collagen. After exactly $5 \mathrm{~min}$ the reaction was stopped by diluting the sample 1:4 with ice-cold $0.9 \% \mathrm{NaCl}$. Protein was precipitated by diluting the sample 1:4 with methanol, followed by centrifugation at $6000 \mathrm{~g}$ for $15 \mathrm{~min}$ at $4^{\circ} \mathrm{C}$. The supernatant solutions were collected and could be used for HPLC analysis without further treatment as described previously (25). The hydroxy fatty acids 12-L-hydroxy heptadeca trienoic acid (HHT) and 12 hydroxy eicosa tetra enoic acid (12-HETE) were measured.

For the analysis of t-PA and PAI, blood was collected in pre-cooled polycarbonate tubes on citrate ( 1 vol $0.11 \mathrm{M}$ citrate, 9 vol blood) and processed to platelet-poor plasma as previously described in detail (26). Plasma was kept frozen at or below $-40^{\circ} \mathrm{C}$. t-PA activity was assayed in euglobulin fractions of plasma using the parabolic rate assay for t-PA as described in detail elsewhere (27). Activity was expressed in $1 \mathrm{U} / \mathrm{ml}$, on the basis of the international standard of t-PA (28). PAI-activity was determined by titration with two-chain t-PA (Organon Teknika, Turnhout, Belgium) using a parabolic rate assay to measure residual t-PA, as described in detail before (29). Inhibition was expressed relative to a pooled plasma sample which was estimated to inhibit $7.6 \mathrm{IU}$ of $\mathrm{t}-\mathrm{PA} / \mathrm{ml}$.

Serum cholesterol and triglycerides were determined by enzymaticcolorimetric autoanalyser methods on a Hitachi autoanalyser (Boehringer, Mannheim, FRG) using Boehringer Mannheim biochemicals. Blood alcohol was also measured enzymatically, using a Boehringer Mannheim test combination (Cat. No. 176290 ).

\section{Statistical analysis}

Statistical evaluation comprised analysis of variance, according to the Latin square design, to test the significance of the main effects of alcohol, age group, time of measurement and meal composition as well as their two factor interactions. Skewed variables were transformed by their logarithms, and the means of the variables presented are geometrical means. 


\section{Results}

\section{Effects of alcohol consumption on platelet function}

In the postprandial phase alcohol consumption tended to increase collagen and ADP induced platelet aggregation as compared to the control treatment (Fig.1). From the four aggregation indices only the ADP-induced percentage of maximum aggregation was significantly affected $(\mathrm{P}=0.025)$ (Fig. 1C). The next morning, when after an overnight fast the plasma alcohol levels had returned to zero, a tendency towards decreased platelet function was observed. The platelet hydroxy fatty acid production induced by the collagen overdose displayed the same pattern: in the evening HHT and 12-HETE tended to increase after alcohol consumption, whereas the opposite was observed the next morning (Fig.1E,F). This twolevel interaction between alcohol treatment and time of measurement was significant for collagen-induced percentage of maximum aggregation and velocity of aggregation $(p=0.014$ and $p=0.008$, respectively), for ADPinduced percentage of maximum aggregation $(p=0.029)$ and for collageninduced HHT and 12-HETE production ( $\mathrm{p}=0.025$ and $\mathrm{p}<0.001$, respectively). Alcohol consumption had no significant effects on $\mathrm{TXB}_{2}$ production during collagen- or ADP-induced platelet aggregation or during blood clotting.

The composition of the meal taken together with the alcohol did not influence the effects of alcohol on platelet function, and neither were differences observed between the two age groups with respect to effects of alcohol on platelet function.

\section{Effects of alcohol consumption on t-PA and PAI activity}

Figure 2 shows the effects of alcohol on t-PA activity in the postprandial phase (Fig.2A) and after fasting overnight (Fig.2B). Alcohol strongly reduced t-PA activity in the postprandial phase in the young and middle-aged group by $29 \%(\mathrm{P}=0.037)$ and $70 \%(\mathrm{P}<0.001)$ respectively. After the overnight fast these effects had disappeared. Furthermore, t-PA levels in the middle-aged men were much lower than those in the young men (mean fasting values 11.7 and $105.6 \mathrm{IU} / \mathrm{ml}$ respectively, $\mathrm{p}<0.001$ ). This, in combination with the reducing effect of alcohol on t-PA activity in the postprandial phase, resulted in very low t-PA activities in the middleaged group after alcohol consumption (mean value $6.4 \mathrm{IU} / \mathrm{ml}$ ). The composition of the meal taken together with the alcohol did not influence the effects of alcohol on t-PA activity. 

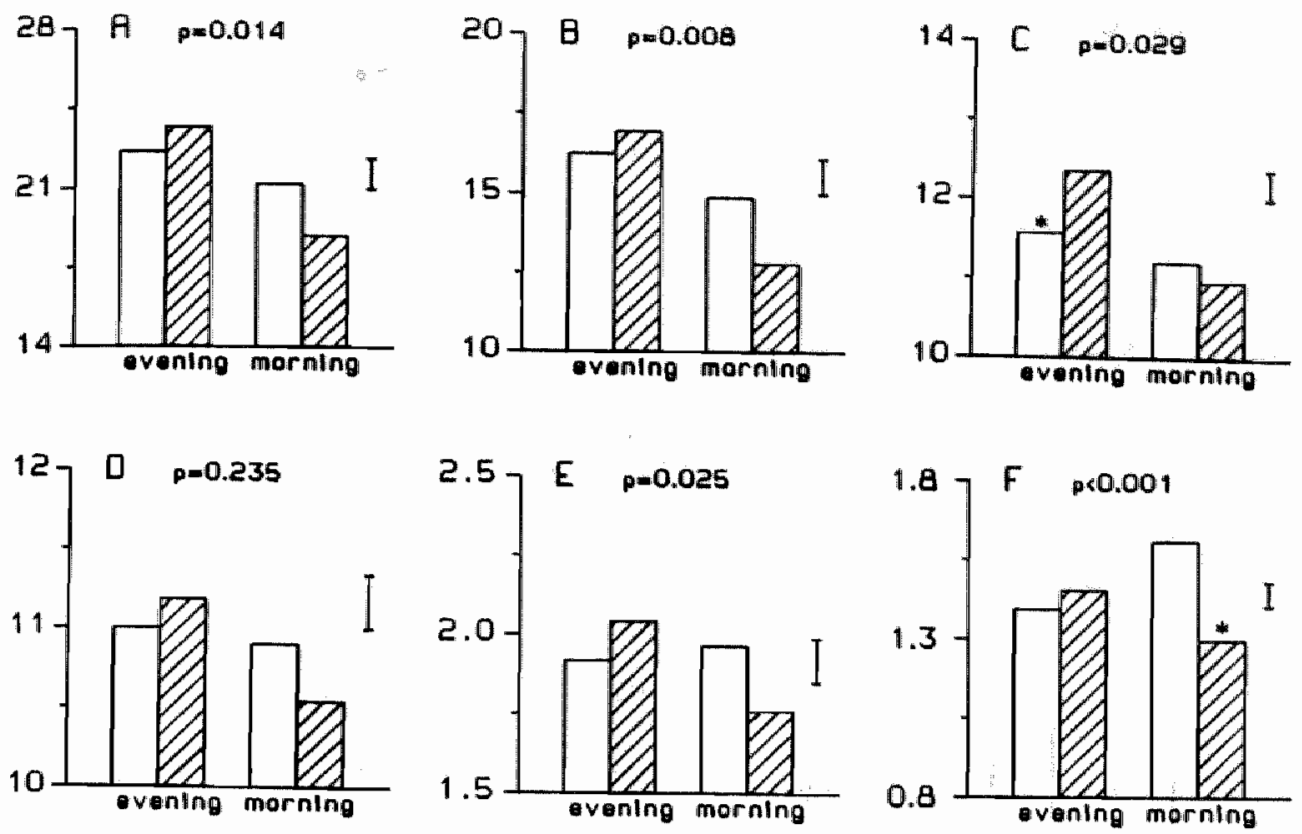

$\square$ Without WZ With alcohol

Figure 1. Effects of alcohol on collagen-induced platelet aggregation $(A, B)$ and $A D P$-induced platelet aggregation $(C, D)$ and on hydroxy fatty acid production $(E, F)(n=16)$.

The p-values indicated in the figure are those for the interactive effect between alcohol treatment and time of measurement. An asterisk indicates a significant difference $(P<0.05)$ between the measurement with and without alcohol. The bars indicate the standard error of difference (SED) derived from the pooled error variance.

Aggregation parameters were calculated as described in Analytical methods.

A - Collagen-induced percentage of maximum aggregation.

$B$ - Collagen-induced velocity of aggregation.

$C$ - ADP-induced percentage of maximum aggregation.

$D$ - ADP-induced velocity of aggregation.

E - Collagen-induced HHT production ( $\mathrm{ng} / 10$ flatelets).

F-Collagen-induced 12-HETE production (ng/10 Slatelets). 


\section{CHAPTER 7}
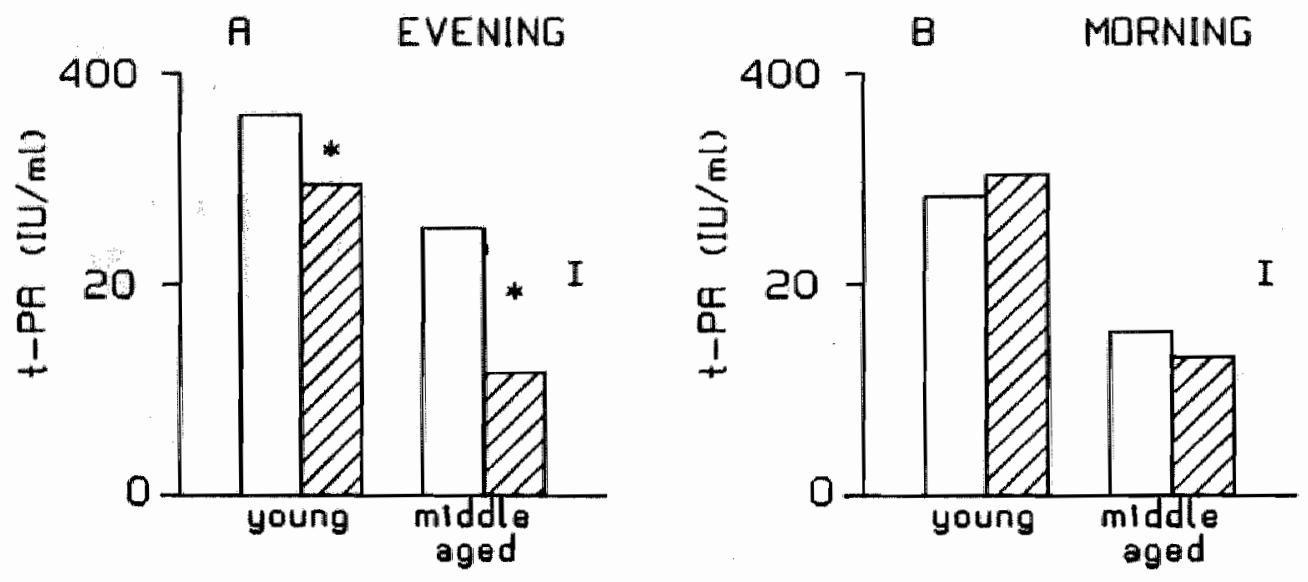

Without

QZ7 With alcohol

Figure 2. Effects of alcohol on plasma t-PA activity in young $(n=8)$ and middle-aged $(n=8)$ men.

An asterisk indicates a significant difference $(P<0.05)$ between the measurement with and without alcohol. The bars indicate the standard error of difference ( $S E D)$ derived from the pooled error variance. t-PA activities are recorded on a logarithmic scale. 


\section{CHAPTER 7}

The effects of alcohol on PAI activity in the postprandial phase are shown in Figure 3. Alcohol consumption increased PAI levels in the middleaged men by $60 \%(\mathrm{p}=0.010)$. The alcohol induced increase in PAI levels in the young men $(+34 \%)$ was not statistically significant $(\mathrm{p}=0.144)$.
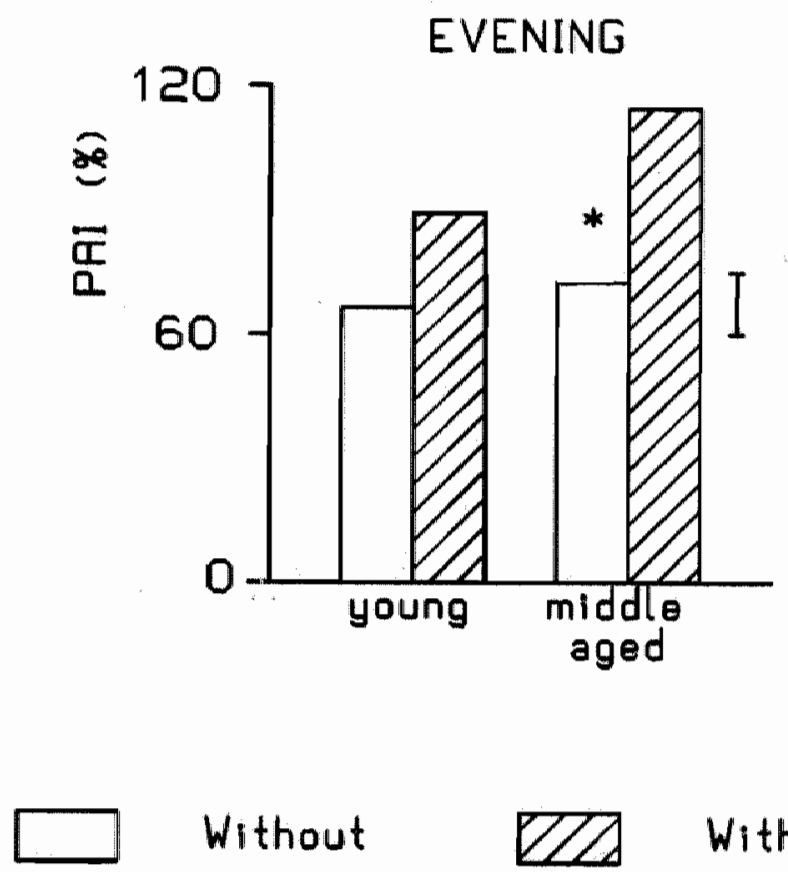

Without

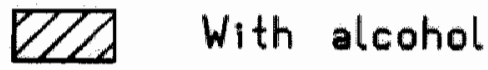

Figure 3. Effects of alcohol on PAI activity in the postprandial phase in young $(n=8)$ and middle-aged $(n=8)$ men.

An asterisk indicates a significant difference $(P<0.05)$ between the measurement with and without alcohol. The bars indicate the standard error of difference ( $S E D$ ) derived from the pooled error variance. 


\section{Discussion}

In the present study, alcohol consumption as compared to the control treatment tended to increase platelet aggregation in the postprandial phase and tended to decrease platelet aggregation the following morning after an overnight fast. The same two-factor interaction between alcohol consumption and time of measurement was found for the platelet production of the cyclooxygenase metabolite HHT and the lipoxygenase metabolite 12 . HETE. Although we have no satisfactory explanation for these observation they might in some way be related to the known effects of alcohol on an early step in arachidonic acid metabolism (30), probably the inhibition of the calcium dependent enzyme phospholipase $\mathrm{A}_{2}$ (31). The present findings, indicating that the effects of alcohol on platelet function are dependent on time of measurement, at least partiy explain the diversity in reported results on effects of alcohol on platelet function.

Although a significant two-factor interaction between alcohol and the time of measurement was observed for platelet aggregation and the platelet production of the hydroxy fatty acids 12-HETE and HHT, no such interaction could be demonstrated for the production of $\mathrm{T} \mathrm{B}_{2}$. This seems to contradict the observed interactive effect between alcohol and time of measurement on HHT production because the cyclooxygenase metabolites $\mathrm{TxB}_{2}$ and $\mathrm{HHT}$ are known to be related as regards rate of production (32). A possible explanation for this apparent discrepancy is the overdose in concentration of collagen used for stimulation of HHT production $(16 \mu \mathrm{g} / \mathrm{ml})$ as compared to the much lower dose of collagen applied for the induction of platelet aggregation and $\mathrm{TxB}_{2}$ formation $(0.4 \mu \mathrm{g} / \mathrm{ml})$.

In our previous studies plasma t-PA activity in the fasting state in healthy young men was found to be reduced by moderate alcohol consumption during a period of five weeks, whereas no effects were found for a period of four days $(21,22)$. Likewise, no effects of one moderate dose of alcohol on 1-PA activity were found in the present study when blood was taken after fasting overnight. However, in the postprandial phase, one hour after the alcohol consumption, a marked decrease of blood t-PA activity was observed in both age groups.

Previously, a decrease of blood fibrinolytic activity shortly after alcohol consumption has been reported (33), which is in agreement with our findings. A reduction of $t-P A$ activity may be the result of either an increased production of its inhibitor PAl, a decreased t-PA production or an increased t-PA elimination. Therefore we also measured the PAI levels in the postprandial phase. The observed effects of alcohol on PAI are in agreement with the decreases in t-PA activity, i.e. strong inhibition in the middle-aged and to a lesser extent in the young men. Fearnley et al. 
(33) have demonstrated an inhibitory effect of beer and wine ingestion on blood fibrinolytic activity, with a peak value two hours after consumption at 1400. The effect had disappeared after about six hours. Accordingly. no effects of alcohol consumption on t-PA activity could be observed after the overnight fast in the present study.

Recently we have observed comparable effects of distilled liquors on t-PA and PAI activity (in preparation). From this we conclude that the effects on t-PA and PAI are most probably due to alcohol and not to other constituents of the red wine or port consumed in this study. However, we cannot exclude the possibility that the other constituents have contributed to the effects on platelet function.

In the middle-aged group, t-PA activity both in the late afternoon and in the morning was lower than in the young group. This is in agreement with reports about decreases in blood fibrinolytic activity early in the morning and a reduced diurnal increase upon aging (34-36). It is of importance to note that in our middle-aged group, which already had lower t-PA activities, the reducing effect of alcohol was significantly stronger than in the younger group ( $\mathrm{p}=0.050$ ).

The above mentioned results indicate that the reduced $t-P A$ activity and to a lesser extent the tendency towards an increased platelet reactivity in the postprandial phase, caused by moderate alcohol consumption, may contribute to a higher risk of a heart attack in this phase, whereas, conversely, the tendency towards a decreased platelet aggregability in the morning, when alcohol has been consumed the preceding evening, possibly lowers the risk. Although platelets and fibrinolysis are known to play an important role, it is hard to tell to what extent changes in these variables correlate with the risk of myocardial infarctions. The available evidence from the literature does at least not indicate that moderate alcohol consumption increases the risk for CVD. Therefore we conclude that the observed effects of alcohol on t-PA activity are probably counterbalanced by beneficial effects of moderate alcohol consumption on other haemostatic factors or by the proposed beneficial effects on lipid metabolism.

\section{Acknowledgements}

This study was supported by the Central Commodity Board for Arable Products, The Hague, Netherlands and the Commodity Board for Spirits, Schiedam, Netherlands. 


\section{References}

1. Marmot MG, Rose G, Shipley MJ. Alcohol and mortality: A U-shaped curve. Lancet 1981;i:580-3.

2. Turner TB, Bennett VL, Hernandez $H$. The beneficial side of moderate alcohol use. Johns Hopkins Med J 1981;148:53-63.

3. Marmot MG. Alcohol and coronary heart disease. Int $\mathrm{J}$ Epidemiol 1984;13:160-6.

4. Moore RD, Pearson T. Moderate alcohol consumption and coronary artery disease: a review. Medicine 1986;65:242-67.

5. Stampfer MJ, Colditz GA, Willett WC, Speizer FE, Hennekens CH. A prospective study of moderate alcohol consumption and the risk of coronary disease and stroke in women. N Engl J Med 1988;319:267-73.

6. Shaper AG, Wannamethee $G$, Walker $M$. Alcohol and mortality in British men: Explaining the U-shaped curve. Lancet 1988;ii:1267-73.

7. Letters to the editor. Alcohol and the U-shaped curve. Lancet $1989 ; \mathrm{i}: 105$.

8. Letters to the editor. Alcohol and the U-shaped curve. Lancet $1989 ; \mathrm{i}: 224-5$.

9. Shaper AG, Wannamethee G, Walker M. Alcohol and the U-shaped curve. Lancet $1989 ; ;: 336$.

10. Fenn CG, Littleton JM. Interactions between ethanol and dietary fat in determining human platelet function. Thromb Haemostas 1984;51:50-3.

11. Galli C, Colli S, Gianfranceschi G. Acute effects of ethanol, caffeine, or both on platelet aggregation, thromboxane formation, and plasma free fatty acids in normal subjects. Drug-Nutrient Interactions 1984:3:61-7.

12. Dunn EL, Cohen RG, Moore EE, Hamstra RD. Acute alcohol ingestion and platelet function. Arch Surg 1981;116:1082-3.

13. Mikhailidis DP, Jeremy JY, Barradas MA, Green N, Dandona P. Effect of ethanol on vascular prostacyclin synthesis, platelet aggregation and platelet thromboxane release. Br Med J 1983;287:1495-8.

14. Hillbom M, Kangasaho M, Lowbeer C, Kaste M, Muuronen A, Numminen $\mathrm{H}$, Effects of ethanol on platelet function. Alcohol 1985;2:429-32.

15. DeWood MA. Spores J, Notske R. Prevelance of total coronary occlusion during the early hours of transmural myocardial infarction. $\mathrm{N}$ Engl $J$ Med 1980;303:897-902.

16. Gram J, Jespersen J. A selective depression of tissue plasminogen activator (t-PA) activity in euglobulins characterizes a risk group among survivors of acute myocardial infarction. Thromb Haemostas $1987 ; 57 ; 137-9$. 
17. Franzen J, Nilsson B, Johansson BW, Nilsson IM. Fibrinolytic activity in men with acute myocardial infarction before 60 years of age. Acta Med Scand 1983;214:339-44.

18. Hamsten A, Wiman B, de Faire U, Blomback $M$. Increased plasma levels of a rapid inhibitor of tissue plasminogen activator in young survivors of myocardial infarction. N Engl J Med 1985;313:1557-63.

19. Hamsten A, Blomback M, Wiman B. Svensson J, Szamosi A, de Faire U, Mettinger $\mathrm{L}$. Haemostatic function in myocardial infarction. $\mathrm{Br}$ Heart $\mathrm{J}$ 1986;55:58-66.

20. Nilsson TK, Johnson O. The extrinsic fibrinolytic system in survivors of myocardial infarction. Thromb Res 1987;48:621-30.

21. Pikaar NA, Wedel M, van der Beek EJ, Dokkum W v, Kempen HJM, Kluft C, Ockhuizen Th, Hermus RJJ. Effects of moderate alcohol consumption on platelet aggregation, fibrinolysis, and blood lipids. Metabolism $1987 ; 36: 538-43$.

22. Veenstra J, Kluft C, Pikaar NA, Pol $H \vee d$, Schaafsma G, Ockhuizen Th. The effects of four days of moderate wine and coffee consumption on fibrinolysis and platelet aggregation. Submitted.

23. Pradelles P, Grassi J, Maclouf J. Enzyme immunoassays of eicosanoids using acetylcholinesterase as label: an alternative to radioimmunoassay. Anal Chem 1985;57:1170-3.

24. Pradelles P, Grassi J, Maclouf J. Dosage enzymoimmunologique des métabolites de l'acide arachidonique utilisant l'acétylcholinesterase d'Electrophorus Electricus. Annales de Biologie Clinique 1985:43:47584.

25. Veenstra J, Pol H v d, Torre H v d, Schaafsma G, Ockhuizen Th. Rapid and simple methods for the investigation of lipoxygenase pathways in human granulocytes. J Chrom 1988;431:413-7.

26. Kluft C, Brakman P, Veldhuyzen-Stolk: Screening of fibrinolytic activity in plasma euglobulin fractions on the fibrin plate. In: Davidson J F, Samama M M, Desnoyers P C (eds) Progress in chemical fibrinolysis and thrombolysis, vol 2. New York, Raven Press 1976:57-65.

27. Verheijen JH, Mullart E, Chang GTG, Kluft C, Wijngaards G. A simple, sensitive spectrophotometric assay for extrinsic (tissue-type) plasminogen activator applicable to measurement in plasma. Thromb Haemostas 1982;48:266-9.

28. Gaffney PJ, Curtis AD. A collaborative study of a proposed International standard for tissue plasminogen activator in human plasma. Thromb Haemostas 1985;53:134-6.

29. Verheijen JH, Chang GTG, Kluft C. Evidence for the occurrence of a fast-acting inhibitor for tissue-type plasminogen activator in human plasma. Thromb Haemostas 1984;51:392-5. 


\section{CHAPTER 7}

30. Rand ML, Packham MA, Kinlough-Rathbone RL, Mustard JF. Effects of ethanol on pathways of platelet aggregation in vitro. Thromb Haemostas 1988;59:383-7.

31. Fenn $\mathrm{CG}$, Littleton JM. Inhibition of platelet aggregation by ethanol in vitro shows specificity for aggregating agent used and is influenced by platelet lipid composition. Thromb Haemostas 1982;48:4953.

32. Lagarde $M$. Roles of cyclooxygenase and lipoxygenase metabolites in platelets. In: Platelets in biology and pathology III. 1987:269-88.

33. Fearnly GR, Ferguson J, Chakrabarti R, Vincent CT. Effect of beer on blood fibrinolytic activity. Lancet $1960 ; \mathrm{i}: 184-5$.

34. Chakrabarti R. Overview of fibrinolysis. Scott Med J 1981:51-6.

35. Rosing DR, Redwood DR, Brakman P, Astrup T, Epstein SE. Impairment of the diurnal fibrinolytic response in man: effect of aging, type IV hyperlipoproteinemia and coronary artery disease. Arc Res 1973;32:7528.

36. Stegnar $M_{*}$ Keber $D$, Pentek $M$, Vene N, Kluft C. Age and sex differences in resting and postocclusion values of tissue plasminogen activator in a healthy population. Fibrinolysis $1988 ; 2$ suppl $2: 121-2$. 


\title{
EFFECTS OF A MODERATE DOSE OF ALCOHOL ON BLOOD LIPIDS AND LIPOPROTEINS POSTPRANDIALLY AND IN THE FASTING STATE
}

\author{
J. Veenstra, Th. Ockhuizen, H. van de Pol, M. Wedel \\ and $\mathrm{G}$. Schaafsma
}

(Alcohol and Alcoholism, 1990:25:371-7)

\section{Summary}

Effects of a moderate dose of alcohol on blood lipids and lipoproteins were studied in volunteers of two age groups (20-30 and 45-55 years), each consisting of eight healthy men. The alcohol ( $30 \mathrm{~g}$ in red port and wine) was consumed during a standard dinner. Two blood samples were drawn: one in the postprandial phase, and one the next morning after fasting overnight. In the postprandial phase, one hour after intake, alcohol increased high-density lipoprotein cholesterol (HDL-C) by $11.5 \%$, triglycerides (TG) by $15.3 \%$ and apolipoprotein $A_{2}\left(\right.$ Apo- $\left.A_{2}\right)$ by $7.3 \%$ $(p=0.002, p=0.044$ and $p=0.024$, respectively). The increase in HDL-C appeared to be mainly attributed to the $\mathrm{HDL}_{2}-\mathrm{C}$ subfraction which increased by $15.3 \%(\mathrm{p}=0.066)$. Furthermore, the increases in HDL-C, HDL $2-\mathrm{C}$ and TG were more pronounced in the middle-aged men then in the young men. After fasting overnight the effects of alcohol had disappeared.

\section{Introduction}

A protective effect of moderate alcohol consumption on the development of coronary heart disease (CHD) has been observed in many epidemiological studies (Reviews 1-3), but is not yet generally accepted (4,5). An increase in high-density lipoprotein cholesterol (HDL-C) level upon moderate alcohol consumption is one of the possible mechanisms that has been put forward to explain the beneficial effect. A positive association between HDL-C and alcohol consumption has indeed been observed in moderate drinkers $(2,3)$. Plasma HDL-C consists of two major subfractions, differing slightly in density: $\mathrm{HDL}_{2}-\mathrm{C}$ and $\mathrm{HDL}_{3}-\mathrm{C}$. Of these, mainly $\mathrm{HDL}_{2}-\mathrm{C}$ is epidemiologically associated with lower risk of $\mathrm{CHD}$.

In previous studies we have investigated the effects of moderate alcohol consumption for 5 weeks (6) and for 20 weeks (submitted) on lipid 


\section{CHAPTER 8}

and lipoprotein variables in the fasting state. Increases in the $\mathrm{HDL}_{3}-\mathrm{C}$ subfraction of $\mathrm{HDL}-\mathrm{C}$ were found, whereas $\mathrm{HDL}_{2}-\mathrm{C}$ remained unaffected by alcohol. Effects of moderate alcohol consumption, for periods ranging from 2 to 6 weeks, on HDL-C have also been reported by others (7-13). Increased $\mathrm{HDL}_{2}-\mathrm{C}$ levels have been found mainly in response to a high dose of alcohol $(60 \mathrm{~g}$ daily for 3 weeks)(13) and in chronic alcoholics $(14,15)$.

In all studies mentioned, lipid variables were measured after fasting overnight, when blood alcohol concentrations had returned to zero. However, alcohol has been shown to have an acute inhibitory effect on hepatic lipase, an enzyme located in the endothelial cells of the hepatic sinusoids and playing a key role in lipoprotein metabolism (16). This leads to the interesting possibility that alcohol not only influences lipid variables, measured in the fasting state, but also postprandially when the alcohol is still present in the circulation. Therefore, the purpose of the present study was to investigate the effects of a moderate dose of alcohol, taken together with either a standard high-protein or a high-fat meal, postprandially ( 1 hour after intake) and after an overnight fast in two groups of volunteers differing in age.

\section{Methods}

\section{Subjects}

Two groups of apparently healthy, non-smoking men participated in this study, one group aged 20 - 30 years (young; $n=8$ ) and one group aged 45 55 years old (middle-aged; $n=8$ ). These age groups were chosen because of the differential risk in cardiovascular incidents. Their average habitual consumption of alcohol varied between 10 and $40 \mathrm{~g}$ per day. They all had a normal liver function, had no familial history of alcoholism and were used to a normal, western life style, including dietary habits. Characteristics of the two groups, derived from the medical examination preceding the experiment, are given in Table 1. No drugs were used during the experiment. The study protocol was approved by the institute's external Medical-Ethical Committee, and the participants signed the informed consent form. 
Table 1. Some characteristics of the two groups of volunteers.

\begin{tabular}{llrrr}
\hline & & \multicolumn{2}{c}{ Young } & \multicolumn{2}{c}{ Middle-aged } \\
\cline { 3 - 5 } & & mean (SD) & mean (SD) \\
\hline Age & (years) & 24.8 & $(2.8)$ & $49.4(3.8)$ \\
Length & $(\mathrm{cm})$ & 182.5 & $(6.8)$ & $174.4(4.6)$ \\
Weight & $(\mathrm{kg})$ & 69.8 & $(5.7)$ & $76.7(12.5)$ \\
Systolic blood pressure & $(\mathrm{mm} \mathrm{Hg})$ & $120.6(9.8)$ & $130.0(12.2)$ \\
Diastolic blood pressure & $(\mathrm{mm} \mathrm{Hg})$ & $73.1(5.9)$ & $76.9(11.9)$ \\
\end{tabular}

${ }_{\mathrm{SD}}=$ standard deviation

\section{Study design}

The total experimental period lasted eight weeks in which each subject received four treatments, each on one day, with two-week intervals. The four treatments comprised two different dinners (in the evening), one rich in protein and the other rich in fat, each at two different alcohol regimes, one with and one without alcohol (factorial design). For each subject the experimental day was always on the same day of the week and the meal always started at the same time in the evening. All subjects were subjected to all four treatments in a randomized order, according to a Latin square design.

The composition of the meals is given in Table 2. Alcohol treatment consisted of a glass of red port and two glasses of red wine $(30 \mathrm{~g}$ alcohol in total) taken half an hour before and during the meal, respectively. The same volume of mineral water was consumed in the treatment without alcohol. The intake of alcohol was verified by measuring blood alcohol levels one hour after the meal and by breath alcohol analysis every 15 minutes in the postprandial phase. The subjects always had blank values for the blood and breath alcohol determinations when no alcohol had been taken, whereas significant alcohol levels were found after alcohol ingestion. The mean blood alcohol concentration, one hour after alcohol intake, was $0.175 \mathrm{~g} / \mathrm{l}(\mathrm{SD}=0.055)$.

Two blood samples were drawn: one in the evening and one after fasting overnight, one hour and fifteen hours after alcohol consumption respectively. The subjects continued their habitual drinking and food pattern during the eight weeks of the experiment. On the experimental 
Table 2. Composition of the meals on the experimental day (pooled portions of 2 days were analyzed).

$\begin{array}{ll}\text { Meal rich } & \text { Meal rich } \\ \text { in protein } & \text { in fat }\end{array}$

$\begin{array}{llcc}\text { Energy } & \text { (kcal) } & 830.0 & 880.0 \\ & \text { (MJ) } & 3.47 & 3.68 \\ \text { Protein } & (\mathrm{en} \%) & 38.0 & 14.0 \\ \text { Carbohydrates } & (\mathrm{en} \%) & 40.0 & 39.0 \\ \text { Total fat } & (\mathrm{en} \%) & 22.0 & 47.0\end{array}$

Fatty acid composition:

$\begin{array}{llll}\text { Saturated } & (\%) & 37.1 & 41.5 \\ \text { Monounsaturated }(\%) & 31.0 & 44.7 \\ \text { Polyunsaturated } & (\%) & 31.9 & 13.5\end{array}$

days, however, they were not allowed to consume any food or alcoholic beverages apart from the drinks and meals supplied.

\section{Analytical methods}

Blood was taken from a vena mediana cubiti by means of a catheter. For HDL subfractionation we used essentially the method of Gidez et al. (17). Very low-density lipoproteins (VLDL) and low-density lipoproteins (LDL) were first removed by precipitation with heparin $(140 \mathrm{U} / \mathrm{mg}, 1.5 \mathrm{~g} / \mathrm{L}$ final concentration) and $\mathrm{MnCl}_{2}(100 \mathrm{mmol} / \mathrm{L})$ for $20 \mathrm{~min}$ at $0^{\circ} \mathrm{C}$. Then dextran sulphate (MW 15,000) was added to a final concentration of $1.4 \mathrm{~g} / \mathrm{L}$ and the mixture left for 30 minutes at $0^{\circ} \mathrm{C}$ before centrifugation. Cholesterol in $\mathrm{HDL}_{2}$ (redissolved dextran sulphate precipitate) and in $\mathrm{HDL}_{3}$ (final supernatant) were determined by the method of Abell et al. (18).

Serum total cholesterol (TC), HDL-C and triglycerides (TG) were determined by enzymatic-colorimetric autoanalyser methods on a Hitachi autoanalyser (Boehringer, Mannheim, FRG) using Boehringer biochemicals.

Serum apolipoproteins were measured by immunoturbidimetric analysis using biochemicals from Boehringer Mannheim Biochemica (Mannheim, FRG). The following antisera were used: anti-human-apolipoprotein A I (Cat.No. 
726 478); anti-human-apolipoprotein A II (Cat.No. 726 486); anti-humanapolipoprotein B (Cat.No. 726 494). The reference calibration serum for apolipoproteins was also purchased from Boehringer (Cat. No. 837 237).

\section{Statistical analysis}

Statistical evaluation comprised analysis of variance, according to the design, to test the significance of the main effects of alcohol, age group, time of measurement and meal composition as well as their twofactor interactions. Skewed variables were transformed by their logarithms, and the means of the variables presented are geometrical means.

\section{Results}

\section{Effects of alcohol in the postprandial phase}

The effects of alcohol in the postprandial phase are summarized in Figure 1. The main effects of alcohol (mean values, $\mathrm{n}=32$ ) are shown in the histograms at the left-hand side. The levels of HDL-C, TG and Apo-A 2 had significantly increased $1 \mathrm{~h}$ after the intake of a meal together with alcohol, as compared to the levels after a meal taken without alcohol. Mean HDL-C levels after alcohol were $11.5 \%$ higher $(P=0.002)$, mean TG levels had increased by $15.3 \%(\mathrm{P}=0.044)$ and mean $\mathrm{Apo-} \mathrm{A}_{2}$ levels by $7.3 \%$ $(\mathrm{P}=0.024)$. Mean $\mathrm{HDL}_{2}-\mathrm{C}$ and $\mathrm{Apo}-\mathrm{B}$ levels also tended to be higher when alcohol was consumed $(P=0.066$ and $P=0.064$, respectively). No main effects of alcohol on TC, $\mathrm{HDL}_{3}-\mathrm{C}$, or Apo- $\mathrm{A}_{1}$ could be observed in the postprandial phase ( $P$-values $0.387,0.544$ and 0.150 , respectively).

The histograms in the middle and right-hand part of Figure 1 ( 8 bars) show the effects of alcohol for the two age groups separately after consumption of the two different meals. Each bar represents the mean value of eight observations. The effects of alcohol on $\mathrm{HDL}-\mathrm{C}$ and $\mathrm{HDL}_{2}-\mathrm{C}$ appeared to occur mainly after the high-protein meal and were more pronounced in the middle-aged volunteers. The alcohol-induced increase in $\mathrm{Apo}_{2} \mathrm{~A}_{2}$, on the other hand, was mainly due to an effect observed after the high-fat meal. The pattern of the histogram for Apo-A, was very similar to that of Apo$A_{2}$, although no significant main effect for Apo- $A_{1}$ was observed.

An increase in TG levels due to alcohol was observed in both age groups and after each meal type, with more pronounced increases occurring in the middle-aged men. 


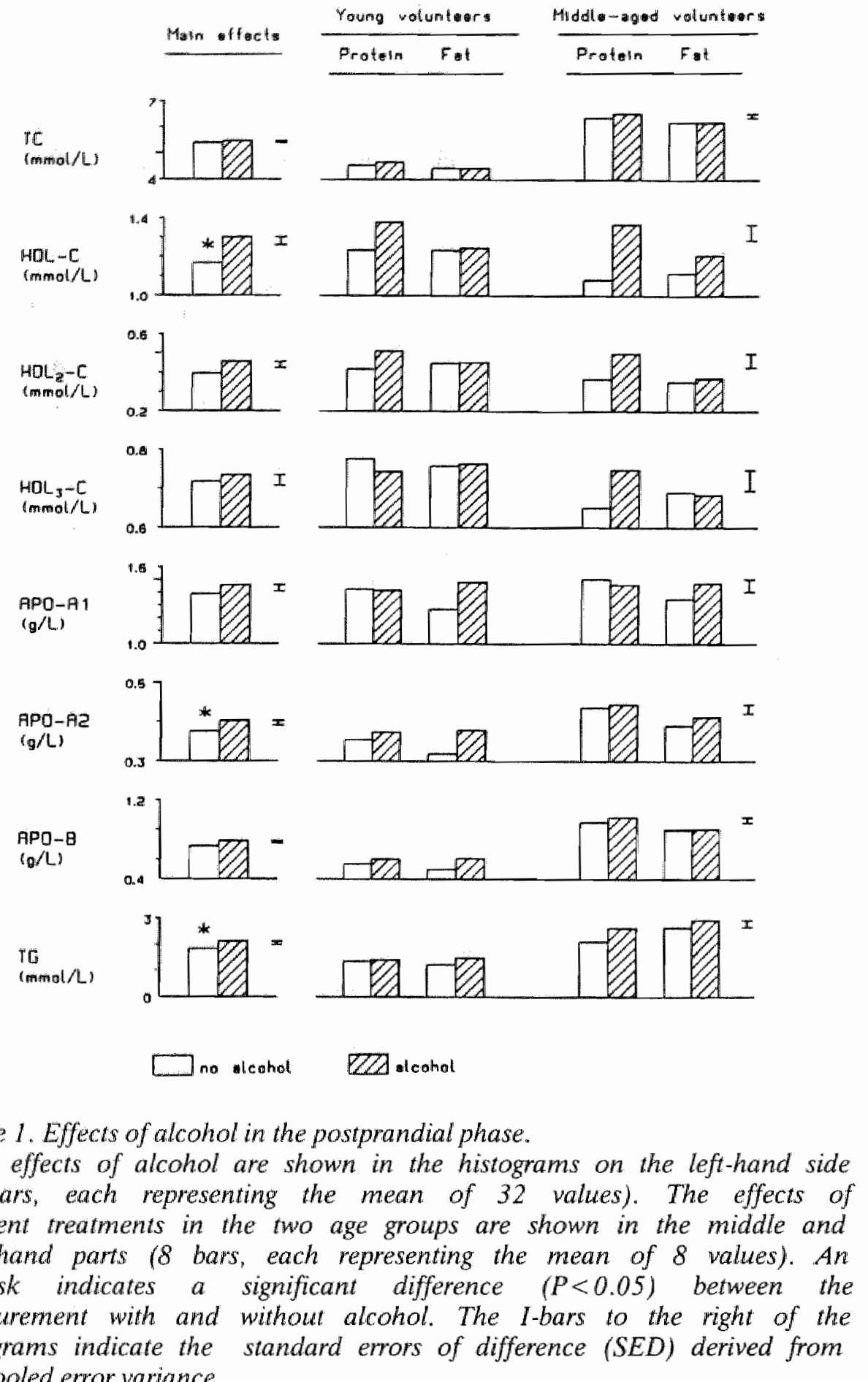

he 


\section{Effects of alcohol after an overnight fast}

After the overnight fast no significant main effects of alcohol were observed. However, the mean levels of $\mathrm{HDL}_{2}-\mathrm{C}, A$ po- $\mathrm{A}_{1}$ and $\mathrm{TG}$ were significantly lower than in the postprandial phase, in the evening before. Mean $\mathrm{HDL}_{2}-$ Clevels had decreased from 0.425 to $0.356 \mathrm{mmol} / \mathrm{L}(\mathrm{P}<0.001)$, and Apo-A $A_{1}$ levels from 1.42 to $1.34 \mathrm{~g} / \mathrm{L}(\mathrm{P}=0.020)$. Mean TG levels in the fasting state were 1.22 , compared to $1.99 \mathrm{mmol} / \mathrm{L}$ in the postprandial phase $(\mathrm{P}<0.001)$.

\section{Differences between the two age groups}

For a number of lipid variables, significant differences were observed between the two age groups. The mean fasting values for all variables measured are summarized in Table 3. TC levels in the middle-aged men were $37.5 \%$ higher than those in the young men $(P<0.001)$. Apo-B and TG levels were also much higher in the middle-aged men $(49.4 \%$ and $114.6 \%$, respectively, $\mathrm{P}<0.001$ for both variables). No significant differences between the two age groups were observed for HDL-C and HDL-C subfractions and for $\mathrm{Apo}_{\mathrm{A}} \mathrm{A}_{1}$ and $\mathrm{Apo-} \mathrm{A}_{2}$.

Table 3. Mean values for fasting lipid-variables of the young and middleaged volunteers.

\begin{tabular}{|c|c|c|c|}
\hline & $\begin{array}{l}\text { Young } \\
\text { volunteers }\end{array}$ & $\begin{array}{l}\text { Middle-aged } \\
\text { volunteers }\end{array}$ & P-value \\
\hline$(\mathrm{mmol} / \mathrm{L})$ & 4.56 & 6.27 & 0.001 \\
\hline HDL-C $(\mathrm{mmol} / \mathrm{L})$ & 1.251 & 1.122 & 0.283 \\
\hline $\mathrm{HDL}_{2}-\mathrm{C}(\mathrm{mmol} / \mathrm{L})$ & 0.416 & 0.305 & 0.087 \\
\hline $\mathrm{HDL}_{3}-\mathrm{C}(\mathrm{mmol} / \mathrm{L})$ & 0.780 & 0.727 & 0.350 \\
\hline Apo-A $A_{1}(g / L)$ & 1.362 & 1.314 & 0.597 \\
\hline Apo- $A_{2}(\mathrm{~g} / \mathrm{L})$ & 0.362 & 0.392 & 0.317 \\
\hline Apo-B $(\mathrm{g} / \mathrm{L})$ & 0.605 & 0.904 & 0.001 \\
\hline $\mathrm{TG} \quad(\mathrm{mmol} / \mathrm{L})$ & 0.786 & 1.687 & 0.001 \\
\hline
\end{tabular}




\section{Discussion}

To our knowledge this is the first report on the effects of a moderate amount of alcohol on blood lipids and lipoproteins in the postprandial phase when the alcohol is still present in the circulation. In two other studies on the postprandial effects the first blood sample was taken when the alcohol was expected to be completely metabolized (4 hours after the intake of $40 \mathrm{~g}$ of alcohol) $(16,19)$.

In the present study an increase in HDL-C, Apo- $\mathrm{A}_{2}$ and $\mathrm{TG}$ levels was observed one hour after the intake of a moderate dose of alcohol, when the mean blood alcohol concentration was $0.175 \mathrm{~g} / \mathrm{L} . \mathrm{HDL}_{2}-\mathrm{C}$ and $\mathrm{Apo}-\mathrm{B}$ also tended to increase. The following morning after an overnight fast the effects had disappeared. Since the study comprised a cross-over design in which all subjects had all four treatments in a randomized order, always at the same time on the same day of the week, the observed effects cannot be attributed to differences between individuals, circadian rhythm or dayto-day fluctuations.

With the rise in HDL-C level (Fig. 1), levels of HDL-C subfractions $\mathrm{HDL}_{2}-\mathrm{C}$ and $\mathrm{HDL}_{3}-\mathrm{C}$ both tended to increase, the increase in $\mathrm{HDL}_{2}-\mathrm{C}$ level being more pronounced and almost reaching significance $(P=0.066)$. This is very interesting since our previous studies and those of others (6-13) suggested that the increasing effect of alcohol on fasting blood HDL-C appeared to be mainly attributed to $\mathrm{HDL}_{3}-\mathrm{C}$ rather than to the more favourable $\mathrm{HDL}_{2}-\mathrm{C}$. Perhaps the reported alcohol-induced increase of $\mathrm{HDL}_{3}-\mathrm{C}$ after an overnight fast are secondary to the postprandial rise of $\mathrm{HDL}_{2}$ levels. Unusually high $\mathrm{HDL}$ levels have been reported in chronic alcoholics (20). Upon cessation of alcohol consumption, a sharp fall in the HDL 2 levels has been observed in alcoholics $(14,15)$, whereas $\mathrm{HDL}_{3}$ levels were less high and showed a much slower decrease. From the rapid decline of $\mathrm{HDL}_{2}$ after cessation of alcohol ingestion it may be concluded that the increased $\mathrm{HDL}_{2}$ levels in alcoholics are only maintained as long as alcohol is present in the circulation. By the same mechanism alcohol perhaps also increases $\mathrm{HDL}_{2}$ in non-alcoholics when moderate blood alcohol concentrations are present. The increases in $\mathrm{HDL}-\mathrm{C}$ and $\mathrm{HDL}_{2}-\mathrm{C}$ observed in the present study disappeared during fasting overnight.

The middle-aged volunteers in the present study had higher TC, Apo-B and TG levels than the young volunteers. On the other hand, their HDL-C. particularly $\mathrm{HDL}_{2}-\mathrm{C}$, tended to be lower. Some differences between both age groups in the effects of alcohol in the postprandial phase could also be observed. The alcohol-induced increase in $T G$ is mainly due to increases in the middle-aged men (Fig. 1). Furthermore, the effects of alcohol on HDL-C 


\section{CHAPTER 8}

and $\mathrm{HDL}_{2}-\mathrm{C}$ are also more pronounced in the middle-aged men, which is indicative of a possible relation between the changes in $\mathrm{HDL}$ and $\mathrm{TG}$.

Whether the transient increases in HDL-C and $\mathrm{HDL}_{2}-\mathrm{C}$ play a role the reported beneficial effects of moderate alcohol consumption depends strongly on the mechanism causing this changes. Since higher HDL-C levels may be indicative of an increased reverse cholesterol transport as well as a decreased clearance of HDL-C, we conclude that the question whether the observed effects are favourable or not cannot be answered from our results and remains to be determined.

Epidemiological studies have suggested that regular daily moderate alcohol consumption is more positively associated with a lower risk of CHD than irregular drinking (21). Our present findings, showing that a moderate dose of alcohol influences lipid metabolism postprandially, opens the possibility that the suggested protective effects of regular moderate alcohol consumption against the development of CHD are to be attributed to transient changes in lipid metabolism in the postprandial phase.

\section{Acknowledgment}

Supported by the Central Commodity Board for Arable Products, The Hague, The Netherlands and the Commodity Board for Spirits, Schiedam. The Netherlands.

\section{References}

1. Marmot MG. Alcohol and coronary heart disease. International Journal of Epidemiology 1984;13:160-7.

2. Moore RD, Pearson TA. Moderate alcohol consumption and coronary artery disease. Medicine 1986:65:242-67.

3. Veenstra J. Moderate alcohol use and coronary heart disease: A Ushaped curve? World Review of Nutrition and Dietetics 1990, in press.

4. Shaper AG, Wannamethee G, Walker M. Alcohol and mortality in British men: explaining the U-shaped curve. Lancet 1988 ;ii:1267-73.

5. Stampfer MJ, Colditz GA, Willett WC, Speizer FE, Hennekens CH. A prospective study of moderate alcohol consumption and the risk of coronary disease and stroke in woman. New England Journal of Medicine 1988;319:267-73.

6. Pikaar NA, Wedel M, vd Beek EJ, van Dokkum W, Kempen HJM, Kluft C, Ockhuizen Th, Hermus RJJ. Effects of moderate alcohol consumption on 
platellet aggregation, fibrinolysis, and blood lipids. Metabolism $1987: 36: 538-44$.

7. Hartung GH, Foreyt JP, Mitchell RE, Mitchell JG, Reeves RS, Gotto AM. Effect of alcohol intake on high-density lipoprotein cholesterol levels in runners and inactive men. Journal of the American Medical Association 1983:249:747-50.

8. Thornton J, Symes $\mathrm{C}$, Heaton $\mathrm{K}$. Moderate alcohol intake reduces bile cholesterol saturation and raises HDL cholesterol. Lancel 1983:ii:819-21.

9. Haskell WL, Camargo C. Williams PT, Vranizan KM. Krauss RM. Lindgren FT. Wood PD. The effect of cessation and resumption of moderate alcohol intake on serum high-density lipoprotein subfractions. New England Journal of Medicine 1984;310:805-10.

10. Couzigou P, Fleury B. Crockett R. Rautou JJ, Blanchard P, Lemoine F, Richard-Molard B, Amouretti $M$, Béraud C. High-density lipoprotein cholesterol and apoprotein A1 in healthy volunteers during long-term moderate alcohol intake. Annals of Nutrition and Metabolism 1984:28:377-84.

11. Burr ML, Fehily AM, Butland BK. Alcohol and high-density lipoprotein cholesterol: a randomized controlled trial. British Journal of Nutrition 1986;56:81-6.

12. Masarei JRL, Puddey IB, Rouse IL, Lynch WJ, Vandongen R, Beilin LJ. Effects of alcohol consumption on serum lipoprotein lipid and apolipoprotein concentrations: Results from an intervention study in healthy subjects. Atherosclerosis 1986;60:79-87.

13. Välimäki M, Taskinen MR. Ylikahri R, Roine R, Kuusi T, Nikkilä EA. Comparison of the effects of two different dosis of alcohol on serum lipoproteins, HDL-subfractions and apolipoproteins A-I and A-II: a controled study. European Journal of Clinical Investigation $1988: 18: 472-80$.

14. Vălimäki M. Nikkilä EA, Taskinen MR, Ylikahri R. Rapid decrease in high-density lipoprotein subfractions and postheparin plasma lipase activities after cessation of chronic alcohol intake. Aitherosclerosis 1986:59:147-53.

15. Taskinen MR, Välimäki M, Nikkilä EA, Kurisi T, Ehuholm C, Ylikahri R. Highadensity lipoprotein subfractions and postheparin plasma lipases in alcoholic men before and after alcohol withdrawal. Metabolism $1982 ; 31: 1168-73$.

16. Goldberg CS. Tall AR. Krumholz S. Acute inhibition of hepatic lipase and increase in plasma lipoproteins after alcohol intake. Journal of Lipid Research 1984;25:714-20. 
17. Gidez LI, Miller GJ, Burstein M, Slagle S, Eder HA. Separation and quantitation of subclasses of human high density lipoprotein subclasses by a simple precipitation procedure. Journal of Lipid Research 1982:23:1206-23.

18. Abell AA, Levy BB, Brodie BB, Kendall FF. A simplified method for the estimation of total cholesterol and the demonstration of its specificity. Journal of Biological Chemistry 1952;195:357-66.

19. Franceschini G. Moreno Y, Apebe P, Calabresi L, Gatti E, Noe D, de Fabiani E, Zoppi F, Sirtori CR. Alterations in lnigh-density lipoprotein subfractions during postprandial lipidaemia induced by fat with and without ethanol. Clinical Science 1988:75:135-42.

20. Bell H, Stromme JH, Steensland H, Bache-Wiig JE. Plasma HDL cholesterol and estimated ethanol consumption in 104 patients with alcohol dependence syndrome. Alcohol and Alcoholism 1985;20:35-40.

21. Gruchow HW, Hoffmann RG, Anderson AJ, Barboriak J.J. Effects of drinking patterns on the relationship between alcohol and coronary occlusion. Atherosclerosis 1982;43:393-404. 



\title{
MODERATE ALCOHOL CONSUMPTION AND PLATELET AGGREGATION IN HEALTHY MIDDLE-AGED MEN
}

\author{
J. Veenstra, H. van de Pol and G. Schaafsma \\ (Alcohol: an International Biomedical Journal in press)
}

\section{Summary}

Changes in platelet aggregation have often been proposed as an explanation for the protective effect of moderate alcohol consumption on the development of coronary heart disease, observed in epidemiological studies. To test the tenability of this assumption, the acute effect of moderate alcohol consumption on platelet aggregation was studied in eight healthy middle-aged men in a controlled study. The intake of alcohol consisted of two glasses of red wine at dinner and two glasses of distilled liquor (Hollands gin), combined with a snack, before bedtime. No acute effects of moderate alcohol consumption on platelet aggregation were observed.

Key words: Alcohol consumption, Platelet aggregation, Human, Healthy volunteers, Coronary heart disease

\section{Introduction}

In many epidemiological studies a protective effect of moderate alcohol consumption on coronary heart disease (CHD) has been observed (reviews 1-4). One of the proposed explanations is that moderate alcohol consumption reduces platelet aggregation. In man, the acute effects of alcohol on platelet aggregation have been investigated in a number of studies (5-13). The results, however, are conflicting. No effects (5-8), inhibitory effects $(9-11)$, as well as stimulative effects $(12,13)$ of alcohol consumption on platelet aggregation have been reported. This discrepancy may be explained by the large diversity in study protocols. In three studies $(9,12,13)$ the volunteers consumed $100 \mathrm{~g}$ of alcohol or more (1 drink contains approximately $10 \mathrm{~g}$ ), and in one study (5) alcohol was taken ad libitum for four hours. In the other studies the amount of alcohol consumed varied broadly between 15 and $90 \mathrm{~g}$. Furthermore, the 
studies varied considerably in type of alcoholic beverage (e.g. whiskey, white wine and alcohol in fruit juice). In all studies mentioned, the alcohol was consumed on an empty stomach, mostly in the morning.

Until now, no data are available on the acute effects on platelet aggregation of a moderate dose of alcohol, consumed at a customary time of the day and under habitual conditions. The aim of the present study was to investigate the acute effects of alcohol on platelet aggregation under carefully controlled conditions mimicking normal life as closely as possible.

\section{Methods}

\section{Subjects}

Eight apparently healthy, non-smoking volunteers, between 45 and 55 years of age, participated in this study. Their average habitual consumption of alcohol varied between 10 and $40 \mathrm{~g}$ per day. They all had a normal liver function, had no familial history of alcoholism and were used to a normal, Western lifestyle, including dietary habits. No drugs were used during the experiment. The study protocol was approved by the Institute's external Medical-Ethical Committee and the participants signed an informed consent form.

\section{Study design}

The total experimental period lasted four weeks in which the subjects received four treatments, each of which lasted three days. During these days, the subjects were housed in the metabolic ward of the department and were not allowed to consume any food or drinks but the meals and drinks supplied. The four treatments comprised two different standard diets, one rich in saturated fatty acids and the other rich in polyunsaturated fatty acids, each at two different alcohol regimes, one with and one without alcohol (factorial design). For each subject the experimental days were always on the same days of the week. The first two days, in which no alcohol was consumed, served as a run-in period. On the third day $40 \mathrm{~g}$ of alcohol was consumed, two glasses of red wine during dinner and two glasses of Hollands gin just before bedtime combined with a snack, 5 hours after dinner. If no alcohol was given, exactly the same volumes of mineral water were consumed. Blood samples were taken at four moments", 1) three hours before dinner, 2) one hour after dinner, 3) one hour after the snack 
and 4) the next morning. Compliance was tested by measuring the biood alcohol concentration. All subjects were subjected to all four treatments in a randomized order, according to a Latin square design.

\section{Analyses}

Blood was taken from a vena mediana cubiti by means of a catheter. For platelet aggregation analyses $20 \mathrm{ml}$ blood was collected by gentle suction into $200 \mu \mathrm{l}$ of $320 \mathrm{~g} / \mathrm{L}$ sodium citrate $\mathrm{pH} \mathrm{7.4.} \mathrm{Aggregation} \mathrm{experiments} \mathrm{were}$ carried out in platelet-rich plasma (PRP) containing $220 \times 10^{6}$ platelets $/ \mathrm{ml}$ in a Lumi Dual aggrometer (Chrono-Log Corp., Havertown, PA). After 3 minutes of preincubation at $37{ }^{\circ} \mathrm{C}$ of $450 \mu \mathrm{l}$ PRP, $50-\mu \mathrm{l}$ aliquots of collagen or ADP suspensions were added to induce aggregation. Aggregation curves were recorded for 5 minutes. For collagen (Hormon Chemie, München, FRG) the final concentrations used were $0.2,0.4$ and $0.7 \mathrm{mg} / \mathrm{L}$ and for ADP (Boehringer-Mannheim, Mannheim, FRG) 0.5, 1.0 and $2.0 \mu \mathrm{M}$. From the aggregation curves the percentage of maximum aggregation and the velocity of aggregation were obtained. For each sample separately, the percentage of maximum aggregation or velocity of aggregation was plotted against the collagen or ADP concentrations. The areas under the curves thus obtained were used as derived variables. The use of these derived variables reduces the number of variables obtained from aggregation studies and also increases the precision of the aggregation parameters.

Platelets were counted on a Sysmex CC-180 Microcellcounter (TOA Medical Electronics Co Ltd; Carson, CA).

Blood alcohol concentrations were determined enzymatically by the method of Beutler and Michal (14), using Boehringer biochemicals (Boehringer, Mannheim, FRG).

\section{Statistics}

Statistical evaluation comprised analysis of variance, according to the design, to test the significance of the main effects of alcohol and meal composition as well as their two-factor interactions. The measurements at moment 1 (before alcohol consumption) were used as a covariate. 


\section{Results}

The mean blogd alcohol concentration one hour after wine consumption was $0.12 \mathrm{~g} / \mathrm{L}$ (range 0.05 to $0.20 \mathrm{~g} / \mathrm{L}$ ) and one hour after the two glasses of Hollands gin $0.23 \mathrm{~g} / \mathrm{L}$ (range 0.16 to $0.32 \mathrm{~g} / \mathrm{L}$ ). After consumption of mineral water the blood alcohol concentration was always $0.00 \mathrm{~g} / \mathrm{L}$.

In all subjects platelet counts were normal at the start of the study (mean $19510 \% / \mathrm{L}$, range 154-297) and remained unchanged during the different treatments.

The results of the platelet aggregation measurements are summarized in

Table 1. The acute influence of moderate alcohol consumption on platelet aggregation in healthy middle-aged volunteers ${ }^{1}$

Parameter Alcohol
Before dinner
$1 \mathrm{hr}$ after dinner
1 hr after the snack
The next morning
Collagen

Percentage of + aggregation

P-value

Velocity of

aggregation

P-value

ADP

Percentage of

aggregation

P-value

Velocity of

aggregation

P-value
221

216

237

0.223

163

176

0.420

197

212

198

226

0.467

0.955

147

143

167

174

0.808

0.726

435

437

413

420

423

387

445

0.675

0.382

0.107

503

516

514

495

519

0.460

515

0.864

1 Values refer to the area under the curve for percentage of aggregation and velocity of aggregation and are expressed in arbitrary units (see methods). 
Table 1. There were no significant effects of alcohol or diet, or twofactor interactions between alcohol and diet on platelet aggregation. The percentage of maximum aggregation and the velocity of each collagen and ADP induced aggregation was also statistically analyzed separately and in none of these analyses significant effects of alcohol were observed.

\section{Discussion}

Our study demonstrates that moderate alcohol consumption has no acute effects on platelet aggregation in healthy middle-aged men. Thus, the reported protective effect of alcohol against CHD is not likely to be attributable to such an acute effect. In a previous study (15), we have investigated the effects of 5 weeks of moderate alcohol consumption in a controlled study and observed an alcohol-induced decrease in platelet aggregability. Four days of moderate alcohol consumption, however, did not influence platelet aggregation (submitted for publication).

Alcohol consumption and platelet aggregability has also been investigated in an epidemiological study (958 participants) by Meade et al. (16). They report a decrease in platelet aggregation with increasing daily alcohol consumption.

We conclude that a moderate intake of alcohol has no acute effect on platelet aggregation in habitual moderate drinkers. Daily moderate alcohol consumption, on the other hand, causes a decreased platelet aggregability in the long term. This long-term effect of alcohol may, among other mechanisms, play a role in the proposed protection of moderate alcohol consumption against CHD. However, one should bear in mind that platelet aggregation is always measured ex vivo and that aggregability in vivo depends on many other factors.

\section{References}

1. Marmot MG. Alcohol and coronary heart disease. Int. J. Epidemiol. 1984;13:160-167.

2. Rohan TE. Alcohol and ischemic heart disease, a review. Aust. N. Z. J. Med. 1984; 14:75-80.

3. Moore RD, Pearson TA. Moderate alcohol consumption and coronary artery disease. Medicine 1986;65:242-267.

4. Veenstra'J. Moderate alcohol use and coronary heart disease: A Ushaped curve? World Review of Nutrition and Dietetics 1990, in press. 


\section{CHAPTER 9}

5. Dunn EL, Cohen RG, Moore EE, Hamstra RD. Acute alcohol ingestion and platelet function. Arch. Surg. 1981;116:1082-1083.

6. Galli $C$, Colli $S$, Gianfranceschi $G$, Maderna P, Petroni A, Tremoli $\mathbb{E}$, Marinovich $M$, Sirtori $C R$. Acute effects of ethanol, caffeine, or both on platelet aggregation, thromboxane formation, and plasma-free fatty acids in human subjects. Drug. Nutr. Interact. 1984;3:61-67.

7. Hillbom M, Muuronen A, Neiman J, Björk G, Egberg N, Kangasaho $M$. Effects of vitamin $E$ therapy on ethanol-induced changes in platelet aggregation, thromboxane formation, factor VIII levels and serum lipids. Eur. J. Clin. Invest. 1987;17:68-74.

8. Neiman J, Jones AW, Numminen $\mathrm{H}$, Hillbom M. Combined effect of a small dose of ethanol and $36 \mathrm{hr}$ fasting on blood-glucose response, breathacetone profiles and platelet function in healthy men. Alcohol Alcoholism 1987;22:265-270.

9. Fenn CG, Littleton JM. Interactions between ethanol and dietary fat in determining human platelet function. Thromb. Haemostas. 1984;51:50-53.

10. Mikhailidis DP, Jeremy JY, Barradas MA, Green N, Dandona P. Effect of ethanol on vascular prostacyclin (prostaglandin $I_{2}$ ) synthesis, platelet aggregation, and platelet thromboxane release. $\mathrm{Br}$. Med. J. 1983;287:1495-1498.

11. Elmér $O$, Göransson $G$, Zoucas E. Impairment of primary hemostasis and platelet function after alcohol ingestion in man. Haemostasis $1984 ; 14: 223-228$.

12. Hillbom $M$, Kangasaho $M$, Löwbeer $C$, Kaste $M$, Muuronen A, Numminen $\mathbf{H}$. Effects of ethanol on platelet function. Alcohol 1985;2:429-432.

13. Hillbom M, Kangasaho M, Kaste $M$, Numminen $H$, Vapaatalo $H$. Acute ethanol ingestion increases platelet reactivity: Is there a relationship to stroke ? Stroke $1985 ; 16: 19-23$.

14. Beutler HO, Michal G. Neue Methode zur enzymatischen Bestimmung von Äthanol in Lebensmitteln. Z. Anal. Chem. 1977;284:113-117.

15. Pikaar NA, Wedel M, van der Beek E, van Dokkum W, Kempen HJM, Kluft C, Ockhuizen Th, Hermus RJJ. Effects of moderate alcohol consumption on platelet aggregation, fibrinolysis, and blood lipids. Metabolism 1987:36:538-547.

16. Meade TW, Vickers MV, Thompson SG, Stirling Y, Haines AP, Miller GJ. Epidemiological characteristics of platelet aggregability. $\mathrm{Br} . \mathrm{Med} . \mathrm{J}$. 1985;290:428-432. 


\title{
ACUTE EFFECTS OF MODERATE ALCOHOL CONSUMPTION ON FIBRINOLYTIC FACTORS IN HEALTHY MIDDLE-AGED MEN
}

\author{
J. Veenstra, C. Kluft, H. van de Pol, G. Dooijewaard and G. Schaafsma.
}

\section{(Submitted)}

\section{Summary}

Acute effects of moderate alcohol consumption on fibrinolytic factors were investigated in eight healthy middle-aged men (between 45 and 55 years) in a carefully controlled study. Alcohol consumption comprised two glasses of red wine during dinner and two glasses of Dutch gin in combination with a snack during the evening ( $40 \mathrm{~g}$ of alcohol in total). During the control treatment corresponding volumes of mineral water were consumed. Blood samples were drawn before dinner (around 1500), one hour after dinner (around 1900), one hour after the snack (around 2300) and the next morning (around 0800). PAl activity was increased by $230 \%(\mathrm{p}<0.001)$ after alcohol consumption at the late evening measurement. PAI-1 antigen levels, however, were not significantly affected. The specific activity of PAI (activity/antigen quotient) was significantly increased by alcohol consumption at all three times of measurement after dinner. As a consequence t-PA activity was reduced by up to $95 \%(\mathrm{p}<0.001)$, around 2300 . Levels of t-PA antigen, on the other hand, were increased after alcohol consumption (up to $+42 \%, \mathrm{p}<0.01$ ). No effects of alcohol consumption on the urokinase plasminogen activator (u-PA) system were observed. We conclude that shortly after moderate alcohol consumption both $\mathrm{t}-\mathrm{PA}$ antigen and PAI activity levels are increased, resulting however in a decreased activity of t-PA. Increased PAI activity persists after an overnight fast.

\section{Introduction}

In the past 10 years many epidemiological studies have shown moderate alcohol consumption to be associated with a lower risk of coronary heart disease (CHD) (reviews 1-4). This lower risk has been attributed (in part) to anti-thrombotic effects of alcohol use, which is supported, for example, by the observations in the Nurses Health Study in a cohort of 87,526 nurses (5). In this study moderate drinkers had a lower risk of 
CHD. The relation between alcohol consumption and stroke, on the other hand, seems to depend on the type of stroke involved. Moderate alcohol consumers have a higher risk of haemorrhagic stroke but lower risk of ischaemic stroke. Since occlusion of blood vessels is involved in both $\mathrm{CHD}$ and ischaemic stroke, effects on haemostatic factors might explain the reported benefits of moderate alcohol use.

In a previous study we have reported effects of 5 weeks of moderate alcohol consumption on platelet function and fibrinolysis (6). A dose dependent decrease in tissue-type plasminogen activator (t-PA) activity and increase in plasminogen concentrations was observed. Additional analysis showed that plasma activities of the fast t-PA inhibitor PAI-1 were significantly increased after 5 weeks of moderate alcohol consumption (7). In a four day experimental period no effects of alcohol on fibrinolytic parameters were observed (8). More recently we have demonstrated strong acute effects of a moderate dose of alcohol on t-PA activity and PAI activity in young and middle-aged healthy men (9). PAI activity was increased, whereas, L-PA activity displayed a strong decrease one hour after the intake of a moderate amount of alcohol. The observed effects were significantly more pronounced in the middle-aged men than in young men.

The aim of the present study was to further investigate the acute effects of moderate alcohol consumption on the fibrinolytic system in middle-aged men in a carefully controlled study.

\section{Methods}

\section{Subjects}

Eight apparently healthy, non-smoking volunteers, between 45 and 55 years of age, participated in this study. Their average habitual consumption of aicohol varied between 10 and $40 \mathrm{~g}$ per day. They all had a normal liver function, had no family history of alcoholism and were used to a normal, Western lifestyle, including dietary habits. No drugs were used during the experiment. The study protocol was approved by the Institute's external Medical-Ethics Committee and the participants signed an informed consent form.

\section{Study design}

The total experimental period lasted four weeks in which the subjects received four treatments, each of which lasted three days. During these 
days, the subjects were housed in the metabolic ward of the Institute and were not allowed to consume any food or drinks but the meals and drinks supplied. The four treatments comprised two different standard diets, one rich in saturated fatty acids and the other rich in polyunsaturated fatty acids (Table 1), each at two different beverage regimes, one with and one without alcohol.

Table 1. Composition of the total daily diet on the experimental days (pooled portions of 2 days were analyzed).

\begin{tabular}{|c|c|c|c|}
\hline & & $\begin{array}{l}\text { Meal rich } \\
\text { in saturated } \\
\text { fatty acids }\end{array}$ & $\begin{array}{l}\text { Meal rich } \\
\text { in polyunsaturated } \\
\text { fatty acids }\end{array}$ \\
\hline Weight & (g) & 2378.0 & 2387.0 \\
\hline \multirow{2}{*}{ Energy } & (kcal) & 2193.0 & 2239.0 \\
\hline & $(\mathrm{MJ})$ & 9.2 & 9.4 \\
\hline Protein & $(\mathrm{en} \%)$ & 12.0 & 12.5 \\
\hline Carbohydrates & $(\mathrm{en} \%)$ & 50.0 & 48.5 \\
\hline Total fat & $(\mathrm{en} \%)$ & 38.0 & 39.0 \\
\hline \multicolumn{4}{|c|}{ Fatty acid composition: } \\
\hline Saturated & $(\%)$ & 52.7 & 34.0 \\
\hline Monounsaturated & $(\%)$ & 35.5 & 25.8 \\
\hline Polyunsaturated & $(\%)$ & 11.8 & 40.2 \\
\hline
\end{tabular}

For each subject the experimental days were always on the same days of the week. The first two days, in which no alcohol was consumed, served as a run-in period. On the third day, $40 \mathrm{~g}$ of alcohol was consumed: two glasses of red wine during dinner and two glasses of Dutch gin in the evening combined with a snack, 5 hours after dinner. In the regimen without alcohol, exactly the same volumes of mineral water were consumed. Blood samples were taken at four moments: 1) three hours before dinner (around 1500), 2) one hour after dinner (around 1900), 3) one hour after the snack (around 2300), and 4) the next morning (around 0800). Compliance was tested by measuring the blood alcohol concentration. All subjects were 
subjected to all four treatments in a randomized order, according to a Latin square design.

\section{Analysis}

Blood was taken from a vena mediana cubiti by means of a catheter and processed to platelet-poor plasma as previously described in detail (10). Plasma was kept frozen at or below $-40^{\circ} \mathrm{C}$. 1-PA activity was assayed in euglobulin fractions of plasma using the parabolic rate assay for t-PA as described in detail (11). Activity was expressed in $1 \mathrm{U} / \mathrm{ml}$, on the basis of the international standard of t-PA (12). PAl-activity was determined by titration with two-chain t-PA (Organon Teknika, Turnhout, Belgium) using a parabolic rate assay to measure residual $t-P A$, as described in detail before (13). Inhibition was expressed relative to a pooled plasma sample which was estimated to inhibit $7.6 \mathrm{IU}$ of $\mathrm{t}-\mathrm{PA} / \mathrm{ml}$.

PAI activity was determined by titration with two-chain melanomal t-PA (14) in a parabolic rate assay essentially as described by Verheijen et al (15). Results are expressed relative to a pooled plasma which has been found to neutrallize $7.6 \mathrm{IU} / \mathrm{ml} \mathrm{t}-\mathrm{PA}$.

PAI antigen and t-PA antigen were measured by ELISA (Tintelize PAI-1 and Imulyse TM 5 t-PA, Biopool, Umea, Sweden), according to the instructions of the manufacturer.

Antigen levels of u-PA were measured by ELISA, in essence as described by Binnema et al (1.6), using donkey anti-(goat $\operatorname{IgG}$ ) IgG conjugated with alkaline phosphatase (Jackson Immunoresearch Laboratories, West Grove, USA) instead of rabbit anti-goat IgG. The assay measures the u-PA antigen present in plasma, irrespective of its molecular form, i.e. pro-u-PA, active U-PA and U-PA in complex with inhibitors.

The plasmin activatable pro-u-PA activity was measured by a biological immuno-assay BIA (17). In the first step of the ELISA and BIA the same immobilized rabbit anti-u-PA $\operatorname{IgG}$ coating is used. The difference between results of the ELISA and BIA for U-PA moieties is considered to represent U-PA inhibitor complexes mainly.

Blood alcohol concentrations were enzymatically determined by the method of Beutler and Michal (18), using Boehringer biochemicals (Boehringer, Mannheim, FRG).

\section{Statistics}

Statistical evaluation comprised analysis of variance, according to the design, to test the significance of the main effects of alcohol and meal composition as well as their two factor interactions. The 
measurements at moment 1 , before alcohol consumption were used as covariable.

\section{Results}

The subjects always had blank values for the blood alcohol determination when no alcohol had been taken, whereas significant alcohol levels were found after alcohol ingestion. The mean blood alcohol concentration, one hour after dinner was $0.12 \mathrm{~g} / \mathrm{L}(\mathrm{SD}=0.041)$ and one hour after the snack $0.23 \mathrm{~g} / \mathrm{L}(\mathrm{SD}=0.048)$.

Irrespective of the alcohol treatment a clear circadian pattern was observed in PAI activity (Fig. 1A) and t-PA activity (Fig.2A). The fatly acid composition of the diet did not influence the effects of alcohol on the variables measured. Therefore the data presented are the mean values of both diets.

When the subjects were on the alcohol regimen, a small increase $(28 \%$. not significant) in PAl activity was observed, one hour after dinner, as compared to the control treatment. Later in the evening, however, after the consumption of two glasses of distilled liquor (around 2300), PAl activity was increased by $230 \% \quad(p<0.001)$. The following morning the difference in PAI activity between alcohol and control treatment was still significant $(p=0.023)$. PAI-1 antigen levels, however, were not significantly influenced by alcohol (Fig.1B). The effects of alcohol on the specific activity of PAI (activity/antigen quotient) are shown in Figure 1C. A significant increase in specific PAI activity caused by alcohol consumption was observed at all three times of measurement after dinner.

t-PA activity was also influenced by alcohol consumption, but in the opposite direction (Fig.2A). t-PA activity one hour after dinner was slightly lower (25\%) as compared to the control treatment (not significant). Later in the evening, however, one hour after the consumption of 2 glasses of distilled liquor (around 2300 ), a very strong decrease in $\mathrm{t}-\mathrm{PA}$ activity of $95 \%$ was observed as compared to the control treatment $(p<0.001)$. The following morning, as a consequence of the diurnal rhythm, t-PA activities on both the alcohol and the control regimen were very low and not significantly different. In contrast to the t-PA activity, t-PA antigen levels were significantly increased one hour after the consumption of 2 glasses of distilled liquor (Fig. 2B). This makes the effect of alcohol on the specific activity of I-PA (Fig. 2C) even more pronounced. 

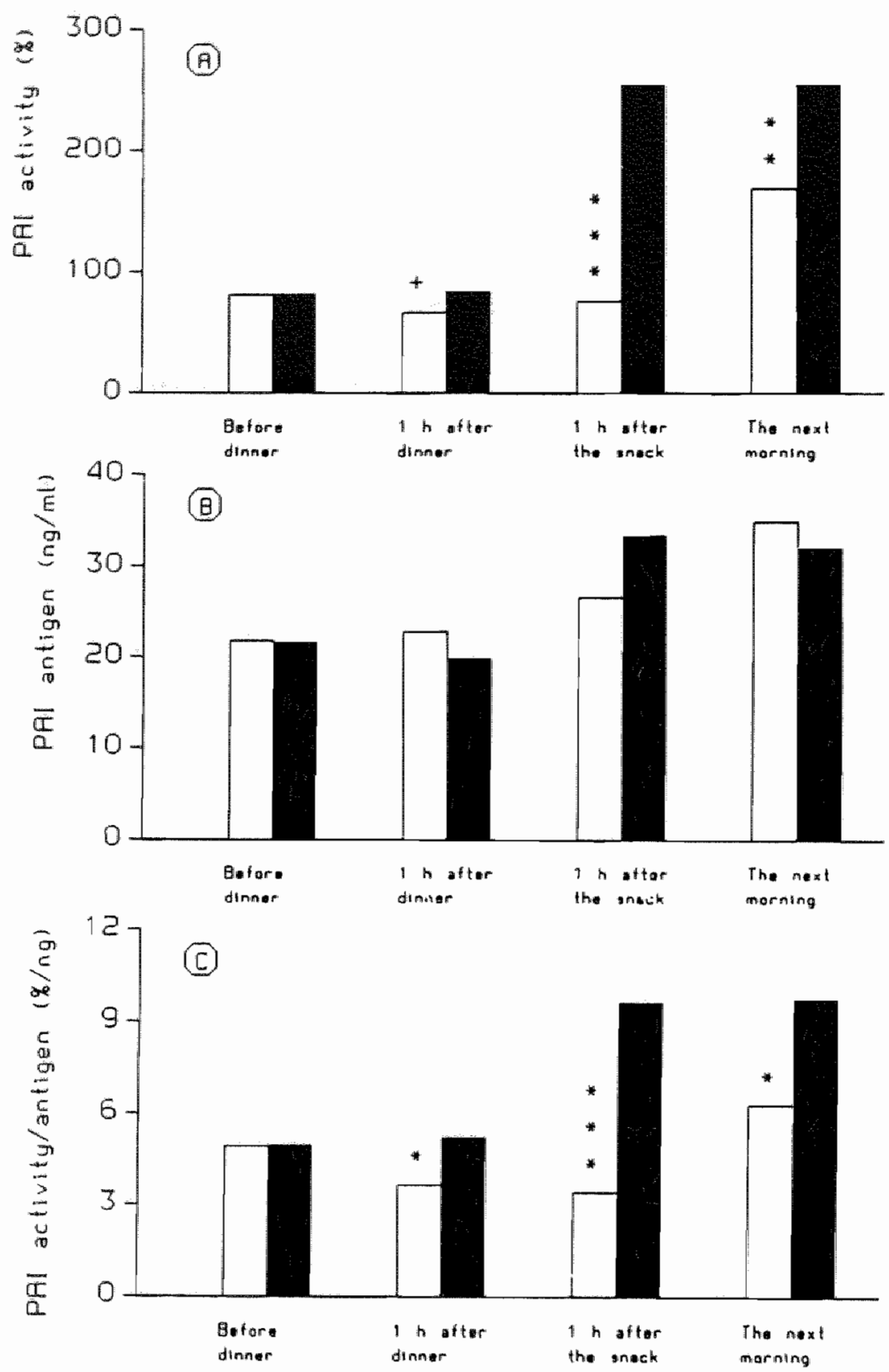

$\square$ without alcohol $\square$ with alcohol

Figure 1. Acute effects of moderate alcohol consumption on PAI activity (A), PAI-1 antigen (B) and specific PAI activity levels (C).

$\left(+: p<0.10 ; *: p<0.05 ; * *: p<0.01 ;{ }^{* * *}: p<0.001\right)$ 

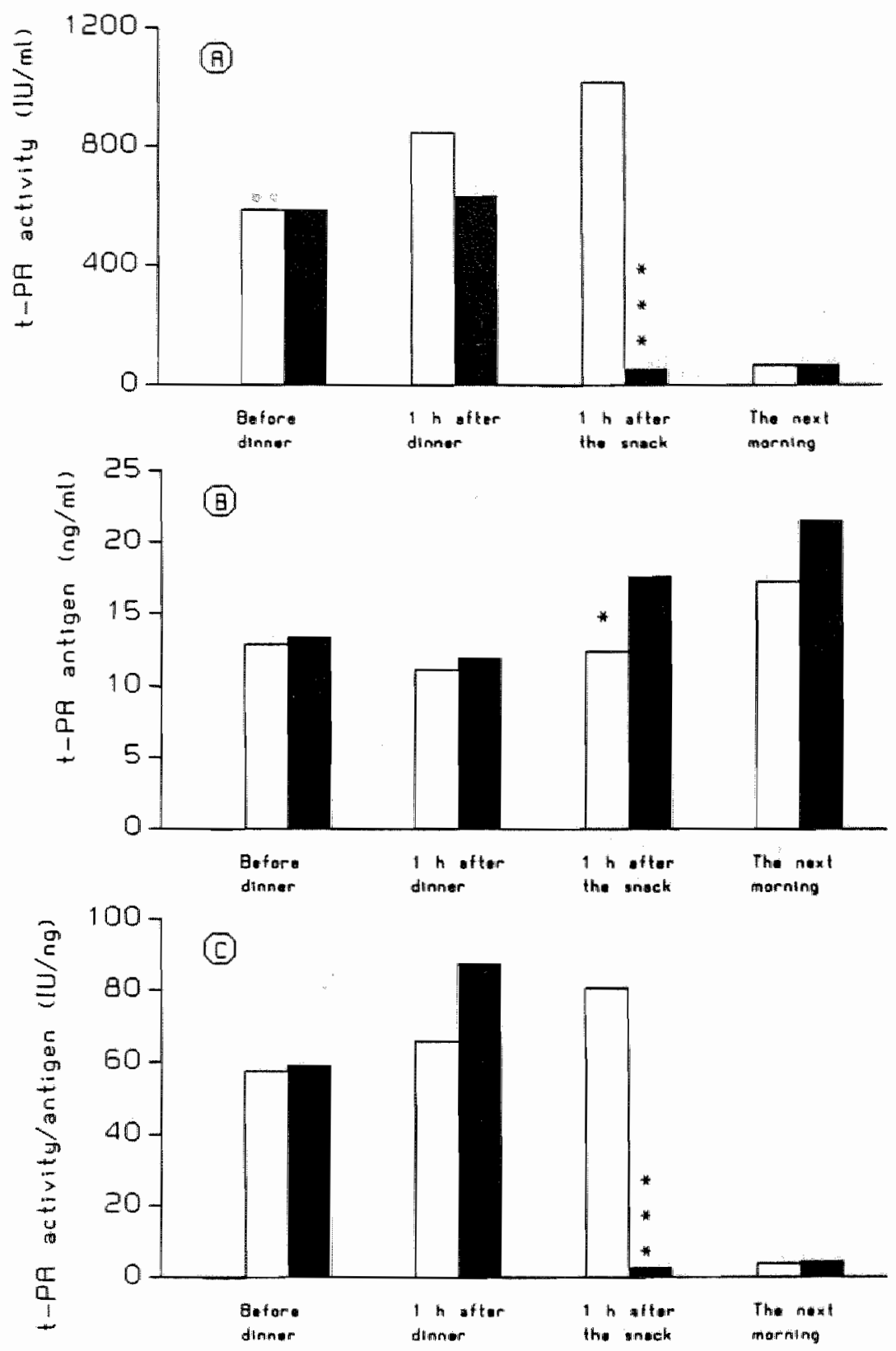

Figure 2. Acute effects of moderate alcohol consumption on t-PA activity $(A), t-P A$ antigen $(B)$ and specific $t-P A$ levels $(C)$.

$\left(+: p<0.10 ;^{*}: p<0.05 ;^{* *}: p<0.01 ;^{* * *}: p<0.001\right)$ 
The results of the measurements of the u-PA system are summarized in Table 2. No significant effects of alcohol could be observed on total u-PA antigen. plasmin activatable pro u-PA and $\mathrm{U}$-PA-inhibitor complex.

Table 2. Levels of U-PA variables one hour after the consumption of 2 glasses of Dutch gin.

\begin{tabular}{lllll}
\hline & & $\begin{array}{c}\text { Alcohol } \\
\text { (SEM) }\end{array}$ & $\begin{array}{c}\text { No alcohol } \\
\text { (SEM) }\end{array}$ & P-value \\
\hline Tolal u-PA antigen & $(\mathrm{ng} / \mathrm{ml})$ & $2.78(0.08)$ & $2.60(0.12)$ & 0.243 \\
Prou-PA & $(\mathrm{ng} / \mathrm{ml})$ & $1.82(0.10)$ & $1.85(0.14)$ & 0.883 \\
u-PA-inhibitor complex & $(\mathrm{ng} / \mathrm{ml})$ & $0.88(0.12)$ & $0.66(0.11)$ & 0.214 \\
\hline
\end{tabular}

\section{Discussion}

Our results indicate that the activity of the fibrinolytic factors PAI and t-PA is strongly influenced by the consumption of moderate amounts of alcoholic beverages. The u-PA levels on the other hand remain unaffected. Since the study comprised a cross-over design in which all subjects had all four treatments in a randomized order, always at the same time on the same day of the week, the observed effects cannot be attributed to differences between individuals, circadian rhythm or systematic day-to-day flluctuations.

Blood librinolytic activity, as assessed by global methods, has been shown to have a circadian rhythm with highest activity in the late afternoon and lowest activity in the early morning (19-21). In addition, 1.PA activity has been shown to parallel this circadian rhythm, which indicates that 1-PA activity is a major determinant of blood fibrinolytic atctivity assessed by global methods (23,24). PAI-1 activity on the other hand, displays a circadian pattern opposite to that of t-PA aclivity from which it is suggested that the observed fluctuations probably originate from changes in PAI-1 levels $(23,24)$. Within-day variations in u-PA are much less pronounced ( 23$)$.

The circadian fluctuations in PAl and 1-PA activity observed in the present study are in agreement with the literature mentioned above. The observed effects of alcohol on 1-PA and PAI activity are in the same order of magnitude as the diurnal variations. This indicates that alcohol 
consumption may be an important additional determinant of blood fibrinolytic activity. Even after an overnight fast the effect of alcohol on PAI activity was still significant. Since in most studies fibrinolytic activity is measured in the early morning our results indicate that alcohol consumption at the previous evening may disturb the outcome of such measurements.

Recently Sumi et al. (25) observed an increase in u-PA after the consumption of the local Japanese spirit 'Shochu'. In contrast, no significant effects of alcohol on the U-PA system were observed in the present study. Possible explanations for this contradiction may be the large differences between the alcoholic beverages used and the higher dose of alcohol consumed in the study of Sumi et al. (up to $47.4 \mathrm{~g}$ ).

Several mechanisms can be put forward to explain the observed effects of alcohol on the t-PA system. The plasma level of t-PA activity depends on a complex variety of local and systemic processes (for a review see 26) which include: 1) Fluctuations in plasma t-PA activity either by changes in the rate of the continuous production by endothelial cells or by acute release; 2) Removal of $\mathrm{t}-\mathrm{PA}$ from the circulation by liver clearance; and 3) Inhibition by specific inhibitors, especially the fast acting t-PA inhibitor PAI-1.

In the present study PAI activity is increased whereas PAI-1 antigen levels remain unchanged by alcohol. This possibly indicates that a t-PA inhibiting agent other than PAI-1 is responsible for the increased PAI activity after alcohol consumption. In this respect Nilsson et al. (27) have demonstrated inhibition of blood fibrinolytic activity between 2 and 3 hours after the consumption of red wine and beer. Six hours after consumption the effects on fibrinolytic activity had disappeared. The inhibition was not attributable to alcohol since after removal of alcohol the wine had the same effect. Moreover, spirits and absolute alcohol had no effect on fibrinolytic activity. On the basis of in-vitro experiments Nilsson et al. concluded that the antifibrinolytic activity of wine and beer was caused by a pectin of low molecular weight. Since, in the present study, maximal PAI activity is reached one hour after the consumption of spirits ( 6 hours after dinner and wine consumption) it is questionable whether the presence of a pectic substance in wine is responsible for all of the observed effects. Another possible explanation for the observed increase in PAI activity may be that alcohol has a direct stimulatory effect on the activity of PAI-1 present in the circulation or that an inhibitor other than PAI-1 is increased by alcohol.

The t-PA activity showed a strong decrease, which is most probably due to the increase in PAI activity, despite an increase in 1-PA antigen levels. 
The alcohol induced increase in PAI activity and decrease in plasma tPA activity is likely to have consequences for the local processes of thrombus formation and subsequent lysis. At the local level t-PA activity is controlled by t-PA incorporation into the thrombus and protection against inhibition of $t-P A$ by PAl-1 after binding to fibrin. The initial PAI-1 activity in a clot is very high, as the result of local platelet release, preventing the clot from lysis. Due to the relatively short half life of PAl-1 of 90 minutes, t-PA activity will increase in time and eventually fibrin lysis will take place. Obviously these processes play an important role in the pathogenesis of CHD. However, the increase in PAI activity and the strong decrease in t-PA activity induced by alcohol seems in striking contrast with the epidemiological finding that moderate alcohol consumption protects against CHD. Maybe the increase in t-PA antigen is of more importance at the local level than a decreased t-PA activity. We conclude that further research is needed on the relation between alcohol consumption, fibrinolysis and CHD. In addition, increased PAI activity and reduced t-PA activity levels have been observed in patients with recurrent deep venous thrombosis and in patients with pulmonary embolism. The possibility that alcohol is involved in these illnesses also needs further attention.

\section{References}

1. Marmot MG. Alcohol and coronary heart disease. Int. J. Epidemiol. 1984;13:160-7.

2. Rohan TE. Alcohol and ischemic heart disease, a review. Aust. N. Z. J. Med. 1984;14:75-80.

3. Moore RD, Pearson TA. Moderate alcohol consumption and coronary artery disease. Medicine 1986;65:242-67.

4. Veenstra J. Moderate alcohol use and coronary heart disease: A Ushaped curve? World Review of Nutrition and Dietetics, in press.

5. Stampfer MJ, Colditz GA, Willett WC, Speizer FE, Hennekens CH. A prospective study of moderate alcohol consumption and the risk of coronary disease and stroke in women. N. Engl. J. Med. 1988;319:26773 .

6. Pikaar NA, Wedel M, vd Beek EJ, van Dokkum W, Kempen HJM, Kluft C, Ockhuizen TH, Hermus RJJ. Effects of moderate alcohol consumption on platelet aggregation, fibrinolysis, and blood lipids. Metabolism 1987;36:538-544.

7. Kluft C, Veenstra J, Schaafsma G, Pikaar NA. Regular moderate wine consumption for five weeks increases plasma activity of the 
plasminogen activator inhibitor 1 (PAl-1) in healthy young volunteers. Fibrinolysis 1990;4 Supp2:69-70.

8. Veenstra J, Kluft C, Ockhuizen Th, v.d. Pol H, Wedel M, Schaafsma G. Effects of moderate alcohol consumption on platelet function, tissuetype plasminogen activator and plasminogen activator inhibitor. Thrombosis and Haemostasis 1990;63:345-8.

9. Veenstra J, Kluft C, Ockhuizen Th, Pikaar NA, v.d. Pol H, Wedel M, Schaafsma G. Effects of four days of moderate wine and coffee consumption on fibrinolysis and platelet aggregation. 1990. Fibrinolysis, in press.

10. Kluft C, Brakman P, Veldhuyzen-Stolk: Screening of fibrinolytic activity in plasma euglobulin fractions on the fibrin plate. In: Davidson J F, Samama M M, Desnoyers P C (eds) Progress in chemical fibrinolysis and thrombolysis, vol 2. New York, Raven Press 1976:5765

11. Verheijen JH, Mullaart E, Chang GTG, Kluft C, Wijngaards G. A simple, sensitive spectrophotometric assay for extrinsic (tissue-type) plasminogen activator applicable to measurement in plasma. Thromb Haemostas 1982;48:266-9.

12. Gaffney PJ, Curtis AD: A collaborative study of a proposed International standard for tissue plasminogen activator in human plasma. Thromb Haemostas 1985;53:134-6.

13. Verheijen $\mathrm{JH}$, Chang GTG, Kluft $\mathrm{C}$. Evidence for the occurrence of a fast-acting inhibitor for tissue-type plasminogen activator in human plasma. Thromb Haemostas 1984;51:392-5.

14. Kluft C, van Wezel AL, van der Velden CAM, Emeis JJ, Verheijen JH, Wijngaards G. Large scale production of extrinsic (tissue-type) plasminogen activator from human melanoma cells. In: Advances in biotechnological processes (Mizrahi A, van Wezel AL, eds) Vol 2, New York: Alan TR Liss 97-110.

15. Verheijen JH, Chang GTG, Kluft C. Evidence for the occurrence of a fast-acting inhibitor for tissue-type plasminogen activator in human plasma. Thromb Haemostas 1984;51:392-5.

16. Binnema DJ, van Iersel JJL, Dooijewaard G. Quantitation of urokinase antigen in plasma and culture media by use of an ELISA. Thromb Res 1986;43:569-77.

17. Dooijewaard $G$, van Iersel JJL, Brommer EJP. Quantitation of pro-UK, UK and UK-inhibitor levels in plasma of patients and healthy man. In: Abstracts of the eight International Congress on Fibrinolysis, Vienna, 1986. Fibrinolysis 1986; Supp: abstract 142.

18. Beutler HO, Michal G. Neue Methode zur enzymatischen Bestimmung von Athanol in Lebensmitteln. Z. Anal. Chem. 1977;284:113-7. 
19. Fearnly GR, Balmforth $G$. Fearnly $E$. Evidence of a diurnal fibrinolytic rhythm; with a simple method of measuring natural fibrinolysis. Clin Sci 1957:16:645-50.

20. Rosing DR, Brakman P, Redwood DR, Goldstein RE, Beiser GD, Astrup T, Epstein SE. Blood fibrinolytic activity in man. Diurnal variation and the response to varying intensities of exercise. Circ Res 1970;27:171-84.

21. Cepelak $V$, Barcal $R$, Cepelakova $H$, Mayer $O$. Circadian rhythm of fibronolysis. In: Davidson JF, Rowan RM, Samama MM, Desnoyer PC (eds.), Progress in chemical fibrinolysis and thrombolysis, Vol 3, Raven Press, New York, 571-578.

22. Simpson HCR, Mann JI, Meade TW, Chakrabarti R, Stirling Y, Woolf L. Hypertriglyceridemia and hypercoagulability. Lancet 1983;i:786-90.

23. Andreotti F, Davies GJ, Hackett D, Khan MI, de Bart A, Dooijewaard G, Maseri A. Kluft C. Circadian variation in fibrinolytic factors in normal human plasma. Fibrinolysis 1988;2 Supp2:90-2.

24. Kluft $C$, Andreotti $F$. Consequences of the circadian fluctuation in plasminogen activator inhibitor 1 (PAI-1) for studies on blood fibrinolysis. Fibrinolysis 1988;2 Supp 2:93-5.

25. Sumi $H$, Hamada $H$, Tsushima $H$, Mihara $H$. Urokinase-like plasminogen activator increased in plasma after alcohol drinking. Alcohol Alcoholism. 1988;23:33-43.

26. Kluft $C$. t-PA in fibrin dissolution and hemostasis. In: Tissue-type plasminogen activator (t-PA): Physiological and clinical aspects Vol 1. Kluft C (ed.) (1988) 47-77.

27. Nilsson IM, Bjorkman SE, Studnitz Wv, Hallen A. Antifibrinolytic activity of certain pectins. Thromb Diath Haemorrh 1962;6:177-87. 


\title{
ALCOHOL CONSUMPTION IN RELATION TO FOOD INTAKE AND SMOKING HABITS IN THE DUTCH NATIONAL FOOD CONSUMPTION STUDY
}

\author{
J. Veenstra, J.A.A. Schenkel, A.M.J. van Erp-Baart, H.A.M. Brants, \\ K.F.A.M. Hulshof, C. Kistemaker, G. Schaafsma and Th. Ockhuizen \\ (Accepted in revised form by the European Journal of Clinical Nutrition)
}

\section{Summary}

The interrelationships between alcohol consumption, energy and food intake and smoking habits were studied in 1145 men and 1171 women, aged 22-49, in the Dutch National Food Consumption Study, in which a 48-hour dietary record method was used. The aim of the study was to investigate whether moderate alcohol consumption is associated with a generally healthier life-style.

A strong relationship between alcohol consumption and energy intake was found. The energy derived from alcohol was obviously not compensated for by lower intake of other nutrients. Alcohol consumption was much higher on weekend days than on midweek days. No differences in nutrient intake were found between non-drinkers, moderate drinkers and heavy drinkers on midweek days. On weekend days, however, there was a slightly higher total fat and saturated fat intake in moderately drinking men. For women cholesterol intake was found higher in moderate and heavy drinkers. Finally, a strong positive relationship between alcohol consumption and smoking was observed.

It is concluded that the observed differences in energy and nutrient intake and in smoking habits are not indicative of a healthier life-style in moderate alcohol users between 22 and 49 years of age. Consequently, the more favourable prognosis of moderate drinkers cannot be ascribed to a more healthy life-style.

\section{Introduction}

In many epidemiological studies moderate consumers of alcohol have been shown to have a lower risk of coronary heart disease (reviews 1-4). Effects of alcohol consumption on factors related to cholesterol metabolism, blood haemostasis and blood pressure have been put forward to 
explain the beneficial effects of moderate alcohol consumption. An alternative explanation, however, might be that moderate alcohol consumption is associated with a healthier life-style.

The aim of the present study was to investigate the relations between alcohol consumption, food intake and smoking habits using data from the Dutch National Food Consumption Study.

\section{Methods}

The Dutch National Food Consumption Study was conducted between April 1987 and April 1988. This survey comprised 5898 persons (2204 households) constituting a representative sample of the Dutch population aged 1-74. Each household kept a two-day record of food consumption. Indoor consumption was recorded for all members of the household, usually by the housewife. Outdoor consumption was noted individually in a personal logbook. Instructions for proper recording were given by specially trained dietitians who also checked the completeness of the dietary records and measured some of the portions of foods and drinks consumed. From the dietary record daily energy and nutrient intakes were calculated using the computerized Dutch Food Composition Table (NEVO). Information on sociodemographic and life-style factors, including smoking habits, was also collected.

In the present study only the data for subjects between 22 and 49 years of age were analysed. Furthermore, people who were on a dietary regimen, vegetarians and pregnant women were excluded from the study because of the unusual character of their food and alcohol consumption. The dietary record was analysed for the first and the second day separately. In this paper the data for the first day are presented. The analyses for the second day were used to check the consistency of the results.

For the analyses of the relation between alcohol consumption and smoking habits chi-square tests were used. The statistical analyses of the relation between alcohol consumption and energy and nutrient intakes were based on analysis of variance using BMDP statistical software (5). Student's t-test was used to test the significance of differences between alcohol categories. In all statistical testing performed the null hypothesis was rejected at $p<0.05$. 


\section{Results}

\section{Alcohol consumption}

Data of 1145 men and 1171 women were analysed. Table 1 shows the distribution of alcohol consumption over the days of the week for men and women separately. On almost all days of the week alcohol consumption among

Table 1. Distribution of alcohol consumption over the days of the week for men and women.

\begin{tabular}{lcccc}
\hline & \multicolumn{2}{c}{ men $(\mathrm{n}=1145)$} & \multicolumn{2}{c}{ women $(\mathrm{n}=1171)$} \\
\hline & $\begin{array}{c}\text { percentage } \\
\text { of } \\
\text { alcohol users }\end{array}$ & $\begin{array}{l}\text { alcohol } \\
\text { consumption } \\
(\mathrm{g}) \text {, users only }\end{array}$ & $\begin{array}{c}\text { percentage } \\
\text { of } \\
\text { alcohol users }\end{array}$ & $\begin{array}{l}\text { alcohol } \\
\text { consumption } \\
(\mathrm{g}) \text {, users only }\end{array}$ \\
\hline Day & $\%$ & mean (SD) & $\%$ & mean (SD) \\
\hline $\begin{array}{l}\text { Monday } \\
\text { Tuesday }\end{array}$ & 47.1 & $37.3(30.0)$ & 34.0 & $23.0(16.6)$ \\
Wednesday & 43.8 & $34.9(24.3)$ & 26.4 & $22.6(15.6)$ \\
Thursday & 51.9 & $36.5(29.2)$ & 31.5 & $22.6(12.0)$ \\
$\begin{array}{l}\text { Friday } \\
\text { Saturday }\end{array}$ & 57.9 & $33.7(19.0)$ & 37.7 & $25.6(20.6)$ \\
Sunday & 64.4 & $45.4(36.1)$ & 36.5 & $31.2(23.4)$ \\
& 71.3 & $49.8(31.7)$ & 52.6 & $29.2(20.5)$ \\
& 68.1 & $44.1(38.1)$ & 42.8 & $31.8(23.8)$ \\
\hline
\end{tabular}

male users was more then $50 \%$ higher than among female users. Furthermore, for both men and women, alcohol consumption was higher on Friday, Saturday and Sunday than on other days of the week. Therefore we decided to look at males and females separately on the basis of their alcohol consumption and also to analyse midweek (Monday, Tuesday, Wednesday and Thursday) and weekend (Friday, Saturday, Sunday) separately. Subjects were classified into non-drinkers, moderate drinkers (men $<35 \mathrm{~g}$, women $<25 \mathrm{~g}$ ) and heavy drinkers (men $>35 \mathrm{~g}$, women $>25 \mathrm{~g}$ ). The distribution across these categories is shown in Table 2 . 
Table 2. Distribution of the study population across the alcohol consumption categories.

Men:

Midweek days

Weekend days Women:

Midweek days Total

\section{Smoking habits}

The relation between alcohol and smoking habits is presented in Table 3. On both midweek and weekend days and for both men and women there was a statistically significant relation between alcohol consumption and smoking. A relatively high percentage of heavy smokers and a relatively low percentage of non-smokers was observed among the heavy alcohol users as compared to the total population. The opposite was seen for the nondrinkers, albeit the differences were less marked there.

\section{Food consumption}

The relation between alcohol and food intake on midweek and on weekend days is summarized in Tables 4 and 5, respectively. In both men and women and on midweek days as well as weekend days, total energy intake showed a significant increase with increasing alcohol consumption. No significant differences, however, were observed between alcohol categories when energy intake was calculated exclusive of the energy from alcohol.

On midweek days there was no relation between alcohol consumption and fat intake. On weekend days total fat intake and intake of saturated fat in moderately drinking men was significantly higher than among nondrinkers and heavy drinkers. These differences, however, were not observed on the second day of the dietary record. For monounsaturated fat, polyunsaturated fat, linoleic acid, cholesterol and $\mathrm{P} / \mathrm{S}$ ratio differences between groups were not significant. 
Table 3. Alcohol consumption and smoking habits on midweek and weekend days.

Non-drinkers Moderate drinkers Heavy drinkers Total

\begin{tabular}{lcccr}
\hline Midweek days & $\%$ & $\%$ & $\%$ & $\%$ \\
\hline Men: & & & & \\
non-smokers & 57.1 & 48.7 & 35.4 & 50.1 \\
$\quad<10$ cig./day & 16.4 & 19.7 & 16.7 & 17.4 \\
$>=10$ cig./day & 26.5 & 31.6 & 47.9 & 32.5 \\
& & Chi-square value: 24.7 & P-value $<0.001$ \\
\cline { 3 - 4 }
\end{tabular}

Women:

\begin{tabular}{llccr} 
non-smokers & 59.4 & 51.4 & 28.0 & 54.2 \\
$<10 \mathrm{cig} /$ day & 14.0 & 17.6 & 10.7 & 14.4 \\
$>=10 \mathrm{cig} . /$ day & 26.7 & 31.1 & 61.3 & 31.4 \\
& & Chi-square value: 38.5 & P-value $<0.001$ \\
\hline
\end{tabular}

Weekend days

$\%$

$\%$

$\%$

Men:

\begin{tabular}{lcccc} 
non-smokers & 58.6 & 63.2 & 42.8 & 53.6 \\
$<10 \mathrm{cig} . / \mathrm{day}$ & 13.8 & 13.5 & 13.9 & 13.8 \\
$>=10 \mathrm{cig} . /$ day & 27.6 & 23.3 & 43.3 & 32.6 \\
& & Chi-square value: 18.3 & P-value $<0.001$ \\
\hline
\end{tabular}

Women:

\begin{tabular}{lrccc} 
non-smokers & 59.9 & 60.7 & 37.5 & 55.3 \\
$<10$ cig./day & 8.8 & 11.2 & 15.4 & 10.8 \\
$>=10$ cig./day & 31.3 & 28.0 & 47.1 & 34.0 \\
& & Chi-square value: 17.6 P-value $=0.002$ \\
\hline
\end{tabular}


Table 4. Alcohol and food consumption on midweek days.

\begin{tabular}{|c|c|c|c|c|c|c|c|}
\hline \multirow[t]{2}{*}{ Nutrients } & \multicolumn{2}{|c|}{ Non-drinkers } & \multicolumn{4}{|c|}{ Moderate drinkers Heavy drinkers } & \multirow{2}{*}{$\begin{array}{l}\text { ANOVA } \\
\text { P-value t-tesf }\end{array}$} \\
\hline & mean & $(\mathrm{SD})$ & mean & (SD) & mean & $(\mathrm{SD})$ & \\
\hline $\begin{array}{l}\text { Men: } \\
\text { Alcohol (g) } \\
\text { Energy, alcohol included (kJ) } \\
\text { Energy, alcohol excluded (kJ) } \\
\text { Total fat (g) } \\
\text { Saturated fat (g) } \\
\text { Monounsaturated fat }(\mathrm{g}) \\
\text { Polyunsaturated fat }(\mathrm{g}) \\
\text { Linoleic acid (g) } \\
\text { P/S ratio } \\
\text { Cholesterol (mg) } \\
\text { Carbohydrates (g) } \\
\text { Protein (g) }\end{array}$ & $\begin{array}{l}0 \\
11191 \\
11184 \\
125.3 \\
50.8 \\
48.4 \\
22.4 \\
18.0 \\
0.45 \\
327 \\
295 \\
91.7\end{array}$ & $\begin{array}{l}(0) \\
(3325) \\
(3323) \\
(45.9) \\
(18.2) \\
(18.8) \\
(13.0) \\
(11.6) \\
(0.23) \\
(155) \\
(104) \\
(28.2)\end{array}$ & $\begin{array}{l}19.2 \\
11484 \\
10916 \\
122.1 \\
49.5 \\
47.8 \\
21.0 \\
16.8 \\
0.44 \\
334 \\
288 \\
89.9\end{array}$ & $\begin{array}{l}(7.8) \\
(2966) \\
(2964) \\
(44.0) \\
(18.5) \\
(18.9) \\
(11.1) \\
(10.0) \\
(0.21) \\
(171) \\
(82) \\
(27.0)\end{array}$ & $\begin{array}{l}54.4 \\
12842 \\
11155 \\
126.0 \\
50.5 \\
50.6 \\
21.2 \\
17.0 \\
0.42 \\
365 \\
294 \\
89.6\end{array}$ & $\begin{array}{l}(25.6) \\
(3621) \\
(3462) \\
(56.1) \\
(20.8) \\
(25.3) \\
(12.4) \\
(10.7) \\
(0.19) \\
(183) \\
(92) \\
(29.0)\end{array}$ & $\begin{array}{l}<0.001 \text { a.b.c } \\
<0.001 \text { b.c }\end{array}$ \\
\hline $\begin{array}{l}\text { Women: } \\
\text { Alcohol }(\mathrm{g}) \\
\text { Energy. alcohol included }(\mathrm{kJ}) \\
\text { Energy. alcohol excluded }(\mathrm{kJ}) \\
\text { Total fat }(\mathrm{g}) \\
\text { Saturated fat }(\mathrm{g}) \\
\text { Monounsaturated fat }(\mathrm{g}) \\
\text { Polyunsaturated fat }(\mathrm{g}) \\
\text { Linoleic acid }(\mathrm{g}) \\
\text { P/S ratio } \\
\text { Cholesterol (mg) } \\
\text { Carbohydrates }(\mathrm{g}) \\
\text { Protein (g) }\end{array}$ & $\begin{array}{l}0 \\
8471 \\
8467 \\
96.8 \\
40.2 \\
38.1 \\
15.7 \\
12.6 \\
0.41 \\
277 \\
217 \\
71.3\end{array}$ & $\begin{array}{l}(0) \\
(2252) \\
(2251) \\
(34.7) \\
(14.9) \\
(15.2) \\
(8.3) \\
(7.5) \\
(0.24) \\
(155) \\
(68) \\
(20.9)\end{array}$ & $\begin{array}{l}14.5 \\
8851 \\
8.421 \\
97.2 \\
40.5 \\
37.8 \\
16.2 \\
13.1 \\
0.43 \\
294 \\
212 \\
73.1\end{array}$ & $\begin{array}{l}(6.5) \\
(2991) \\
(2975) \\
(44.6) \\
(18.5) \\
(19.1) \\
(9.8) \\
(8.7) \\
(0.25) \\
(150) \\
(78) \\
(25.9)\end{array}$ & $\begin{array}{l}41.5 \\
9520 \\
8301 \\
97.0 \\
40.5 \\
38.7 \\
15.1 \\
12.4 \\
0.39 \\
284 \\
207 \\
71.0\end{array}$ & $\begin{array}{l}(16.7) \\
(2751) \\
(2660) \\
(37.4) \\
(16.8) \\
(15.7) \\
(7.8) \\
(7.0) \\
(0.20) \\
(14.8) \\
(76) \\
(20.0)\end{array}$ & $\begin{array}{c}<0.001 \text { a.b.c } \\
0.002 \text { b }\end{array}$ \\
\hline
\end{tabular}

\# a: significant difference between non-drinkers and moderate drinkers

b: significant difference between non-drinkers and heavy drinkers

c: significant difference between moderate drinkers and heavy drinkers 


\section{CHAPTER 11}

Table 5. Alcohol and food consumption on weekend days.

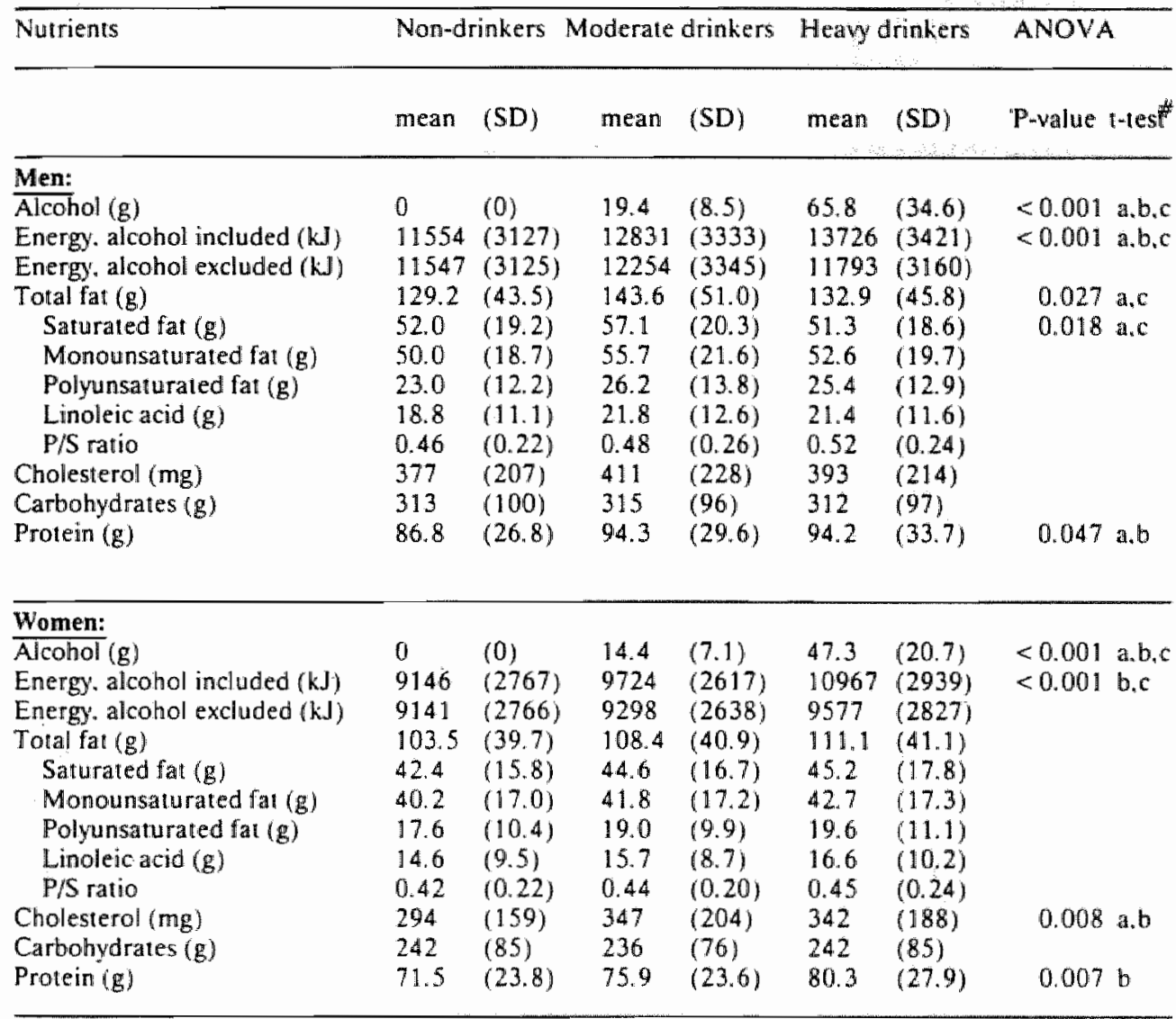

\# a: significant difference between non-drinkers and moderate drinkers

b: significant difference between non-drinkers and heavy drinkers

c: significant difference between moderate drinkers and heavy drinkers 
In women no relations between alcohol and fat consumption were observed for weekend days. The intake of cholesterol, however. was significantly higher for moderate as well as heavy drinkers than for nondrinkers.

No differences in intake of carbohydrates were observed between nondrinkers, moderate drinkers and heavy drinkers.

On weekend days protein intake was significantly related to alcohol consumption in both men and women. Heavily drinking men and women consumed more protein than non-drinkers, and moderately drinking men also had a higher protein intake. In the analyses of the second day of the dietary record the differences in protein intake did not reach statistical significance.

\section{Discussion}

The strength of the Dutch National Food Consumption Study is that the population studied is representative of the Dutch population with respect to gender, age and socio-demographic characteristics. Furthermore, the data are randomly sampled over the year so that all seasons are equally represented. A drawback of the two-day dietary record method used is that data on alcohal and food consumption are only sampled on two days. Therefore, on the individual level, alcohol and food intake might not reflect the usual situation and subjects characterized in this study as non-drinkers need not necessarily be teetotallers. The use of a dietary record instead of a recall method, however, guarantees that the data, especially those on alcohol consumption, are as accurate as possible, and reflect reality at the population level. Alcohol consumption data derived from dielary recall methods are known to be often heavily underreported. This probably explains the relatively high alcohol intake found in the present study as compared to other data on alcohol consumption in the Netherlands.

In our preparatory analyses large differences in alcohol consumption were observed between men and women, between age groups, and between midweek and weekend days, which is in agreement with earlier findings in the Netherlands (6). Although we had not studied this beforehand we expected comparable differences for food consumption. For this reason we decided to study midweek and weekend days separately in the largest age group of the survey, i.e. men and women between 22 and 49 years of age. Because of the large difference in alcohol consumption between men and women it also seemed appropriate to use different ranges defining moderate and heavy drinkers for men and women. In previous studies of this kind, 
midweek and weekend days were not analysed separately and no different alcohol categories were used for men and women (7-9).

Alcohol consumption in the Netherlands, as estimated from sales and excise figures, is not very high as compared to other industrialized countries (10). Nevertheless. the present study shows that average alcohol consumption in the heavily drinking group is quite high. On midweek days no less then $11.0 \%$ of the adult men drink 4 glasses or more $(>40 \mathrm{~g}$ allcohol). On weekend days such an amount is even used by $28.6 \%$ of the men. Women are drinking much less. Only $3.3 \%$ of the women drink more than 4 glasses on midweek days and $10.7 \%$ use that dose on weekend days. However, sensible drinking limits for women are of course also lower than formen (11).

The present study clearly shows that the energy provided by alcohol is not compensated for. The alcohol is simply added to the diet. This may be due to the fact that in the Netherlands most of the alcohol is consumed at the end of the day, separately from the meals. Despite the strong and consistent relationship between alcohol consumption and energy intake, the quetelet index (data not shown) was only increased to a small extent in men who reported heavy drinking on midweek days. The lack of an overall effect of alcohol on quetelet index might be explained by the observed relationship with smoking, which is known to be related with a lower body weight, or by physical activity, of which no data are available.

Food consumption among moderate drinkers was not found to tend consistently towards a healthier diet. For weekend days we found even a slightly higher consumption of total fat and saturated fat in moderately drinking men and a higher cholesterol intake in moderately and heavily drinking women. Comparing the intake of these nutrients on weekend days with the midweek intake we may conclude that in the weekend the diet contains more fat and cholesterol, especially when alcohol is used. This may be attributed partly to the (Dutch) habit of laking some kind of a fatty snack logether with alcohol.

Finally, a strong relation between alcohol consumption and smoking was observed, which is in agreement with findings in many other epidemiological studies (12-14).

In conclusion, the observed differences in energy and nutrient intake and smoking habits are not indicative of a healthier life-style among moderate alcohol users. The present findings do not provide an explanation for the proposed decreased risk of coronary hearl disease in moderate drinkers. 


\section{References}

1. Marmot MG. Alcohol and coronary heart disease. Int. J. Epidemiol. 1984;13:160-7.

2. Rohan TE. Alcohol and ischemic heart disease, a review. Aust. N. Z. J. Med. 1984;14:75-80.

3. Moore RD, Pearson TA. Moderate alcohol consumption and coronary artery disease. Medicine 1986;65:242-67.

4. Veenstra J. Moderate alcohol use and coronary heart disease: A Ushaped curve? World Review of Nutrition and Dietetics. 1990, in press.

5. Dixon WJ, Brown MB, Engelman L, Hill MA, Jennrich RI. BMDP statistical software manual. Berkeley: University of California Press, 1988.

6. Philipsen $H$, Knibbe RA, van Reek J. Alcohol consumption in the Netherlands as a social phenomenon. In: Proceedings of the symposium Alcohol Health and Society, Centre for Agricultural Publishing and Documentation, Wageningen, the Netherlands 1983:53-70.

7. Gruchow HW, Sobocinski KA, Barboriak JJ, Scheller JG. Alcohol consumption, nutrient intake and relative body weight among US adults. Am J Clin Nutr 1985;42:289-95.

8. Jones BR, Barrett-Connor E, Criqui MH, Holdbrook MJ. A community study of calorie and nutrient intake in drinkers and nondrinkers of alcohol. Am J Clin Nutr 1982;35:135-9.

9. Jacques PF, Sulsky S, Hartz SC, Russell RM. Moderate alcohol intake and nutritional status in nonalcoholic elderly subjects. Am J Clin Nutr 1989;50:875-83.

10. How many alcoholic beverages are being consumed throughout the world? Schiedam, the Netherlands: Produktschap voor gedistilleerde dranken. 1988.

11. Royal College of Physicians and Psychiatrists. Alcohol: Our favourite drug, Travistock, United Kingdom. 1987.

12. Klatsky AL. Friedman GD, Siegelaub AB. Alcohol and mortality. A tenyear Kaiser-Permanente Experience. Annals of Internal Medicine 1981:95:139-45.

13. Marmot MG, Rose G, Shipley MJ, Thomas BJ. Alcohol and mortality: A Ushaped curve. Lancet 1981;:580-3.

14. Stampfer MJ, Colditz GA, Willett WC, Speizer FE, Hennekens CH. A prospective study of moderate alcohol consumption and the risk of coronary heart disease and stroke in women. New Engl J Med 1988;319:267-73. 


\section{GENERAL DISCUSSION AND CONCLUSIONS}

Epidemiological studies have shown a remarkably consistent inverse relationship between moderate alcohol consumption and CHD risk (Chapter 2). The aim of the studies described in this thesis was to investigate possible underlying mechanisms related to cholesterol metabolism, platelet function and fibrinolysis.

\section{Cholesterol metabolism}

The positive association between alcohol consumption and HDL-C levels, which has been observed in many epidemiological studies, is the most frequently cited explanation for the lower risk of CHD in moderate alcohol users. In the experimental studies performed by our group the effects of moderate alcohol consumption, in doses ranging from 20 to $40 \mathrm{~g}$ of alcohol per day, on fasting HDL-C levels were studied for periods of 20 weeks (Chapter 4), 5 weeks (Appendix 1) and 4 days (Chapter 6) respectively.

In the 20-week study, a significant increase in HDL-C was observed. This effect was mainly attributable to a significant increase in the $\mathrm{HDL}_{3}$ C subfraction, whereas $\mathrm{HDL}_{2}-\mathrm{C}$ was not significantly intluenced. Similar results were observed in the 5 -week cross-over study. No significant main effects on the HDL-C subfractions were observed within 4 days of moderate alcohol consumption.

The consumption of a moderate dose of alcohol during dinner has been shown to significantly increase HDL-C levels in the postprandial phase, 1 hour after dinner (Chapter 8). With this rise in HDL-C both HDL C subfractions, $\mathrm{HDL}_{2}-\mathrm{C}$ and $\mathrm{HDL}_{3}-\mathrm{C}$, tended to increase, the increase in $\mathrm{HDL}_{2}$ $\mathrm{C}$ being more pronounced. In addition, the levels of apolipoprotein $\mathrm{A}_{2}$ and triglycerides had also significantly increased 1 hour after atcohol consumption. The effects of alcohol disappeared after fasting overnight, which is in agreement with the results of the 4-day study (Chapter 6).

The experimental studies described in this thesis have shown that moderate alcohol consumption significantly raises the levels of HDL-C. The acute rise in $\mathrm{HDL}-\mathrm{C}$ is mainly attributable to $\mathrm{HDL}_{2} \mathrm{C}$, whereas in the long term moderate alcohol consumption mainly affects the $\mathrm{HDL}_{3}-\mathrm{Clevel}$. The findings of an increase in HDL-C after long-term moderate alcohol consumption is in agreement with the experimental and epidemiological findings in the literature, discussed in Chapter 2. There are no previous reports, however, on the acute effects of moderate alcohol consumption on blood lipids and lipoproteins. The present findings, showing that a 
moderate dose of alcohol influences lipid metabolism postprandially, opens the possibility that the suggested protective effects of regular moderate alcohol consumption against the development of CHD are to be attributed to transient changes in lipid metabolism in the postprandial phase. In this respect, it has been reported that regular users of moderate doses of alcohol have a lower risk of coronary occlusion than irregular alcohol consumers irrespective of their level of consumption (Chapter 2). The question as to whether the observed increase in HDL-C is beneficial, however, depends on the mechanism causing this increase. Higher HDL-C levels may be indicative of an increased reverse cholesterol transport from peripheral tissues to the liver, as well as a decreased clearance of HDL_C. Further detailed studies into the precise mechanism of the acute and chronic effects of alcohol on lipid metabolism are needed to answer this question.

\section{Platelet function}

A decrease in platelet aggregability might contribute to a lower risk of CHD. In this thesis the acute effects of moderate alcohol consumption were investigated in two studies (Chapters 7 and 9). In the first study, platelet function 1 hour after the consumption of $30 \mathrm{~g}$ of alcohol as red port and wine tended to increase. In the second study no acute effects of moderate alcohol consumption on platelet aggregation were observed. In this second study platelet aggregation was measured under even more carefully controlled conditions. First, the volunteers were housed in the metabolic ward of our department, and second, platelet aggregation was also measured before alcohol consumption so that an analysis of covariance could be performed.

Four days of moderate alcohol consumption (Chapter 5) had no significant effect on platelet aggregation in the fasting state. After 5 weeks of moderate alcohol consumption, however, an alcohol-induced decrease of platelet aggregation in the fasting state was observed (Appendix 1).

Besides the study of Pikaar et al. (Appendix 1), no experimental data on long-term alcohol consumption and platelet function are available. The results of studies into the acute effects of alcohol consumption on platelet function, on the other hand, are conflicting. No effects, inhibitory effects, as well as stimulatory effects have been reported (see Table 2. Chapter 2). This discrepancy may be explained by the very large variation in methodology and study design. In most of the studies the volunteers consumed excessive amounts of alcohol, and in one study alcohol 
was even taken ad libitum for four hours. Another difference with the studies in this thesis is that in all other studies alcohol was consumed on an empty stomach, mostly in the morning. Thus, essentially no experimental data on moderate alcohol consumption, at a customary time of the day and under habitual conditions, and platelet aggregation are available from the literature.

From our results it is concluded that consumption of a moderate dose of alcohol has no acute effect on platelet aggregation in habitual moderate drinkers. Daily moderate alcohol consumption, on the other hand, causes a decreased platelet aggregability after a few weeks. This is in agreement with the epidemiological observation of an inverse relationship between alcohol consumption and platelet aggregation (Chapter 2). Such a long-term effect of moderate alcohol consumption may, among other mechanisms, play a role in the proposed protection of moderate alcohol consumption against CHD. However, one should bear in mind that platelet aggregation is always measured ex vivo and that aggregability in vivo depends on many other factors.

\section{Fibrinolysis}

Besides platelet aggregability, fibrinolysis is a major determinant of haemostasis. The literature on the effects of alcohol on fibrinolysis is reviewed in Chapter 3. Epidemiological studies have shown a positive association between alcoliol consumption and fibrinolytic activity and a negative association between alcohol and fibrinogen. Most experimental studies, on the other hand, show an acute decrease in fibrinolytic activity after the consumption of alcoholic beverages.

In the studies mentioned above, fibrinolytic activity thas only been studied with global assays. At present, the value of these assays is subject to serious doubts since the outcome depends largely on the procedures used and its relevance in vivo is not clear. In the past decade, more specific assays have been developed to measure the activities and the antigen concentrations of the two major determinants of fibrinolysis, tissue-type plasminogen activator (t-PA) and its fast-acting inhibitor PAI. From the literature, however, no data are avalliable on the acute or long-term effects of moderate alcohol consumption on t-PA and PAI.

The acute effects of alcohol on t-PA and PAI were investigated in two studies included in this thesis (Chapters 7 and 10). In Chapter 7, a strong decrease in plasma t-PA activity in young and middle-aged men is described, whereas PAI activity significantly increased in the middle-aged 
men and tended to increase in the young ones. These results were confirmed in a subsequent study (chapter 10) and, besides t-PA and PAI activity, the antigen levels of t-PA and PAI-1 were also measured. t-PA antigen levels significantly increased after alcohol consumption and PAI-1 antigen levels remained unaffected. The absence of an effect on PAI-1 antigen possibly indicates that a t-PA inhibiting agent other than PAI-1 is responsible for the increased PAI activity after alcohol consumption. In this latter study, it was also found that PAI activity, after alcohol consumption in the evening, was still significantly elevated in the next morning, after an overnight fast. Since in most studies fibrinolytic factors have been measured early in the morning our results indicate that alcohol consumption in the previous evening disturbs the outcome of such measurements.

No effects of moderate alcohol consumption on t-PA activity in the fasting state were observed within four days (Chapter 5). After 5 weeks of regular moderate alcohol consumption, however, a dose-dependent decrease in t-PA activity after fasting overnight was observed (Appendix 1). Additional analyses showed that this decrease in t-PA activity was accompanied with a four-fold increase in PAI activity (Appendix 2). Finally, the effects of 5 weeks of weekend drinking were also tested. The volunteers consumed 14 glasses of wine during 3 weekend days and abstained during midweek days. In contrast to daily consumption of two glasses of wine for five weeks, weekend drinking did not affect PAI activity. This finding is very interesting since irregular alcohol consumers, irrespective of the level of consumption, have been shown to be at higher risk of coronary occlusion than regular users of moderate doses (Chapter 2). However, for the reason mentioned above, it is possible that the effects measured after 5 weeks of moderate alcohol consumption at least in part, are just the remnants of an acute effect of alcohol consumption the day before. The measurements after weekend drinking, on the other hand, were performed only after a few days in the middle of the week. which could also explain the absence of an effect on PAI activity.

In conclusion, the results of studies on alcohol and fibrinolysis are contradictory. Alcohol consumption is epidemiologically associated with increased fibrinolytic activity, whereas decreases in fibrinolytic activity and 1-PA activity and increases in PAI activity have been observed in experimental studies. Further research is needed to explain this contradiction and to investigate the mechanisms and consequences of the effects of alcohol. Some very recent epidemiological studies have indicated a possible relationship between lipid metabolism and fibrinolysis. This relationship also needs further attention, not only in alcohol, but also in lipid research. 


\section{Possible underlying mechanisms}

So far, the effects of moderate alcohol consumption on lipid metabolism, platelet function and fibrinolysis have been described as independent effects without mutual relationships. However, the many other fuelds of biomedical research on alcohol have made it quite clear that alcohol has its effects on almost all organs and tissues of the human body.

Alcohol changes the levels and activities of numerous enzymes. Alcohol has an effect on carbohydrate. fat. protein, hormone and vitamin metabolism. The water and mineral balance is influenced by alcohol and alcohol consumption affects the function and structure of the gastrointestinal tract. The function of blood platelets and cells of the immune system can also be influenced by alcohol. Finally, alcohol influences almost all neurotransmitter receptors and ion channels of the central nervous system and has profound effects on behaviour.

It is not likely that all these effects of alcohol are caused by different specific effects of the alcohol molecule. In fact, the alcohol molecule is quite small and, unlike many other drugs, the structural conformations of alcohol are not very unique. A number of mechanisms can be put forward which might explain the various effects of alcohol mentioned above:

1 - Alcohol changes the fluidity of all cell membranes, and through this mechanism alcohol can interfere in potentially all membraneassociated processes;

2 - The metabolism of alcohol in the liver can influence many other liver processes; and

3 -Acetaldehyde, the first metabolite of alcohol, has a high affinity for lysine and may therefore cause struclural and functional changes in proteins and polypeptides.

These mechanisms will be explained in further detail in the following paragraphs.

Fluidity of cell membranes

The cell membrane separates the cell from its environment. Therefore, all interactions between the cell and the environment are membraneassociated processes. The specific cell functions and the intracellular homeostasis is regulated by membrane-bound enzymes, hormone receptors, and 
transmembrane transport processes. The structure of the cell membrane can be seen as a biological compromise. On the one hand, the membrane must have some mechanical rigidity in order to maintain the integrity and shape of the cell, and on the other hand, the membrane has to be fluid enough to facilitate the function of membrane-bound enzymes, receptors and channels. The mobility and the structure of the membrane proteins depend on the fluidity of the lipid bilayer of the membrane. Regional differences in the fluidity of the membrane probably facilitate the function of proteins in a specific membrane domain (1).

Alcohol has been shown to have an acute in-vitro fluidizing effect on membranes. After chronic alcohol consumption, however, an altered membrane lipid composition results in a reduced membrane fluidity and a decreased sensitivity to the acute fluidizing effects (2). This adaptation of the membrane has been shown to occur in chronic alcoholics (3). The acute fluidizing effect of alcohol is also likely to occur in vivo after the consumption of a moderate amount of alcohol. Although the alcohol concentration for a measurable fluidizing effect in vitro is fairly high (above $0.5 \mathrm{~g} / \mathrm{L}$ ), one must realize that the alcohol concentrations in the gastrointestinal tract and the liver can also be quite high and that membranes of different cells and even different domains of the same cell membrane (1) may vary in sensitivity to alcohol. Whether long-term moderate alcohol consumption has an effect on membrane fluidity or composition is still unknown. Moreover, the in-vitro studies and studies in alcoholics are mainly concerned with overall membrane fluidity rather than the action of alcohol on specific domains of the membrane.

In theory, in all the effects of alcohol on CHD risk factors described in this thesis, changes in membrane fluidity may play a role.

Metabolism of alcohol in the liver

Alcohol is mainly metabolized in the liver, and in moderate alcohol consumers alcohol dehydrogenase $(\mathrm{ADH})$ is the major alcohol-metabolizing enzyme. After alcohol consumption, when the $\mathrm{ADH}$ enzyme is fully active, it accounts for between 70 and $100 \%$ of the liver's energy requirement, which is normally met by fat oxidation. Furthermore, the activity of ADH results in an increased NADH/NAD ratio which influences the activity of numerous other enzymes. Besides this indirect effect of alcohol on the metabolic processes in the liver, alcohol and its first metabolite acetaldehyde may have a direct toxic effect. Acetaldehyde is thought to be a causative factor in liver injury after chronic alcohol abuse. 
The liver probably plays an important role in the effects of alcohol observed in this thesis. First, the observed acute increase in plasma triglycerides presumably originates from the reduction in fat oxidation by the liver and increased synthesis of VLDL from free fatty acids that otherwise had been oxidized. By the same mechanism, prolonged heavy alcohol consumption may result in the development of a fatty liver. Second, HDL, considered as an important factor in reverse cholesterol transport, is produced and released by the liver. It has been shown that the induction of hepatic microsomal enzymes, not only by alcohol but also by other drugs, is associated with increases in HDL-C and $A_{p o-} A_{1}(5,6)$. Finally, besides lipid metabolism the liver is also involved in the clearance of the fibrinolytic factors t-PA and PAl and probably also in the production of PAI-1 (7).

\section{Acetaldehyde}

Acetaldehyde is the first intermediate product in the metabolism of alcohol. Acetaldehyde is further metabolized into acetate by the enzyme acetaldehyde dehydrogenase (ALDH). After the consumption of a moderate amount of alcohol $(0.25 \mathrm{~g} / \mathrm{kg})$ the mean blood acetaldehyde concentration was $3.4 \mu \mathrm{mol} / \mathrm{L}$, whereas the peak blood alcohol concentration was 6.7 $\mathrm{mmol} / \mathrm{L}$ (8). The large difference between acetaldehyde and alcohol concentrations is caused by the fact that the formation of acetaldehyde is the rate-imiting step in allcohol metabolism.

In the past decade, more and more studies have shown that acetaldehyde reacts with all kinds of proteins and peptides. This binding of acetaldehyde has been identified as a Schiff base binding with the epsilon amino group of lysine residues (9). Part of the acetaldehyde-lysine adducts stabilize, resulting in an irreversible covalent binding, which is similar to the glycosylation of proteins by glucose. The stabilization of the adducts can be enhanced in vitro by reducing agents. Besides the epsillon amino group of lysine, acetaldehyde can probably bind to the alpha amino group of an amino terminal amino acid of a protein. In addition. condensation products of acetaldehyde and endogenous amines, such as dopamin and serotonin, have been proposed to play a role in the behavioural effects of alcohol $(10,11)$.

Thus, despite the much lower concentration of acetaldehyde after alcohol consumption as compared to alcohol, acetaldehyde can alter the structural and functional properties of potentially every protein and peptide. Depending on their biological half-life. these changes in the properties of proteins may result in long-term effects after a single 
acetaldehyde "loading". It has been shown that even after 28 days of abstinence, social drinkers have higher levels of haemoglobin-associated acetaldehyde than teetotallers (12).

Acetaldehyde modification of enzymes or receptors may also play a role in the effects of alcohol consumption on CHD risk indicators. For example, the large decrease in t-PA activity after a moderate dose of alcohol, which is accompanied with an increase in t-PA antigen levels, might result from the binding of acetaldehyde at the active site of the enzyme. A similar effect has been reported for several other enzymes (13). For example, acetaldehyde has been found to bind with the 10 lysine residues of a ribonuclease enzyme, one of which (lysine-41) is located at the active site of the enzyme (14). An increase in acetaldehyde adduct formation corresponded with a decrease in catalytic activity. Specific protection of the active site, however, by addition of the substrate phosphate almost completely prevented the inhibition of enzyme activity.

The possibility that reversible or irreversible acetaldehyde adduct formation plays a role in the effects observed in the present thesis will be subject of future studies. In this respect, it may be of interest to note that acute increases in blood acetaldehyde levels, induced by alcohol consumption after treatment with the ALDH inhibitor calcium carbimide, results in strong cardiovascular effects and an increased risk of myocardial infarction and stroke (15).

In conclusion, the mechanisms mentioned above may underly the observed changes in cardiovascular risk indicators studied in the present thesis. The effects of moderate alcohol consumption on lipid metabolism and haemostasis parameters observed in the studies reported in this thesis are summarized in Table 1 (page 153). Measurements show that the blood alcohol concentration in these experiments never surpassed a level of $0.5 \mathrm{~g} / \mathrm{L}$. From Table 1 it can be concluded that even the consumption of moderate amounts of alcohol has a considerable influence on a number of risk indicators for cardiovascular disease.

\section{Possible mutual relationships}

In the acute studies, the strongest effect of alcohol on blood lipids was the effect on triglycerides, whereas no significant effect on triglycerides was observed after 5 or 20 weeks of moderate alcohol consumption in young adults. The possibility that the short-term and longterm effects of alcohol on HDL and apolipoproteins are secondary to the 
Table 1: Summary of effects of moderate alcohol consumption on lipid metabolism and haemostasis parameters.

\begin{tabular}{|c|c|c|c|}
\hline Period & $\begin{array}{l}\text { Lipid } \\
\text { metabolism }\end{array}$ & $\begin{array}{l}\text { Platelet } \\
\text { aggregation }\end{array}$ & Fibrinolysis \\
\hline $\begin{array}{l}\text { Acute effects, in } \\
\text { the postprandial } \\
\text { phase }\end{array}$ & $\begin{array}{l}\text { Triglycerides } \uparrow \\
\text { HDL-C } \uparrow \\
\text { Apo-A }\end{array}$ & No effects & $\begin{array}{l}\text { PAI activity } \uparrow \\
\text { t-PA activity } \downarrow \\
\text { t-PA antigen } \uparrow\end{array}$ \\
\hline $\begin{array}{l}\text { Effects after } 4 \\
\text { days, in the } \\
\text { fasting state }\end{array}$ & $\mathrm{Apo-} \mathrm{A}_{1} / \mathrm{B} \uparrow$ & No effects & No effects \\
\hline $\begin{array}{l}\text { Effects after } 5 \\
\text { weeks, in the } \\
\text { fasting state }\end{array}$ & $\mathrm{HDL}_{3}-\mathrm{C} \uparrow$ & $\begin{array}{l}\text { Collagen- } \\
\text { induced } \\
\text { aggregation }\end{array}$ & $\begin{array}{l}\text { t-PA activity } \downarrow \\
\text { PAI activity } \uparrow\end{array}$ \\
\hline $\begin{array}{l}\text { Effects after } 20 \\
\text { weeks, in the } \\
\text { fasting state }\end{array}$ & $\begin{array}{l}\mathrm{HDL}-\mathrm{C} \uparrow \\
\mathrm{HDL}_{3}-\mathrm{C} \uparrow\end{array}$ & & \\
\hline
\end{tabular}

acute effects of alcohol on triglycerides will be the subject of further studies.

Another possible mutual relationship is the association between triglycerides and fibrinolytic factors already mentioned. In epidemiological studies, a positive association between plasma triglycerides and PAI-1 levels has been observed. In addition, VLDL and LDL lipoproteins have been shown to enhance the production of PAI-1 by endothelial cells in vitro (16). It has also been shown that, depending on the type of fat in the diet, plasma triglycerides in rats are negatively associated with t-PA activity (17). So, it is quite possible that the effects of alcohol consumption on the fibrinolytic factors 1-PA and PAI are mediated by plasma triglyceride or VLDL levels.

Finally, the effects on both blood lipids and fibrinolytic factors possibly play a role in the long-term effect of alcohol consumption on blood platelet function. Platelet function was shown to be mediated by the fatty acid composition of plasma lipids $(18,19)$, probably by influencing 
the production of prostanoids from arachidonic acid. A strong positive association between plasma fibrinogen concentration and platelet aggregation has also been reported $(20)$. In the present study, no effects of alcohol on plasma fibrinogen were observed. In epidemiological studies, however, alcohol consumption is negatively associated with fibrinogen (Chapter 3). It is possible that the decrease in platelet aggregation after 5 weeks of moderate alcohol consumption compensates for the decrease in t-PA activity. The existence of such a compensatory effect is very difficult to assess in an experimental or epidemiological study. Theoretically, the net result of this proposed effect could be a lower risk of $\mathrm{CHD}$ after a period of moderate alcohol consumption. The strong and acute alcohol-induced decrease in t-PA activity, however, possibly increases the risk of CHD directly after alcohol consumption. The latter could explain the relationship between heavy alcohol consumption and sudden coronary death, observed in recent Finnish and Swedish studies (2124).

\section{Different types of alcoholic beverage}

In all studies presented in this thesis wine was used as alcoholic beverage. In the studies into the acute effects, apart from two glasses of red wine at dinner, one glass of red port was consumed as appetizer or, in the second study, two glasses of Hollands gin were consumed during the evening. The use of these beverages was preferred to the use of a solution of pure alcohol since the purpose of our studies was to investigate the effects of moderate alcohol consumption under conditions resembling normal life as closely as possible.

So, from the results presented it cannot be excluded that some beverage constituents other than alcohol are responsible for the observed effects. A large body of evidence from the literature (Chapters 2 and 3), however, shows that the protective effects of alcohol consumption on risk of CHD and the effects of alcohol on CHD risk indicators are not specific for any alcoholic beverage. Lower risk of CHD and a negative association between alcohol consumption and HDL-C have been observed for beer, wine and spirits. The decrease in fibrinolytic activity, as assessed by global assays, has been observed after beer and wine consumption, but pure alcohol lowered fibrinolytic activity as well. Sometimes the reported effect of a specific type of beverage on CHD risk in an epidemiological study is found to be more pronounced, but this may simply be caused by the specific drinking habits of the population studied. An effect of beer is 
more likely to be found in a population drinking primarily beer than in a population where wine and spirits consumption dominates.

Very recently, we have performed a study in which the effects of $40 \mathrm{~g}$ of alcohol consumed during dinner in the form of spirits, wine or beer were studied in a group of middle-aged volunteers. The blood alcohol levels after the consumption of spirits were significantly higher than after wine or beer consumption. Therefore, theoretically, the effects of the same amount of alcohol from spirits could be more pronounced than the effects after beer and wine consumption. The preliminary results of this latest study (data not shown), however, indicate that the effects of alcohol on triglycerides and HDL-C are comparable to those observed in the studies presented and that there are no significant differences between the different types of alcoholic beverage.

\section{Consequences of the observed effects for the risk of CHD}

What are the consequences of the observed effects, summarized in Table 1 , for the risk of CHD?

In epidemiological studies HDL-C, the apolipoproteins Apo- $\mathrm{A}_{1}$ and $\mathrm{Apo-}$ $\mathrm{A}_{2}$, and fibrinolytic activity are positively associated with alcohol consumption, whereas for platelet aggregation an inverse relationship has been observed (Chapters 2 and 3 ). The results of these studies have often been used as an explanation for the observed lower risk of CHD in moderate alcohol consumers, as compared to teetotallers. A serious drawback of the epidemiological studies, however, is that it is very difficult to assess whether an association is causal. In other words, the possibility that the observed relationships between alcohol consumption and CHD risk indicators result from confounding factors cannot be exchuded in these observational studies. The results presented in this thesis, on the other hand, clearly show that even moderate alcohol consumption has a direct influence on the CHD risk indicators, acutely as well as in the long term. From this it may be concluded that the associations between alcohol and CHD risk indicators, and consequently between alcohol and CHD risk, found in epidemiological studies, are likely to be causal.

\section{Food intake and smoking habits}

Besides a biological mechanism, a healthier life-style could provide an alternative explanation for the observed lower risk of $\mathrm{CHD}$ in moderate alcohol users. Therefore, we studied the relationship between alcohol 
consumption food intake and smoking habits in men and women aged 22-49 on the basis of data contained in the Dutch National Food Consumption Study (Chapter 11).

Strong positive associations between alcohol consumption and energy intake and between alcohol consumption and smoking were found. Moreover, on weekend days a sllightly higher intake of total fat and saturated fat was observed in moderately drinking men, and among women a higher cholesterol intake was found in moderate and heavy drinkers. Despite the strong and consistent relationship between alcohol consumption and energy intake, the body mass index had only slightly increased in men who reported heavy drinking on midweek days. The lack of an overall effect of alcohol on body mass index might be explained by the observed relationship with smoking, which is known to be related with a lower body weight, or by physical activity, on which no data are available. Another explanation is that energy derived from alcohol may be considerably lower than the theoretical value of $7 \mathrm{kcal} / \mathrm{g}$.

Although a 48-hour dietary record method was used in this survey, which entails certain limitations, the results do no: support the hypothesis of a healthier life-style among moderate alcohol consumers.

\section{Conclusions}

Several mechanisms were investigated that might explain the observed lower risk of CHD in moderate alcohol consumers. The consumption of moderate amounts of alcohol has an acute effect as well as a long-term effect on lipid metabolism and on the fibrinolytic factors t-PA and PAI. In the long term, moderate alcohol consumption also affects platelet function. A combination of effects of moderate alcohol consumption on lipid metabolism, fibrinolysis and platelet function may explain the lower risk of CHD. It is also shown in this thesis that, at least in the Netherlands, moderate alcohol consumption is not associated with a healthier life-style as far as food intake and smoking habits are concerned. Thus, the lower risk of CHD probably results from the direct influence of moderate alcohol consumption on biological factors that determine CHD risk.

\section{General implications}

In this thesis, the relationship between moderate alcohol consumption and $\mathrm{CHD}$ risk is discussed. The conclusions underline the sense of sensible 
drinking limits. Considering the possible negative side effects of promoting alcohol use, however, the conclusions of this study should not be used to promote alcohol consumption among non-drinkers. Moreover, it should be realized that the lower risk of $\mathrm{CHD}$ is mainly observed in population studies and is not necessarily applicable to all individuals. On the other hand, the conclusions may be used to persuade excessive drinkers to lower their alcohol consumption to sensible limits.

\section{References}

1. Gibson Wood W, Schroeder F. Membrane effects of ethanol: bulk versus lipid domains. Life Sciences 1988;43:467-75

2. Hunt WA. Alcohol and biological membranes. The Guilford Alcohol Studies Series. The Guilford Press, New York, London. 1985

3. Beaugé $F$, Stibler $H$, Borg $S$. Abnormal fluidity and surface carbohydrate content of the erythrocyte membrane in alcoholic patients. Alcoholism: Clin Exp Res 1985;9:322-6

4. Beaugé F, Stibler H, Borg S. Alterations of erythrocyte membrane organisation in alcoholics. Alcohol Alcoholism 1987;s1:561-5

5. Luoma PV, Sotaniemi EA, Pelkonen RO. Alcohol, HDL-cholesterol, and liver microsomal induction. Lancet 1984;1:47

6. Lieber CS, Savolainen M. Ethanol and lipids. Alcoholism: Clin Exp Res 1984;8:409-23

7. Sprenger ED, Kluft C. Plasminogen activator inhibitors. Blood $1987 ; 69: 381-7$

8. Jones AW, Neiman J, Hillbom M. Concentration-time profiles of cthanol and acetaldehyde in human volunteers treated with the alcohol sensitizing drug, calcium carbimide. Br J Pharmac 1988;25:213-21

9. Tuma DJ, Newman MR, Donohue TM, Sorrell MF. Covatent binding of acetaldehyde to proteins: Participation of lysine residues. Alcoholism: Clin Exp Res 1987;11:579-84

10. Davis VE, Walsh MJ. Alcohol, amines, and alkaloids: A possible bioch : cal basis for alcohol addiction. Science 1970;167:1005-7

11. Cohan $v$, Collins $M$. Alkaloids from catecholamines in adrenal tissue: Possible role in alcoholism. Science 1970;167:1749-51

12. Peterson CM, Jovanovic-Peterson L, Schmid-Formby F. Rapid association of acetaldehyde with hemoglobin in human volunteers after low dose ethanol. Alcohol 1988:5:371-4 
13. Mauch TJ, Donohue TM, Zetterman RK, Sorell MF. Tuma DJ. Covalent binding of acetaldehyde selectively inhibits the catalytic activity of lysine-dependent enzymes. Hepatology 1986;6:263-9

14. Mauch TJ, Tuma DJ, Sorrell MF. The binding of acetaldehyde to the active site of ribonuclease: alterations in catalytic activity and effects of phosphate. Alcohol Alcoholism 1987;22:103-12

15. Peachey JE, Sellers EM. The disulfiram and calcium carbimide acetaldehyde mediated ethanol reactions. Pharmac Ther 1981;15:89-97

16. Mussoni L, Maderna P, Camera M, Bernini F, Sironi L, Sirtori M, Tremoli E. Atherogenic lipoproteins and PAI-1 release by endothelial cells. In: Proceedings of the Workshop on Life Style \& Fibrinolysis. Fibrinolysis 1990; suppl:

17. Padró $\mathrm{T}$, Emeis $\mathrm{J} J$, Beynen $\mathrm{AC}$. Effect of dietary fatty acids on plasma fibrinolytic components in rat. In: Proceedings of the Workshop on Life Style \& Fibrinolysis. Fibrinolysis 1990;suppl:

18. Renaud S, Dumont Ex Godsey F, Suplisson A, Thevenon C. Platelet functions in relation to dietary fats in farmers from two regions of France. Thrombos Haemostas 1978;40:518-31

19. Renaud S, Morazain R, Godsey F, Dumont E, Symington IS, Gillanders EM, O'Brien JR. Platelet functions in relation to diet and serum lipids in British farmers. Br Heart J 1981;46:562-70

20. Meade TW, Vickers MV, Thompson SG, Stirling Y, Haines AP, Miller GJ. Epidlemiological characteristics of platelet aggregability. $\mathrm{Br}$ Med J 1985;290:428-32

21. Suhonen O, Aromaa A, Reunanen A, Knekt P. Alcohol consumption and sudden coronary death in middle-aged Finnish men. Acta Med Scand 1987;221:335-41

22. Koskenvuo M, Kaprio J, Kesaniemi A, Poikolainen K. Alcohol related diseases associated with ischaemic heart disease: A three-year followup of middle-aged male hospital patients. Alcohol Alcoholism $1986 ; 21: 251-6$

23. Lithell $H$, Aberg $H$, Selinus I, Hedstrand $H$. Alcohol intemperance and sudden death. Br Med J 1987;294:1456-8

24. Rosengren A, Wilhelmsen L, Pennert K, Berglund G, Elmfeldt D. Alcohol intemperance, coronary heart disease and mortality in Middle-aged Swedish men. Acta Med Scand 1987;222:201-13 


\section{MODERATE ALCOHOL CONSUMPTION AND RISK OF CORONARY HEART DISEASE}

Cardiovascular disease (CVD) accounts for about $40-50 \%$ of total mortality in affluent societies. Most CVD deaths can be attributed to coronary heart disease (CHD). In the past decades evidence has been found that life-style factors influence the risk of CHD. Besides smoking, lack of physical exercise and possibly stress, a surplus of dietary cholesterol, saturated fatty acids, salt and energy contribute to a higher risk of $\mathrm{CHD}$.

Excessive alcohol use is another. CHD risk factor. In contrast, in the past decade, moderate alcohol use has frequently been claimed to reduce this risk. The association between alcohol consumption and CHD risk or between alcohol consumption and total mortality has often been reported to be U-shaped, i.e. moderate drinkers would be at lower risk than both teetotallers and heavy drinkers.

In epidemiological studies, a lower risk of CHD in moderate drinkers as compared to non-drinkers has often been reported (Chapter 2). The aim of the studies presented in this thesis was to investigate mechanisms that might explain the lower risk of CHD in moderate alcohol consumers. For this purpose the long-term and acute effects of moderate alcohol consumption on factors related to cholesterol metabolism, platelet function and fibrinolysis were investigated in a number of experimental studies with human volunteers (Chapters 4-10). In addition, the relationships between alcohol consumption and food intake and between alcohol use and smoking habits was investigated on the basis of data contained in the Dutch National Food Consumption Study (VCP), in order to investigate the possibility that moderate alcohol consumption is associated with a healthier life-style (Chapter 11).

A positive association between alcohol consumption and HDL-C, which has been observed in many epidemiological studies, is the most frequently cited explanation for the lower risk of CHD in moderate alcohol users. HDL-C probably plays an important role in the so-called 'reverse cholesterol transport'. This transport of cholesterol from the tissues, where it can damage vascular walls, to the liver, where it is converted into bile acids and excreted via the bile, is an essential element in the body's defence against accumulation of cholesterol. In the studies presented in this thesis, the effects of moderate alcohol consumption on HDL-C were investigated for periods of 20 weeks (Chapter 4), 5 weeks (Appendix 1) and 4 days (Chapter 6). In addition, the acute effects were investigated (Chapter 8). In the 20-week study as well as in the 5-week 


\section{SUMMARY}

study an increase in HDL-C was observed (measured in the morning after an overnight fast), which was mainly attributable to an increase in the $\mathrm{HDL}_{3}$. $C$ subfraction. In the 4-day study no effects of alcohol on the HDL-C subfractions were observed. The consumption of a single moderate dose of alcohol during dinner also influenced the $\mathrm{HDL}-\mathrm{C}$ levels in the postprandial phase, one hour after alcohol consumption. With this acute rise in HDL-C both HDL-C subfractions, $\mathrm{HDL}_{2}-\mathrm{C}$ and $\mathrm{HDL}_{3}-\mathrm{C}$, tended to increase, the increase in $\mathrm{HDL}_{2}$-C being more pronounced. In addition, the levels of Apo$A_{2}$ and triglycerides had also significantly increased 1 hour after alcohol consumption.

The observed increases in HDL-C after a few weeks of moderate alcohol consumption are in agreement with the experimental and epidemiological data from the literature. No previous studies, however, have been reported in which the acute effects of moderate alcohol consumption were investigated in the postprandial phase, when the alcohol is still present in the circulation. The present findings, showing that a moderate dose of alcohol influences lipid metabolism postprandially, opens the possibility that the suggested protective effects of regular moderate alcohol consumption against the development of $\mathrm{CHD}$ are to be attributed to transient changes in lipid metabolism in the postprandial phase. The increase in HDL-C fits into the hypothesis of a protective effect of moderate alcohol consumption on CHD. Increases in HDL-C, however, may also be indicative of a reduced clearance of HDL-C and the question whether the observed effects are beneficial cannot be answered with certainty. More information is needed about the mechanisms underlying the acute and chronic effects of moderate alcohol consumption on lipid metabolism.

Besides lipid metabolism, haemostasis also plays an important role in the risk of CHD. A decrease in platelet aggregability, for example, might contribute to a lower risk of CHD. In epidemiological studies an inverse relationship between alcohol consumption and platelet aggregation has been observed. In agreement with this, a decrease in platelet aggregation was observed after 5 weeks of moderate alcohol consumption (Appendix 1). In the 4-day sludy (Chapter 5), however, alcohol had no effect and in the postprandial phase, a moderate dose of alcohol also had no significant effect on platelet aggregation (Chapters 7 and 9 ). So, it can be concluded that the consumption of a moderate dose of alcohol probably has no acute effect on platelet aggregation in moderate drinkers. After a few weeks, on the other hand, moderate alcohol consumption leads to a decrease in platelet aggregation. The latter finding is in accordance with the relationship between alcohol consumption and platelet aggregation observed in epidemiological studies. Such a decrease in platelet aggregation fits into the hypothesis of a lower risk of CHD accompanying moderate alcohol 
consumption. However, one should bear in mind that platelet aggregation is measured in vitro and that aggregation in vivo depends on many other factors.

Besides the aggregability of blood platelets, fibrinolysis is an important factor in haemostasis. Until recently, all studies into the effects of alcohol on fibrinolysis used global methods for the analysis of fibrinolytic activity (Chapter 3). At present, however, the value of these global methods is open to serious doubt and new and more specific methods have been developed to measure the activity and antigen levels of the two most important fibrinolytic factors, tissue-type plasminogen activator ( $t$ PA) and plasminogen activator intibitor (PAI). An increase in PAI and a decrease in $t-P A$ results in a decreased fibrinolytic activity and may therefore contribute to a higher risk of CHD. In the literature, however. no attention is paid to the effects of moderate atcohol consumption on these specific fibrinolytic factors.

In the present study, a significant increase in PAl activity and in tPA antigen levels has been observed shortly after the consumption of a moderate amount of alcohol. The activity of A-PA, on the other hand, showed a strong decrease (Chapters 7 and 10). A decrease in t-PA activity and an increase in PAI activity were also observed in the 5-week study (Appendices 1 and 2). The mechanism of the observed changes and the consequences for the fibrinolytic activity in vivo are not yet quite clear. The strong decrease in t-PA activity may increase the risk of an infarct and therefore conflicts with the hypothesis of a lower risk of CHD. The observed increase in t-PA antigen, on the other hand, possibly indicates compensation for the decrease in t-PA activity. For the haemostasis we can conclude that the net result of the effects of moderate alcohol consumption on platelet aggregation and fibrinolysis for the haemostasis in vivo is unknown at present. It is possible that the effects on platelet aggregation result from changes in fibrinolysis and there are even recent indications of a relationship between the changes in the fubrinolytic factors I-PA and PAI and changes in lipid metabolism. especially triglycerides.

During the experiments in which the acute effects of moderate alcohol consumption were studied, the blood alcohol concentrations were also measured. In all subjects the alcohol levels remained under $0.5 \mathrm{~g} / \mathrm{L}$. Thus. from the present investigations it can be concluded that alcohol, even in moderate doses, influences factors reiated to cholesterol metabolism as well as to platelet function and fibrinolysis. Consequently, it is also quite possible that moderate alcohol consumption influences the risk of CHD favourably. 
Besides al biological mechanism, a healthier life-style could also contribute to a lower risk of $\mathrm{CHD}$ in moderate alcohol users. Strong positive associations between alcohol consumption and energy intake and between alcohol consumption and smoking were found (Chapter 11). Moreover, on weekend days a slightly higher intake of total fat and saturated fat was observed in moderately drinking men, and among women a higher cholesterol intake was found in moderate and heavy drinkers. Despite the strong and consistent relationship between alcohol consumption and energy intake, body mass index had only slightly increased in men who reported heavy drinking on midweek days. The lack of an averall effect of alcohol on body mass index might be explained by the observed relationship with smoking, which is known to be related with a lower body weight, or by physical activity, on which no data are available. Another explanation is that the caloric value of alcohol may be considerably lower than the theoretical value of $7 \mathrm{kcal} / \mathrm{g}$. Although a 48 -hour dietary record method was used in this survey, which entails certain limitations, the results do not support the hypothesis of a healthier life-style among moderate alcohol consumers.

In conclusion, the observed lower risk of CHD probably results from a direct influence of moderate alcohol consumption on biological factors that determine the risk of $\mathrm{CHD}$. 


\section{MATIG ALCOHOLGEBRUIK EN RISICO OP CORONAIRE HARTZIEKTEN}

Zo'n 40-50\% van de totale sterfte in de westerse samenleving wordt veroorzaakt door hart- en vaatziekten (HVZ). Een groot deel hiervan is toe te schrijven aan coronaire hartziekten (CHZ). In de afgelopen decennia is meer en meer duidelijk geworden dat verschillende leefstijlfactoren het risico op $\mathrm{CHZ}$ kunnen beinvloeden. Naast roken, gebrek aan lichaamsbeweging en mogelijk stress kan een voeding met te veel cholesterol, verzadigd vet, zout en energie bijdragen aan een hoger risico. Een andere belangrijke risicofactor is overmatig alcoholgebruik. Matig alcoholgebruik daarentegen wordt regelmatig in verband gebracht met een lager risico. De relatie tussen de alcoholconsumptie en het risico op $\mathrm{CHZ}$ wordt daarbij vaak omschreven als een $\mathbf{U}$ - of $\mathbf{J}$-vormige curve, volgens welke matige drinkers een lager risico hebben dan niet-drinkers en zware drinkers.

In epidemiologisch onderzoek is een lager risico op $\mathrm{CHZ}$ bij matige drinkers, in vergelijking met niet-drinkers, veelvuldig aangetoond (Hoofdstuk 2). Het doel van het huidige onderzoek was het bestuderen van mechanismen die het lagere risico op $\mathrm{CHZ}$ bij matige drinkers zouden kunnen verklaren. Hiertoe werden in een serie experimentele studies bij gezonde mannelijke vrijwilligers zowel de lange termijn als de acute effecten van matig alcoholgebruik onderzocht op factoren die gerelateerd zijn aan cholesterolmetabolisme, bloedplaatjesfunctie en fibrinolyse (Hoofdstukken 4-10). Bovendien werd de relatie tussen alcoholgebruik en voedings- en rookgewoonten bestudeerd in data van de Nederlandse voedselconsumptiepeiling (VCP) om na te gaan of matig alcoholgebruik mogelijk geassocieerd is met een gezondere levensstijl (Hoofdstuk 11).

Een positieve associatie Iussen alcoholconsumptie en het HDL-C, die is waargenomen in vele epidemiologische studies, is de meest gebruikte verklaring voor het lager risico op $\mathrm{CHZ}$ bij matige drinkers. Het HDL.C speelt vermoedelijk een rol in het zogenaamde "reverse cholesterol transport". Dit transport van cholesterol vanuit de weefsels, waar het de vaatwanden kan beschadigen, naar de lever. waar het wordt omgezet in galzuren en het lichaam via de gal verlaat, is een essentieel clement in de verdediging van het lichaam tegen accumulatie van cholesterol. In het huidige onderzoek werden de effecten van matig alcoholgebruik op het HDL-C bestudeerd over perioden van 20 weken (Hoofdstuk 4), 5 weken (Appendix 1) en 4 dagen (Hoofdstuk 6). Bovendien werden de acute effecten bestudeerd (Hoofdstuk 8). Zowel over 20 als over 5 weken werd een verhoging van het HDL-C (gemeten "s ochtends vroeg na een nacht vasten) waargenomen. die voornamelijk was toe te schrijven aan een verhoging van de $\mathrm{HDL}_{3}{ }^{-\mathrm{C}}$ - 
subfractic. In de studie over 4 dagen werd geen effect op de HDL-Csubfracties watgenomen. De consumptie van een eenmalige matige dosis alcohol tijdens het diner beinvloedde ook de HDL-C-concentratie in de postprandiale lase, gemeten 1 uur na alcoholconsumptie. Deze acute verhoging van het HDL-C werd veroorzaakt door cen stijgende tendens in beide HDL-C-subfracties, maar de stijging in de $\mathrm{HDL}_{2}-\mathrm{C}$-subfractie was sterker. Bovendien werd er een stijging van de concentraties van apolipoprotene $\mathrm{A}_{2}$ en triglyceriden waargenomen.

De gevonden verhogingen in HDL-C na enkelle weken matig alcoholgebruik zijn in overeenstemming met de experimentele en epidemiologische gegevens uit de literatuur. Er zijn echter geen eerdere studies bekend waarin de acute effecten van matig alcoholgebruik zijn onderzocht in de postprandiale fase, op het moment dat de alcohol nog in thet bloed aanwezig is. Een regelmatig terugkerende acute verhoging van het HDL-C in de postprandiale fase zou, naast de meer lange termijn effecten van alcohol op het HDL-C, een bijdrage kunnen leveren aan een toename in het reverse cholesterol transport. De verhogingen van het HDL-C passen in de hypothese van een beschermende werking van matig alcoholgebruik op $\mathrm{CHZ}$. Stijgingen in het HDL-C kunnen echter ook duiden op een verminderde clearance van het HDL-C; de vraag of de waargenomen effecten gunstig zijn valt dan ook niet met zekerheid te beantwoorden. Hiervoor zal er eerst meer bekend moeten zijin over het mechanisme dat ten grondslag ligt aan de acute en chronische effecten van matig alcoholgebruik op het lipidemetabolisme.

Naast het lipidemetabolisme speelt ook de hemostase een belangrijke rol in het risico op $\mathrm{CHZ}$. Zo kan een verlaging van de aggregatie van bloedplaatjes bijdragen tot een lager risico. In epidemiologisch onderzoek wordt er een inverse relatie waargenomen tussen alcoholgebruik en bloedplatjesaggregatie. In overeenstemming hiermee werd nat 5 weken matig alcoholgebruik (Appendix 1) een verlaging van de blocdplaatjesaggregatie waargenomen. In de studie over 4 dagen werd echter geen effect gevonden (Hoofdstuk 5). Ook in de postprandiale fase had een matige dosis alcohol geen significant effect op de aggregalie van de bloedplaatjes (Hoofdstuk 7 en 9). Hieruil kan worden geconcludeerd dat de consumptie van een matige dosis warschijnlijk geen acuut effect heeft op de bloedplaatjesaggregatie bij matige drinkers. Daarentegen leidt matig alcoholgebruik op termijn van enkele weken $10 t$ een lagere bloedplaatjesaggregatie. Dit laatste is in overeenstemming met het in epidemiologisch onderzoek gevonden verband tussen alcoholgebruik en de bloedplatjesaggregatie. Een dergelijke verlaging van de aggregatie van bloedplaatjes past in de hypothese van een lager risico op $\mathrm{CHZ}$ door matig alcoholgebruik. Men dient echter niet te vergeten dat de bloedplaatjesaggregatic een variabele is die altijd "ex 


\section{SAMENVATTING}

vivo" wordt gemeten en dat de aggregatieneiging in vivo afhangt van nog vele andere factoren.

Naast de bloedplaatjesaggregatie is de fibrinolyse een belangrijke factor in de hemostase. Tot voor kort werd in het onderzoek naar de effecten van alcohol op de fibrinolyse uitsluitend gebruik gemaakt van globale methoden om de fibrinolytische activiteit te meten (Hoofdstuk 3). Momenteel wordt de waarde van deze methoden echter sterk in twijfel getrokken. Er zijn inmiddels meer specifieke bepalingen ontwikkeld om de activiteit en de antigenconcentraties van de twee belangrijkste factoren van de fibrinolyse te meten, het "tissue-type plasminogen activator" (tPA) en de fysiologische remmer van het t-PA, het "plasminogen activator inhibitor" (PAI). Een stijging van het PAI en een daling van het t-PA heeft een daling van de fibrinolytische activiteit tot gevolg en kan dus bijdragen tot een verhoogd risico op $\mathrm{CHZ}$. In de literatuur is tot op heden echter nog geen aandacht besteed aan de effecten van matig alcoholgebruik op deze specifieke fibrinolysefactoren.

In het huidige onderzoek werd kort na de consumptie van een matige dosis alcohol een significante stijging van de PAl-activiteit en de 1-PAantigenconcentratie waargenomen. De t-PA-activiteit, daarentegen, vertoonde een zeer sterke daling (Hoofdstuk 7 en 10). Een daling van de tPA-activiteit en stijging van de PAI-activiteit werd ook waargenomen in de studie over 5 weken (Appendices 1 en 2). Wat het mechanisme is dat ten grondslag ligt aan deze effecten en wat de consequenties zijn voor de fibrinolyse in vivo is niet met zekerheid te zeggen. De sterke daling in t-PA-activiteit zou het risico op een infarct kunnen verhogen en past dus zeker niet in de hypothese van een lager risico op $\mathrm{CHZ}$. Daarentegen duidt de waargenomen stijging in t-PA-antigen mogelijk op compensatie voor de daling in t-PA-activiteit. We kunnen wat de hemostase betreft concluderen dat het netto resultaat van de verschillende effecten van matig alcoholgebruik op de fibrinolyseparameters en de bloedplaatjesaggregatio op de hemostase in vivo nog niet geheel duidelijk is. De mogelijkheid bestaal dat de effecten op de bloedplaatjesaggregatie het gevolg zijn van de veranderingen in de fibrinolyse en er zijn zelfs recente aanwijzingen dat veranderingen in de fibrinolysefactoren I-PA en PAl mogelijk samenhangen met veranderingen in het lipidemetabolisme, met name de triglyceriden.

Tijdens de experimenten waarin de acute effecten van matig alcoholgebruik werden bestudeerd is ook de bloedalcoholconcentratie gemeten. Deze bleef in alle individuen onder de 0,5 promille. Samenvattend kunnen we op basis van het huidige onderzoek concluderen dat alcohol reeds in matige doseringen van invloed is op factoren die gerelateerd zijn aan zowel het cholesterolmetabolisme, de bloedplaatjesfunctic als de 
fibrinolyse. Her is dus zeer wel mogelijk dat ook het risico op $\mathrm{CHZ}$ door matig alcoholgebruik gunstig wordt beinwloed.

Naast een biologisch mechanisme zou een gezondere levensstijl kunnen bijdragen aan een lager risico op $\mathrm{CHZ}$ bij matige drinkers. $\mathrm{Er}$ werden sterke positieve associaties gevonden tussen alcoholgebruik en de totale energieconsumptie en tussen alcoholgebruik en roken (Hoofdstuk 11). Bovendien was de alcoholconsumptie in het weekend licht geassocieerd met een hogere consumptie van totaal vet en verzadigd vet bij matig drinkende mannen, en was de cholesterolconsumptie zowel hoger bij vrouwen die matig als bij hen die veel drinken. Ondanks de sterke en consistente relatie tussen alcoholgebruik en energieinname was de Quetelet-index alleen licht verhoogd bij mannen die een hoge alcoholconsumptie rapporteren op doordeweekse dagen. De afwezigheid van een overall effect van alcohol op de Quetelet-index kan mogelijk worden verklaard door de gevonden relatie met roken, warrvan bekend is dat het is geassocieerd met een lager lichaamsgewicht, of door een relatie met de lichamelijke activiteit. waarover geen gegevens bekend zijn in het VCP-bestand. Een andere verklaring is dat de energiebijdrage van alcohol mogelijk aanmerkelijk lager is dan de theoretische waarde van $7 \mathrm{kcal} / \mathrm{g}$. Hoewel er in het VCPonderzoek gebruik is gemaakt van een 48-uurs opschrijfmethode, hetgeen bepaalde beperkingen met zich meebrengt, ondersteunen de bovengenoemde resultaten niet de hypothese van een gezondere levensstijl bij matige alcoholgebruikers in Nederland.

Het wargenomen lagere risico op $\mathrm{CHZ}$ bij matige drinkers is dus vermoedelijk het resultaat van een directe invloed van matig alcoholgebruik op biologische factoren die het risico op $\mathrm{CHZ}$ bepalen. 


\title{
EFFECTS OF MODERATE ALCOHOL CONSUMPTION ON PLATELET AGGREGATION, FIBRINOLYSIS, AND BLOOD LIPIDS
}

\author{
N.A. Pikaar, M. Wedel, E.J. van der Beek, W. van Dokkum, H.J.M. Kempen, \\ C. Klurt, Th. Ockhuizen and R.J.J. Hermus
}

(Metabolism 1987;36:538-43)

\section{Summary}

To investigate the effect of moderate alcohol consumption on blood constituents related to cardiovascular disease, 12 male volunteers consumed (instead of their usual alcoholic drinks) four different standardized amounts of red wine in addition to their habitual diet. Each dose was given to the subjects during a period of 5 weeks in a randomized order, all subjects receiving the four doses. They consisted of 0,2 and 4 glasses/d. providing 0,23 and $46 \mathrm{~g}$ alcohol/d as well as in "binge drinking" (14 glasses in the weekend, comparable to an average of 2 glasses/d). The results showed a clear dose-related response to drinking for several blood constituents. Most marked was a decrease in the tissuetype plasminogen activator activity and to a lesser degree an increase in plasminogen levels. Collagen-induced platelet aggregation was reduced, affecting all parameters measured. Levels of $\mathrm{HDL}_{3}$ - cholesterol, gammaglutamyltransferase, and urate showed a small but significant increase. No change was noted in the levels of alkaline phosphatase, alanine-aminotransferase, aspartate-aminotransferase, bile acids, folate, fibrinogen, the ADP-induced platelet aggregation, platelet secretion, or in haematologic values. The results are only partially in accordance with the presumed protective action of moderate drinking on the cardioyascular system and show a stronger response to the consumption of alcohol in coagulation and fibrinolysis factors than in blood lipids.

\section{Introduction}

Epidemiologic studies have shown a U-shaped relationship between alcohol consumption and cardiovascular disease (CVD), moderate drinkers having a lower risk than abstainers and alcoholics (1). Possible explanations relates to effects of alcohol consumption on blood lipid and 
lipoprotein levels as well as on the process of thrombogenesis (2). In experimental as well as in epidemiologic research, a positive relation between alcohol consumption and the HDL-cholesterol (HDL-C) level of the blood was found (3-5). The HDL-C level appears to be inversely related to CVD (4), but still the subfractions of HDL involved and the role of the separate fractions are unknown (6). With regard to thrombogenesis platelet count, platelet aggregation, fibrinogen level, and fibrinolytic activity maty be involved (2).

We investigated the effect of regular, moderate alcohol consumption in young men under strictly standardized drinking conditions. Of main interest were the effects on blood lipids -particularly HDL-fractions platelet function and four haemostatic variables. In addition, some liver function and haematologic tests were included to monitor possible adverse effects of the alcohol consumption.

\section{Methods}

\section{Subjects}

Twelve apparently healthy male students ( 21 to 29 years) participated in the study. The following selection criteria were applied: age 20 to 30 years, moderate habitual alcohol consumption (an average of maximally two glasses of alcoholic beverages per day), no drug use especially those influencing haemostasis, no smoking and trustworthy to follow the instructions. A dietary evaluation by means of a questionnaire with special emphasis on drinking habits, a routine hematologic test and a clinical examination formed part of the selection procedure. All subjects gave written informed consent. The study protocol was approved by the Institute's medical-ethical committee.

\section{Study Design}

Throughout the 20 weeks of the experiment, divided in four periods of 5 weeks, the subjects (all living at home) continued their habitual activities and food pattern except the drinking of alcohol. The food consumption pattern and drug use were monitored at the end of each experimental period by means of a one-day record. In addition to their usual diet they drank four different doses of red wine. One single lot of red table wine of a brand regularly consumed in the Netherlands was used. The four doses were: no wine, two glasses/d, four glasses/d and "binge drinking" (no wine from Monday till Thursday, four glasses on Friday, five 


\section{APPENDIX 1}

on Saturday, and five on Sunday i.e., the same amount per week as the two glasses/d dose), one dose given for a period of 5 weeks. Each subject drank all doses in a randomized order, according to a Latin square design, balanced for carryover effects from a previous period (7).

In weeks 4 and 5 of every period measurements were performed in all subjects to determine whether a steady state had been achieved. For practical reasons measurements concerning aggregometry, bleeding time, and anthropometry were done in six subjects in week 4 and in the other six subjects in week 5 .

\section{Analytical Methods}

After an overnight fast venous blood was taken by means of a venacatheter, inserted after half an hour's rest in a sitting position and processed for the different analyses as described below. Serum was prepared by centrifugation after clotting for half an hour at room temperature and for two hours at $4^{\circ} \mathrm{C}$.

Total serum cholesterol was determined by the method of Abell et al. (8), total triglycerides by the method of Giegel et al. (9). The Gaubius Institute TNO which performed these analyses is certified by the WHO Collaborating Center for Blood Lipid Research in Atherosclerosis and Ischaemic Heart Disease, Prague. For HDL-subfraction-action we used essentially the method of Gidez et al. (10). VLDL and LDL were first removed by precipitation with heparin $(0.15 \% \mathrm{w} / \mathrm{v}$ final concentration) and $\mathrm{MnCl} 2(100 \mathrm{mmol} / \mathrm{L})$ for 20 minutes at $0^{\circ} \mathrm{C}$. Then dextransulphate (MW 15.000 ) was added to a final concentration of $0.14 \% \mathrm{w} / \mathrm{v}$ and the mixture left for 30 minutes at $0^{\circ} \mathrm{C}$ before centrifugation. Cholesterol in $\mathrm{HDL}_{2}$ (redissolved dextran-sulphate precipitate) and in $\mathrm{HDL}_{3}$ (final supernatant) were determined by the method of Abell et al. (8). Alkaline phosphatase (AP), alanine-aminotransferase (ALAT), aspartate-aminotransferase (ASAT), gamma-glutamyltransferase (GGT), and urate in serum, were analyzed by standard methods, using a Cobas Bio Centrifugal Analyzer (Hoffmann-La Roche. Basel. Switzerland).

Serum bile acids were assayed enzymatically with the kit Enzabile (Nyegaard. Oslo); 5-methyltethrahydrofolate (5-Me-THF) was extracted from serum with a boiling borate buffer and determined by a radioimmunoassay (SimulTRAC kit. Becton Dickinson Immunodiagnostics, Orangeburg, NY).

Blood for coagulation and fibrinolysis parameters was collected free flowing in precooled polycarbonate rubes on citrate $(1 \mathrm{vol} 0.11 \mathrm{~mol} / \mathrm{L}$ citrate and 9 vol blood) before $10 \mathrm{AM}$ from resting volunteers and processed to platelet poor plasma as described in detail (11). Plasma was kept frozen at $-40^{\circ} \mathrm{C}$. Factor VII: ag and fibrinogen were assayed by 
electroimmunodiffusion (12) using goat antiserum (Central Laboratory of the Blood Transfusion Service, Amsterdam) and a home-made rabbit antiserum (courtesy $\mathrm{Dr} W$. Nieuwenhuizen) respectively, and Agarose 15 (BDH Chemicals Ltd. Poole, Engeland). In case of fibrinogen $0.2 \%$ disodium EDTA was added to increase the mobility of the fibrinogen (13). Plasminogen was measured in an activity assay using streptokinase (Kabivitrum, Amsterdam) for activation and S 2251 (Kabivitrum, Amsterdam) for assay of activity according to Friberger et al. (14). Results are given in percentages relative to a pooled plasma (11). Tissue-type plasminogen activity (t-PA) in plasma euglobulin fractions was measured with a parabolic rate assay (15). Activity is expressed in $U / L$ compared to a home standard of $t-P A$ (courtesy of Dr J.H. Verheijen). One unit of this standard equals 6 international t-PA units (16).

Platelet aggregation and ATP-secretion were studied on a Lumi Dual Agrometer (Chrono-Log Corp, Havertown, PA). Venous blood (20 mL) was collected by gentle suction into $2 \mathrm{~mL}$ of trisodium citrate $3.8 \%(\mathrm{w} / \mathrm{v})$.

Subsequently, platelet rich plasma (PRP) and platelet poor plasma (PPP) were prepared by centrifugation. PRP was diluted with PPP to give standardized PRP with a final platelet count of $200 \times 10^{6} / \mathrm{mL}$. Platelet aggregation was incluced by adding $50 \mu \mathrm{L}$ of ADP solution (Cluster Kit, Dade, Miami) diluted with saline to $450 \mu \mathrm{L}$ standardized PRP to give a final concentration of $1.0,2.5$, and $5.0 \mu \mathrm{mol} / \mathrm{L}$. Similarly, aggregation was induced by adding $5 \mu \mathrm{L}$ collagen solution (Hormon Chemie, Munchen, West Germany) with a final concentration of 1 and $4 \mu \mathrm{g} / \mathrm{mL}$. Chronolume luciferin-luciferase reagent was used to measure ATP concentration as an indicator of the platelet secretion. reaction (Chronolume, Chronolog Corp: Havertown, PA) (final concentration $3.8 \mathrm{mg} / \mathrm{mL}$ ) Aggregation curves. recorded up to five minutes after the addition of $\mathrm{ADP}$, generally showed reversible "primary" and "secondary" aggregation. The heights of both were expressed as extent of aggregation in \%, while maximal velocities were calculated from the tangents at the steepest slope of the aggregation curve. From the curves obtained after induction with collagen, lag time. induction time, change in shape of thrombocytes, maximal aggregation, and maximal velocity of aggregation were computed.

Hematologic cell counts were performed in EDTA-K blood on the Sysmex 8 parameter semi-automated apparatus CC-180 (TOA Medical Electronis Co Lid.Caron,CA). After blood sampling the subjects had breakfast and one hour later measurements of blood pressure, bleeding time, an anthropometry were performed. Bleeding time was measured (17) with a disposable device. "Simplate II" (General Diagnostics, Warner-Lambert Co, Morris Plains, NJ). Systolic and diastolic blood pressure (sitting position, Korotkov phase 1 and 5 ) measurements were conducted by one single observer, using a London 


\section{APPENDIX 1}

School of Hygiene Sphygmonanometer (18). Anthropometric measurements comprised body weight height, and four skinfolds (19).

\section{Statistical Analysis}

The results were analyzed with ANOVA according to the experimental design, using the statistical package GENSTAT (20). In the analysis dose effects were adjusted for effects of a dose applied in the previous period. Carryover effects over more than 5 weeks of a specific dose were assumed to be negligible. This assumption was checked to some extent by investigating if the variables measured did change in weeks 4 and 5 as a result of treatments applied in the previous period (this effect was not observed). If no such carryover effects were found, unadjusted means were presented. If the $F$ values from the ANOVA were significant at the $5 \%$ level, differences between mean values were tested with the method of the least significant difference (21). After examination of the residuals for the ANOVAs, a number of variables had to be transformed by logarithms; for these variables geometrical means were presented.

\section{Results}

\section{Changes Related to Alcohol Consumption}

A number of the measured variables had been influenced by the consumption of the different doses of red wine, as shown in Table 1. Some related but unaffected variables have been tabulated as well.

\section{Platelets}

Aggregation after induction with $1 \mu \mathrm{g} / \mathrm{mL}$ collagen is clearly influenced by the alcohol dose: the induction time lengthens with increasing dose $(P=.03)$, the maximal aggregation percentage $(P=.01)$ and aggregation velocity decrease $(P=.03)$ due to drinking of alcohol (Table 1). Lag time and change of shape were not influenced by the alcohol doses given. Aggregation after induction with $4 \mu \mathrm{g} / \mathrm{mL}$ collagen and with $1 \mathrm{mmol}$, $2.5 \mathrm{mmol}$. and $5 \mathrm{mmol}$ ADP (not tabulated) do not show an effect. The induction time was significantly longer when four glasses were consumed in a previous period than when 0 or 2 glasses were consumed in a previous period, irrespective of the dose given in the next period $(1.28 * 1.01$ and 0.99 min, respectively). ATP-secretion after induction with 5 mmol ADP was not found to be dependent on alcohol consumption. 


\section{APPENDIX 1}

\section{Haemostatic Plasma Factors}

Plasminogen shows a dose-related effect of alcohol consumption $(\mathrm{P}=.01)$ : the values increase with increasing alcohol dose differences between abstaining and drinking were significant; t-PA values decrease with increasing alcohol dose $(P=.02)$, only the results for the dose of four glasses being significantly smaller than those after abstaining. There is no change in fibrinogen or factor VIII: ag levels.

Table 1. Mean values of blood variables in response to red wine consumption.

\section{0 glasses 2 glasses Binge 4 glasses}

Platelet aggregation

(collagen $1 \mu \mathrm{g} / \mathrm{mL}$ )

Lag time (min)

Induction time ( $\mathrm{min})$

0.81

0.90

$1.67^{\mathrm{a}}$

$1.94^{\mathrm{ab}}$

0.92

0.88

Shape change $(\mathrm{cm})$

0.47

Maximum aggregation (\%)

Aggregation velocity $(\% / \mathrm{min})$

$52.2^{\mathrm{a}}$

0.54

$39.1^{\text {a }}$

$38.5^{b}$

$2.09^{\mathrm{b}}$

$2.10^{\mathrm{b}}$

Hemostatic factors

Plasminogen $(\%)$

t-PA (U/L)

$87.5^{\mathrm{a}}$

$24.8 \mathrm{~b}$

0.58

0.54

$41.2 \mathrm{~b} \quad 39.5 \mathrm{~b}$

$28.0^{b} \quad 26.8^{b}$

Lipids

Total cholesterol $(\mathrm{mmol} / \mathrm{L})$ *

$90.8^{\mathrm{a}}$

$90.9^{\mathrm{b}}$

$92.0^{\mathrm{b}}$

$93.3^{b}$ $48.4^{\mathrm{ab}}$ $56.4^{\mathrm{ab}} 23.5^{\mathrm{b}}$

$\mathrm{HDL}_{3} \mathrm{C}(\mathrm{mmol} / \mathrm{L})$

3.72

$\mathrm{HDL}_{2}-\mathrm{C}(\mathrm{mmol} / \mathrm{L})$

$0.78^{\mathrm{a}}$

3.74

0.39

$0.82^{\mathrm{ab}}$

3.72

$0.82^{a b}$

3.75

triglycerides $(\mathrm{mmol} / \mathrm{L})$

0.80

0.40

0.39

$0.84^{b}$

Others

GGT (U/L)

$8.4^{\mathrm{a}}$

0.78

0.76

0.42

0.76

Uric acid (umol/L) $302.0^{\mathrm{a}}$

$9.0^{b}$

$9.2 \mathrm{bc}$

$9.7^{\mathrm{c}}$ $309.4^{a b} 322.8^{b} 323.8^{b}$

Geometrical means.

Means not sharing a superscript are significantly different at the $5 \%$ level. 


\section{APPENDIX 1}

\section{Lipids}

No effect of the treatments on the mean levels of total cholesterol and triglycerides were observed. $\mathrm{HDL}_{3}-\mathrm{C}$ levels tend to increase with increasing dose as shown in Table 1. The results for the dose of fourglasses are significantly higher than those after abstaining. It appears that when four glasses of red wine a day are consumed, $\mathrm{HDL}_{2}-\mathrm{C}$ levels moderately rise from week 4 to week 5 (mean values of 0.37 and $0.46 \mathrm{mmol} / \mathrm{L}$ respectively, $\mathrm{P}=.01$ ) and triglyceride levels fall somewhat (mean values of 0.85 and $0.66 \mathrm{mmol} / \mathrm{L}$ respectively, $\mathrm{P}=.05$ ).

\section{Miscellaneous}

GGT and uric acid show clearcut dose-related effects ( $P=.00$ and $\mathrm{P}=.04$, respectively): with increasing dosage the levels increased, as shown in Table 1. AP, ALAT, ASAT, bile acids, 5-Me-THF, blood pressure, and bleeding time did not show any effects. Alcohol consumption was not found to influence haematologic values ( $\mathrm{RBC}, \mathrm{WBC}, \mathrm{Hb}, \mathrm{Ht}, \mathrm{MCV}, \mathrm{MCH}, \mathrm{MCHC}$, and PLT).

\section{Changes in Time}

Some variables seemed not to respond to the different doses of red wine, but to the experiment as such $(20$ weeks). These findings are summarized in Table 2. The weights of the subjects showed a slight but significant decrease between the first and the second period of the study and remained stable during the rest of the experiment.

Table 2. Mean values of variables, changing over the four periodes of the experiment, irrespective of the alcohol dose.

\begin{tabular}{|c|c|c|c|c|}
\hline & I & II & III & IV \\
\hline Weight (kg) & $72.0^{\mathrm{a}}$ & $71.4^{b}$ & $71.3^{b}$ & $71.7^{b}$ \\
\hline Body fat $(\%)$ & $14.7^{\mathrm{a}}$ & $14.5^{a b}$ & $13.8^{b}$ & $13.7^{6}$ \\
\hline Systemic blood pressure ( $\mathrm{mm} \mathrm{Hg}$ ) & 119.5 & 119.9 & 122.3 & $121.7 \mathrm{~b}$ \\
\hline Diastolic blood pressure $(\mathrm{mm} \mathrm{Hg})$ & $63.9^{\mathrm{a}}$ & $64.5^{a c}$ & $67.0^{\mathrm{DC}}$ & $68.1^{\mathrm{b}}$ \\
\hline Bleeding time (s) & $437.0^{a}$ & $351.0^{b}$ & $342.0^{0}$ & $367.0^{\mathrm{ab}}$ \\
\hline
\end{tabular}

Means not sharing superscript are significantly different at the $5 \%$ level 


\section{APPENDIX 1}

This reduction in weight is accompanied by a significant decrease $(P=.04)$ in percentage of body fat of the subjects. Diastolic blood pressure rises slowly during the study period $(\mathrm{P}=.02)$ and bleeding time shows a marked difference $(\mathrm{P}=.02)$ between the first period and the last three periods (437 seconds (s) versus a mean value of $353 \mathrm{~s}$ ).

\section{Discussion}

A decrease in aggregability by the presence of alcohol in the blood is described (22,23), but little is known about the long-term effects of alcohol on platelet aggregation in the fasting state. In an epidemiologic study Meade et al. (24) reported a descreased aggregability (induced by ADP), related to higher levels of habitual alcohol consumption. Likewise, Renaud et al. (25) observed a negative correlation between alcohol intake and platelet aggregability, especially when saturated fat dominated in the diet. In our study, moderate alcohol consumption in the form of red wine reduced platelet aggregability (after induction with $1 \mathrm{mg} / \mathrm{mL}$ collagen) in the fasting state, all parameters of the aggregation curve showing a logical coherence. The induction with $4 \mu \mathrm{g} / \mathrm{mL}$ collagen may have been too strong for aggregation to show significant effects.

Information about the influence of drinking on coagulation and fibrinolysis is scarce. In an epidemiologic study by Meade et al. (26), fibrinolytic activity, measured by a clot lysis technique, appeared to increase with alcohol consumption, while fibrinogen levels were falling. Barboriak (27), discussing the variables potentially influencing CVD, cites that blood coagulation was found to be reduced and fibrinolytic activity to be enhanced by alcohol consumption. Elmer et al. (23) did not observe an acute effect of whisky consumption on fibrinolysis. On the contrary, ingestion of cider inhibited plasma fibrinolytic activity in a concentration-dependent manner (28). The inconsistent results may be due to the application of different types of beverage and of analytical methods. In our study fibrinolysis appeared to be clearly affected by wine consumption. Plasminogen levels rise moderately with an increasing dose. indicating increasing fibrinolytic potential. However, this is amply compensated for by a large decrease in t-PA, the level at the four-glass dose being roughly one third of that in abstinence. The changes appear to be specilic since the other haemostatic components studied do not change significantly. The decrease in t-PA may be due to an increase in inhibitors in the euglobulin fraction. This possibility is under investigation.

The increase in total HDL-C due to alcohol consumption is welldocumented. Data from five study populations yielded a positive 


\section{APPENDIX 1}

association of alcohol consumption with HDL-C (3). Thornton et al. (5) found that in a drinking period of 6 weeks HDL-C levels amounted to 1.25 $\mathrm{mmol} / \mathrm{L}$ and dropped to $1.04 \mathrm{mmol} / \mathrm{L}$ in an abstinence period. In a study on biochemical markers of alcohol consumption, Shaper (29) found HDL-C values of $1.04,1.16$, and $1.19 \mathrm{mmol} / \mathrm{L}$ when 0,1 to 3 , and 4 to 6 glasses were drunk daily. These results are comparable with the sum of $\mathrm{HDL}_{2}$ and $\mathrm{HDL}_{3}-\mathrm{C}$ values obtained in our experiment, being $1.17,1.22$, and $1.27 \mathrm{mmol} / \mathrm{L}$ for 0,2 and 4 glasses a day, respectively. Reports about effects of drinking on the separate HDL-fractions are contradictory (6). Haskell et al. (30) observed that drinking resulted in an increase in total HDL-C and in $\mathrm{HDL}_{3}$ mass (ca 14\%), whereas $\mathrm{HDL}_{2}$-mass did not change. These results were confirmed in a cross-sectional survey of 77 adult males (31). Taskinen et al. (32) obtained different results. $\mathrm{HDL}_{2}$-mass in fasted serum increased by $23 \%$ within three days on a dose of $5.5 \mathrm{~g}$ alcohol $/ \mathrm{kg}$ body weight whereas $\mathrm{HDL}_{3}$-mass remained unchanged. Haffner et al. (33) reported alcohol intake to be positively related to $\mathrm{HDL}-\mathrm{C}$ and to $\mathrm{HDL}_{2}-\mathrm{C}$ in men and to $\mathrm{HDL}_{3}-\mathrm{C}$ in women.

The drinking pattern did not affect the level of total cholesterol in our experiment while total HDL-C showed an increase with increasing dose, in good agreement with other findings $(5,29)$. The $\mathrm{HDL}_{3}$-fraction increases depending on the dose, the level obtained at the four-glass dose being significantly higher than during abstinence. A nonsignificant increase (ca $8 \%$ ) is seen for the $\mathrm{HDL}_{2}$-fraction at the four-glass dose compared with abstinence. There is no clear dose response. Both $\mathrm{HDL}_{2}-\mathrm{C}$ and triglyceride levels significantly change from week 4 to week 5 only at the four glass dose, indicating that adaptation to drinking is rather slow. Our results are in agreement with those of Haskell et al. (30). Williams et al. (31), and Haffner et al. (33), but not with those of Taskinen et al. (32). The deviating results of Taskinen et al. may be due to diferrences in study design (a period of only 2.5 days) and methodology (31). Interpretation of the effect of alcohol consumption on HDL-fractions is difficult as yet. Levels of $\mathrm{HDL}_{2}-\mathrm{C}$ have epidemiologically been associated with a decrease in CVD while $\mathrm{HDL}_{3}-\mathrm{C}$ does not show a distinct relationship (6,34).

Many investigators are looking for biochemical markers indicative of alcohol use. Most parameters showed a poor predictive value $(29,35-37)$. GGT is used to discrimininate between drinkers and abstainers $(35,37)$. Allen (37) found GGT values of 8,40 , and $89 \mathrm{U} / \mathrm{L}$ for abstainers, persons consuming 1.5 to 4.5 drinks per day, and persons drinking more, respectively. Our results are much lower and more in agreement with those of Shaper (29) who reports $13.8,15.1$, and $18.6 \mathrm{U} / \mathrm{L}$ for 0.1 to 2 , and 3 to 6 drinks daily, respectively. The increase in urate level is comparable with those stated elsewhere $(29,37)$. In our study GGT and urate show a 


\section{APPENDIX 1}

significant but small dose response, confirming their uselessness as indicators for alcohol consumption. The effect of HDL-C also used as a marker has been discussed above. In our study no influence of drinking on the levels of AP, ALAT, ASAT, MCV, and MCH was observed. Moreover, the results discussed above prove that the liver function of the volunteers were hardly affected by drinking of the doses of alcohol as applied. This is also confirmed by the absence of a significant response of the bile acid level, which is considered to be a sensitive indicator of liver damage by some (38), although others dispute its value (39).

There is strong epidemiologic evidence that the regular use of large quantities of alcohol is related to higher blood pressure and a greater prevalence of hypertension $(40,41)$. After adjustment for Quetelet index, age, and smoking habits, blood pressure was reported to increase linearly with alcohol consumption (40). Arkwright et al. (41) found that alcohol consumption correlated with systolic pressure but not with diastolic pressure. Systolic pressure increased progressively with alcohol consumption (ca $1 \mathrm{~mm} \mathrm{Hg} / \mathrm{drink} / \mathrm{d})$. Men who drank 1 to $160 \mathrm{~mL} / \mathrm{w}(0$ to 2 drinks/d) had significantly higher mean systolic pressure than teetotalers. Klatsky et al. (42) observed that men taking two drinks per day or less had the same blood pressure as nondrinkers. The blood pressures of our subjects were low $(120.9 / 65.9 \mathrm{~mm} \mathrm{Hg})$ and did not show any dose-related response, although diastolic pressure rose during the experiment, independent of the dose. Systolic pressure also increased, but not significantly. These effects might be due to a slightly higher (mean) amount of alcohol consumed during the whole experiment compared to the habitual situation while the response to alcohol is too slow to show up in the separate 5-weeks periods. Little is known about the effect of drinking on bleeding time. Haut and Cowan (22) noticed among other effects a prolonged bleeding lime immediately after alcohol ingestion. Elmer et al. (23) observed a prolongation of the bleeding time one hour after drinking at a plasma alcohol concentration of $19.3 \mathrm{mmol} / \mathrm{L}$. In our study bleeding time did not respond to the dose of alcohol so that no net effect of the different coagulation factors occurred. The drop in bleeding time occurring between the first period and the other ones is difficult to explain.

Regarding the haematologic values, attention should be given to the nonresponse of $\mathrm{MCV}, \mathrm{MCH}$, and the platelet count. $\mathrm{MCV}$ is known as a marker of alcohol consumption, since even moderate drinkers display an increase (43). Cushman et al. (36) claim MCV to be the most sensitive individual, marker in males. $\mathrm{MCH}$ is mentioned as a marker by Shaper (29). Alcohol abuse is sometimes accompanied by thrombocytopenia (22). The folate levels 


\section{APPENDIX 1}

in the fasting state of this study appeared not to be influenced, although it has been reported to decrease after acute drinking (44).

In this study, body weight decreased in the second period and stabilized afterwards. The weight loss can mainly be accounted for by loss of body fat, and suggests a lower intake or a higher energy expenditure in the experimental period, compared to the habitual diet. It is not likely that a major change in the diet of the volunteers is responsible for this effect. The volunteers kept their normal dietary pattern, adding the required number of glasses of wine and omitting the alcoholic beverages usually consumed.

Some of the blood constituents measured in this experiment respond to the consumption of alcohol, especially the platelet aggregation (induced with $1 \mu \mathrm{g} / \mathrm{mL}$ collagen) and tissue plasminogen activator: minor responses are observed for plasminogen $\mathrm{HDL}_{3}-\mathrm{C}, \mathrm{GGT}$ and wrate, the effects being dose-related. However, it should be noted that the differences between abstaining and drinking are most evident, whereas the results for the different types of drinking are predominantly nonsignificant (Table 1).

Although the results for "binge" drinking tend to be situated between those in the 0 - and four-glass periode, they do in no case differ significantly from those in the two-glass period. It should be stressed that the changes in concentration of the different constituents manifest themselves in the fasting state, i.e., without any alcohol in the blood. Since measurements were performed in weeks 4 and 5 of each period. however, it remains uncertain how rapid changes took place. The rising level of HDL-C and the falling level of triglycerides in week 5 compared to week 4 in the period of the highest dose suggest that adaptation for these variables is rather slow. The carryover effect on induction time when four glasses had been consumed in a previous period also indicales that effects on platelet aggregation are lasting as well. The alcohol consumption in our study was restricted to red wine only. Consequently, some of the results can be specifically due to the consumption of red wine or to the change in type of beverages habitually consumed.

In conclusion, it appears from our study that regular, moderate drinking of red wine in a 5-week period has scarcely or no effects at all on liver function, haematologic values, and blood pressure. It remains unclear which underlying mechanisms are responsible for the presumed protective effect of moderate alcohol consumption on cardiovascular disease. Effects on lipid constituents appear to be slight in the period studied while interpretation remains difficult. On the other hand, alcohol consumption rather strongly affects the mechanism of haemostasis. The reduced platelet aggregation and the increased plasminogen level should be interpreted as a favourable and the decrease in I-PA level as an 


\section{APPENDIX 1}

unfavourable aspect. A study is in progress to elucidate the interaction on the various haemostatic factors and of the long-term response of different variables.

\section{References}

1. Marmot MG, Rose G, Shipley MJ, et al: Alcohol and mortality: A Ushaped curve. Lancet 1:580-583, 1981

2. Marmot MG: Alcohol and coronary heart disease. Int J Epidemiol 13:160167, 1984

3. Castelli WP, Gordon T, Hjortland MC, et al: Alcohol and blood lipids. The cooperative lipoprotein phenotyping study. Lancet 2: 153-155, 1977

4. Barboriak JJ, Gruchow HW, Anderson AJ: Alcohol consumption and the diet-hart controversy. Alcohol Clin Exp Res 7:31-34, 1983

5. Thornton J.Symes $\mathrm{C}$, Heaton $\mathrm{K}$ : Moderate alcohol intake reduces bile cholesterol saturation and raises HDL-cholesterol. Lancet 2:819-821, 1983

6. Lieber CS: To drink (moderately) or not to drink? $N$ Engl J Med 310:846-848, 1984

7. Cochran WG, Cox GM: Experimental Designs. New York, Wiley 1957

8. Abell AA, Levy BB, et al: A simplified method for the estimation of total cholesterol and the demonstration of its specifity. J. Biol Chem $195: 357-366,1952$

9. Gigel JL, Ham AB, Clena W: Manual and semiautomated procedures for measurement of triglycerides in serum. Clin Chem 21: 1575-1581, 1975

10. Gidez LI, Miller GJ, Burstein $M$, et al: Separation and quantitation of subclasses of human high density lipoprotein subclasses by a simple precipitation procedure. J Lipid Res 23:1206-1223, 1982

11. Kluft C, Brakman P, Veldhuysen-Stolk EC: Screening of fibrinolytic activity in plasma euglobulin fractions on the fibrin plate. In Davidson JF, Samama MM, Desnoyers PC (eds): Progress in Chemical Fibrinolysis and Trombolysis, vol 2: New York, Raven, 1976, pp 57-65

12. Laurell CB: Quantitative estimation of proteins by electrophoresis in agarose gel containing antibodies. Anal Biochem 15:45-52, 1966

13. Nieuwenhuizen W, Vermond A. Hermans J: Human fibrinogen binds EDTA and citrate. Tromb Res 22:659-663, 1981

14. Friberger $P$, Knos $M$, Gustavsson $S$, et al: Methods for determination of plasmin, antiplasmin and plasminogen by means of substrate S-2251. Haemostat is $7: 138-145,1978$

15. Verheijen $J H$, Mullaart $E_{\text {s }}$ Chang GTG, et al: A simple, sensitive spectrophometric assay for extrinsic (tissue-type) plasminogen 


\section{APPENDIX 1}

activator applicable to measurement in plasma. Thromb Haemostasis 48 : $266-269,1982$

16. Gaffney PJ, Curtis AD: A collaborative study of a proposed International standard for tissue plasminogen activator (t-PA). Thromb Haemostatis $53: 134-136,1985$

17. Babson SR, Babson, AL: Development and evaluation of a disposable devise for performing simultaneous duplicate bleeding time determinations. Am J Clin Pathol 70: 406-408, 1978

18. Rose GA, Holland WW, Crowley EA: A sphygmomanometer for epidemiologists. Lancet 1:296-300, 1964

19. Durnin JVGA, Wamersley J: Body fat assessed from total body density and its estimation from skinfold thickness: measurement on 481 men and women from 16 to 72 years. Br J Nutr 32: 77-97, 1974

20. Genstat, A General Statistical Program. Oxford, Numerical Algorithms Group Limited, 1980

21. Snedecor GW, Cochran WG: Statistical Methods. Ames, Ilowa State University, 1967

22. Haut MJ, Cowan DH: The effect of ethanol on hemostatic properties of human blood platelets. Am J Med 566: 22-33, 1974

23. Elmer O, Goransson G, Zoucas E: Impairment of primary hemostatis and platelet function after alcohol ingestion in man. Haemostasis 14:223228,1984

24. Meade TW, Vickers MV, Thompson SG et al: Epidemiological characteristics of platelet aggregability. $\mathrm{Br}$ Med J 290: 428-432, 1985

25. Renaud S, McGregor L. Martin JL: Influence of alcohol on platelet functions in relation to atherosclerosis, in Pozza G. Micossi $P$, Catapano AL (eds): Diet, Diabetes and Atherosclerosis. New York. Raven, 1984, pp 177-187

26. Meade TW, Chakrabarti R. Haines AP et al: Characteristics affecting fibrinolytic activity and plasma fibrinogen concentrations $\mathrm{Br} \mathrm{Med} J \mathrm{~J}$ : $153-156,1979$

27. Barboriak JJ: Alcohol, lipids and heart disease. Alcohol 1: 341-345, 1984

28. Anderson JA, Gow LA, Ogston D. Influence of cider on the fibrinolytic enzyme system. Acta Haematol 69:344-348, 1983

29. Shaper AG. Pocock SJ, Ashby D, et al: Biochemical and haematological response to alcohol intake. Ann Clin Biochem 22: 50-61, 1985

30. Haskell WL, Camargo C. Williams PT, et al: The effect of cessation and resumption of moderate alcohol intake on serum high-densitylipoprotein subfractions. N Engl J Med 310:805-810, 1984 


\section{APPENDIX 1}

31. Williams PT, Krauss RM, Wood, RD, et al: Associations of diet and alcohol intake with high-density lipoprotein subclasses. Metabolism 34:524-530, 1985

32. Taskinen MR, Valimaki $M$, Nikkila EA, et al: Sequence of alcoholinduced initial changes in plasma lipoproteins (VLDL and HDL) and lipolytic enzymes in thumans. Metabolism 34: 112-119, 1985

33. Haffner SM, Applebau-Bowden D, Wahl PW, et al: Epidemiological correlates of high density lipoprotein subfractions, apolipoproteins A-I, A-II, and D, and lecithin cholesterol acyltransferase. Effects of smoking, alcohol and adiposity. Arteriosclerosis 5:169-177, 1985

34. Ballantyne FC, Clark RS, Harrisson SS, et al: High density and low density lipoprotein subfractions in survivors of myocardial infarction and in control subjects. Metabolism 31:433-437, 1982

35. Peterson B, Trell $E$, Kristensson $H$, et all: Comparison of gammaglutamyltransferase and other health screening tests in average middle-aged males, heavy drinkers and alcohol non-users. Scand J Clin Lab Invest 43: 1441-149, 1983

36. Cushman $P$, Jacobson $G$, Barboriak $\mathbb{J} J$, et al: Biochemical markers for alcoholism: Sensitivity problems. Alcohol Clin Exp Res 8:253-257, 1984

37. Allen JK, Adena MA: The association between plasma cholesterol, high density-lipoprotein cholesterol, triglycerides and uric acid in ethanol consumers. Ann Clin Biochem 22:62-66, 1985

38. Editorial: Serum bile acid in hepatobiliary disease. Lancet 2:11361138,1982

39. Cravetto C. Molino G, Biondi AM et al: Evaluation of the diagnostic value of serum bile acid in the detection and functional assessment of liver diseases. Ann Clin Biochem 22: 596-605, 1985

40. Cooke FM, Frost GW, Stokes GS: Blood pressure and its relationship to low levels of alcohol consumption. Clin Exp Pharmacol Physiol 10:229. 233, 1983

41. Arkwright PD, Beilin LJ, Rouse I, et al: Effects of alcohol use and other aspects of lifestyle on blood pressure levels and prevalence of hypertension in a working population. Circulation 66:60-66, 1982

42. Klatsky AL, Friedman GD, Soiebelaub AB, et al: Alcohol consumption and blood pressure. Kaiser-Permanente multiphasic health examination data. N Engl J Med 296:1191-1200, 1977

43. Unger KW, Johnson D: Red blood cell mean corpuscular volume: A potential indicator of alcohol usage in a working population. Am J Med Sci 267: 281-289, 1974

44. Paine CJ, Eichner RE, Dickson V: Concordance of radioassay and microbiological assay in the study of ethanol-induced fall in serum folate level. Am J Med Sci 266: 135-138, 1973 


\title{
REGULAR MODERATE WINE CONSUMPTION FOR FIVE WEEKS INCREASES PLASMA ACTIVITY OF THE PLASMINOGEN ACTIVATOR INHIBITOR 1 (PAI-1) IN HEALTHY YOUNG VOLUNTEERS
}

\author{
C. Kluft, J. Veenstra, G. Schaafsma and N. A. Pikaar
}

(Fibrinolysis, 1990:4 Supp2:69-70)

\section{Summary}

Daily consumption for 5 weeks of 2-4 glasses of red wine by young healthy volunteers causes an increase in activity of PAI-1 in blood collected in the morning. Five weeks of weekend drinking (3 days) had no effect.

KEYWORDS. Plasminogen activator inhibitor-1. Alcohol. Wine.

\section{Introduction}

Since the early reports of Fearnly et al. (1) and Nilsson et al. (2), it has been known that the consumption of alcoholic beverages, such as beer and wine, has an acute effect on blood fibrinolytic activity. The effect has been recorded as a reduction in blood fibrinolytic activity by global assays and appears maximally in the first few hours after drinking. No residual effect was observed after an overnight fast. Recent studies indicate that an increase in t-PA inhibition is responsible for the effect (3).

For five weeks we studied the effects of two dosages, as well as regular and intermittent moderate wine consumption, on the plasma activity levels of the major plasminogen activator inhibitor, PAI-1, in blood samples after an overnight fast. 


\section{Methods}

\section{Study design}

For four periods of five weeks twelve healthy male students (21-29y, latin square design of 20 weeks) consumed 0,2 or 4 glasses of red wine per day instead of their usual mean daily alcohol intake of maximally two glasses. Additionally, in one of the four periods, they consumed 14 glasses of wine (an amount similar to two glasses of wine per day) in the weekends only ( 3 days with 4,5 and 5 glasses respectively, binge drinking) (4). After binge drinking, blood was sampled midweeks.

One single lot of red table wine, of a brand regularly consumed in the Netherlands, was used.

\section{Analytical Methods}

The t-PA inhibitory capacity of plasma was measured at a fixed time in the morning (before 10.00 a.m.) from fasting individuals, using a functional parabolic rate assay according to Verheijen et al. (5). PAI-1 contribution to t-PA inhibition was assessed by the inhibition of an excess of a monoclonal antibody directed to PAI-1 (6,7), and expressed as the amount of neutralized t-PA (IU).

\section{Results}

It was found that regular consumption of either 2 or 4 glasses of wine each day increased t-PA inhibitory activity of plasma to a similar extent. Binge drinking did not induce changes in $t-P A$ inhibition level (see Table 1).

Only part of the I-PA inhibition in the used assay is due to PAI-1 (8). To identify the change in t-PA inhibitory activity, a monoclonal antibody with the ability to quench PAI-1 activity was used (6). As shown in Figure 1 the increase in t-PA inhibition (4 glasses of wine daily) is due to an about four-fold change in PAI- 1 activity. 
Table 1. Effect of wine consumption for five weeks on t-PA inhibition of plasma.

\begin{tabular}{lll}
\hline \multicolumn{1}{c}{ Wine } & \multicolumn{2}{c}{ t-PA inhibition } \\
\hline 0 glasses / day & 4.9 & $(4.3-6.4) \mathrm{IU} / \mathrm{ml}$ \\
2 glasses / day & 6.3 & $(4.6-7.8) \mathrm{IU} / \mathrm{ml}\left({ }^{*}\right)$ \\
4 glasses / day & 6.4 & $(5.4-7.6) 1 \mathrm{U} / \mathrm{ml}(\#)$ \\
binge & 4.4 & $(3.3-6.3) 1 \mathrm{U} / \mathrm{ml}$ \\
\hline
\end{tabular}

Median values with interquartile range.

Different from 0 glasses / day $p<0.025\left(^{*}\right)$ and $p<0.01(\#)$ : paired students t-test.

\section{PRI-1 activity (IU/ml)}

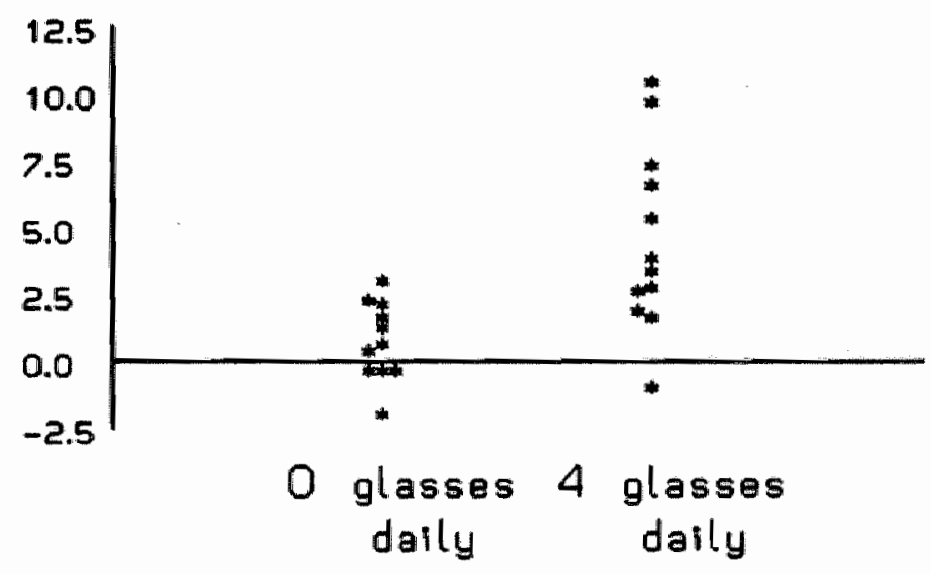

Figure 1. Specific PAI-1 activity after five weeks without alcohol consumption (left) and after five weeks consumption of 4 glasses of wine daily (right). PAI-1 activity is determined as the 1-PA inhibitory activity quenched by a monoclonal antibody directed to PAI-1. Medians are 0.9 and $4.0 \mathrm{IU} / \mathrm{ml}$. 


\section{Discussion}

Moderate wine consumption of 2 to 4 glasses daily for 5 weeks results in an increase in plasma activity of PAI-1. This increase was observed following an overnight fast, after which the acute effects of alcohol consumption have alleady ceased $(1,2,9)$.

To obtain the observed effect on PAI-1 it is necessary to maintain a prolonged and regular alcohol consumption. This is evidenced by the fact that a single episode of four days of alcohol consumption (10) was insufficient to cause the effect. Also, binge drinking did not induce an effect on PAI-activity. This might be due to either absence of effect or a transient effect already nullified upon sampling the wednesday/thursday after the wekend.

This suggests that wine or alcohol consumption needs to be defined carefully with regard to regular consumption. It would be interesting to study what degree of irregularity (absence for one day a week, two days a week?) would prevent an effect on PAI-1.

\section{References}

1. Fearnly GR, Ferguson J, Chakrabarti R, Vincent CT. Effect of beer on blood fibrinolytic activity. Lancet 1960;1:184-186

2. Nilsson IM, Björkman SE, v. Studnitz W, Hallen A. Antifibrinolytic activity of certain pectins. Thromb Diath Haemorrh 1962;6:177-187

3. Veenstra J, te Wierik E, Kluft C. Alcohol and fibrinolysis. Fibrinolysis 1990;4 Supp2:64-8.

4. Pikaar NA, Wedel M, van der Beek E, van Dokkum W, Kempen HJM, Kluft C. Ockhuizen Th. Hermus RJJ. Effects of moderate alcohol consumption on platelet aggregation, fibrinolysis and blood lipids. Metabolism 1987:36:538-543

5. Verheijen $J \mathrm{H}$, Chang GTG, Kluft $\mathrm{C}$. Evidence for the occurrence of a fast-acting inthibitor for tissue-type plasminogen activator in human plasma. Thromb Haemostas 1984;51:392-5

6. Nielsen LS, Andreasen PA, Grondahl-Hansen J, Huang JH, Kristensen P, Dar K. Monoclonal antibodies to human 54,000 molecular weight plasminogen activator inhibitor from fibrosarcoma cells. Inhibitor neutralization and one-step affinity purification. Thromb Haemostas $1986: 55: 206-21.2$

7. de Maat MPM. Kluft C, de Boer K, Knot EAR, Jie AFH. Acid treatment of plasma for the inactivation of plasminogen activator inhibitor-1 (PAI1). Thromb Res $1988 ; 52: 425-430$ 


\section{APPENDIX 2}

8. Kluft C, Jie APH, Sprengers ED, Verheijen JH. Identification of a reversible inhibitor of plasminogen activators in blood plasma. FEBS Lett 1985:190:315-318

9. Veenstra J, Kluft C, Ockhuizen Th, van de Pol H, Wedel M, Schaafsma G. Effects of moderate alcohol consumption on platelet function, tissuetype plasminogen activator and plasminogen activator inhibitor. Thrombosis and Haemostas 1990;63:345-8

10. Veenstra J, Kluft $C$, Ockhuizen Th, Pikaar NA, van de Pol H, Wedel M, Schaafsma G. Effects of four days of moderate wine and coffee consumption on fibrinolysis and platelet aggregation. Fibrinolysis 1990 , in press 


\section{Curriculum vitae}

Jan Veenstra was born in Roden on 14 August 1959. After having completed HAVO (higher general secondary education) at the Wessel Gansfort College in Groningen, in 1978, he worked for three years in a garage in Roodeschool. In 1981. he started studying at the HLO (higher laboratory education) in Groningen. He completed this study in 1985 in two directions: clinical chemistry and medical microbiology. In October 1985 he was appointed as laboratory technician at the Section Physiology (Head: Dr Ir G. Schaafsma) of the Department of Human Nutrition (Head: Dr Th. Ockhuizen) of the TNO-CIVO Toxicology and Nutrition Institute (Director: Prof Dr Ir R.J.J. Hermus) located at Zeist. Since 1989 he has worked as project leader of the Alcohol Research programme and of the Alcohol Documentation Centre at the TNO-CIVO Toxicology and Nutrition Institute. At present he is attending the M.Sc. course in Nutrition at King's College, University of London, U.K.

Jan Veenstra is married to Petra Hanko. Their son Niels was born in January 1990. 